\title{
Reproduction Disruptions: \\ an exploration of personal and social meanings of conception difficulties
}

\author{
by
}

Heather Bromberg

\begin{abstract}
A thesis submitted to the Faculty of Graduate Studies and Research In partial fulfillment of the degree of Doctor of Philosophy
\end{abstract}

\author{
Department of Sociology and Anthropology \\ Carleton University \\ Ottawa, Ontario
}

O2008 by Heather Bromberg 


$\begin{array}{ll}\begin{array}{l}\text { Library and } \\ \text { Archives Canada }\end{array} & \begin{array}{l}\text { Bibliothèque et } \\ \text { Archives Canada }\end{array} \\ \begin{array}{l}\text { Published Heritage } \\ \text { Branch }\end{array} & \begin{array}{l}\text { Direction du } \\ \text { Patrimoine de l'édition }\end{array} \\ \begin{array}{l}\text { 395 Wellington Street } \\ \text { Ottawa ON K1A 0N4 } \\ \text { Canada }\end{array} & \begin{array}{l}\text { 395, rue Wellington } \\ \text { Ottawa ON K1A 0N4 } \\ \text { Canada }\end{array}\end{array}$

Your file Votre référence

ISBN: 978-0-494-47473-0

Our file Notre référence

ISBN: 978-0-494-47473-0

NOTICE:

The author has granted a nonexclusive license allowing Library and Archives Canada to reproduce, publish, archive, preserve, conserve, communicate to the public by telecommunication or on the Internet, loan, distribute and sell theses worldwide, for commercial or noncommercial purposes, in microform, paper, electronic and/or any other formats.

The author retains copyright ownership and moral rights in this thesis. Neither the thesis nor substantial extracts from it may be printed or otherwise reproduced without the author's permission.
AVIS:

L'auteur a accordé une licence non exclusive permettant à la Bibliothèque et Archives Canada de reproduire, publier, archiver, sauvegarder, conserver, transmettre au public par télécommunication ou par l'Internet, prêter, distribuer et vendre des thèses partout dans le monde, à des fins commerciales ou autres, sur support microforme, papier, électronique et/ou autres formats.

L'auteur conserve la propriété du droit d'auteur et des droits moraux qui protège cette thèse. $\mathrm{Ni}$ la thèse ni des extraits substantiels de celle-ci ne doivent être imprimés ou autrement reproduits sans son autorisation.
In compliance with the Canadian Privacy Act some supporting forms may have been removed from this thesis.

While these forms may be included in the document page count, their removal does not represent any loss of content from the thesis.
Conformément à la loi canadienne sur la protection de la vie privée, quelques formulaires secondaires ont été enlevés de cette thèse.

Bien que ces formulaires aient inclus dans la pagination, il n'y aura aucun contenu manquant.

\section{Canada}




\begin{abstract}
This study explores the meanings that women attribute to their experiences of conception difficulties as well as the social context in which they are experienced. Stories from a web-based sample of 327 women who were trying to conceive or had recently become pregnant after experiencing some difficulty trying to conceive were analyzed using a grounded theory methodology to determine the impact of conception difficulties on their lives and relationships and the meanings they assigned to the experience. Overwhelmingly, the theme of "disruption" emerged as the most significant aspect of the experience. Women noted disruptions to their life goals and biographies, their identities and concepts of self and femininity, their emotions and body concepts and their relationships and interactions with their spouses and others. They discussed a variety of ways of making sense of the experience. On the whole they accepted medical definitions and solutions, but not to the exclusion of other ways of interpreting their experiences. Responses revealed that pronatalism and other socially dominant ideals, particularly those associated with middle-class values, played a role in shaping the experience of conception difficulties for many participants and in contextualizing it as a disruption. However, participants used a number of means to mitigate the negative impact on themselves, their identities, and their relationships. Additionally, they navigated the experience and interactions with others in a way that served their own interests, made sense within the context of their experiences, and offered a significant measure of control over their experiences. The disruption also provided opportunities for self growth and reflection, relationship growth, and opportunities to explore personal world-views. Findings suggest that, in spite of increased role opportunities for women over the past generation, social ideals prescribing motherhood for married women persist and continue to impact significantly upon the experience of trying to conceive.
\end{abstract}




\section{Acknowledgements}

Many people have offered assistance, counsel and support as I worked on this project. I am pleased to have the opportunity to thank them:

First, I am tremendously grateful to the women who shared their stories about their conception difficulties.

Throughout the writing and research process, my adviser, Professor Flo Kellner, offered the perfect blend of wise scholarly counsel, encouragement and freedom. I have learned enormously from her and appreciate her patience, many thoughtful suggestions, and the numerous careful readings of drafts of the thesis. I am especially thankful for her generosity with her time and her willingness to continue to supervise during her retirement.

I would like to thank other members of my committee: Professor Katharine Kelly for her support and insightful suggestions, particularly in the final stages of writing, and for helping to develop the concept of "disruption" more fully; and Professor Steven Prus for his help with organization of the thesis and assistance with understanding and presenting statistical data. Thank you also to external examiner Professor Charlene Miall for her detailed review of my thesis and also to internal examiner Professor Aviva Freedman.

Although they were not there to guide me to the end, I am grateful for the early assistance of Professors Valda Blundel, Francesco Lorrigio, Charlie Laughlin, and especially my initial adviser, Professor Rob Shields. Professor Shields was an ideal mentor to me: he offered guidance, consistent support- even when I floundered, numerous professional opportunities, and he helped immeasurably to develop my skills, confidence and enthusiasm for scholarship. I benefited tremendously from our discussions, his interest, and his work. I am also grateful that he encouraged me to complete the project although he was unable to supervise from afar.

Thank you to Dr. Norman Barwin who answered questions about counseling requirements, issues of access to infertility treatments and insurance coverage for infertility treatments in Ontario.

Thank you to the staff at Interlibrary Loans at Carleton University Library whose professionalism and efficiency greatly eased the task of researching and writing the thesis.

Thank you to FertilityFriend.com guides Alicia, Christie, Marie, Nichoel, Ruby and Wendy who are so competent and independent that they did not miss me when I was absorbed in the final stages of completing the thesis.

My gratitude to my husband, Frederic Montoya, cannot be overstated. Frederic offered tremendous emotional support and encouragement and did more than his share in many 
arenas so that I could have the time and space needed to complete this project. Additionally, Frederic offered professional expertise and intellectual stimulation that contributed enormously. He designed and built custom software to collect and analyze qualitative data. He assisted with graphs and tables and he helped to run and interpret the statistical analyses. Talking to him about my research and writing throughout the entire process was also very helpful and I always appreciate his ideas and intellect.

Deepest gratitude goes to my parents, Gerri and Larry Bromberg, for lifelong unconditional support of all kinds.

Thanks to my children, Tristan and Tamara, for love, light, laughter and indescribable joy. This is dedicated to you. 


\section{Table of Contents}

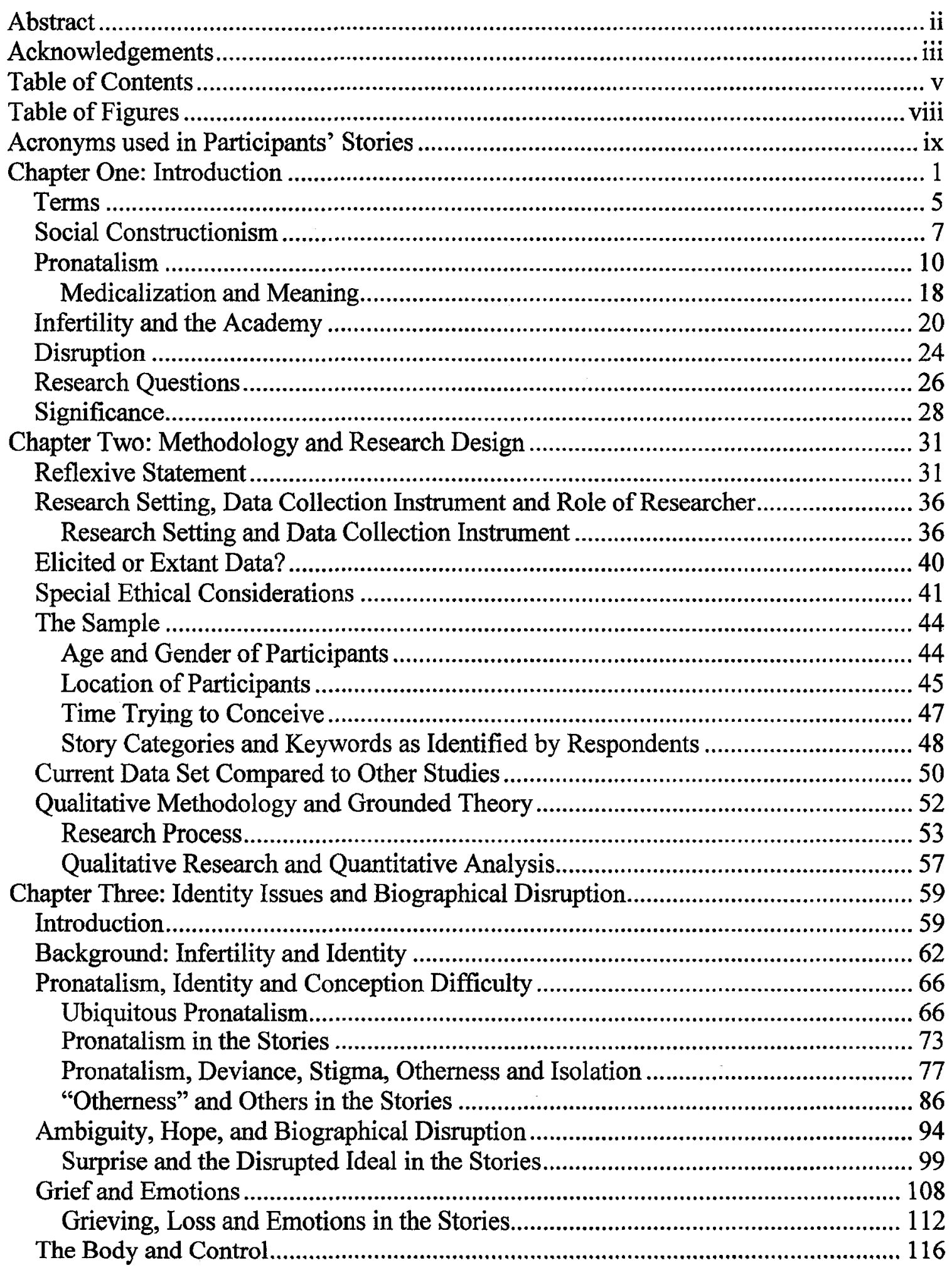


The Body and Control in the Stories......................................................................... 119

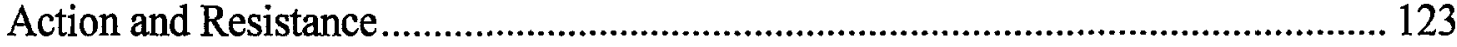

Support and Resisting Stigma.......................................................................... 124

Support in the Stories........................................................................................... 125

Taking Back Control............................................................................................ 128

Opportunities for Personal Growth............................................................................... 133

Results from Bivariate Analysis of Identity-Related Themes in the Stories ............... 135

Chapter Summary .................................................................................................. 141

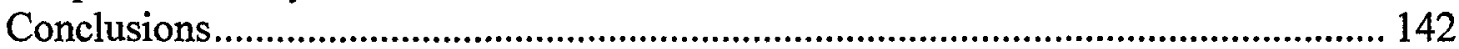

Chapter Four: Gender, Sex and the Spousal Relationship ............................................ 147

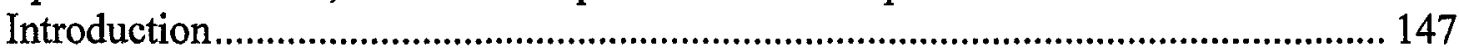

Marriage, Parenthood and Pronatalism.................................................................. 152

Marriage, Planning, and Worthiness in the Stories...................................................... 155

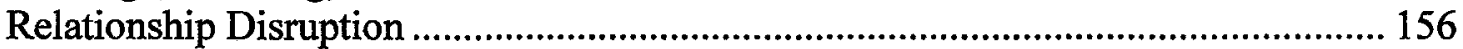

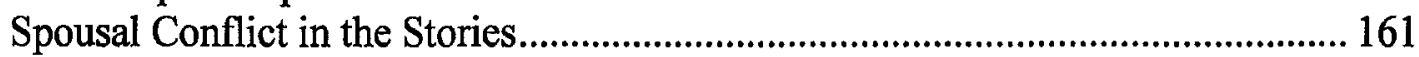

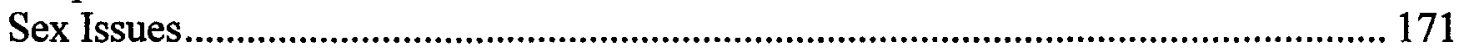

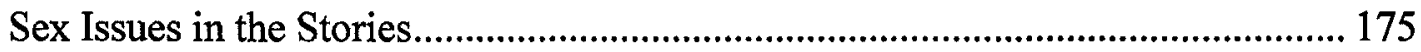

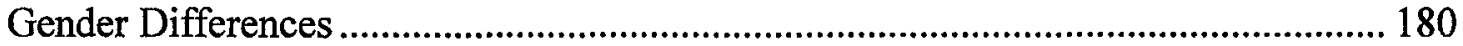

Support, Closeness, and Growth in Spousal Relationships .......................................... 188

Results from Bivariate Analysis of Relationship Themes Noted in the Stories .......... 193

Chapter Summary ............................................................................................... 195

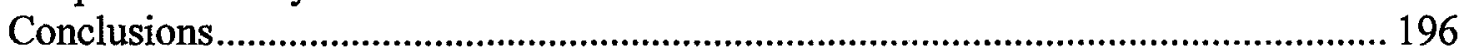

Chapter Five: Making Sense; Medicalization and Alternative Interpretations................ 199

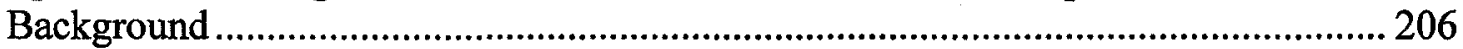

Medicalization and Making Sense of Illness ....................................................... 206

Infertility and personal meaning-making............................................................. 227

From the Story Gallery .................................................................................... 232

The Medical Maze: Accepting, Interpreting, Challenging and Navigating

Experiences within the Medical Model .............................................................. 234

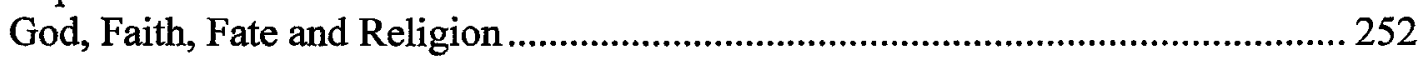

Culpability, Regret and Volition....................................................................... 258

Secular Meaning-Making.................................................................................... 264

Results from Bivariate Analysis of "Making Sense" Themes in the Story Gallery ... 267

Chapter Summary .................................................................................................. 268

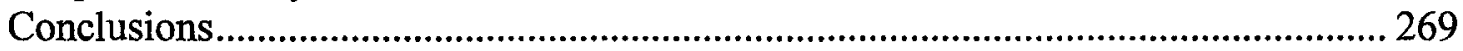

Chapter Six: Conclusions......................................................................................... 273

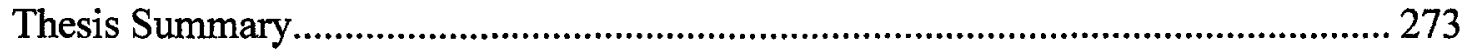

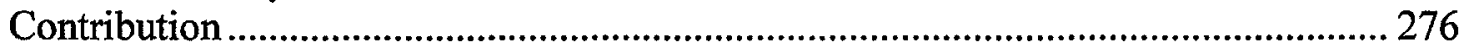

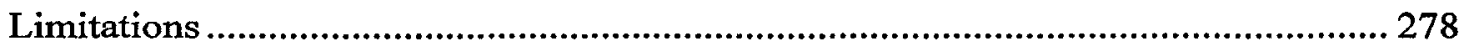

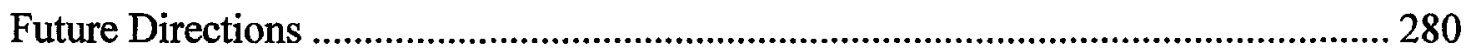

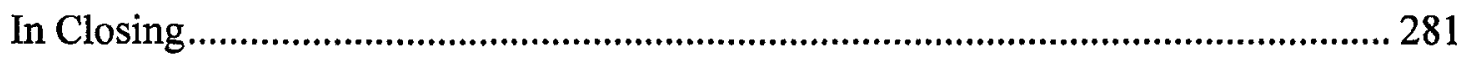

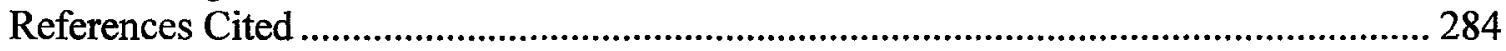

Appendix 1: Questionnaire and Consent Form.................................................................. 303

Appendix 2: Tag Cloud of Free-Form Keywords......................................................... 308

Appendix 3: Initial Taxonomy of Findings/Qualitative Meta-synthesis ........................ 311

Appendix 4: Selected Analytic Codes ............................................................................ 315 
Appendix 5: Selected Screenshots from Fertilityfriend.com ...................................... 319

Appendix 6: Selected Cross-tables Discussed in the Thesis. 


\section{Table of Figures}

Figure 1 Age Distribution of Participants ........................................................................ 45

Figure 2 Country of Respondents ........................................................................... 46

Figure 3 Pie Chart Showing Country of Respondents....................................................... 46

Figure 4 Participants' Time Trying to Conceive in Months................................................ 47

Figure 5 Story Categories Selected by Respondents ....................................................... 48

Figure 6 Respondents' Selected Keywords ......................................................................... 49

Figure 7 Current Sample Compared to Selected Previous Samples................................... 51

Figure 8 Emerging Core Category: Disruption/Interruption .............................................. 56

Figure 9 Screenshot of FertilityFriend.com front page...................................................... 319

Figure 10 Screenshot of front page of FertilityFriend.com cont. ..................................... 320

Figure 11 Screenshot of front page cont. ...................................................................... 321

Figure 12 Screenshot of Software Data Entry Page...................................................... 322

Figure 13 Screenshot of Annotated Fertility Chart.......................................................... 323

Figure 14 Message Board Screenshots ............................................................................ 324 


\section{Acronyms used in Participants' Stories}

A number of acronyms are used by the participants in their stories which have been cited throughout the thesis. To provide clarity to the reader, these are included below.

2WW: Two week wait (before taking a pregnancy test)

AF: Aunt Flo(w), menstrual period.

BBT: Basal Body Temperature (temperature taking to indicate ovulation)

BD: Baby Dance. Have intercourse for conception purposes.

BFN: Big Fat Negative (pregnancy test)

BFP: Big Fat Positive (pregnancy test)

CD: Cycle Day

CM: Cervical mucous, also known as cervical fluid, fluid produced by the cervix as ovulation approaches

CP: Cervical Position

DH, DD, DS: Dear Husband, Dear Daughter, Dear Son

DPO: Days Past Ovulation

EDD: Estimated Due Date

EWCM: Egg white (fertile) cervical mucous.

FF: Fertility Friend (fertilityfriend.com)

FSH: Follicle Stimulating Hormone

HPT: Home pregnancy test

IUI: Intra-uterine insemination

IVF: In-vitro fertilization

LOL: Laughing out loud

M/C: Miscarriage

O: Ovulation

OPK: Ovulation Prediction Kit

PG: Pregnant

PCOS: Polycystic Ovary Syndrome

POAS: Pee on a stick (take a pregnancy test)

RE: Reproductive Endocrinologist- Fertility Specialist

SA: Sperm Analysis

TTC: Trying to conceive 


\section{Chapter One: Introduction}

Over the past few decades, there has been a trend in Western countries towards postponing childbearing although the vast majority of women and men still expect to have children and still consider two children to be ideal (Lampic, Svanberg et al. 2006). It remains rare for a married couple to intentionally decide to remain childless (Mosher and Bachrach 1982; Daniluk 1988; Abma and Martinez 2006). Nonetheless, a significant minority of couples experience difficulty meeting these ideals and struggle with conception difficulties or infertility.

Infertility is commonly defined as the inability to conceive or to carry a child to term after twelve months of unprotected intercourse (Mosher and Pratt 1993). The prevalence of infertility based on this definition has recently been estimated to range from $3.5 \%$ to $16.7 \%$ of the population in more developed nations and from $6.9 \%$ to $9.3 \%$ in less developed nations, with a median worldwide prevalence estimated at $9 \%$ (Boivin, Bunting et al. 2007). In Canada, infertility is estimated to affect $8.5 \%$ of married women between the ages of 18 and 44 (Royal Commission on New Reproductive Technologies 1993). In the United States, infertility is estimated to affect $7 \%$ of married women between the ages of 15 and 44 (Stephen and Chandra 2006). When "lifetime" infertility is considered, rather than "current" infertility of women of reproductive age, the prevalence is estimated to be around 15\% (Stephen and Chandra 2000; Boivin, Bunting et al. 2007).

Medical causes of infertility can be nearly equally attributed to both female and male factors with female factors accounting for about a third of all infertility and male factors accounting for another third of causes, and the remaining third of causes attributed 
to either a combination of issues with both partners or "unexplained infertility" (American Society of Reproductive Medicine 1996-2008). Most women experiencing conception difficulties, however, will eventually conceive, either spontaneously or through infertility treatments (Taylor 2003). The female partner's age is perhaps the most significant factor determining infertility and the likelihood of conception. The American Society of Reproductive Medicine (2003) reports that the likelihood of infertility and the chance of remaining childless increase substantially beyond age 30 and then again dramatically after age 35 until infertility is most probable beyond age 44 .

The association of conception difficulties with increasing age is of great interest as couples embark on parenthood later in life. The age of first birth and the proportion of women without children beyond 25 years of age have been increasing since the 1970s (Baldwin and Nord 1984; Abma and Martinez 2006). A recent report from Statistics Canada (2008) notes that " $[\mathrm{t}]$ he average age of women giving birth rose steadily in the past 20 years, from 27.0 years in 1986 to 29.3 years in 2006 ". Further, "[i]n 2006, for the first time, the fertility rate of Canadian women aged 30 to 34 surpassed that of women aged 25 to 29 . This rate has been higher than the rate for women aged 20 to 24 since 1989 (Statistics Canada 2008)."

Although couples are increasingly delaying childbearing on average, and age is considered to be the most significant factor affecting conception probability, this has not, surprisingly, translated into an increase in the overall prevalence of infertility. Recent figures suggest that there has actually been some decline in the rate of infertility in recent years, though due to population composition factors, the absolute number of infertile couples has increased (Stephen and Chandra 2006; Boivin, Bunting et al. 2007). Public 
perception, however, is that infertility is increasing (Norris 2001). Factors contributing to this misperception include: an increase in the absolute number of infertile couples due to the large baby boomer cohort reaching (and now largely past) reproductive age; couples seeking infertility services more quickly due to concerns about age; less secrecy about infertility; increased media attention to infertility and reproductive technology; more physicians specializing in infertility; greater availability of fertility drugs and treatments; and fewer infants available for adoption (Mosher and Pratt 1993; Norris 2001).

I would argue as well, and will discuss this further in the pages ahead, that this misperception may also be a result of a subtle, yet fairly successful, current pronatalist campaign exhorting (the right) women to reproduce and embrace motherhood (lest they miss their chance) possibly at the expense of other fulfilling and socially rewarding activities and identities. Trends regarding voluntary childlessness would support this position. Voluntary childlessness increased between 1982 and 1988, held steady for some time, and then began to decrease between 1995 and 2002 (Abma and Martinez 2006) ${ }^{1}$. In Canada, the birthrate has been steadily increasing over the past few years. "Births continued an upward trend that began in 2002. From 2005 to 2006, the annual birth increase is 3.6\%, the highest growth since 1989 (Statistics Canada 2008)." The total fertility rate, or the average number of children per woman, was up from 1.54 in 2005 to 1.59 in 2006 (Statistics Canada 2008). Although this is the highest fertility rate since 1998, there is still concern that this is well below the replacement level of 2.1 (Statistics Canada 2008).

\footnotetext{
${ }^{1}$ The authors of the study suggest that the decrease in voluntary childlessness might be due to increasing ease of combining employment and childrearing.
} 
Additional misperceptions about infertility include the misplaced notion that it largely affects professional, affluent, middle-class, white couples, when non-white couples of lower socio-economic backgrounds are actually disproportionately affected (Hirsch and Mosher 1987). More affluent couples are, however, considerably more likely to seek medical treatment (Hirsch and Mosher 1987; White, McQuillan et al. 2006) raising issues of class and access. This also raises issues which will be discussed in the pages ahead about class and the construction of worthy versus unworthy parents.

Although infertility is now largely defined as a medical problem with medical solutions (Becker and Nachtigall 1992; Greil 2002; Sandelowski and de Lacey 2002), about half of women who experience conception problems do not actually seek medical assistance (Stephen and Chandra 2000; Boivin, Bunting et al. 2007). Because this population has been difficult to identify, they have been underrepresented in most research about infertility. Most scholarly work has thus focused on the experiences of white, middle-class, treatment-seeking women to the exclusion of those who chose not to, had yet to, or could not access medical treatment (Bunting and Boivin 2007). An advantage of the current study is that it is perhaps more heterogeneous and includes (though is not limited to) people who may have been previously inaccessible: people earlier in the experience who have yet to seek medical help and those who chose not to or did not have the resources to seek medical help or traditional organized support. Characteristics of the study sample are discussed in the following chapter.

The current cultural setting for women experiencing conception difficulties is somewhat different than it was just a few decades ago. A generation ago there was concern about overpopulation; there were fewer medical solutions to involuntarily 
childlessness; there were fewer medical practitioners specializing in infertility; there were more social solutions to childlessness, particularly adoption; there was little public awareness and understanding about infertility; there was less acceptance of alternative family styles, including child-free marriages; and there were less opportunities for women to have meaningful roles and status outside of motherhood and marriage. Today there is concern about maintaining the population in Western societies; women are starting their families later; there are few social solutions to infertility; there is increased awareness and even some fear about infertility; there are increased medical solutions and an increased number of medical practitioners specializing in infertility and there is increased acceptance and prevalence of alternative families and alternate roles for women. In spite of these changes, as I will discuss in the following pages, the personal experience of conception difficulties appears to be, in many ways, relatively unchanged for the participants in this study compared to that noted several decades earlier (Menning 1977; Pfeffer and Woolett 1983; Miall 1986; Rehner 1989). This is a testament to the strength of the ideals that make conception difficulties so painful and disruptive.

\section{Terms}

This thesis is about the experiences of women having difficulty getting pregnant, the meaning they assign to their experiences and the social context in which they make this meaning. So far, I have mostly used the term infertility and have used the standard definition of non-conception after twelve months of non-contraceptive intercourse. This is a medical definition and is the current favored term to reflect the experiences of couples trying to conceive within a medical framework. Infertility, however, does not tell the whole story. Infertility evokes the limbo-state of being "not yet pregnant" (Greil 
1991a) while engaging in medical tests and treatments. This definition does not necessarily apply to everyone who is trying to conceive, those who have not been trying a full twelve months, those who have stopped trying to conceive, or those who do not use medical treatments. Griel $(1991 \mathrm{a}, 6)$ also notes that couples who do not meet this clinical definition may have similar thoughts, emotions and self-definitions as people who do meet the definition. Alternately, the experience may be portrayed as involuntary childlessness (Miall 1985; Miall 1986; Monach 1993; Letherby 1999) which is more a social state than a medical definition. The concept of involuntary childlessness, however, does not necessarily include people who grew their families through non-biological means after trying to conceive a biological child or those who are experiencing difficulty conceiving a second child and, unlike infertility, this term suggests some permanence. Discussions about barrenness (which evoke images of the wrath of God) and sterility (which, like infertility is perceived as an attribute of the body, but unlike infertility, is seen to be a permanent condition) have largely been abandoned (Marsh and Ronner 1996) though the lexicon and its associations seem to have left an imprint on our collective psyche.

Although most related literature discusses "infertility", I have mainly used the terms "trying to conceive" or "conception difficulties" within the thesis. These are the terms most frequently used by the participants of this study, many of whom do not meet the clinical definition of "infertility" and also do not necessarily see themselves as medically infertile or anticipate being permanently involuntarily childless. These terms seem to be more morally neutral and practically suitable for the purposes of this thesis than other available terms. When discussing the work by others, however, I use the terms 
that they used, so within the thesis the experience may at once be designated as one of "infertility", "involuntary childlessness" or "trying to conceive". While this may seem to result in a certain inconsistency in terminology throughout the thesis, the various terms are used to convey subtle differences in meaning.

\section{Social Constructionism}

Social constructionism questions the existence of essential truths and “....insists that we take a critical stance toward our taken-for-granted ways of understanding the world, including ourselves (Burr 2003, 2-3)." According to the social constructionist position, what we take for granted as natural and normal are actually constructed artifacts that reflect and reinforce socially, culturally and historically situated values (Gergen 1985). Social constructionism emerged as a theoretical orientation in contrast to the realist, essentialist ideal that there is an objective, identifiable reality that can be discovered (Burr 2003, 5-6). Conventional knowledge, from the social constructionist standpoint, is not based upon objective and unbiased observation of the world (Burr 2003 , 3). Rather, truth is the product of power relations, never neutral, always acting in someone's interest (Lupton 2003, 12). In this vein, knowledge is the result of social relations and is subject to change (Lupton 2003,13). Even defining a particular social issue as a "problem" involves social construction based on societal values, with various groups and individuals maintaining an interest in the definitions (Goode and Ben-Yehuda 1994; Spector and Kitsuse 2001).

Social constructionist thought incorporates the following elements: a critical stance towards seemingly taken for granted knowledge and ideas; an awareness of the historical and cultural specificity of ways of understanding; and the idea that knowledge 
and truth are sustained and constructed by social processes and interactions that are embedded within existing power relations (Burr 2003, 2-5). Foucault's work on power relations within medical practice (1973), law (1995) and within understandings of sexuality (1988) is largely credited for providing much of the antecedents for current social constructionist thought (Burr 2003, 18; Lupton 2003 11-12), particularly within medical sociology (Turner 1997).

Within this framework, culture and social structure shape the way we understand and interpret our bodies, illness and disease (Freund and McGuire 1999, 189) and are historically and culturally relative (Burr 2003, 3-4). They are specific to, and dependent upon, prevailing social and economic relations (Burr 2003, 4). A social constructionist perspective contends that “... scientific knowledge and biological discourses about the body, health and illness are produced through subjective, historically determined human interests, and are subject to change and reinterpretation (Gabe, Bury et al. 2004, 130)." Medical knowledge and medical practice, then, are socially constructed and contribute to the shaping of social relations (Bury 1986).

Interpretations and experiences of conception difficulties are also shaped by the ideology and social structure of society (Greil 1991a, 7; Scritchfield 1995). Even the quick look above at the various terms that have been applied to the experience of trying to conceive and the subtle differences in their meanings and their connotations shows us something about the ways in which societal values shape our interpretations and understandings. The experience and the meanings associated with it are dependent upon the values of society. Ideas and values associated with gender roles, the social value of children, expectations about marriage and family, the value placed on science and 
medicine and the importance of biological ties all play a role in shaping the experience and the way people make sense of their experiences of trying to conceive (Greil 1991a, 7). Griel (1991a, 7) and Scritchfield (1995) refer to this social meaning-making in the context of infertility as "the social construction of infertility". Socially constructed values influence a couple's decision that they want to be parents and that they want raising children to be part of their marriages. When conception difficulties prevent or delay couples from attaining these goals and desires, social constructionism also plays a role in one's interpretations and responses. It impacts the way the experience is perceived on a personal and emotional level; it impacts the relationship between spouses; and it plays a role in determining the ways in which it is understood and the ways in which resolution is sought.

This social construction of conception difficulties is the predominant lens through which I examine the experiences of the participants in this study. Dominant middle class values associated with worthiness, the value of the nuclear family and biological kinship, hard work and its rewards, the role of science, technology and medicine and the value placed on control of one's body and self-efficacy all impact on the experiences of the participants, but are also perpetuated and reinforced within their stories and frame the way they are told. Meanings of femininity and masculinity, gender roles and expectations within marriage are also social constructions that impact upon the trying to conceive experience while they are also simultaneously reinforced and reflected within the experiences and perceptions of participants.

As they relate to conception difficulties, these social constructions can largely (though not entirely) be discussed within the related contexts of pronatalism (discussed in 
more detail below and in Chapters Three and Four) and medicalization (discussed below and in greater detail in Chapter Five). Among feminists, the use of the social constructionist framework has caused some tension and debate as it has been used to imply that women are unable to exert autonomy and agency over their decisions since they are said to be shaped within the context of dominant power relations that serve patriarchy (Meyers 2001). In Chapters Two, Five and also in the final chapter, I address the issue of the tension that the use of the social constructionist framework has caused while seeking to explore both social and personal meanings of conception difficulties as well as some of its limitations.

\section{Pronatalism}

\section{What is Pronatalism?}

From a social constructionist perspective, the concept of pronatalism, defined as '... any attitude or policy that is 'pro-birth,' that encourages reproduction, that exalts the role of parenthood (Peck and Senderowitz 1974)" influences the experience of those struggling with conception difficulties. Elements of pronatalism that impact upon people experiencing conception difficulties include the following social values: married couples should have children and should desire children (Veevers 1980; Miall 1985); children strengthen marriage and are an expression of marital love; children are essential to the well-being of men and women, especially women; a need for parenthood is innate; and having children confirms both feminine and masculine identity (Monach 1993, 46). The widespread perception of the nuclear family as "normal" is testimony to the powerful hold of pronatalist ideals. 
Menning $(1977,87-94)$ and Monach $(1993,52-54)$ note the pervasiveness of pronatalist ideology, suggesting that pronatalism and the value of the family and the motherhood ideal are reinforced in art, religion, mythology, advertising, entertainment and the media, all of which tend to romanticize and glamorize families with children. Pronatalism is also present in politics, the political process and social policies which universally favor parents over non-parents (Monach 1993, 53). Letherby (1999) adds that media images that present positive stereotypes of the traditional patriarchal family structure in which femininity is defined by marriage, domesticity and childbirth support pronatalist ideologies.

Adams $(1997,13)$ suggests that a "normalization process"' exists that works to maintain such ideals through discursive and institutional practices and this defines some practices as legitimate and places others in the margins. In this way, childlessness is in the margins and conception difficulties are disruptive to attaining what is "normal". The normalization process makes people want to conform to the norm (Adams 1997). This was perhaps most evident during the post-war baby boom when parenthood was especially exalted and family-life and the "good life" were seemingly synonymous (May 1995, 138). According to May $(1995,129)$ :

The ideology of domesticity, focused on the nuclear family with children, came to embody the hope for the future of the nation and the ultimate achievement of happiness and personal fulfillment for its citizens. The dual functions of patriotism and personal happiness marked a change in the concept of parenthood and marginalized the childless in unprecedented ways.

Adams $(1997,15)$ suggests that this is a kind of "moral regulation" that works by limiting the forms of expression that are available to us. What we believe is "normal" are actually representations of dominant interests (Adams 1997, 15). 


\section{Pronatalism as Social Control}

The concept of pronatalism ${ }^{2}$ as an instrument of social control was discussed in some detail by early feminist Leta Hollingworth as early as 1918:

The fact is that child-bearing is in many respects analogous to the work of soldiers: it is necessary for tribal or national existence; it means great sacrifice of personal advantage; it involves danger and suffering, and, in a certain percentage of cases, the actual loss of life. Thus we should expect that there would be a continuous social effort to insure the group interest in respect to population, just as there is a continuous social effort to insure the defense of the nation in time of war. It is clear, indeed, that the social devices employed to get children born, and to get soldiers slain, are in many respects similar (Hollingworth 2000, 355).

According to Hollingworth (2000), social control was needed to maintain the birthrate because women (in whom she suggested there was insufficient scientific evidence of a "maternal instinct") would not otherwise voluntarily take on the dangers of birth and pregnancy, nor the long and tedious years of labor and self-sacrifice needed to bear and raise children. She identifies a number of mechanisms of social control intended to impel women to bear and raise children, many of which are still relevant nearly a century later: promotion of ideals, such as the "womanly woman" enthusiastically engaging in maternal activities; the influence of public opinion, particularly via newspapers; laws; religious beliefs; education and socialization; art idealizing motherhood; taboos prohibiting discussions about the pain and dangers of childbirth and the monotonous, unpleasant nature of some features of child-rearing; the magnification of the joys and compensations of motherhood; and "bugaboos" which erroneously suggested negative implications of bearing no children or only one child and positive implications of bearing and raising children (Hollingworth 2000). These elements of social control can influence and

\footnotetext{
${ }^{2}$ She did not use this term, but rather called her article "Social devices for impelling women to bear and rear children". It was reprinted in 2000 with the title "Leta S. Hollingworth on Coercive Pronatalism".
} 
reinforce what is known as maternal instinct (Hollingworth 2000). While pronatalism assigns mothers an indelible moral identity, it also confers on them care-giving obligations which limit their employment opportunities, advancement prospects and longterm earning power (Meyers 2001).

\section{Selective Anti-Natalism}

Pronatalism exists alongside selective anti-natalism. Pronatalist values encourage some (fit, suitable, married) women to have children and at the same time discourages childbearing among others such as those that are very young, unmarried, lesbian, disabled, drug-addicted, aging, poor, or otherwise "unsuitable" (May 1995; Meyers 2001; Park 2002). The best evidence of anti-natalism is perhaps the policy implementing the forced sterilization of "unsuitable" women in the early part of the twentieth century when the low birth rate among middle-class women engendered fears of "race suicide" (May 1995). May (1995, 95-125) documents the process by which tens of thousands of "undesirables" in the United States were forcibly sterilized during the first several decades of the twentieth century. Forcible sterilization was carried out against the "feeble-minded", immigrants, poor women and women who engaged in "anti-social behaviors" and was believed to be an efficient and cost effective method of solving social problems (May 1995, 96-97). Forced sterilization of the poor apparently had the support of tax-payers who felt that the children of poor women were a drain of public resources (May 1995, 109). May $(1995,125)$ notes: "The successes of negative eugenics show how powerfully ideas of parental worthiness became woven into the social and cultural fabric." 


\section{Pronatalism in Historical Context}

To further make the case for pronatalism as a social construction, we can look at how attitudes about motherhood and reproduction and the value of children have changed historically and depend upon social and economic circumstances. In the $17^{\text {th }}$ and $18^{\text {th }}$ centuries, for example, the value of children was based on what they could give to the community and having one's own children was less important (Marsh and Ronner 1996, 19). At this time, there were also more opportunities for childless couples to care for children who were not biologically their own as childrearing was more communal and defined less by biological and legal ties than it would become later (May 1995, 31). An inability to have biological children at this time was seen as God's will (barrenness) and a woman unable to conceive a child would rarely have considered consulting a physician (Marsh and Ronner 1996). Families had an unsentimental attitude towards children, although children were seen as valuable for their economic contribution and for the sake of maintaining the community (Zelizer 1985; May 1995, 25). This lack of sentiment can be partially attributed to the high infant mortality rate which affected the degree to which parents were willing to invest emotionally in individual children (May 1995, 25). As children's economic value decreased and mortality rates dropped and individualism increased, children were constructed as priceless treasures (Zelizer 1985; Marsh and Ronner 1996). Zelizer, in Pricing the Priceless Child (1985) discusses the process by which childhood became increasingly sentimentalized in post-Colonial times and after the industrial revolution as children became decreasingly "useful" (or increasingly "useless") from an economic perspective. 
Most disquieting, perhaps, is that active pronatalist campaigns and policies have historically been put in motion when women appeared to be attaining the most autonomy (Sandelowski 1990b; Marsh and Ronner 1996). After the Civil War in the United States, for example, the birthrate dropped as some women began to make room for education and interests outside of the domestic sphere and there was much social concern about how to get (the right) women to reproduce more (Marsh and Ronner 1996, 75-76). This was the moment when physicians introduced the concept of "sexual science" which suggested that women had a "biological mandate" to marry and bear children, that failing to do so contravened scientific laws and their health depended on childbearing (Marsh and Ronner 1996, 78). Education and career aspirations were proposed to have a "sterilizing effect" on women (Sandelowski 1990b; Marsh and Ronner 1996). This pronouncement coincided with women's increased assertions for independence and political rights (Sandelowski 1990b). Again, in relation to the post war baby boom in the 1950s, Sandelowski (1990b, 491) notes: “Despite women's apparent adherence to the renewed pronatalist standard, the zeal with which both professional and popular literature on women prescribed marriage and motherhood betrayed the concern that these domestic goals were not the only ones attracting women."

\section{Pronatalism Now}

Notably, pronatalism was identified as a paramount factor related to the negative personal impact of involuntary childlessness several decades ago (Menning 1977, 92-94; Miall 1986). Menning (1977, 92) also cites Hollingworth's (2000) article originally published in the early years of the previous century about "social devices compelling women to bear and rear children" and suggests that similar social devices continued, at 
the time she was writing, to motivate women towards bearing and raising children. In 1977, she speculated that the impact of feminism and anti-sexism and the availability of birth control $^{3}$ did not yet impact her contemporaries but would be felt in another generation (Menning 1977, 99). A generation later, as I will discuss within the thesis, its hold is as strong as ever, in spite of increased opportunities for alternate roles and economic independence for women.

It may seem ironic to those struggling to conceive, but there is great current concern that educated, middle-class women are postponing motherhood into their thirties or forties or even forgoing motherhood altogether (George 2007). The May 28, 2007 Maclean's cover story was called "Hey Lady! What will it take to make you breed?" (George 2007) and discussed the negative impact of slow population growth among university educated, married couples on the future labor supply.

Most telling, perhaps, was the media frenzy created in 2002, when Sylvia Ann Hewlett's popular book Creating a Life: Professional Women and the Quest for Children $^{4}$ (Hewlett 2002a) was released. Hewlett (2002a; 2002b; 2004) claimed a high prevalence of dissatisfaction among professional childless women in their forties and suggested that young, career-minded women should make finding a mate their top priority and embark on childrearing before embarking on careers. Her premise was that career women were not happy once their reproductive years had passed. In spite of all their successes, what they really desired, what they really should have done was make

\footnotetext{
${ }^{3}$ Menning (1977) also mentions concerns about population control in the 1970s that would be felt in a later generation. Currently, however, population ageing and "baby shortages" are of greater policy concern in the West. (Grant and Hoorens 2006)

${ }^{4}$ See also Hewlett's article, "Fast track women and the quest for children" in Fertility and Sterility (2004) and "Executive women and the myth of having it all" published in the Harvard Business Review (2002) for a succinct glance at her perspective.
} 
motherhood a priority. Why did this story get so much media attention? The author was featured in a lengthy segment on television's 60 Minutes (Arnst 2002). The title of Business Week's review is "The Loneliness of High Powered Women" (Arnst 2002). Time devoted their April 15, 2002 issue to Hewlett's results. The Time cover showed a woman lovingly cradling a briefcase and working on an electronic hand-held device and reads: "Babies vs. Career: The biological odds are against a woman over 35 bearing children. That reality is reopening the debate over kids and careers." Two weeks later, Dunson, Colombo et al's (2002) publication that female fertility begins to decline significantly by the late twenties (earlier than previously believed) also garnered a great deal of media attention with stories being picked up by the Associated Press and CNN (CNN 2002). The overwhelming message to professional women who planned to have children in the future was this: Stop postponing motherhood. Women who wait too long will be sorry. The Macleans article (George 2007) also notes the impact of celebrity tabloids which make motherhood look breezy and beautiful, especially when it includes "blissful mommy props" such as designer diaper bags and luxury strollers. It is not a stretch to suggest that women are affected by the simultaneous messages associating delaying childbearing with loneliness and dissatisfaction and motherhood with warmth, celebrity and beauty. This social framework provides some context for the experience of women trying to conceive. The ways in which pronatalism affirms its strength despite societal changes and the ways in which it has adapted to maintain its appeal in spite of increased role options for women will also be discussed.

\footnotetext{
${ }^{5}$ Hewlett's premise (and the popular media's collusion with it) that women could achieve greater happiness by starting families before starting careers has been appropriately lambasted (see for example Franke-Ruta 2002).
} 


\section{Medicalization and Meaning}

With regards to conception difficulties, pronatalism is linked to another social construct that is relevant to the thesis: medicalization. Medicalization is the process whereby human conditions that fall outside of accepted social norms are redefined as medical problems with medical solutions (Becker and Nachtigall 1992). Medicine is said to operate as a mechanism of social control by claiming expertise and authority over matters that were not previously defined in the medical sphere (Nettleton 1995, 27). The authority of medicine to define reality is particularly persuasive because of its close bonds with scientific knowledge which has a privileged status in hierarchies of belief in western society (Starr 1982, 4). According to Starr, $(1982,4)$ :

The history of medicine has been written as an epic of progress, but it is also a tale of social and economic conflict over the emergence of new hierarchies of power and authority, new markets and new conditions of belief and experience. In America, no one group has held so dominant a position in this new world of rationality and power as the medical profession.

Medicalization critics claim that the problem with medical authority is that it creates a situation of dependency and obedience since physicians have the knowledge and thus the power to define experiences within this context (Starr $1982,4-11)$.

For middle class women in Western society, medicalization of infertility is nearly complete although it is relatively recent (Becker and Nachtigall 1992; Greil 2002). The social problem of involuntary childlessness became the medical problem of infertility (Becker and Nachtigall 1992). Prior to the 1950s, infertility was largely considered an emotional problem (Whiteford and Gonzalez 1995). Medicalization began in the 1960s and 1970s with the development of synthetic drugs that could control ovulation and the 
development of laparoscopy which allowed doctors to see women's internal reproductive system (Whiteford and Gonzalez 1995). "This shift [towards medicalization] has occurred in tandem with increased medical emphasis on infertility, including increasing numbers of physicians who specialise in reproductive endocrinology, an escalation of research on infertility, and the development of reproductive technology (Becker and Nachtigall 1992, 457)." Medicine, then, is said to be a mechanism of social control, as women who encounter stigmatization due to an inability to meet societal norms associated with pronatalism, seek medical assistance and submit to medical authority to relieve their sense of deviance (Becker and Nachtigall 1994; Whiteford and Gonzalez 1995).

Some feminists (Corea 1985b; Corea 1985a; Klein 1989b; Menzies 1994) have argued that the socially constructed, pronatalist context (in addition to the authority of the medical profession which they say mirrors capitalist and patriarchal social relations) thus makes the use of reproductive technologies unethical and coercive because women are compelled by patriarchal societal expectations, rather than their own free will, to use them at great risk and possible harm to themselves (Menzies 1994; Søbirk Petersen 2004). I agree with Søbirk Peterson (2004) and Sandelowski (1990a; 1993) that this argument is faulty and that the women concerned are in the best position to make informed decisions about their use. Responses from participants in Chapter Five will also show that submission to medical authority has been overstated, although medicine itself is not widely challenged. If pronatalist societal expectations cause women experiencing conception difficulties to experience distress and stigmatization, efforts should be made to reduce the impact of pronatalism and validate alternate ideals and lifestyles, not limit 
women's options (medical or otherwise) to resolve their distress. Shedding light on the pronatalist context should in no way limit women's choices with regards to reproductive technologies. The relationship between pronatalism, medicalization and making sense of conception difficulties is discussed in greater detail in Chapter Five.

\section{Infertility and the Academy}

Prior to the $1980 \mathrm{~s}^{6}$, little scholarly attention was paid to social aspects of infertility. Discussions about infertility were, until relatively recently, largely relegated to medical texts and concerned bio-medical causes, treatments and solutions, epidemiology and medical psychology (Van Balen and Inhorn 2002). Even dialogue about psychological and emotional aspects of infertility mainly took place in medical journals up until the late 1980s (Seibel and Taymor 1982; Mahlstedt 1985; Morse and Van Hall 1987; Raval, Slade et al. 1987; Daniluk 1988; Paulson, Haarmann et al. 1988; Hirsch and Hirsch 1989). This work was important for recognizing some of the personal and emotional components of infertility, but lacked significant social context and rarely acknowledged the vested interests of medical professionals in representing the experience simultaneously as a disease and an emotional crisis and those seeking medical solutions as "desperate".

In the past two decades there has been increased interest in reproduction as a socially and culturally constituted phenomenon, largely fueled by feminist and ethical interests in reproductive technologies, growth in medical sociology and increased interest in the socially constructed nature of women's reproductive experiences (Van Balen and

\footnotetext{
${ }^{6}$ Concern about social aspects of infertility grew post-1978 after the birth of the first "test tube" (IVF) baby.
} 
Inhorn 2002). This work focuses on the social context of reproduction and calls attention to the ways in which dominant social values are represented and reinforced within experiences of infertility. Still, much of it does little to validate women's personal experiences (Sandelowski, Holditchdavis et al. 1990; Sandelowski 1993). Early feminist discussions which criticized the use of reproductive technologies as being instruments of capitalism and patriarchy (Corea 1985b; Corea 1985a; Klein 1985; Klein 1989a; Klein 1989b) particularly have been criticized for failing to authenticate the experiences of the women who use them, for depicting them as irrational, lacking consciousness, placid, and without agency (Sandelowski 1990a; Sandelowski and de Lacey 2002).

Differences in representations of the experience of infertility are very much the product of the situation of those making the representations (Strickler 1992) and this can be seen in the literature as well as the data collected for this and other related studies. One's position is embedded in vested interests and purported values may be seen as tools for making claims, defining the problem and constructing solutions rather than as underlying motivations for a particular position (Strickler 1992). The main bodies of literature on infertility represent at least three very different positions with vested interests: medical professionals, infertile women and feminists. While they cannot, of course, all be painted with the same brush, as a whole, they occupy very different orientations and concerns. Physicians, for example, largely see reproduction as an area of professional specialization, with professional rewards, and frame the problem in a clinical manner (Strickler 1992). Infertile women are constructed as patients and infertility is a disease in this discourse (Sandelowski and de Lacey 2002). Where social and personal meanings are considered within the medical discourse, these may be seen to justify 
medical treatment and thus reinforce the position of those making the claims, although this is not explicitly acknowledged. Infertile couples also have a vested interest: getting their "own" biological baby, maintaining control, meeting a social norm, attaining a life goal, and getting access to resources to meet their medical and psychological needs (Strickler 1992). The infertile are thus interested in representing themselves as deserving of sympathy and resources and this can also be seen in their representations of themselves and the experience (Sandelowski and de Lacey 2002). Their interests converge with those of medical professionals because they are entitled to resources and sympathy when infertility is constructed as a disease located in the individual body (Sandelowski and de Lacey 2002). In this discourse, infertile women are "heroic sufferers" (Sandelowski and de Lacey 2002). While medical professionals and the infertile themselves do not usually acknowledge the larger social context and social meanings of reproduction, feminist discourse on infertility and reproductive technology begins with the position that motherhood has been used to justify the limitation of women's opportunities and that women's reproductive capacity should not be controlled by physicians (Strickler 1992). The use of reproductive technology and the construction of infertility as a disease, feminists suggest, reinforces motherhood as women's central (and limiting) role and usurps women's power over their own reproduction, thus threatening the feminist goal to expand women's choices, autonomy and control over their lives (Strickler 1992). Feminist discussions, then, revolve around these social issues rather than the clinical meanings of the physicians or the individual, personal meanings of the infertile.

Accounts of the experience of infertility from the fields of psychology and the social sciences also construct the experience in ways that are embedded in vested 
interests (Sandelowski and de Lacey 2002). Depicting the infertile as emotionally distressed, for example, constructs them as in need of counseling and psychological services and widens the range of the professionalization of infertility (Sandelowski and de Lacey 2002). Ethnographers and sociologists have vested interests also and "use" infertility as a currency to expose the "culture" embedded in science, technology and seemingly taken for granted notions about the value of children and motherhood (Sandelowski and de Lacey 2002). We are not all having the same conversation and we are not all talking to each other. In various contexts, different discourses are privileged and used to make claims.

Recently there has been a call, particularly among feminists, for the development of wider, more nuanced positions regarding the experiences of women struggling to conceive (Woollett 1996; Franklin 1997b; Franklin 1997a; Ulrich and Weatherall 2000; Conrad 2007). The various discourses need to be integrated. This thesis makes an effort in this direction, but I want to especially privilege the personal meanings. I have attempted here to honor, discuss and pay tribute to the rich, personal meanings of conception difficulties as well as acknowledge and discuss the importance of the social context in which those meanings are made and the various interests of the stakeholders. The participants are recognized as navigating their environment and a profound disruption to their lives rationally, making sense of their experiences in a way that is dignified, makes sense for them, and demonstrates their ability to exert control and make choices that serve their interests. I acknowledge both benefits and limitations of medical technology and discuss how perceptions of their benefits and limitations are socially constructed. I discuss how the pursuit of biological parenthood is mediated by dominant 
social values and ideals, particularly those associated with pronatalism, but also how that pursuit makes sense contextually for the participants. Infertility is located in the body and in social meanings. The experience is personally experienced and culturally mediated. The people talking about it have stakes in how it is constructed. In spite of alternative role options for women, pronatalist values that privilege motherhood as the primary role for women and require parenthood for married couples are as strong as ever.

\section{Disruption}

With the above issues in mind, the central theme of the thesis is that of disruption. Using a grounded theory methodology, disruption, in a variety of guises, emerged as the pivotal theme in the data collected and analyzed for the thesis. When the "normal" is disrupted, this provides an opportunity to examine those seemingly natural social assumptions and associated behaviors (Bury 1982). The cultural meaning of children, childlessness, feminine identity and motherhood, then, can be explored via the sense of disruption that is experienced when conception does not occur as planned. The social context defines what is normal so disruption occurs within a social context where normalcy and stability are defined by prevailing ideals (Becker 1997, 15). When we talk about disruption, then, we also talk about normalcy and stability (Becker 1997, 15). Looking at disruption, an experience where things do not happen as desired or anticipated, where things are not normal and stable, also reveals something about taken for granted values, ideals and cultural constructs (Becker 1997, 15). The experience of disruption, then, can highlight the nature of social constructs and how social values and ideals are felt and enacted by individuals. 
This is discussed in the body of the thesis. Chapter Three, Identity Issues and Biographical Disruption, discusses the ways in which conception difficulties are experienced as an inability to meet a social norm and portrayed as disruptive to concepts of one's self as healthy, complete, functioning and "normal". The ways in which conception difficulties are seen to disrupt life goals and plans, make it difficult to plan for the future, and the ways in which conception difficulties are expressed as disrupting relationships with others are also explored. Chapter Four, Gender, Sex and the Spousal Relationship discusses social ideals, disruption and conception difficulties in the context of sex, gender, and the relationship between spouses. Finally, Chapter Five, Making Sense: Medicalization and Alternative Meanings addresses the ways in which participants interpreted and made sense of the experience and the associated disruption and the social context in which interpretations were made. Each chapter includes a literature review and a discussion of the relevant issues and discusses those issues with regards to responses from the participants as well as results from a bivariate analysis of themes identified in the stories based on various characteristics of the participants. The experience of disruption, then, in its many dimensions, from the point of view of the participants, is in the foreground. The background question examines the social context: Why is the experience portrayed and perceived to be so disruptive?

The concept of disruption and the ways in which this is experienced when a significant life goal and a significant aspect of one's planned identity cannot be reached may also aid in understanding of other situations. In the thesis, I describe the ways that conception difficulties in particular are experienced as a significant life disruption. The impact on relationships and emotions, feelings about the self and one's body are 
considered and the ways that people find meaning in the disruption are examined. This may be useful to further develop the concept in relation to a host of unanticipated, disruptive life experiences (divorce, the death or illness of a loved one, involuntary migrations, job loss, chronic disease, disability, a spouse's infidelity, academic failures, bankruptcy, homelessness, etc). Findings here may be applicable to more general questions about unexpected personal disruptions: Which social ideals create a sense of disruption when they are not met? Can a framework for the experience of personal disruptions be developed? Is there a pattern to the experience of disruption? Do other kinds of encounters with disruption similarly impact upon identity? Do they similarly affect relationships, emotions and world views? What methods do people use to normalize the sense of disruption and find meaning in it? Looking at conception difficulties with disruption as the central theme may be a step towards answering some of these questions in other contexts as well.

\section{Research Questions}

The research process is discussed in greater detail in the following chapter on methodology. The significant questions and concepts are briefly summarized below. They relate to the intersection and relationship between the three following themes: disruption (the core concept); pronatalism (the social context); and conception difficulties (the illustration).

Conception Difficulty: The initial analysis focuses on the stories of 327 women who were trying to conceive. These stories address the following illustrative questions which are considered within the thesis: 
1. How do women trying to conceive portray their personal experiences of conception difficulties and assign meaning to them?

2. How do social factors affect the meaning that is assigned to the experience?

3. What can an analysis of this new data sample add to discussions about the personal and social meanings of infertility/involuntary childlessness?

Pronatalism: Analysis of the stories revealed that the social context of pronatalism and other socially dominant ideals continue to play a significant role in shaping the experience of conception difficulties and the ways in which the participants assigned meaning to the experience. With regards to pronatalism, the following questions are considered:

1. How does the social context of pronatalism continue to shape the experience of trying to conceive and affect the way one makes meaning in the face of conception difficulties?

2. In what ways do the participants resist the potentially negative impacts of pronatalist ideals and navigate the context in a way that serves their own interests?

3. How do conception difficulties provide an opportunity for reconsidering dominant social ideals such as pronatalism?

Disruption: Finally, analysis of the stories showed that conception difficulties were primarily experienced as a significant life disruption when internalized societal norms, particularly those defined within the context of pronatalism could not immediately be met. Disruption occurred when conception difficulties prevented participants from following an anticipated (normative) life trajectory and assuming an anticipated 
(normative) identity. This created the opportunity to further explore disruption as a social concept. The following questions are explored with regards to disruption:

1. What is the experience of disruption like as it relates to conception difficulties?

2. What are the dimensions of this disruption?

3. What aspects of life are affected by disruption?

4. How does one make meaning from disruption?

5. Can the concept of disruption as illustrated here with regards to conception difficulties be applied to other social contexts as well?

\section{Significance}

This is not the first qualitative study that explores a wide range of personal and social meanings of conception difficulties (Pfeffer and Woolett 1983; Miall 1986; Sandelowski 1988; Greil 1991a; Monach 1993; Becker 1994; Letherby 1994). I am also not the first to identify disruption as a pivotal element of the experience (Greil 1991b; Becker 1994). Others have also used a social constructionist framework to examine infertility or called upon the concept of pronatalism or normative beliefs about motherhood to situate the experience (Menning 1977; Miall 1986; Greil 1991a; Monach 1993; Becker and Nachtigall 1994; Scritchfield 1995; Whiteford and Gonzalez 1995; Letherby 1999; Ulrich and Weatherall 2000). The concept of biographical disruption has been explored by Bury (1982) in relation to chronic illness and Becker (1997) illustrates how people create continuity after disruptive life experiences, making use of a variety of life experiences, including infertility. The following aspects of this thesis, however, offer an opportunity to build upon this work. 
1. The broad internet based sample of stories from 327 women worldwide has allowed me to explore the experience from a wider range of perspectives than has previously been possible and has allowed the inclusion of individuals with characteristics that have been excluded from previous studies. I have been able to compare the different ways that the experience impacts on women with various characteristics. The sample characteristics are discussed in greater detail in the following chapter.

2. With disruption emerging as the dominant theme within the stories, I have been able to explore it as a concept in multiple dimensions and identify and discuss key elements of disruption as they relate to conception difficulties. I have situated this within the context of socially dominant ideals to which the majority of the participants seem to want to conform.

3. My position with regards to the site from which the participants were recruited has allowed for a creative methodology. Notably, the research for the project is a living resource for the participants or other interested parties as the stories analyzed for this project (as well as stories submitted later) are publicly available online. The value of the stories, thus, extends beyond this thesis.

4. This work contributes to building a more nuanced perspective about the experience of conception difficulties that considers both the social context and the importance of personal, individual meanings. The outlook is one that acknowledges aspects of pronatalism and medicalization and other socially dominant ideals as potentially limiting, socially constructed ideologies. I examine the way they impact on the experiences of women trying to conceive, but also 
represent the participants sympathetically and identify a number of ways that women resist or normalize negative impacts on their identities, future goals, relationships and their world views. I also consider the ways in which the experience offers opportunities for self growth and relationship growth and potentially challenges normative and dominant social constructs.

5. Examining the social context of pronatalism as a significant factor influencing the experience of conception difficulties, noted as an instrument of social control nearly a century ago (Hollingworth 2000) and as impacting negatively upon the experience of conception difficulties a generation ago (Menning 1977; Miall 1986), offers an opportunity to explore the ways in which it continues to influence women's experiences, how its impact and its characteristics may have changed over the past generation, and the ways in which it may be resisted and navigated.

6. Finally, this work is a potential stepping stone to further the concept of disruption as it might be applied to other sociological contexts both within and beyond issues of reproduction and health. 


\section{Chapter Two: Methodology and Research Design}

This chapter discusses the methodology and research design of the project. In addition to describing the data collection and analysis methods, it includes a reflexive statement, a description of the research setting and a discussion of the role of the researcher. A discussion of ethical considerations and a description of the sample of participants are included.

\section{Reflexive Statement}

Researchers are increasingly encouraged to acknowledge their own positions, interests and biases with regard to the research questions they address. This is particularly the case for researchers using qualitative methods. Auerbach and Sliverstein $(2003,27)$ advise qualitative researchers that subjectivity and values cannot be controlled; instead they should be acknowledged and reflected upon in a systematic way. According to Hammersly and Atkinson $(1983,25)$, "By including our own role within the research focus and systematically exploiting our participation in the world under study as researchers, we can develop and test theory without placing reliance on futile attempts to empiricism, of either positivist or naturalist varieties." Additionally, acknowledging one's own perspective reflexively reduces the distance between the researcher and research "subjects" and is thus less objectifying (Steier 1991, 2). Reflexivity is also important where the interpretation of representations of others is an issue and as such is one response to the "crisis of representation"7 (Clifford, Marcus et al. 1986; Marcus and

\footnotetext{
${ }^{7}$ Representation was initially declared "in crisis" with the 1986 publications of Writing Culture by Clifford and Marcus and Anthropology as Cultural Critique by Marcus and Fischer. As this "crisis" was brought to the fore, researchers increasingly began to acknowledge that no representation is objective and free from
} 
Fischer 1986; Sandelowski 2006). Because the nature of the representations made are inextricably linked to the outlook and background of those making them, explicitly acknowledging the researcher's position and interests has been included as a dimension to evaluate the rigor of qualitative research (Hall and Callery 2001). To this end, I briefly discuss how I came to be interested in the lives and experiences of women experiencing conception difficulties and how my own positions and perspectives may affect my outlook.

I occupy a variety of positions with regards to the research subject: I am a mother who shares with the participants of this study a feeling that children enhance my life and that motherhood is a personally rewarding experience ${ }^{8}$; I earn my living providing a service to women who are trying to conceive; I am a feminist interested in ensuring women's ability to maintain autonomy over their reproductive lives. Below I discuss how these positions may affect my perspective and offer some background about how I came to be interested in the experiences of women trying to conceive.

My immersion into the lives of women with conception difficulties began in 1997 when I co-created FertilityFriend.com, a website where women learn how to chart and interpret their fertility signs (basal body temperature data, cervical fluid observations, menstrual cycle days, etc.) and keep track of all their fertility data using the internet. My initial motivations for creating the site were twofold. First, I had a feminist-inspired desire to bring fertility awareness ${ }^{9}$, an easy, empowering, non-invasive and drug-free

bias. Over twenty years later, it is widely acknowledged that representations are not objective, but are shaped by context, including the position of the researcher.

${ }^{8}$ The moral dimension of motherhood is demonstrated here as I am aware that it would be suspect to publicly identify my position as "mother" anywhere but in the first rank or to acknowledge any ambivalence about its rewards.

${ }^{9}$ Fertility Awareness (FAM) is a method of charting fertility signs, such as basal (resting) body temperature, cervical fluid observations and menstrual cycle days so that a woman can note when she is 
method to manage one's fertility, to the mainstream (Marshall 1997; Winstein 1999; Weschler 2002). Second, and in keeping with my academic interests at the time, (Bromberg 1996a; Bromberg 1996b) I wanted to participate in the emerging internet revolution which, in the mid to late nineties, seemed to me to promise exciting new opportunities for education, connection, empowerment, democracy and communication. The internet of the mid to late nineties was exciting to me and I shared with others of the moment (Rheingold 1993; Reid 1994; Turkle 1995) an attitude of utopian optimism (with only a small grain of skepticism) with regards to the potential of computer-mediatedcommunication.

From the very beginning, the site almost exclusively attracted women planning pregnancies and women experiencing conception difficulties. This quickly became the focus of the site. A community message board, an electronic support system and a number of educational features and related content were integrated into the site. As I worked with my partner to develop content and tools to support and address the concerns and interests of these women, engaged in online support, and as I saw them connecting with one another on the message board, bonding over their common experiences, I was introduced to their world. I was frequently moved by their experiences and I became deeply interested in and sympathetic to their struggles and concerns.

I have heard from women trying to conceive (largely from reviewing the stories that form the data for this project and also on internet message boards where women experiencing infertility connect) that "only those who have experienced infertility can

most/least fertile, when she has ovulated and when she should expect her menstrual period (or a positive pregnancy test result). This can be used to avoid or increase the chances of conception. Women who are trying to conceive can use this information to determine if they are ovulating and if they are timing intercourse to coincide with their fertile time. 
understand it." At times I have thus felt uncomfortable acknowledging that I did not personally experience conception difficulties. Nonetheless, with sympathy and respect, I believe I can contribute meaningfully to the discussion without this personal experience. I aspire to produce results that are respectful and sympathetic to people experiencing conception difficulty and my aim is to reflect their experiences and concerns and represent them with dignity.

Similar to the majority of the research participants for this project, I "always knew" I wanted to be a mother "when the time was right." Like them, I see parenting as a rewarding, life-enhancing, valuable pursuit. This taken-for-granted-ness of parenthood as a "natural" stage in nearly everyone's life, when "suitable" conditions, such as marriage and financial security, are met, reveals a great deal about the (pronatalist) values of a society. A strictly feminist methodology would elucidate and possibly castigate the socially constructed nature of such beliefs and values and demonstrate the ways in which they limit women's choices and opportunities and contribute to their suffering when those ideals are not met (and even when they are). It would require a critique of the values of a society where (some/worthy) women achieve their most valued identity via motherhood (so why would it still be socially undervalued?), an identity that has historically limited women's autonomy and economic opportunities; where other socially valuable roles are still often denied to them; where limiting traditional gender roles persist; and where biological ties are seen as preferable to social ties such as those created via adoption or fostering. It would fully interrogate the way infertility has become an individual problem with individual, largely, medical solutions, when we should be looking at collective, social solutions, especially preventing infertility by addressing social and environmental 
factors and honoring and respecting a variety of social roles for men and women. In relation to age-related infertility especially, the most pressing issues would be: Why do women still have to decide between delaying or forgoing career ambitions and embracing parenthood in a way that men do not? Why must the trade-off for conceiving before career and education aspirations are met, before fertility begins to decline, so often still mean economic dependence for women and limited career options? Why must women individually and strategically navigate this minefield of "choices" when we should instead be seeking ways to ensure, via daycare and parental leave policies, and the modification of corporate and social attitudes, that family and career aspirations should not be mutually exclusive for men or women? Why does the motherhood mandate persist in spite of enormous social and professional gains and increased options for women?

Such a discussion would, I expect, ultimately reveal that "having it all", something young women have come to anticipate through rhetoric, often really turns out to mean having a little bite of everything and still feeling unsatisfied and exhausted.

These issues are not in the forefront of the thesis, although I believe they are important. In a different context, these could be concerns that I would want to explore further and address in greater detail. Certainly they are here, but in the background. As a feminist, this creates some tension. I want to simultaneously represent the participants as autonomous, self-determined, and with agency, and I want to privilege their voices above all others, and I want to identify how some choices, desires and ways of making meaning are constrained by pronatalism and other outmoded social ideals (Meyers 2001). My primary concerns, however, are the lived experiences, interests and issues of women experiencing conception difficulties and my allegiance ultimately lies with them. Any 
critique herein is meant as a critique of the context, not the individuals. Where it is not possible to reconcile these (at times) seemingly conflicting perspectives, I want to lean towards honoring, validating and respecting the experience of the participants.

Like, Sandelowski (1990a; 1993), and I suspect like most of the research participants themselves, I believe that these individual women, unless they desire it themselves, should not be required to play a role in these academic, social and political debates. They should not be criticized for the choices they make to reach their personal goals; they should not have their choices limited and their values maligned; and they should certainly not be implicated in the reproduction of patriarchy or capitalism for pursuing their own personal life goals (Sandelowski 1990b). Many of these debates do not really serve the immediate interests of women experiencing conception difficulties, who mostly request compassion, understanding and a respect for their right and ability to determine their own best future.

\section{Research Setting, Data Collection Instrument and Role of Researcher}

\section{Research Setting and Data Collection Instrument}

The "setting" or source of data for this research is a subset of stories from the "Trying to Conceive Story Gallery" on FertilityFriend.com ${ }^{10}$. The Trying to Conceive (TTC) Story Gallery is an online database of women's own stories, written in their own words in response to a series of guiding questions about their experiences of conception difficulties. The stories were collected from women who had used FertilityFriend.com to

\footnotetext{
${ }^{10} \mathrm{~A}$ few screenshots of selected pages from FertilityFriend.com are included in Appendix 5 to offer a view of the nature of the site at a glance.
} 
chart and interpret their fertility signs while trying to get pregnant and are accessible on the internet. ${ }^{11}$ The Trying to Conceive Story Gallery is described on the website as follows:

FertilityFriend.com's Story Gallery is a place to share and find real life, authentic stories about all aspects of the Trying to Conceive (TTC) journey. FertilityFriend.com members are encouraged to share their personal stories and experiences. We welcome stories from members at all stages of the TTC journey and those who have already become pregnant.

The sample for this project includes the first 327 stories from the database. The stories included in the subset were submitted between October, 19, 2006 and July 9, 2007. The first 80 submissions were collected between October 19, 2006 and October 26,2006 before the database was publicly viewable. This was to achieve enough initial diversity so that future participants would not be overly influenced by previously published stories. On October 26,2006 , the first 80 stories were published directly to the website and future submissions were published within approximately one week of submission. The public database currently has 1586 stories $^{12}$ and submission is ongoing. Each story has its own unique web address and may be accessed on the internet. ${ }^{13}$ As of September 12, 2008, the TTC Story Gallery had received over 415000 page views from site visitors.

The instrument used to collect the stories and data from the participants was an online form on FertilityFriend.com. The form is copied in its entirety in Appendix 1. To begin, participants were presented with an "Information, Consent and Disclosure Form."

\footnotetext{
${ }^{11}$ The Story Gallery can be found at: http://www.fertilityfriend.com/sg/.

${ }^{12}$ On September, 12, 2008

${ }^{13}$ To find the full story of an extract that has been cited in the thesis, add "story\#\#\#\#\#\#.html" to the end of the following web address: http://www.fertilityfriend.com/stories/ (where \#\#\#\#\#\# represents the figures cited after the quotation).Though the public web address for stories cited is provided in this dissertation, participants can remove their stories themselves from the public database so it is possible that a story that has been cited will no longer be accessible.
} 
Once they had agreed to the terms, they were asked to categorize their story, provide a limited amount of demographic information (their age, how long they had been trying to conceive, and their geographical location) and optionally, whether they were trying for their first or subsequent children and some limited medical information. They were then presented with a series of guiding questions intended to contextualize their trying to conceive story. Respondents typed their responses online and submitted them electronically. At each stage they were given the opportunity to return to the gallery without submitting their story. They were also given an opportunity to edit the story before submitting it to the gallery. After the story was reviewed, it was formatted (automatically) and published in the gallery. Stories were not edited for grammar, typos or spelling, but if personally identifying information, explicit medical advice, or product or business promotion were included in the story, these were removed or, in some cases (if the story did not include other significant content) the story was rejected. Otherwise, the stories were accepted as submitted without changes. Respondents are able to remove their story from the public gallery at any time.

Using an online form to reach research participants has a few limitations. First, there is the issue of rapport. In a face to face interview, developing rapport may lead to a richer, more candid story. I have no way to know whether stories may have been deeper and richer with a face to face interview. Alternately, it is possible that the anonymity of the internet, or the knowledge that the story would be read by others in similar situations led to deeper, richer disclosures. An additional limitation is that it is possible to write misleading stories since it is impossible to verify who is really at the keyboard. This is unlikely however, as there is no real motivation to do so and the participants were people 
who were actively using the online service at FertilityFriend.com. Another limitation is that of follow-up. I did not have the opportunity to ask a participant to clarify or expand on any particular stream of thought that may have provided a greater understanding or contributed to a more in depth analysis. Additionally, the stories (like any single interview or questionnaire) are snapshots of an experience that can best be described as a process and so reflect the point of view of participants in that current moment. The stories reflect the vantage point of the writer from a particular point in time, mostly while they are still engaged in a journey of sorts. In most cases, the ending of the story (if there ever could be one) is still unknown.

What may have been lost in depth in particular stories was perhaps made up for in breadth. An advantage to using an online submission form on a busy internet site was that a large number of people from a variety of backgrounds could respond. It was possible to collect a large number of stories representing a wide variety of experiences in a relatively short amount of time. Additionally, the sample is somewhat different from samples which rely on local respondents. With an online sample, people at various stages of their trying to conceive experience and those representing a variety of perspectives could participate rather than only those who could be reached via local affiliations such as local support groups and clinics and acquaintances. This potentially allows access to some of the estimated $50 \%$ of infertile couples who do not seek medical treatment for their condition (Boivin, Bunting et al. 2007) or those who do not seek support from organized support groups who have been underrepresented in previous samples. 


\section{Elicited or Extant Data?}

Charmaz (2006a) makes the distinction between elicited and extant data where elicited texts are produced in response to a researcher's request while extant texts are created for some other purpose, generally not by the researcher, but are used as data. The "Trying to Conceive Story Gallery" from which the sample for this project was drawn is perhaps both elicited and extant. It is elicited in that I was the person who designed it: I developed the questions, the description and the consent form and once it was online, I was the person who reviewed the submitted stories and placed them online. As I was doing all this, I realized that it would be the foundation for this project and this formed some basis for the structure of the questionnaire and the questions asked. It was important that it was created in such a way as to be acceptable for this project. However, it is also extant because it was not created solely for the purpose of this project. It was also, and was perhaps primarily, intended to be a component of FertilityFriend.com and to be of value to women experiencing conception difficulties so that they could easily find stories from others to which they could relate. It is widely used in this capacity every day. Though I stopped collecting data to analyze for the purpose of this project, the gallery attracts new submissions every day and continues to operate and be accessible online. I continue to review and accept new submissions every week in my role at the site. Unfortunately, some information that might have been interesting and relevant for this thesis, such as information about education, income, religion, ethnicity, etc., was specifically not elicited. This was a carefully weighed decision based on a long term vision for the Story Gallery as primarily a community resource. I realized that this information could have, to some degree, enhanced the academic contribution of this 
thesis and the future academic possibilities of the data. Nonetheless, I felt that these questions, unlike those about their personal experiences, may have alienated the participants and made them feel "used" since these factors are not likely very interesting or relevant to them. This may have made them less likely to want to share their stories or view the stories as a community asset and ultimately may have prevented the long term viability of the gallery.

When describing the proposed project and my organizational role to the coordinator of Carleton University's Ethics Committee, I was advised to seek approval for "research based on secondary use of data" and additionally to obtain consent from the co-administrator of the site. These were both obtained prior to commencing the collection and analysis of data for this project.

\section{Special Ethical Considerations}

This shifting of roles described above- from researcher to service provider and back again- would seem, on the face of it, to require some special ethical and methodological considerations. Nonetheless, I believe that offering the stories as a service to the participants (and any interested party with access to a web browser) rather than simply collecting them and analyzing them for limited academic purposes enhances the ethics of the project (and certainly makes the stories available to more people). Indeed, when considering the possible ways that I could explore the experiences of the women trying to get pregnant and using FertilityFriend.com, creating the Story Gallery appealed to me because it could be both an academic resource and a personal resource for the participants themselves. Infertility is lonely and for many women, the core experience of infertility is the "contemplation of nothingness" (Rehner 1989, 18). 
Sharing stories can be a step towards healing, breaking isolation, and combating negative myths and stereotypes (Rehner 1989, 18).

Such sharing of stories authenticates feelings and restores a sense of balance- it is always a comfort to know that you are not losing your mind. The sharing of stories, the blending of voices, also indicates that although there are different modulations, our story is essentially harmonious, collective. In speaking of our shock and anger, our fear, our sense of futile purpose and shattered self-images, we can validate the common experience of infertile women and believe, again, that our lives are vital and interconnected. If we speak clearly and patiently enough others will hear us. We will be able to give them the gift of understanding us (Rehner 1989, 19).

Despite these advantages, there are very few exemplars of similar research situations. A few that provided some ethical and practical guidance are discussed below:

Internet research itself is not new. There has been much discussion about the particular ethical guidelines associated with it (Eysenbach and Till 2001; Sixsmith and Murray 2001; Murray and Sixsmith 2002; Haigh and Jones 2005). Operating a website for the dual purposes of service delivery and research as described above, however, is not particularly common and there has been little discussion of the unique ethical considerations associated with it (Flicker, Haans et al. 2004, 24). Of notable exception is Flicker et al's (2004) candid discussion about the ethical issues the researchers faced in their development and study of the University of Toronto based "Teen-Net" project, the multifold purpose of which was to provide youth with a place to express themselves; give youth an opportunity to connect with one another; and study how youth support each other in peer environments (Flicker, Haans et al. 2004, 126). Their account provided some guidance.

Another guiding example was the "DIPEx" (database of patients' experiences) site. Though they do not expressly talk about their ethical concerns, the creators of 
DIPEx, before the launch of their website, expressed its mandate in the following way: "DIPEx aims to identify the questions that matter to people when they are ill and has potential for informing patients, educating healthcare professionals, and providing a patient-centred perspective to researchers and those who manage health services (Herxheimer, McPherson et al. 2000, 1540)". A later paper, published two years after its initial launch in 2001 describes DIPEx's aim like this: "The primary aim of DIPEx is to describe the widest practicable range of experiences from the patients' points of view and to provide a rich information resource for patients affected by the diseases and for those who look after them (Herxheimer and Ziebland 2003, 209)." Using the qualitative data gathered from the contributors to the DIPEx site, the creators have published a number of studies (Chapple and Ziebland 2004; Ziebland, Chapple et al. 2004; Prinjha, Chapple et al. 2005). The DIPEx creators say that they are publishing findings from the qualitative data to share their findings with those who communicate and deal with patients in an effort to influence the ways in which doctors and health workers listen to and interact with patients (Herxheimer and Ziebland 2003). Herxheimer and Ziebland $(2003,209)$ also note that "... patients telling their story have a sense of altruism and solidarity with others, analogous to giving blood. We have been struck by how they feel more part of the community in sharing their story; some may even gain greater self-understanding and self-esteem. Many participants have become enthusiastic about DIPEx and feel a bond with it."

Similarly, the Trying to Conceive Story Gallery is intended as a resource to the participants and the research based on the stories is intended to address the experiences and interests of the participants. Like the DIPex respondents who felt sharing their story 
was a positive experience, a number of participants of this study also noted that they hoped their story would be of benefit to others and others noted that they found the stories helpful as well. Some comments about the Story Gallery from participants are cited below:

Without the internet I never would have had this opportunity. Being able to read other people's stories was inspiring and suddenly opens up your girlfriend advice pool from just a few friends to an ocean full. (story521322670167; United States; Age: 29; Months TTC: 5)

I have been enlightened and touched by reading other women's stories of their TTC tribulations and successes. It has opened the door to a new realm of human and parental experience for me. (story311271566335; United States; Age: 41; Months TTC: 2)

I have greatly benefited from all the stories told by others who are struggling with infertility. (story24188365246; United States; Age: 32; Months TTC: 60 )

It's nice to hear others' stories, otherwise l'd feel alone. (story681834256497; United States Age: 27 Months TTC: 4)

These responses are very promising that the Trying to Conceive Story Gallery can be both a fruitful academic resource as well as a valuable personal resource for those most concerned with the issues.

\section{The Sample}

\section{Age and Gender of Participants}

The participants for this project were 327 women between the ages of 18 and 44 who had used the internet to track their fertility signs using FertilityFriend.com. Though men's experiences of conception difficulty have been understudied and deserve further investigation (Mason 1993, 5), this sample explores the experiences of women only. This was primarily due to access since FertilityFriend.com is geared towards women, yet 
exploring only women's experiences allowed me to engage with them in greater depth. The average age of the respondents was 30.24 years. The mode was 27 years and the median was 30 years. The following graph shows the age distribution of the participants.

Figure 1 Age Distribution of Participants

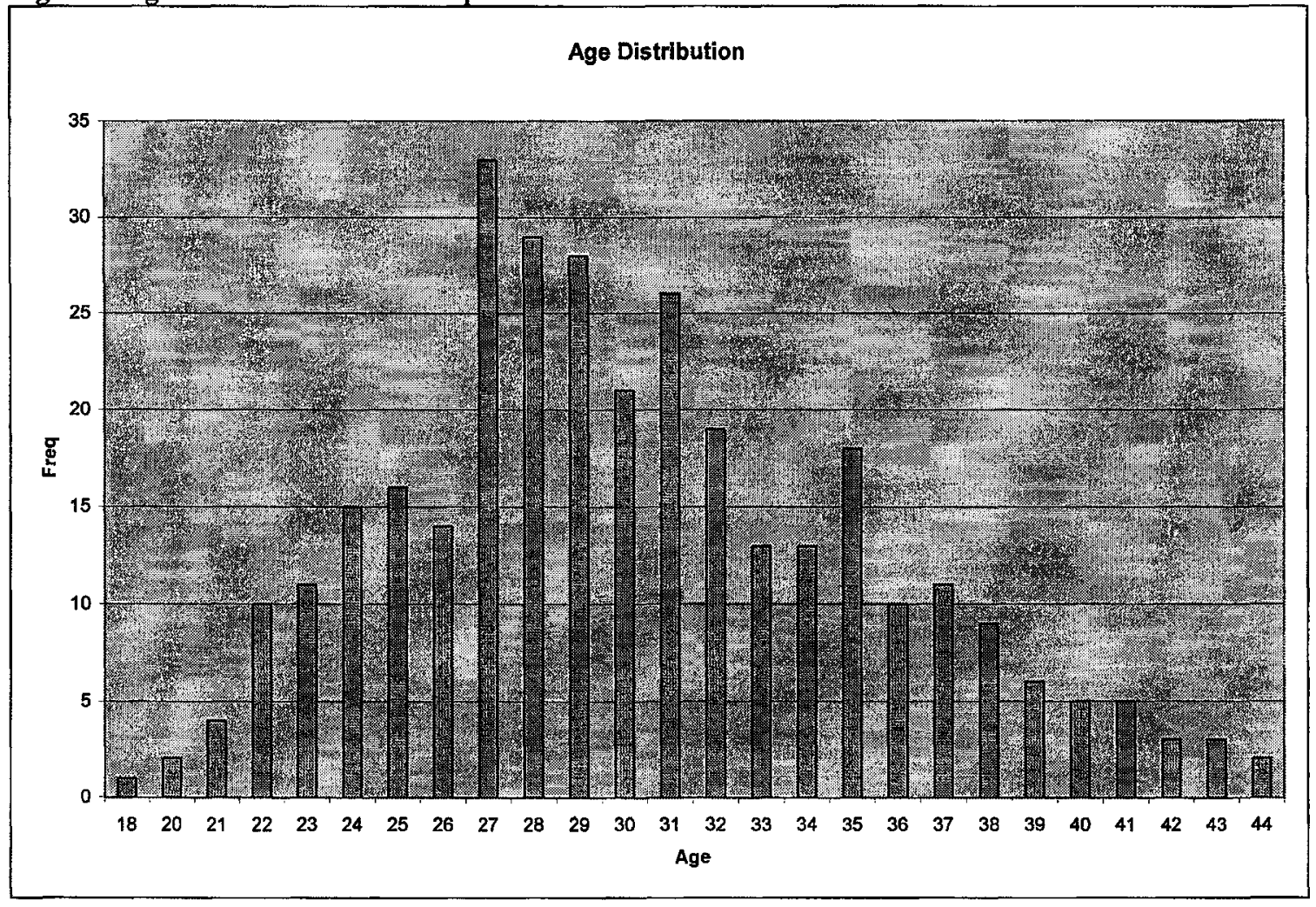

\section{Location of Participants}

Conducting research on the internet allows for people to respond from a wide range of geographical locations. Even so, the vast majority of the 327 participants (75.23\%) came from the United States. The remainder of the participants were primarily located in The United Kingdom (7.95\%), Canada (7.34\%), Australia (4.28\%), Ireland $(1.53 \%)$ and New Zealand (0.92\%). The following table and pie chart illustrate the geographical distribution of respondents. 
Figure 2 Country of Respondents

\begin{tabular}{|lrr|}
\hline Countries: & Count & \multicolumn{2}{c|}{ Percent } \\
Country & 246 & 75.23 \\
United States & 26 & 7.95 \\
United Kingdom & 24 & 7.34 \\
Canada & 14 & 4.28 \\
Australia & 5 & 1.53 \\
lreland & 3 & 0.92 \\
New Zealand & 9 & 2.75 \\
Other & 1 & 0.31 \\
Belgium & 1 & 0.31 \\
Mauritius & 1 & 0.31 \\
Netherlands & 1 & 0.31 \\
Cameroon & 1 & 0.31 \\
Luxembourg & 1 & 0.31 \\
Pakistan & 1 & 0.31 \\
Argentina & 1 & 0.31 \\
Norway & 1 & 0.31 \\
Antigua and Barbuda & &
\end{tabular}

Figure 3 Pie Chart Showing Country of Respondents

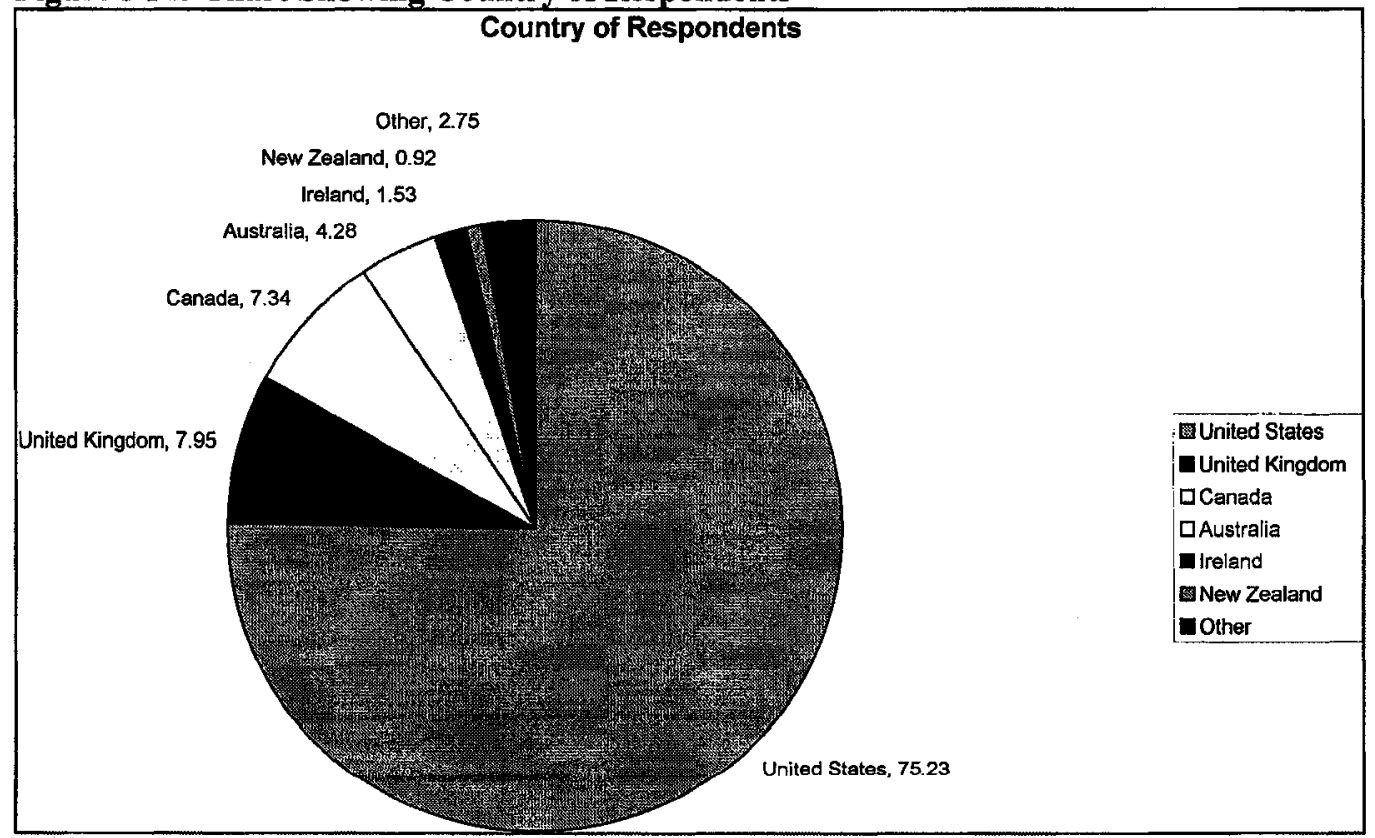




\section{Time Trying to Conceive}

Participants were also asked to indicate how long, in months, they had been trying to conceive. Recruiting participants from the internet, rather than from clinics and support groups means that responses reflect the experiences of people at all stages, rather than only those who have already sought medical or local emotional support and have thus likely been trying longer. The graph below illustrates the length of time participants had been trying to conceive.

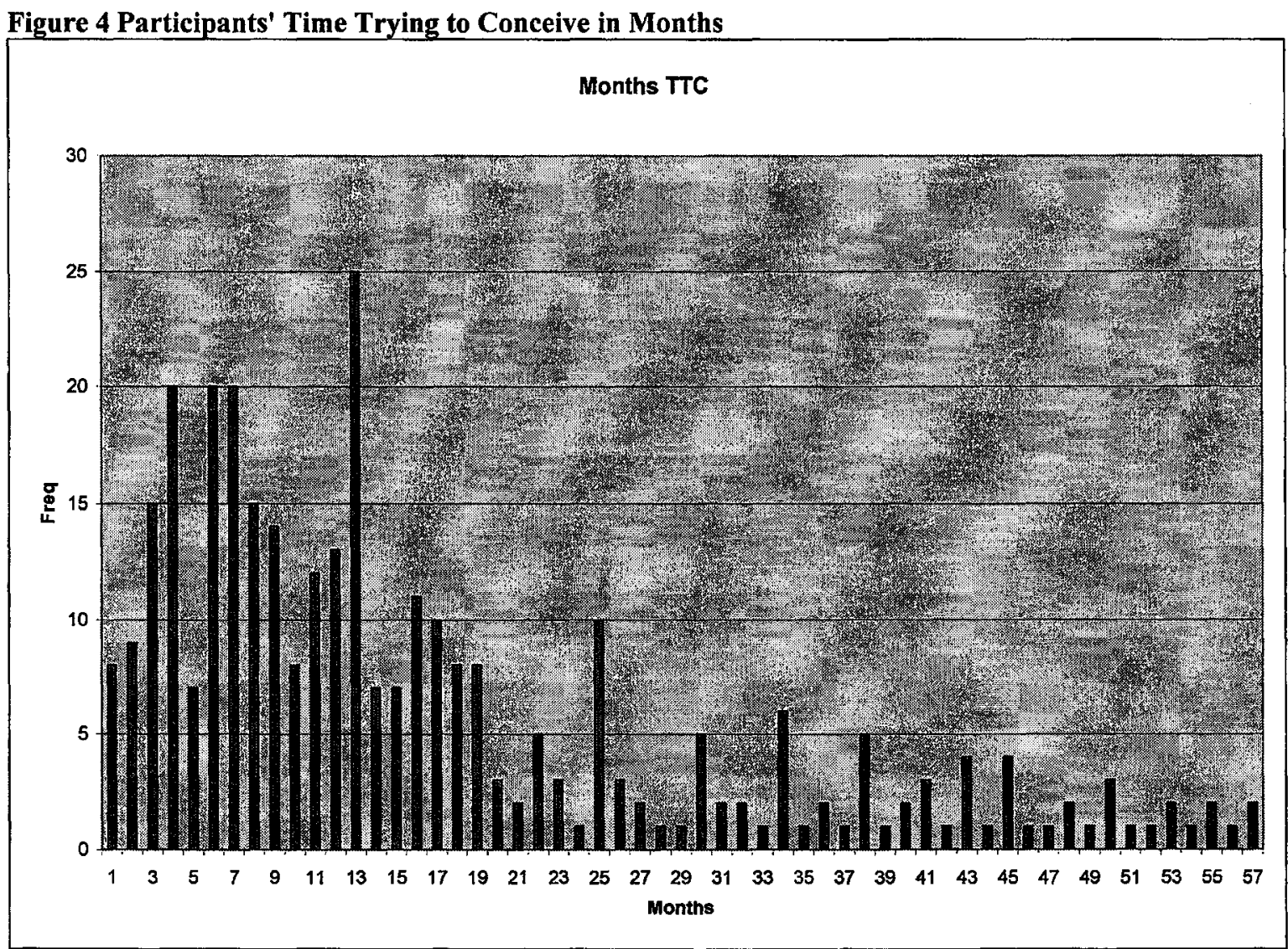

The average time trying was 17.92 months. Both mode and the median were twelve months. 


\section{Story Categories and Keywords as Identified by Respondents}

To contextualize the stories, respondents were asked to identify a category and optionally, some keywords for their stories. The pie graph below illustrates the category that respondents assigned to their story from the following choices: Trying to Conceive (44.04\%); Pregnancy after Trying to Conceive (36.09); Trying to Conceive with Miscarriage/Loss (19.27\%); and Adoption after Trying to Conceive (0.61\%). The story categories can overlap (for example, one respondent may be telling her story after pregnancy was achieved, though her trying to conceive experience may have included a miscarriage). Respondents were asked to choose just one category to help contextualize the story and so that readers searching for a particular kind of story could have them easily sorted based on what the writer indicated it was primarily about.

Figure 5 Story Categories Selected by Respondents

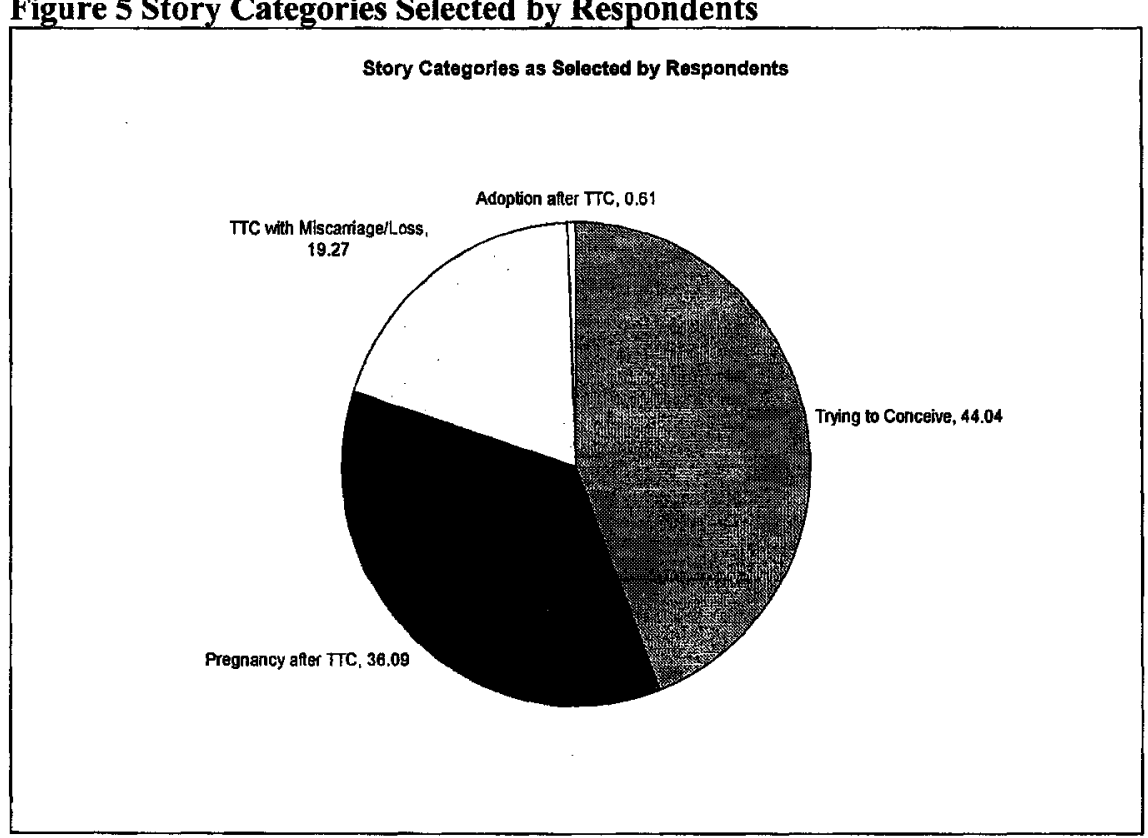


Respondents were also asked to (optionally) indicate whether they had sought medical help (61.56\%); had undergone fertility-related tests and treatments (55.94\%) and whether they had been diagnosed with a fertility-related condition (40.63\%). They were also given the option to indicate whether they were trying for their first (58.75\%) or subsequent (36.56\%) children. The following graph illustrates the responses to these optional keyword categories.

Figure 6 Respondents' Selected Keywords

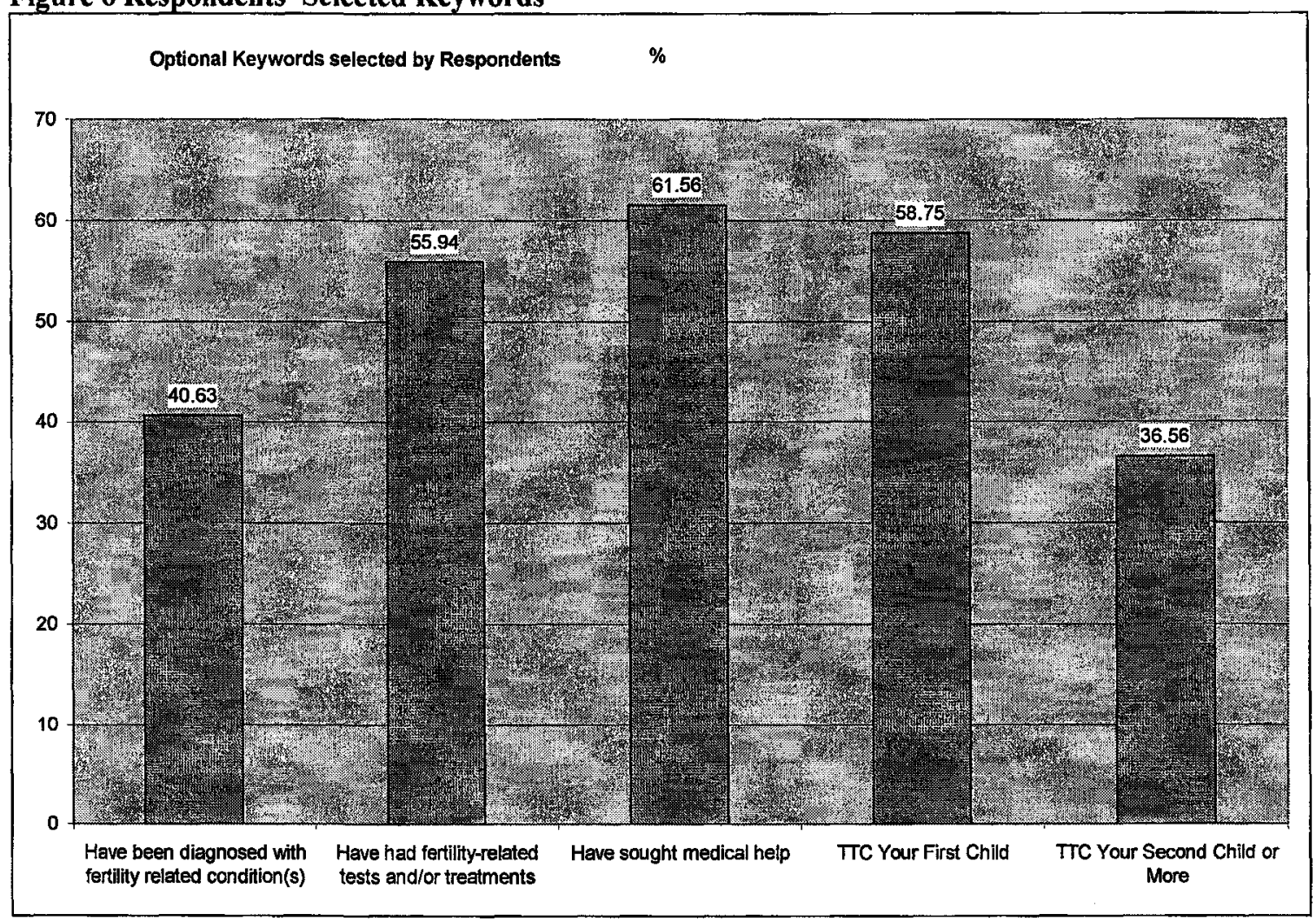

To add additional context, respondents could assign their own "free form" keywords to indicate to readers important aspects of their story or to help readers find stories relevant 
to their own situations. In total, 276 different free-form keywords were ascribed to the stories by their writers. These are presented as a tag cloud ${ }^{14}$ in Appendix 2.

\section{Current Data Set Compared to Other Studies}

To provide some context for the current study, I have compared the characteristics of the current sample with selected other qualitative studies of personal experiences with infertility. The following table illustrates some differences in the current sample relative to selected previous samples. Notably, the sample is larger than most previous samples; involves more people who did not seek treatment; includes more people trying to conceive their second or subsequent child; and includes more people who have not been trying to conceive as long as others in previous studies. The differing characteristics of the current sample compared to previous samples offers an opportunity to broaden understandings of the experience and compare the experience based on these factors.

\footnotetext{
14 "A Tag Cloud is a text-based depiction of tags [in this case the free-form keywords] across a body of content to show frequency of tag usage and enable topic browsing. In general, the more commonly used tags are displayed with a larger font or stronger emphasis... (Wikipedia, accessed 2008)."
} 
Figure 7 Current Sample Compared to Selected Previous Samples

\begin{tabular}{|c|c|c|c|}
\hline $\begin{array}{l}\text { Author and } \\
\text { Year }\end{array}$ & $\begin{array}{l}\text { Number of } \\
\text { Participants }\end{array}$ & $\begin{array}{l}\text { Recruitment } \\
\text { Method }\end{array}$ & Participant Profile \\
\hline $\begin{array}{l}\text { Clarke, Martin- } \\
\text { Mathews et al } \\
2006 \text { (does not } \\
\text { mention when } \\
\text { data were } \\
\text { collected) }\end{array}$ & $\begin{array}{l}110 \text { women, } \\
68 \text { men, } \\
\text { couples } \\
\text { interviewed } \\
\text { together }\end{array}$ & $\begin{array}{l}\text { Subset of larger } \\
\text { study of } 203 \\
\text { couples } \\
\text { undergoing } \\
\text { treatment in } \\
\text { Canada, } \\
\text { recruited from } \\
\text { university } \\
\text { fertility clinic }\end{array}$ & $\begin{array}{l}\text { Treatment seeking, mean age of women } \\
\text { was } 31 \text {, men was } 34 \text {; mean length of } \\
\text { time trying to conceive was } 4.4 \text { years; } \\
\text { mostly experiencing primary infertility, } \\
8 \% \text { experiencing secondary infertility }\end{array}$ \\
\hline Letherby 2002 & 65 women & $\begin{array}{l}\text { Newspaper ads } \\
\text { and magazines, } \\
24 \text { interviews } \\
\text { and } 41 \text { written } \\
\text { correspondence }\end{array}$ & $\begin{array}{l}\text { White, middle class, ages } 20 \mathrm{~s}-70 \mathrm{~s} \text {, } \\
\text { majority had sought treatment, } \\
\text { infertile/involuntarily childless currently } \\
\text { or in the past }\end{array}$ \\
\hline Becker 1994 & $\begin{array}{l}118 \text { couples, } \\
\text { men and } \\
\text { women } \\
\text { interviewed } \\
\text { together }\end{array}$ & $\begin{array}{l}\text { Flyer in } \\
\text { physician } \\
\text { office, } \\
\text { RESOLVE } \\
\text { meetings, } \\
\text { people already } \\
\text { in the study, } \\
\text { adoption } \\
\text { counselor }\end{array}$ & $\begin{array}{l}\text { Upper middle-class, treatment seeking; } \\
\text { mean age of women was } 36, \text { men, } 38 ; \\
17 \% \text { were not white; time trying to } \\
\text { conceive not noted }\end{array}$ \\
\hline Monach 1993 & $\begin{array}{l}30 \text { couples, } \\
\text { men and } \\
\text { women } \\
\text { interviewed } \\
\text { together }\end{array}$ & $\begin{array}{l}\text { New referrals to } \\
\text { infertility clinic }\end{array}$ & $\begin{array}{l}\text { White, middle class couples (one ethnic } \\
\text { minority); all treatment seeking; ages } \\
20-37 \text {, mean age of } 28 \text {; mean duration of } \\
\text { infertility was } 26.7 \text { months, median of } \\
20 \text { months; } 25 \text { primary infertility; } 5 \\
\text { secondary infertility }\end{array}$ \\
\hline Griel 1991a & $\begin{array}{l}22 \text { couples, } \\
\text { men and } \\
\text { women } \\
\text { interviewed } \\
\text { separately }\end{array}$ & $\begin{array}{l}\text { Snowball } \\
\text { sample starting } \\
\text { with RESOLVE }\end{array}$ & $\begin{array}{l}\text { White, middle class; all had sought } \\
\text { treatment; average duration of infertility } \\
\text { was } 6.7 \text { years according to wives, } 5.2 \\
\text { years according to husbands }\end{array}$ \\
\hline Current study & 327 women & Internet sample & $\begin{array}{l}\text { Socio-economic background unknown, } \\
\text { presumed middle-class; mean and } \\
\text { median age were } 30 \text { years; mean time } \\
\text { TTC was } 17.92 \text { months, median was } 12 \\
\text { months; } 61.56 \% \text { noted they had sought } \\
\text { medical help; } 55.94 \% \text { noted they had } \\
\text { fertility related tests/treatment; } 58.75 \% \\
\text { noted they were trying to conceive their } \\
\text { first child. }\end{array}$ \\
\hline
\end{tabular}




\section{Qualitative Methodology and Grounded Theory}

The primary goal of this project was to identify and explore the salient experiences of a particular sample of women trying to conceive and the ways in which these women attribute meaning to their experiences. As such, a qualitative methodology was applied to the sample of stories. A qualitative methodology is best suited to research such as this where the purpose is to make sense of phenomena as they are understood, given meaning and experienced from a subjective point of view (Conrad 1990, 1257). Qualitative research allows the researcher to find out what people are thinking and doing and to gain details about feelings, thought processes and emotions that are more difficult to learn about through more conventional, quantitative methods (Strauss and Corbin 1998). In relation to illness and disease (categories into which conception difficulties arguably fit), Gerhardt $(1990,1149)$ notes that the impact of a disease or treatment on a person may be neglected in clinical practice and that this purpose can be best served by collecting and analyzing data from an experiential perspective. This is the domain of qualitative analysis.

There are a number of ways to analyze qualitative data such as interviews, observations and stories (Strauss and Corbin 1998). The submitted stories were analyzed using a grounded theory methodology such as that developed and described by Glaser and Strauss (1967). Grounded theory was chosen for its practicality and flexibility. Grounded theory is "grounded" in the data itself as a way to generate analysis (Glaser and Strauss 1967; Strauss and Corbin 1998) and fosters seeing the data in fresh ways (Charmaz 2006a). Key to a grounded theory approach is the constant analytic interplay 
between the researcher and the data (Strauss and Corbin 1998, 13). Charmaz, (2006a, 5) identifies the following flexible guidelines as defining components of grounded theory research: simultaneous involvement in data collection and analysis; constructing analytic codes and categories rather than preconceived hypotheses; using a constant comparative method at every stage of analysis; advancing theory development at every stage; conducting the literature review after developing an independent analysis.

\section{Research Process}

Initially, my primary research concern was the ways in which the internet might contribute to the creation of new experiences of health and healthcare, challenge medical authority, and how the internet and internet based research could facilitate new healthcare initiatives and further understanding of health experiences. The collected stories, which are from women who used the internet to manage their fertility and find support for their conception struggles were meant to provide this insight. The submitted stories, however, did not speak primarily to this concern. Although many women did answer the question about using the internet as a health management and support tool and spoke about their experiences related to that, the richest and deepest descriptions were not about the internet. Rather than scour the data for content that fit the initial question, which might have been possible, I remained open to finding something different and the focus gradually shifted. As it turned out, and as I saw as the analysis progressed, the stories revealed the various ways the participants' lives, goals, relationships and identities had been disrupted by their struggle to conceive and how they dealt with and found meaning in that disruption. Charmaz $(2006 \mathrm{a}, 46)$ notes that it is not unusual to develop new research questions as I did during the analysis and coding process. 
The stories were read initially, without note-taking, as they were submitted and accepted into the online Story Gallery. This provided a general overview and immersion into the data. At this time, I made sure that the stories were acceptable for the public gallery (with no advertising, solicitations or personally identifying information) and I allowed myself to be drawn into and moved by the stories. I did not specifically look for analytic codes and categories or make notes at this initial reading. As the stories were accepted, I copied the text into a word processing document to make printing, reading and note taking easier. Initial, near line-by-line coding took place in stages, several stories at a time, during this second reading of the text document. At this time, I used a constant comparative method, and memos and notes expressing potential analytic codes were taken in the margins of the printed document (Strauss and Corbin 1998, 57-77). A focused coding followed where I selected what appeared to be the most salient and frequent of the initial codes (Charmaz 2006a, 57) and categorized them into an initial taxonomy of categories and subcategories (Strauss and Corbin 1998, 113; Sandelowski and Barroso 2006, 199). This initial taxonomy is included in Appendix 3.

To organize the data and codes and better identify the data associated with the codes, custom software was developed specifically for this project and was integrated with the online submission and review form. ${ }^{15}$ The software allowed me to assign codes and categories (as well as merge and delete codes) for each story and to parse data from the stories that could be associated with each code and later cited.

Though my methodology is primarily qualitative, identifying the codes with the custom software allowed me to see which codes appeared with the greatest frequency and

\footnotetext{
${ }^{15}$ Frederic Montoya, co-founder of FertilityFriend.com wrote the software so that it was suitable for this project and also for ongoing use in relation to the TTC Story Gallery on FertilityFriend.com.
} 
this was helpful to make sense of the importance particular issues. Though a count of the number of times a code was noted in the data is included, this is a descriptive rather than an inferential statistic. Counting began after a particular code was added and coding occurred continuously throughout the analysis process. For example, it was toward the end of the second reading that I noted that a number of women remarked on the mood swings they experienced as a result of taking certain fertility medications. I then added this as a code within the "medicalization" category, searched the previous stories (electronically) for keywords such as "mood swings" and "Clomid" and assigned the code to those stories and subsequent stories where appropriate. I did not re-read all the stories from start to finish to determine if other stories should also be assigned that code. Similarly, in the "Body" category, for example, I had initially included "tracking cycles and signs" as a code, but continued coding showed me that nearly every story could be assigned this particular code and I stopped taking note of this. I stopped reviewing new stories when "theoretical saturation" was reached and additional stories did not reveal new analytic data (Glaser and Strauss 1967; Strauss and Corbin 1998). The results of this coding procedure, along with notes on which codes were merged or deleted can be found in Appendix 4.

In a grounded theory methodology, "axial coding" is the process of relating categories to subcategories, examining the ways in which the categories crosscut and link (Strauss and Corbin 1998, 124). This process results in discovering a "core" or "central" category (Strauss and Corbin 1998, 146-147) and "reassembles the data you have fractured during the initial coding to give coherence to the emerging analysis (Charmaz $2006 \mathrm{a}, 60)$ ". The central theme that emerged to link the various categories and 
subcategories in this analysis was that of disruption: disrupted relationships, disrupted identities, disrupted plans, disrupted emotions, disrupted ways of seeing and making sense of the world. The figure below illustrates how disruption emerged as the central theme during the analysis process.

Figure 8 Emerging Core Category: Disruption/Interruption

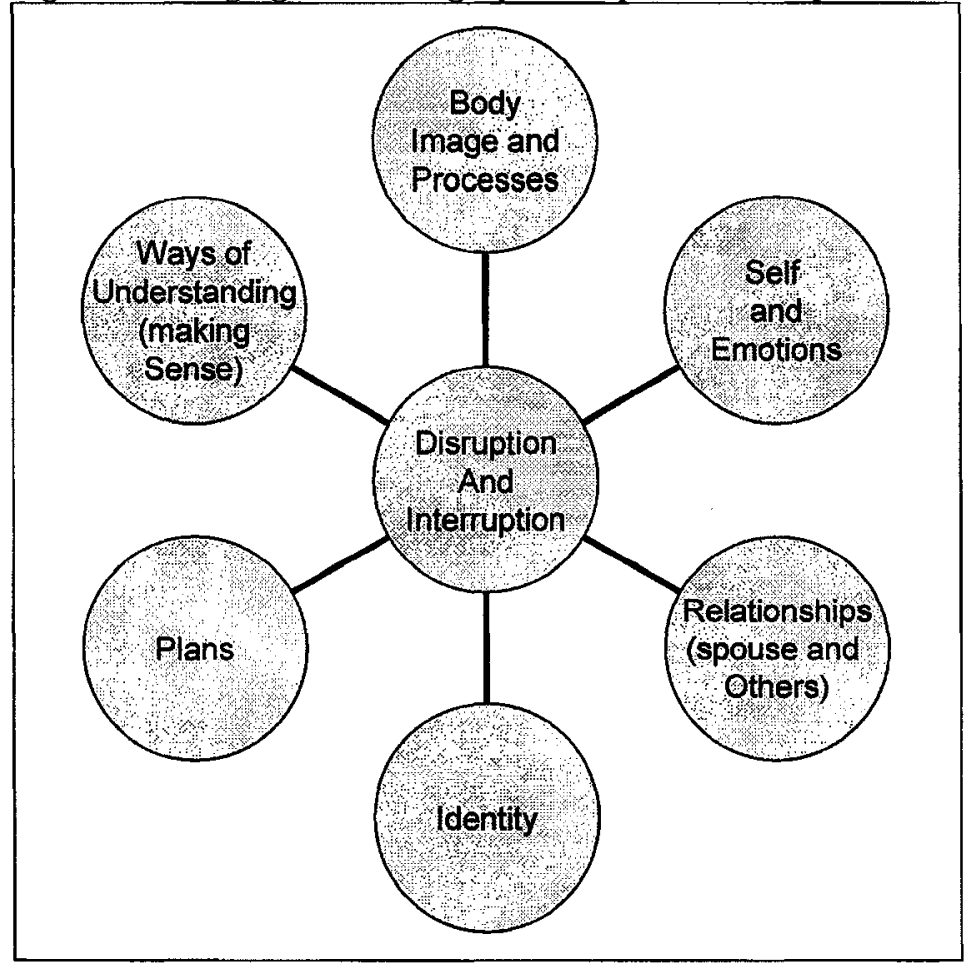

Additionally, the data spoke to the ways the participants dealt with and attributed meaning to this disruption.

As I reviewed the data and later reviewed drafts of the thesis and discussed my findings with my committee members, it appeared that the sense of disruption was due to an inability to meet ideal social norms, particularly those associated with pronatalism. With this in mind, I re-examined the findings with the idea that "a sense of disruption occurs when individuals are not easily able to meet idealized norms for which they have been socialized" and looked for ways that pronatalism and other social ideals impacted 
the experience and ways of making sense of it. This provided an opportunity to explore the extent to which pronatalism continues to impact on women trying to conceive in spite of increased role opportunities for women and increasing acceptance of alternative family styles. Along with normative ideals associated with pronatalism, ideals about selfefficacy and control, ideals about romance and spousal relationships and ideals about the value of science and medicine, justice and individualism appeared to play a role in shaping the experience. This is explored further in the following chapters.

\section{Qualitative Research and Quantitative Analysis}

Quantitative analysis can enhance the findings of in-depth qualitative research (Babbie 1998). The coding procedure described above, along with the unique and diverse sample characteristics, allowed me to create cross-tables (Appendix 6) and conduct a bivariate analysis to compare the prevalence of themes identified in participants' stories based on the following characteristics: age, ${ }^{16}$ parity, ${ }^{17}$ time trying to conceive, ${ }^{18}$ and whether or not medical assistance was sought. Data was exported into SPSS version 17 (SPSS Inc., Chicago, IL, USA) which was used for the analysis and statistical calculations. Two-tailed chi-square tests were used to determine significance and $\mathrm{P}$ values of less than 0.05 were considered significant. Only themes that were noted ten or more times were included in this analysis. Because of this and because some data were optional, the total number of participants in these analyses is not the same as the total

\footnotetext{
${ }^{16}$ I compared women who were under 30 years of age with women who were 30 or older. This age was chosen because it was both the mean and median age of participants and it is the age at which fertility declines dramatically (Dunson and Colombo et al 2002).

${ }^{17}$ Parity here refers to the number of children a woman has. I compared women trying for their first child versus those trying for a subsequent child.

${ }^{18}$ I compared women trying for a year or more with those trying for less than a year. One year was chosen as it was the median length of time trying among participants and also because one year of trying to conceive is the clinical definition of infertility.
} 
number of stories analyzed. Results of this analysis as they relate to the thesis are discussed at the end of the following substantive chapters and offer additional insights based on the characteristics of the participants. 


\section{Chapter Three: Identity Issues and Biographical Disruption}

The single biggest realization for me during this journey was how TTC affects your identity. How it is like grieving the loss of something you never had, but you should have. That you spent your whole life just believing you had it, and everyone around you believed it too. We make assumptions and so do others and it leads to a build up of hope and a break down of identity when you feel you have failed, or God has failed or your body has failed. I felt defected inside, as a human, as a person. I remember an intense hatred for my body and how it was letting me down. The anger was so intense it was like poison inside me, with no explanation or resolve. (story37514134118; United States Age: 31 Months TTC: 60)

\section{Introduction}

The above quote, extracted from the Trying to Conceive Story Gallery, elegantly expresses the feelings of frustration, identity loss, failure and brokenness that are often expressed by women who experience difficulties getting pregnant. Women who have always considered future-motherhood to be a central component of their life goals and planned identities frequently note that conception difficulties can be a significantly disruptive experience in a multitude of ways. Feelings of disruption to relationships, lifeplans and goals, ways of considering one's body, family and the future were frequently noted by women writing in the Trying to Conceive Story Gallery.

The stories reveal, that at the time of writing, ${ }^{19}$ motherhood was the most central aspect of most of the participants' planned identities; that achieving this goal/status was something that had been expected and taken for granted throughout their lives; that difficulty achieving it came as a devastating shock and surprise and felt like 'losing

\footnotetext{
${ }^{19}$ It is important to note that the expressions are snapshots, usually taken soon after a woman learns that conception will not be easy, and that identity is fluid. Feelings of failure and identity shock which are expressed in the stories may be subsequently relieved or resisted as a person re-evaluates her life plans and goals or as the reproductive years pass.
} 
control'; that it was seen as the most worthy of possible life goals and identities, not to be relinquished in the face of difficulty; and difficulty achieving it often left them feeling isolated, depressed, frustrated, confused, defective, envious of others, misunderstood by others and feeling the need to navigate and negotiate contact and communication with others. Such contact and communication with others often reinforced feelings of failure and identity loss. Additionally, the ambiguous nature of the experience, where there was always some element of hope or something new to try, often resulted in repeated cycles of hope followed by despair that was frequently described by the participants using "rollercoaster" as a metaphor. The social constructs which impacted the experience and which were reflected within it were not generally questioned to any great extent by participants. This again testifies to their continuing dominance and the extent to which they are embedded in our lives and outlooks. Nonetheless, participants did express ways in which they resisted the negative impact on their identities, garnered support and actively worked to maintain a sense of control.

This chapter focuses on the impact of conception difficulties on the identities and biographies of women affected. The continued importance of pronatalism and the concepts of deviance and stigma in relation to infertility and childlessness are also considered. Additionally, the impact and interplay of identity and biography issues in relation to conception difficulties on emotions, feelings about the body and contact with others are also discussed. Responses from participants suggest that conception difficulties can have a profound impact on women's identities and biographies in a number of ways. This impact is simultaneously shaped by the ubiquitous, lasting, and pervasive social context of pronatalism which continues to impact on women's experiences and 
interpretations of experiences, and experienced and navigated personally in a variety of ways in diverse circumstances. Responses from the writers in the Trying to Conceive Story Gallery, however, also indicate that women experiencing conception difficulties utilize a variety of strategies to mediate and limit the negative impact of conception difficulties on their self concept. The stories additionally reveal the diverse ways in which women facing conception difficulties actively engage in controlling aspects of their experience that they can control and the ways in which they navigate the changing terrain of their expectations and their sense of themselves. Women also noted ways in which the experience offered opportunities for personal growth and challenged some previously held ideals.

Findings from this study support earlier work about conception difficulties and its wrenching impact on identity, biography and emotions (Menning 1977; Pfeffer and Woolett 1983; Matthews and Matthews 1986a; Matthews and Matthews 1986b; Miall 1986; Sandelowski and Pollock 1986; Sandelowski 1987; Greil 1991a; Greil 1991b; Monach 1993; Becker 1994). The women writing in the TTC Story Gallery, although experiencing conception difficulties decades later than most of those participating in the studies cited above, in a different cultural landscape, and with differing characteristics, are, as I will show, similarly affected by the experience. The experience of conception difficulties continues to wreak havoc with women's self-conceptions, emotions and plans for their futures. Societal changes that offer increased role options for women do not appear to have reduced the negative personal impact of conception difficulties for those who desire motherhood and experience conception difficulties. Although the media images supporting positive stereotypes of motherhood and patriarchal family structures 
have changed over time (Letherby 1999), they continue to impact negatively on the experiences of women who "fail" to meet those ideals. There was very little evidence of any great challenge to these constructs found in the stories of women writing in the Story Gallery. Encouragingly, however, women in this sample were more likely to resist those negative impacts through the use of support networks, actively taking control of their experiences and highlighting the opportunities for personal growth that the experience offered-including adjusting some taken-for-granted perceptions about feminine identity and self-efficacy.

\section{Background: Infertility and Identity}

Expectations about motherhood play a role in shaping feelings about one's identity and one's future. When these expectations are not met, it can change a person's approach to marriage, parenthood, and the rest of life (Deveraux and Hammerman 1998, 6). Particularly for women, being able to conceive is related to self-esteem, identity, sexuality and body image (Lalos, Lalos et al. 1986) and may be characterized by a feeling of identity loss and a sense of personal failure (Greil 1991b). Woollett $(1991,49)$ suggests that "having children is central to most women's adult identity, whether or not they have strong employment or career orientations." Becoming a parent is thus an important source of self identity and anticipated identity, one that fits into constructed notions of who one is and how one fits into the world (Atwood and Dobkin 1992). Difficulties achieving this disrupt and disturb these constructed senses of identity, leaving people feeling confused and fearful (Atwood and Dobkin 1992).

Themes emerging from the literature describe the impact of infertility on identity in the following ways: infertility can become the focus for identity; it is often 
accompanied by feelings of loss of control and attempts to regain control; feelings of defectiveness and reduced competence; a sense of statuslessness and ambiguity; feelings of alienation from the fertile world; a sense of social stigma; and difficulty assigning meaning to the infertility experience (Greil 1997). Infertility, like chronic illness or a disability, may additionally be experienced as "role failure" where the individual is unable to meet social role expectations; the condition may become the focal point of the person's life and they may feel their identity is "spoiled" and that their interactions with others are unsatisfactory because of the condition (Greil 1991b).

Sandelowski and Pollock (1986) note the feeling of "otherness" and "separateness" often experienced by infertile women which was expressed by their informants as "being singled out"; "not fitting in and being left out"; feeling like "no one understands"; and feeling "defective". Motherwell and Prudent (1998) say that involuntary childlessness reactivates one's earliest experiences of loss, grief, shame and failure and that a woman must simultaneously cope with the loss of the actual child, as well as her hopes and dreams for the future that are tied up in the symbolism of the future child.

A restricted perception of female identity can leave the childless woman vulnerable to feelings of shame and grief as she grapples with both internal and external sociocultural pressures to have children (Motherwell and Prudent 1998). Miall (1985; 1986) notes that infertility or involuntary childlessness is usually discovered later in life, after one's identity has already been established as "normal" and planned around expectations about bearing and raising children and that conception difficulty threatens this sense of normality. The foundation for these expectations may have been 
progressively laid throughout her life through "rehearsals of identity in relation to child rearing... (Olshansky 1987a, 58)." Chapman (2005) says:

I believe the biological imperative for a woman to reproduce to be so ingrained in the psyche that pivotal things happen in relation to her own power and identity if she can't. Many a woman fantasized as a child at playing 'mummy' and later as an adolescent about her body being able to create a child as a natural phase of her development. There is a blow the psyche if she cannot do what her own mother has done.

Olshansky (1987) discusses the process by which infertile people take on the identity of themselves as "infertile" first, informally, by trying different things on their own to achieve pregnancy, and then formally, by seeking medical help. Infertility, then, can become a part of one's identity, or even the most significant aspect of one's identity, replacing one's sense of oneself as fertile and a future mother and diminishing other merits and accomplishments (Remennick 2000). As a person "works" to solve the problem of infertility, other important identities get pushed aside (Olshansky 1987a). The infertile identity usurps other, more positive identities and results in feelings of decreased self-esteem and a decreased feeling of self-worth (Olshansky 1996). According to Olshansky, $(1987 \mathrm{~b}, 61)$ the desirable outcome of this infertility work is to finally shed the identity of self as infertile so that other identities can again take a central focus. This can be done by "overcoming" infertility (by getting pregnant), "circumventing" infertility (achieving pregnancy through technological means) or by "reconciling" infertility (adopting or choosing to be child-free) (Olshansky 1987a). Gonzalez (2000) also describes the experience of infertility as a process which is felt as an "assault" on one's personal identity. Rehner $(1989,49)$ notes that accepting or shedding an identity of "infertile" is not so clear-cut. She asks, "When does the pain begin or end? When do we 
lose confidence and control over our lives? At what point do we lose our sense of self and purpose? When and how do we begin to heal ourselves?"

It is also important to note, that for some women, "mother" is not necessarily the only identity they have anticipated occupying (Olshansky 1987b). Deciding to have both a career and children may already be a difficult decision, one that is further compounded when infertility is superimposed on it (Olshansky 1987b). The availability of alternatives, however, does not appear to reduce the impact when childlessness is not chosen.

Letherby (2002a) additionally suggests that while infertility may come as a "shock" to one's identity, the associated feelings of grief, shame and failure are but one aspect of a person's multi-dimensional life and that portrayals of infertile women as desperate serve to create negative caricatures of infertile women. She further notes the shifting nature of identity, indicating that issues of 'infertility/involuntary childlessness/non-motherhood' are more or less significant at different times in one's life (Letherby 1999). Additionally, women experiencing conception difficulties are not necessarily a homogenous group and so their experiences are not necessarily uniform or universally shaped by identical circumstances (Letherby 1999).

In an attempt to understand women experiencing conception difficulties in a more nuanced, multi-faceted fashion that depicts them with a measure of active control over their desires and choices, a few authors (Rehner 1989; Sandelowski 1993; Franklin 1997a; Letherby and Williams 1999; Letherby 2000; Ulrich and Weatherall 2000; Letherby 2002a; Letherby 2002b; Parry 2005) are careful to avoid representing infertile women as universally bitter and desperate, as a unified group, or acting solely within the confines of a script provided by patriarchy. While the social context of pronatalism is 
important for making sense of women's experiences as they live through and navigate the experience of conception difficulties, it is also helpful to look at their personal, social and economic realities (Ulrich and Weatherall 2000) and their diverse experiences and understandings.

Nonetheless, several common themes emerge in discussions about the impact of infertility on one's identity. Most prevalent are issues about the ability to control one's body and the ways in which challenges to the body and its reproductive functioning may also be challenges to one's sense of identity; the ways in which the ambiguous nature of the experience affects concepts of the self and one's future; the ways in which the experience disrupts life plans and goals and one's way of seeing one's self; and finally, the relevance of pronatalist social values and ideologies and the ways in which a "failure" to meet these societal ideals and expectations impacts identity by diminishing one's sense of self.

\section{Pronatalism, Identity and Conception Difficulty}

\section{Ubiquitous Pronatalism}

Pronatalist social expectations requiring motherhood for "suitable" women were discussed briefly in Chapter One. Feelings about identity and motherhood (or nonmotherhood) occur within this social context whereby motherhood is frequently seen as an integral if not the primary social role for adult women. Letherby (2002a, 284) notes: "As motherhood is valued rhetorically (even though it has little material and social status) non-motherhood is defined as lesser. Non-mothers or women who achieve motherhood in 
unconventional ways are defined in lay, medical and even some social science and feminist literature as 'problematic, 'unnatural' 'abnormal."'

Gillespie (2000) notes that social perceptions of femininity and the social role of women have been traditionally constructed within the context of the symbolism and practices surrounding motherhood. Motherhood and women's desire for it have traditionally been seen as natural, inevitable, unquestioned and central to constructions of normal femininity (Gillespie 2000). Wirtberg (1999) suggests that parenthood has, for centuries, been perceived as a required component of personal fulfillment, social acceptance, achievement of full adult status, religious membership, sexual identity and psychological adjustment. These societal norms, along with pro-birth policies and positive portrayals of parenting and motherhood form the basis of pronatalist ideals on which identity expectations are formulated (Whiteford and Gonzalez 1995).

Women's sense of self, self-esteem and femininity are shaped by interactions with these kinds of sociocultural norms and expectations (Motherwell and Prudent 1998) which lead them to respond to the strong cultural pressure to have and desire children (Whiteford and Gonzalez 1995). Likewise, the strong negative impact of conception difficulties, infertility and involuntary childlessness are also related to these pervasive pronatalist views about marriage and motherhood (Miall 1986) which transcend social divisions such as race, class, age, religion and ethnicity (Veevers 1980; Miall 1986; Whiteford and Gonzalez 1995). Indeed, all societies place a great value on having children and most people still see having children as an essential part of their lives (Bos 2007). The inability to fulfill this societal norm and the associated, anticipated, social role can leave women feeling like they are violating society's expectations, feeling inadequate 
and as if they have lost their purpose in life (Gonzalez 2000). Their identity and their expectations about their lives are disrupted.

Several authors (Veevers 1972; Peck and Senderowitz 1974; Menning 1977; Miall 1986; Greil 1991a, 51-52; Monach 1993, 55-56; Gillespie 2000) offer ample evidence to claim that parenthood is constructed as socially normal and non-parenthood is seen as abnormal, or deviant. Pronatalism is firmly grounded in our social organization and holds considerable influence over us, especially those who do not conform to its ideals (Monach 1993, 52). Greil (1991a, 52) further suggests that pronatalism and the parenthood norm are so deeply embedded in the structure of social interaction that it is not something that is simply learned once, but is rather something that is continually relearned in the course of everyday life, in media presentations, and everyday observations and interactions. Particularly, the question "do you have children?" one of the most frequently asked questions after meeting someone for the first time, conveys the message that being a parent is an integral part of being an adult, and "after a while, 'no' can come to feel like the wrong answer (Greil 1991a, 52)".

Monach $(1993,59)$ suggests that it is not surprising that people who are unable to fulfill the injunction to have children experience their social position as isolated and painful since there is such a great weight of normative pressure to choose and attain the parent role. Additionally, widely held beliefs and psychoanalytic theories which purport that parenthood is a normative developmental stage representing full adulthood and that the realization of personal potential is connected to the achievement of parenthood further reinforce the strong hold of pronatalism on our identities and expectations about our lives (Monach 1993, 54). 
Gillespie (2000) suggests that essentialist and pronatalist discourses that construct motherhood as central to feminine identity are entrenched in our culture and reinforced in religion, politics, modern science and modern medicine and are enmeshed in these powerful, hegemonic, ideological doctrines. She says that "...the nurturance of children has historically been seen to be what women $d o$ and mothers have been seen to be what women are, constituting the central core of normal, healthy feminine identity, women's social role and ultimately the meanings of the term woman (Gillespie 2000225 )."

Even in the face of tremendous gains in the workplace and the strides women have made in asserting increasing choice in their lives in the past several decades, feminine identity and motherhood continue to be linked (Motherwell and Prudent 1998). This is felt particularly intensely among women who identify strongly with traditional feminine roles and see motherhood as a way to acquire status (van Balen and TrimbosKemper 1995). The results of this study support this position.

The normative, taken-for-granted, and mandatory nature of motherhood as a source of identity for women in pronatalist society means that childless women need to "explain themselves" (Woollett 1991, 52) and are excluded from a rite of passage that marks the psychological and physical transformation from youth to maturity (Rehner $1989,22)$. If motherhood is normative, non-motherhood, then, can be construed as somehow deviant. Non-mothers may be seen as "unnatural" and may be pitied or even vilified (Gillespie 2000).

They must deal with negative characterizations of themselves and their situation (Sandelowski 1993, 72) which may include being seen as "selfish and maladjusted... (Lasker and Borg 1994, 13)." Lisle $(1996,30)$ suggests that "the specter of the woman 
without a child can invoke an image of the woman who hates children, the archetypal anti-mother, the non-nurturing female." They may be presumed to be immoral, overly sexual or harbor a dislike of children (Motherwell and Prudent 1998). They may be branded as both frigid and licentious (Rehner 1989, 28). Their lives are seen as empty, missing the warmth and fulfillment of motherhood (Woollett 1991).

The cultural prejudice against non-mothers is reflected even in the language used to characterize women who do not reproduce: "barren", "dried up", "selfish", "sterile" (Woollett 1991; Motherwell and Prudent 1998). These words "...signify a denial of growth and fruitfulness (Rehner 1989, 22-23)." As Rehner (1989, 14-15) further notes:

...the word "infertility" is unpleasant. Like its synonyms "sterility" and "barrenness", it is loaded with psychological and cultural associations of personal and sexual inadequacy, failure, impotence, unnaturalness, even religious guilt and punishment. In searching to authenticate her experience, the infertile woman must deal with language that further erodes her sense of wholeness.

Further, In Judeo-Christian biblical stories, "barrenness" is a curse and children are a blessing (Miall 1986; Rehner 1989, 24-25; Atwood and Dobkin 1992). The cultural stories depict infertile women as "sour, brittle, faithless, selfish and bitter (Rehner 1989, 23)." In interpretations of biblical stories (for example, the stories of Sarah, Rachel, Hannah and Elizabeth), childlessness is frequently seen as a withdrawal of God's favor and the restoration of fertility is seen as the return of the favor of God (Monach 1993, 50). These "stories of patriarchy" act to confirm any sense of inadequacy that infertile women may feel (Rehner 1989, 23). In language, mythology, history and theology, infertile women are portrayed as the negative other, as "anti-women, unwomen, unnatural, unsexed and unblessed (Rehner 1989, 22)." 
In a social context where childlessness is seen as aberrant and suspect, infertile women may even be blamed or held responsible for their own "failure". They may encounter assumptions that they themselves are somehow thwarting conception (Rehner 1989, 28). Sandelowski notes: "Recent studies of the social milieu of the infertile document... the misconceptions that if only they tried harder, or did not try so hard, or had sex the right way, or had the right mental attitude, or really wanted a child, a pregnancy would result (1990b, 497)." Common public (and often erroneous) perceptions about the causes of infertility, which include the notion that infertility has psychological causes ("it's all in your head" or "just relax"), that it relates somehow to sexual incompetence or sexual inadequacy, or that it is wholly a woman's problem, contribute to the sense of failure and inadequacy that infertile women may feel (Miall 1985).

Particularly, psychogenic explanations for infertility which purported that infertility had mental or psychological causes, such as an unconscious fear or hostility towards reproducing, popular until the past few decades, placed the blame for infertility on the infertile women themselves (Sandelowski 1990b). As recently as 1998, Human Reproduction, one of the leading journals in reproductive endocrinology, published an article which used three case studies of professional women seeking psychological counseling in relation to their conception difficulties to suggest a link between ambivalence about parenthood and unexplained infertility (Christie 1998). Although psychogenic causes are no longer seriously considered to be linked to infertility in most medical literature, and it is now widely accepted that any increase of psychological disturbances manifest by infertile women are likely to be consequences rather than causes of infertility (Seibel and Taymor 1982; Morse and Van Hall 1987; Sandelowski 1993, 72; 
Greil 1997; Apfel and Keylor 2002; Wischmann 2003; Monach 2005) ${ }^{20}$, there remains, nevertheless, an undertone of blame towards infertile women in discussions about the causes of infertility.

This is especially true where infertility may be assumed to be related to women's own choices (Sandelowski 1990b; Woods, Olshansky et al. 1991). Supposed choices that may be presumed to be linked to infertility, such as delaying childbearing, using contraception, having abortions, engaging in pre-marital sex, contracting sexually transmitted diseases, working in environments that are stressful or require exposure to toxins, still cast blame on infertile women themselves (Sandelowski 1990b). According to Sandelowski, "contemporary literature on infertility continues the theme of female volition, a modern convergence of the ideas that infertility is in part a consequence of deliberate efforts to thwart instinct and nature and that it is a manifestation of disguised will $(1990 \mathrm{~b}, 496) . "$ Woods and Olshansky $(1991,186)$ suggest that "[l]inking IUD use to tubal damage, birth control pills to ovulation disorders, abortions to cervical damage, and decisions to delay childbearing to lowered fertility indicts women for their lifestyles...,21 In such a context, it is not astonishing that women experience feelings of guilt, shame, aberrance and feelings of loss of self worth when faced with conception difficulties. This impact is discussed within this chapter. Surprisingly, the stories themselves also seemed to reinforce and reflect pronatalist values. Not only did pronatalism mean that women were negatively impacted by conception difficulties, but it was largely used to frame their

\footnotetext{
${ }^{20}$ Davis-Floyd (2000) notes, however, that it has now become taboo to mention that anything other than physiological factors could cause infertility and that this limits ways to solve the problem. All we can do, she suggests, is fix our "broken body-machines" and we can not even talk about taking a psychological journey to examine possible unconscious reasons conception has not occurred.

${ }^{21}$ The ways in which women revisit these previous "decisions" when making sense of conception difficulties will be discussed in Chapter Five.
} 
experiences and tell their stories as well. There was little evidence of alternative frameworks even though alternate roles for women are increasingly accepted and available.

\section{Pronatalism in the Stories}

\section{Pronatalism: Hope, Perseverance and the Possibility of Miracles}

One of the intended purposes of the Trying to Conceive Story Gallery was, like most support groups, to ease the isolation of women experiencing conception difficulties by facilitating the sharing of feelings among women with similar experiences. In this vein, many women did note that it was helpful to read about other women with similar experiences and that the stories did make them feel less alone. Some of these responses were cited in Chapter Two in relation to methodology. In another context, a range of stories from childless/childfree women might also have acted as a challenge to narrow definitions of feminine identity (Motherwell and Prudent 1998). Ironically, and unexpectedly, however, the stories (though not universally) rather seemed to reinforce the pronatalist ideology that itself seemed to be at least partially responsible for causing the participants so much pain and grief in the face of their conception difficulties. Again, this supports the position that pronatalism maintains its impact. Indeed, it continues to be reproduced, reconstituted and experienced in the discourse, actions and interactions of the participants of this study.

Women reading and writing the stories were likely to offer and receive the message that they should not give up trying to be a mother; that it is the most worthy of all pursuits; that there is always hope; that miracles are possible and may be just around the corner; and that no hurdle is too high to jump in pursuit of motherhood. While there 
were several stories about the unfair judgments and assumptions others (discussed later in this chapter) there were few stories about or from women finding meaning and happiness in other pursuits or choosing to abandon the pursuit of motherhood to find meaning and a positive sense of identity elsewhere. This lack is possibly due to the timing of the solicitation of the stories, which, for many was just at the moment they realized or suspected they had some fertility impairment, soon after getting a positive pregnancy test result after trying to conceive for a long time, or, at the moment they decided to start trying to conceive. In each case, this is likely to occur before an alternate sense of identity would be considered or desired. Alternatively, it could be the nature of experiencing conception difficulties since there is always "hope" unless a definitive medical diagnoses that absolutely precludes conception is given. Nonetheless, the prevalence of pronatalist values in the stories themselves indicates their ubiquity and the continued importance of this context for shaping feelings about identity in relation to conception difficulties. In most cases, pronatalism was reinforced through metaphors of miracles and the values of hope and persistence.

Hope and persistence are seen to be important for making sense of a significant life disruption and taking responsibility for a medical condition (Becker 1997, 122). Hope and perseverance are not necessarily irrational. Actively maintaining hope may avert a sense of despair and resentment and allows a person to keep trying to achieve something they desire. Perseverance and maintenance of hope, also noted in studies by Sandelowski $(1987 ; 1989)$ and Greil and Porter $(1989 \mathrm{~b})$ also allow a person to stave off later regret because, no matter the outcome, they can feel that they pursued all available possibilities (Sandelowski, Harris et al. 1989). This theme is perpetually present in the stories. The 
stories themselves, though made public in an effort to ease isolation and resist the sense of otherness frequently experienced by participants, may have inadvertently played a role in reinforcing pronatalist ideals and the appropriateness of medical solutions at any cost. Woollett (1996), has suggested that support groups, such as RESOLVE (discussed later in this chapter) and their associated newsletters and communications may also reinforce pronatalism and delay the acquisition of an alternate identity for infertile women by exhorting them to 'keep trying' and 'never give up hope'.

A few extracts from the stories demonstrating the themes of hope, persistence and the possibility of miracles are included below:

I encourage all women who dream of having a baby to keep trying and never give up! (story461008664427; United States; Age: 29; Months TTC: 6)

We now have our beautiful baby girl that we were TTC in this story. She is one month old and absolutely perfect. We are so in love. TTC is very stressful, and I wanted to give up many times but I am so glad that I didn't. My advice is never give up. Try everything you can, because that precious baby just around the corner. When you hold it in your arms and look into its perfect eyes, you will know it was worth all the stress, time, and money. (story79629564501; Australia; Age: 25; Months TTC: 42)

We both want a baby so much. I know all of this will seem like it was nothing once we get a positive pregnancy test and make far enough to hear the heartbeat. (story681834256750; United States; Age: 29; Months TTC: 5)

No matter how long or how impossible the journey seems, it can happen and we are proof of that. So take heart that it can happen and don't give up on your dreams. (story261708421289; United Kingdom; Age: 42; Months TTC: 23)

I KNOW that I will have a child, I believe that in my heart. How or when I can't answer but I know that I will never give up on trying. (story291881172626; Australia; Age: 32; Months TTC: 19)

I know how hard it is to be on the other side, not pregnant yet, and not knowing when it will happen. I know what it feels like to read these words 
and still feel empty inside because it has not happened to me yet. I know how hard it is to continue to have hope when constantly given a negative test result. I believe in miracles and I believe everything happens for a reason. Please do not give up hope because it can happen to you as it did to me and other women out there! (story911266305852; United States; Age: 37 ; Months TTC: 17 )

\section{Pronatalism: Not for Everyone}

Pronatalism does not apply to all members of society: just those who are constructed as deserving and worthy. Women experiencing conception difficulties frequently express rage, dismay, and confusion at the injustice of the ease with which "unsuitable" or seemingly undeserving or ungrateful women can become parents while they must struggle. Such constructions of worthy versus unworthy potential parents may simultaneously reinforce and reflect the pronatalist ideal that parenthood is appropriate for secure, married couples and also highlight the women's own inability to attain the associated status. That even teenagers and drug-addicts can get pregnant may accentuate their own feeling that they have failed at something so essentially basic. It may also threaten their sense of themselves as worthy and may force them to question their own sense of the world as just. Even though these "suitable" women experienced difficulty conceiving, this did not cause them to challenge the concept of worthiness in relation to parenthood. The concept held strong and caused feelings of outrage and unfairness. Concepts of worthy and unworthy parents and the associated feelings of injustice were expressed in the following ways:

I never realized how difficult this road was. It seems so unfair at times, there are all these young girls that get pregnant and can't afford to care for a baby and here we are wanting one so badly. (story571956681163;

United States; Age: 44; Months TTC: 17) 
I get really angry when I see a young mum ignoring her child's cry, I just want to lock the mum away and snatch the baby. (story77164215748; United Kingdom; Age: 20; Months TTC: 7)

This experience has made me bitter and resentful of those who have it easy (and don't appreciate how easy they have it). It has made me angry at those who had it easy and complain throughout the pregnancy of feeling sick, fat, ugly, etc. I would love to feel those things if I could have a baby at the end of it. (story96829939358; United States; Age: 29; Months TTC: 40)

It makes me rage when I see pregnant women smoking, or hear of abuse of children, and I know that people who don't deserve children can have as many as they like, and we can't even have one. (story36818748967; Ireland; Age: 34; Months TTC: 34 )

Then there are times when I hear of children being mistreated and it makes me so angry that those people can have children and I can't. (story181995168651; United States; Age: 39; Months TTC: 30)

Why is it that we have such trouble conceiving and yet any 13 year old can do it in the backseat of a Chevrolet?? (story79629564731; United States; Age: 36 ; Months TTC: 15)

\section{Pronatalism, Deviance, Stigma, Otherness and Isolation}

The notion of childlessness as deviance from societal norms and a failure to conform to social ideals within the context of pronatalism offers some insight into the feelings of otherness, failure, defectiveness, isolation and liminality that are often experienced by those who do not fit into society's conventions prescribing parenthood for married couples ${ }^{22}$. The feelings of otherness and isolation derive from both real and perceived feelings of social unacceptability as well as a lack of empathy from friends and family who are unable to understand the depth of despair felt by an infertile person (Cousineau and Domar 2007). The infertile, childless woman, or the woman who has

\footnotetext{
${ }^{22}$ Lasker and Borg $(1994,13)$ also note that this external pressure and internal trauma also extends to people who have just one child, since "only" children are stereotyped as spoiled and maladjusted and it is seen as cruel to deprive a child of a sibling.
} 
achieved motherhood unconventionally, may be seen as "other" compared to the feminine "ideal mother" (Letherby 1999). Letherby $(1999,369)$ utilizes Simmel's concept of "the stranger" to theorise the position of the infertile/childless woman, saying:

This is a concept that includes belonging and not belonging, commonality and difference, acceptance and exclusion... all relationships are characterized by attributes of nearness and distance. Thus, as individuals and as group members people are linked into diverse networks and circles; in relation to some of them, they find themselves in the position of strangers whilst in relation to others they are part of the mainstream group.

Occupying the position of 'the stranger' means occupying an ambivalent status which affects one's identity and one's interactions with others (Letherby 1999). This position builds upon earlier discussions of deviance and stigma in relation to childlessness and pronatalism.

Veevers $(1972 ; 1973 a ; 1980)$ initiated the discussion of childlessness as deviance, particularly with reference to voluntary childlessness. Miall $(1986,268)$ built upon this notion with respect to the experience of infertility and involuntary childlessness, saying that " $[w]$ hen cultural norms and values encourage reproduction and celebrate parenthood, childlessness becomes a potentially stigmatizing status which can adversely affect the identities and interpersonal relationships of married persons." Additionally, a number of authors (Miall 1985; Miall 1986; Greil 1991b; Whiteford and Gonzalez 1995; Remennick 2000; Clarke, Martin-Matthews et al. 2006) have utilized Goffman's (1963) concept of stigma to discuss the ways in which infertility/childlessness can affect one's social identity and define them as "lesser" or "other" when they do not meet the societal ideal which proscribes parenthood for adult, married people. Stigma, in this context, refers to an attribute (here, a lack of biological children) possessed by individuals that makes them 
different from others in their category that makes them less desirable, reduced, discounted, discredited, tainted (Goffman 1963, 2-3).

Goffman $(1963,7)$ describes how stigma is experienced when one does not fit the social norm in the following way:

...the standards he has incorporated from the wider society equip him to be intimately alive to what others see as his failing, inevitably causing him, if only for moments, to agree that he does indeed fall short of what he really ought to be. Shame becomes a central possibility, arising from the individual's perception of one of his one attributes as being a defiling thing to possess, and one he can readily see himself as not possessing.

Stigma is said to mirror culture in such a way that the dominant group can decide which human differences are desired and which are undesired and in this way reflects the value judgments of a dominant group (Coleman 1986). Failure to possess the attributes deemed desirable by the dominant social group can be experienced as a stigma, as a failure to conform to society, as norm infractions (Page 1984, 4). People possessing the stigma may feel personally responsible for this failure (Becker and Arnold 1986). "Those experiencing stigma may feel that their whole identity is tarnished because of a particular attribute. Such feelings may be intense; experienced in many situations; and persist for long periods of time (Page 1984, 17-18)." In reference to infertility, Miall (1985, 387) says that " $[t]$ he data are clear, social context determines that infertile women will be subject to stigmatization." She reports that through interactions with others, infertile women are stigmatized, publicly diminished, and made to feel deviant (Miall 1985). Greil (1991a, 133) describes the stigmatizing experience of infertility like this:

... the heart of the experience of infertility appears to lie in the inability to proceed with one's life according to life course norms that are both reinforced by others and accepted as valid by the affected individual. Given this pervasive sense of failure... the world can appear as a place full of discrediting messages about the self, even absent deliberate attempts on 
the part of fertile people to stigmatize the infertile. Fertile people promote the stigmatization of the infertile not so much by deliberately discriminating as by promoting a definition of normality that excludes the infertile.

One may wonder why the pain of infertility and the associated stigma is described so acutely when western society now offers women viable alternatives to the motherhood role. Indeed, as Becker and Arnold (1986) note, in heterogenous societies, the stigmatized may reject stigmatization. Additionally, there are a range of "femininities and masculinities" that are available to women and men even though some are more highly privileged and socially accepted than others (Clarke, Martin-Matthews et al. 2006, 97). Further, social change and the opportunity for new roles for women mean that cultural discourses associated with "the motherhood imperative" increasingly co-exist with a range of alternative and competing discourses (Gillespie 2000).

Certainly, childlessness as a stigmatizing condition in the context of pronatalism has been largely challenged. The challenge, however, has predominantly been about the choice not to have children and to be not defined as lesser if one decides not to have children (Veevers 1972; Veevers 1973a; Veevers 1980; Morell 1994; McAllister and Clarke 1998; Gillespie 2000). Rehner $(1989,13)$ notes that fertile people can now choose not to have children without stigma because feminists have dismantled and exposed romantic myths about motherhood. This may unfairly make the grief women experience due to infertility and the failure to fit what may seem to some like quaint ideals even seem unjustified or obsessive. The disruption and associated stigma, grief, and assault on identity, however, may also indicate the persistence of such norms and values, even in the face of a seemingly increasing array of opportunities and alternatives. 
The feminist argument that mandatory biological motherhood is socially constructed and serves patriarchy forces infertile women to confront social and cultural issues that fertile women are never asked to confront (Sandelowski 1993). Fertile women do not have to explain why they want biological children or why they do not want abused, abandoned, relinquished children or children from different racial backgrounds or any other child that may be in need of parents (Sandelowski 1993, 74). Sandelowski (1990b, 498) says:

Like the mid-twentieth century medical clinicians who equated reproductive outcome with reproductive desire, some feminist writers equate women's desire for children with their oppression as women, viewing this desire and the anguish women feel when it remains unfulfilled as socially constructed rather than authentically experienced... [S]ome feminists exploit these women by implicating them in a patriarchal project aimed at dividing and destroying women.

It may be more helpful to view the experience as simultaneously socially constructed and authentically experienced in diverse ways. Pronatalism and its idealized values may be socially constructed, but this does not minimize the desires and grief experienced by women who accept those values. One can accept that the "infertile other" is defined in terms of relations with men and the social roles embedded in patriarchy (Rehner 1989, 119) and that dominant Western discourses of womanhood are constructed in such a way that motherhood is viewed as women's biological destiny (Ulrich and Weatherall 2000). Nevertheless, the socially constructed nature of pronatalist ideals and norms does not mean that women experiencing conception difficulties suffer less, that their distress is irrational (Ulrich and Weatherall 2000) or that their desires are not multi-faceted, uniquely-shaped, reasoned, complex, and valid. 
In any case, the suggestion that mandatory motherhood serves patriarchy, along with increased opportunities for women, has not had the effect of dismantling pronatalism. Indeed, even though there has been discussion about motherhood and mothering as socially constructed and more women are participating in the workplace than ever, this has not degraded the social value of biological parenting (Cousineau and Domar 2007). The persistent pronatalist ideal counter-acts advances in reliable contraceptives and expanding work opportunities for women that could make childlessness possible and desirable for some women (Park 2002). Arguably, in the past couple of decades, pronatalism has had a stronger hold than in the previous two decades, with a social emphasis on "family values" silencing discourses which emerged from feminists and environmentalists in the sixties and seventies (Park 2002).

Certainly the involuntary nature of childlessness for those who desire children and accept dominant, pronatalist ideologies, makes the response and experience quite different from those who are voluntarily childless and actively and deliberately reject pronatalist ideologies. Both groups may be forced to contend with cultural expectations that define them as deviant, but having made the choice to remain childless may be less distressing than having little to no control over one's childless status (Motherwell and Prudent 1998). ${ }^{23}$ Women who link biological parenthood with happiness are more likely to be distressed about infertility and their childless status and are more likely to ruminate than women who do not link biological parenthood and happiness (Brothers and Maddux 2003). While voluntarily childless people may attempt to justify their behavior and choices and may adopt an alternative value system, involuntarily childless people are

\footnotetext{
${ }^{23}$ The voluntarily childless may argue that they experience greater stigma since they are deviant both in having no children and in desiring no children and thus garner scorn rather than pity (Park 2002).
} 
likely to provide "excuses" for their "failure" since their values and those of their friends and family are likely to see childlessness as inappropriate and undesirable (Matthews and Matthews 1986b). They largely accept the dominant cultural viewpoint that children are desirable, will bring happiness and fulfillment, and that they are not fully adult and their marriages are not complete without them. This is reinforced by the people and images around them which heighten their own sense of inadequacy (Butler and Koraleski 1990). Having made the decision to try to conceive, they make the value they place on childbearing and childrearing evident to themselves and others (Butler and Koraleski 1990).

Stigma is possible because they and the people around them accept the mainstream pronatalist values. Furthermore, the perception of stigma is greatest when they deeply identify with the universal expectation of motherhood and cannot meet this norm (Remennick 2000). Indeed, there is evidence to suggest that women who identify more strongly with traditional sex roles are more likely to suffer from the felt stigma of infertility and the associated loss of psychological well-being than women who have other roles available to them (Morse, C.A and Van Hall, E 1987). Sandelowski (1993, 73) suggests that "they are both inside and outside accepted society: they are normal by conforming to motivational cultural norms by wanting children and deviant by violating cultural norms by not having them."

For these couples who wish to have children and are committed to becoming parents, conception difficulties may come as a "shock" to their identities (Matthews and Matthews 1986b). It may even require a complete reevaluation of goals and selfperceptions. Motherwell and Prudent $(1998,149)$ suggest that 
The woman who has organized her identity and her dreams around creating a family has many feelings about the absence of children and loss of choice such as tremendous yearning, sadness, shame, envy, and rage. The realization that she will not be able to fulfill her life dream as planned may result in feelings of helplessness and hopelessness, as it may raise profound questions about the meaning of her life.

Furthermore, they may feel isolation that is both internal and external. As they feel or expect the judgment and pity of others, and as they witness their friends and acquaintances experiencing pregnancy and parenthood, they may withdraw further and isolate themselves further in order to protect themselves since such contact reinforces their marginal status in a child-oriented society (Matthews and Matthews 1986a). Family and friends may also be unfairly critical when a woman does not become a mother and they may imply that her identity is incomplete (Mahlstedt 1985).

Childless women who desire children may feel that they do not have the attention and respect that people with children have and may feel different and "left out" (Mahlstedt 1985). Further, friends and family who have children and feel awkward about their own children may contribute to the feelings of isolation by avoiding the infertile woman or couple (Mahlstedt 1985). The sense of otherness and the associated pain and loneliness is constantly reinforced for the infertile woman- when she sees a pregnant woman, sees television commercials with giggling children, receives birth announcements, buys birthday presents for other people's children and feels the alienation of friends with children as their interests increasingly diverge (Mahlstedt 1985). Her sense of difference is constantly reinforced in these strained social interactions (Sandelowski and Pollock 1986). A failure to bear children in the context of pronatalism, can thus mean a sense of failure as a woman and can mean that the childless woman is denied access to the world of shared experience occupied by mothers 
(Sandelowski 1993, 77). She is left out. She has "failed" both to fulfill her own desire and has also failed to fulfill a powerful societal mandate (Lasker and Borg 1994). This failure devalues one's sense of self due to the associated stigmatizing feelings of shame, guilt, inadequacy, devaluation and incompleteness (Whiteford and Gonzalez 1995) and is an insult to a woman's self-esteem (Mahlstedt 1985). Such a "failure" to meet the cultural conscription that requires children after a certain time of marriage, means that women without children are subject to scrutiny (Sandelowski 1993, 78) and made to feel "spoiled" and inferior to "normals" (Whiteford and Gonzalez 1995).

Goffman's (1963) differentiation between visible and invisible stigma and issues of "disclosure" are relevant to this sense of scrutiny. Infertility and childlessness can be seen to be both visible and/or invisible in industrial societies. It is visible in that it is easy to notice that someone (married) is childless by their lack of children, yet it is invisible in that it is not possible to know, without further information, whether or not this is a desired or undesired status. Griel $(1991,135)$ notes that this ambiguity is only present in industrial societies where reasonable motives exist for not having children.

This sense of being outside the norm, with a "spoiled" identity and the associated scrutiny and ambiguity as well as the secrecy about sexual and reproductive issues produces interaction problems and the infertile woman must engage in "information management" deciding whether, what and who to tell (Sandelowski 1993, 78; Whiteford and Gonzalez 1995). Whiteford and Gonzalez $(1995,30)$ note:

Women are reluctant to talk about infertility even with their husbands; husbands are unwilling to undergo medical tests, and no one wants to tell their mother-in-law... couples refrain from telling family, friends, and coworkers about their fertility problems and, consequently suffer the constant joking questions and comments about their sexual behavior and potential (and absent) outcomes. 
The necessity of managing the information and keeping secrets can further exacerbate one's sense of isolation. Isolation, alienation, difference and otherness are themes which occur repeatedly in discussions about the impact of infertility on women's identity. "This conceptualization of being the 'other,' being culturally rejected, being forced into isolation... is caused by perceived deviation from the group norm (Whiteford and Gonzalez 1995, 29)."

\section{"Otherness" and Others in the Stories}

In the literature on infertility/childlessness and identity, stigma, deviance and “otherness" are significant themes (Miall 1985; Miall 1986; Greil 1991b; Monach 1993; Whiteford and Gonzalez 1995; Lisle 1996; Woollett 1996; Parry 2005). The inability to achieve what most people can seemingly easily achieve, something expected by societal norms and anticipated as a natural life event, leads to feelings of defectiveness, isolation and difference. Some of these negative aspects seem to be something the sufferers cast upon themselves based on their own goals, beliefs and desires, and some of this is experienced largely due to negative interactions with and comparisons with others. Respondents in this study expressed their feelings of "otherness" in the following ways: feeling defective; feeling isolated and "left out", feeling envious of others; experiencing difficulty managing information and contact with others; dealing with insensitive comments from others; feeling like "no one understands"; feeling pressure from others, and feeling like the experience was unfair. These findings are consistent with findings from a number of previous studies (Miall 1985; Matthews and Matthews 1986a; Miall 1986; Olshansky 1987a; Sandelowski 1987; Greil 1991b; Monach 1993; Whiteford and 
Gonzalez 1995; Letherby 1999; Gonzalez 2000; Exley and Letherby 2001). Feelings of isolation, defectiveness and alienation and feeling like one is not a "proper woman" due to the inability to conceive biologically reinforce and demonstrate the persistence of pronatalist social expectations about motherhood and identity and the linked association of womanhood and motherhood, in spite of increased role options for women. The concept that one must be able to conceive to be a "proper woman" is left largely unchallenged even though increasing numbers of women are choosing not to have children. The key seems to lie in the ability to choose.

\section{Failure/Defective}

Difference, deviance and otherness were frequently expressed as a feeling of being "defective", "broken", "worthless" or a "failure":

Through this whole ordeal, I have, as a woman, felt broken. Like a toy that has no batteries. What use am I if I can't perform the ONE simple function we were created for-- procreation. (story99988039578; United States; Age: 24; Months TTC: 22)

TTC is one of the hardest, heartbreaking experiences I have ever been through. You feel stupid and weak. You feel like a failure as a woman, because you can't do the one thing that you were made to do. (story821856146168; United States; Age: 24; Months TTC: 18)

I feel like a failure... (story611810701062; United States; Age: 33; Months TTC: 3 )

I feel less and less like a full and proper woman the further we go and the more failure we have to face. (story36818748967; Ireland; Age: 34; Months TTC: 34)

I would never want anyone to feel as horrible and worthless every time I got that negative HPT. (story281110581933; United States; Age: 26; Months TTC: 11)

It makes me feel like something is wrong with me. (story041968078814; United States; Age: 27; Months TTC: 30 ) 
I felt like a failure, who couldn't provide another child for my husband or a sibling for my son. (story261708422064; Canada; Age: 21; Months TTC:

9)

\section{Isolated and "Left Out"}

A number of women also expressed their feelings of isolation, feelings that frequently were exacerbated by their own withdrawal. Feelings of isolation and the need to withdraw from social interaction again indicate the lack of alternate social roles for women who do not or cannot occupy the motherhood role. Adult women who are not mothers may become isolated and have difficulty interacting with their contemporaries who are mothers.

It makes me feel a lesser member of my community, as I cannot get involved in local issues as a childless woman (playground fundraising, schools etc). (story36818748967; Ireland; Age: 34; Months TTC: 34 )

...It seems I notice more pregnant women and little babies now. I want to join that club and it hurts me that my body won't give in to me. (story571956681163; United States; Age: 44; Months TTC: 17)

With each loss I've withdrawn from those around me and have not wanted to share much of what is going on with those around me. It's so hard to feel alone with this. (481468590560; United States; Age: 33; Months TTC: 13)

I haven't been acting the same since I have been TTC-I don't hang out with friends anymore, and when I have time alone I just cry because it bothers me that much. (story87351897590; United States; Age: 21; Months TTC: 24)

Most of my friends/family don't know what to say or how to relate to us. It's been a very isolating experience. And in the end, there's no easy answer -- every option has the ultimate risk. (story451307654622; United States; Age: 35; Months TTC: 24)

[I] got the news that [a co-worker] was pregnant and had been for a while and was scared to tell me. It hurt worse to know that she was scared to tell me. (story451307654521; United States; Age: 24; Months TTC: 18) 


\section{Envy, Otherness and Injustice}

Feelings of otherness, isolation and deviance were typically highlighted when one's "failure" was juxtaposed against the "success" of others. For the participants of the TTC Story Gallery, this often made the celebrations of others, and the sight of others reaching the milestones that they seemed unable to attain, moments of despair and discomfort which seemed to showcase their own loss, difference, and grief. It brought their own sense of disruption to the foreground. A number of women questioned the unfairness of others achieving motherhood easily when they were experiencing such difficulty.

It hurt deep inside me to see young Mothers with their infants, even seasoned Mothers with their family of three. As people around me either become pregnant accidentally or know someone who did, I began to really ask, "Why not me?" Seeing large families made me feel the bitter sting of jealousy-- why should anyone get 8 kids when I can't have one? It was sad, hurtful, and generally unfair. (story 99988039578 ; United States; Age: 24; Months TTC: 22)

I never in my life thought it would be this hard to get pregnant. I am a lot more sensitive then I used to be. Seeing pregnant woman, new babies and going to baby showers is very hard. My [brother-in-law] and his wife are newly pregnant. I'm very happy for them but it's very hard for me to take. (story911266305294; United States; Age: 27; Months TTC: 17)

I have become resentful and jealous of friends who get pregnant quickly. I'm happy for them, but it is hard on me, and no one understands that until you go through it. (story121687063787; United States; Age: 25; Months TTC: 16)

...it bothered me to go to my own best friend's baby shower because it hurt me so bad to see all the baby stuff and how exited she was and yet I feel like I will never know that feeling. (story87351897590; United States; Age: 21 ; Months TTC: 24)

I am slowly getting to the point where I am having a hard time being around pregnant women. At first I was gung ho about asking them all kinds of questions and learning about their experiences, but as time passes, 
I find myself avoiding them. When I learn of another pregnancy of a friend or family member, I am outwardly happy for them, but I usually go home and shed a couple of tears. I just can't understand why this blessing hasn't happened for us! (story09444455060; United States; Age: 31; Months TTC: 10)

After all tests showed no infertility problems, I was diagnosed with Secondary Infertility. What was this and how could I have it??? Apparently I was fine, I just couldn't get pregnant. I hated life and everyone around me. I had resentment towards my husband which took its toll on our relationship. At one point during my TTC journey 6 people in my family were pregnant and boy did I hate them. Why is it they got to be pregnant so easily and I had to struggle?! (story98214780452; United States; Age: 32; Months TTC: 26)

It is really heartbreaking. I find it hard to be around friends that are pregnant, and I typically fall apart when I am invited to a baby shower. (story75766615057; United States; Age: 26; Months TTC: 12)

Two days after I lost the baby, my best friend announced she was pregnant. She hadn't been trying... she was still nursing her daughter ... I felt so angry, so betrayed by her, so downright miserable! I felt like she had STOLEN my baby from me! I couldn't believe that she was pregnant, this woman who was still nursing her BABY, someone who still HAD a baby in the house was pregnant and I wasn't. It seemed so unfair. Our friendship really suffered because I couldn't get past the resentment or anger I felt towards her, not to mention the insane jealousy! (story261708422064; Canada; Age: 21; Months TTC: 9)

\section{"No One Understands"}

Women experiencing conception difficulties frequently felt that their experience was not understood or acknowledged by the people close to them and this also increased their feelings of isolation and loneliness. Perhaps there is no widely known "socially appropriate" way to acknowledge the struggles associated with this kind of disruption from the "normal" expected life course.

Our family and friends have been as supportive as they can, but of course it's hard for people to understand, especially with our age. Some of our family thinks we're just being too impatient, which is obviously offensive, as is the "advice" that some people give, but you just have to correct them 
kindly and remember that they just mean well (most of them!).

(story 121687063945; United States; Age: 22; Months TTC: 26)

When people tell me "I am so sorry" I feel as though they are just saying that because they don't know what else to do. Most people pretend like they understand, when really they don't...The loneliness, isolation, and emptiness is almost unbearable at times. (story501920540485; United States; Age: 28; Months TTC: 20)

It was hard to talk about with friends that didn't understand, I felt pretty alone. (story071045618198; United States; Age: 26; Months TTC: 21)

\section{"Just Relax": Insensitive Others}

Insensitive or ignorant comments from others, including "well-meaning advice", was also experienced as something that highlighted and reinforced the "otherness" of women experiencing conception difficulties and had the effect of increasing pressure and feelings of failure and difference that they already felt. Again, it appears that many people do not know how to interact sympathetically with those who do not meet pronatalist social norms.

Confused, hurt, and sad, I took a step back and tried to piece together what it all meant. The words, "just relax", "go on vacation", "maybe you aren't supposed to be a mom" were a huge part of my life and it hurt a lot. (story99988039578; United States; Age: 24; Months TTC: 22)

I am still amazed at the things people say without thinking. Asking if we have tried everything or giving suggestions. Some people even say, "well maybe it's better". I am at an age where people assume I have kids and can't understand it when they find out I don't. (story181995168651; United States; Age: 39 ; Months TTC: 30 )

I get so sick of the "Just relax and it'll happen", or "It'll happen when you least expect it". Or, my favorite "Just try not to think about it". How can I NOT think about it with babies everywhere??? It's also difficult going to family functions and people are like "When are you guys gonna have kids"? (story501920540485; United States; Age: 28; Months TTC: 20)

... everyone kept telling me to relax and I just wanted to scream I KNOW!!!! (story94369560855; Canada; Age: 31; Months TTC: 6) 


\section{Shame, Information Management and Secrets}

The sense of shame and defectiveness that many women seem to feel as they experience difficulty conceiving, along with the insensitive comments made by outsiders, friends and family, often leads people to manage the information that they share with others and sometimes leads them to feel ashamed or embarrassed in social situations where they cannot hide their condition. Hiding themselves and their situation and constantly being on guard may further exacerbate feelings of isolation and otherness.

Here, disruption from the "normal" includes a component of shame.

It's difficult when people ask us about TTC or when we plan on TTC, most the time I am honest and tell them that we are "reproductively challenged". But there are other times when I don't tell them the truth. (story121687063787; United States Age: 25 Months TTC: 16)

One of the worst parts about TTC is going to the [reproductive endocrinologist] or specialist. You are forced to sit in the waiting room and pray that no one you know walks in. It turned my secret into a public display. I sobbed and told my nightmare story to my RE, a stranger... (story511633333960; United States; Age: 30; Months TTC: 19)

I was filled with shame and embarrassment. I would have told people if I could have. I would have unburdened myself, but every time I tried to talk about it I couldn't stop crying and was depressed for days. I didn't want anyone feeling sorry for me or whispering behind my back. Those who did know tried to send me "it could be worse" emails or were overlyencouraging. (story511633333960; United States; Age: 30; Months TTC: 19)

It can be difficult to attend baby showers, and it can be very embarrassing to have to explain to others why we aren't conceiving. "When are you guys going to have another baby?" "Have you thought about adoption?" "Maybe you're eggs are too old, now." "Maybe if you try this..." It is an endless set of comments that really point to the ignorance of infertility. (story73296122015; United States; Age: 41; Months TTC: 13)

I have definitely become more sensitive to personal questions. The other day at work, a relative stranger asked me, "Do you have kids?" I replied, 
"No." She asked, "Why not? Don't you want kids?" This kind of thing is really irritating to me now. I am dreading going to family events now because I know that I will be facing that question over and over again. Argh, why can't my husband knock me up already? (story09444455060; United States; Age: 31; Months TTC: 10)

I made a new rule not to discuss TTC issues with friends and family. I found that with or without intending to, they say hurtful things. This has taken over a year longer than I thought that it would! (story931742093105; United States; Age: 25; Months TTC: 17)

TTC and infertility have affected my friendships in a major way. Nearly all our friends have children and none have been through infertility. It has been difficult dealing with their many pregnancies and new babies, difficult for them as well as us. Some are very sensitive to our plight, some seem oblivious! We have learned along the way who is 'safe' to be around and who will be insensitive. We have not cut off contact with anyone and we of course send gifts and best wishes to friends on their new arrivals, but it is very difficult. But for the most part, I feel safest when I am in our house with the answerphone switched on and then I know I won't be taken aback by an unexpected announcement or careless comment. TTC and infertility have shown me who my true friends are and I have been surprised at who they are. My best friend is no longer my best friend, but an old acquaintance! (story36818748967; Ireland; Age: 34; Months TTC: 34)

\section{Pressure from Others}

External pressure from family members, particularly potential grandparents who desire grandchildren, also appeared to reinforce feelings of failure and heighten the sense of loss for women experiencing conception difficulties. The disruption associated with conception difficulties, then, is not confined to the individual woman or couple affected since the inability to conceive also affects the desired and anticipated life course of others.

I am getting pressure from [my husband's] father to provide him with more grandchildren, little does he know that we are having (and have had previously) so much trouble TTC. (story55415587449; Australia; Age: 29; Months TTC: 15) 
I have found my husband to be really supportive, but I cannot say the same for family and relatives. Sometimes I just want to forget about TTCing but they never let me forget. The worst are reminder of how their kids/brothers/sisters started TTCing after me and already have a number of kids. Somehow that is supposed to make me feel better?

(story971599854372; Pakistan; Age: 27; Months TTC: 74)

$\mathrm{DH}$ and I felt the family pressure for kids from the day we were married. They didn't mean to push, they were just all excited to have more babies to spoil. They just didn't realize how much it hurt. (story481468590495; United States; Age: 25; Months TTC: 7)

Family and friends are asking me at least once a month, how I'm feeling, if I have anything to share with them. When the hedging doesn't work, they come right out and bluntly ask if I'm pregnant yet. (story681834256750; United States; Age: 29; Months TTC: 5)

My husband has no brothers or sisters but comes from a large extended family. His mother is very anxious for grandchildren and pressures us lot. (story951127757522; United States; Age: 40; Months TTC: 8)

\section{Ambiguity, Hope, and Biographical Disruption}

The nature of infertility and conception difficulties, where there may always be "hope" and where diagnoses are often vague and uncertain, and where treatment options escalate to become increasingly interventionist, make it difficult to construct an alternate reality and to plan an alternate identity. Complete certainty that conception is impossible is rare and there always seems to be something new to try that offers hope. In this vein, Sandelowski $(1986 ; 1987 ; 1993,69)$ notes that ambiguity is among the most common feeling among women experiencing infertility, that they are likely to feel like they are "in limbo", "on hold", "dangling", "in a gray area". The open-ended nature of infertility and the technological interventions that are available simultaneously offer people a realistic hope and also make it difficult for them to accept infertility and adjust their sense of self and identity and their plans for the future (Greil 1991b). Infertility is an experience of 
"perpetual uncertainty" where it may not even be easy to know when it is appropriate to grieve (Rhener 1989, 12). Because people struggling with conception difficulties do not know if their condition is temporary or permanent, their status is ambiguous, uncertain, unclear (Clarke, Martin-Matthews et al. 2006).

Becker $(1997,120)$, in a comprehensive discussion of biographical disruption and illness also uses infertility to illustrate how a significant life disruption challenges the way one looks at the future and casts a person into "limbo":

I have found that a period of limbo inevitably follows a life disruption like infertility. When people discovered they were infertile, their sense of order was disrupted, and life lost its meaning. Their hopes for the future had been the ground for their sense of continuity, and because they could not foresee the future, they consequently felt unable to proceed to the next phase of life. Their culturally derived sense of being propelled through time had stopped. They felt trapped in the present. The need to envision a future for themselves became the pivot on which all life turned.

Becker $(1997,120)$ suggests that seeing the disruption in terms of "limbo" helps people to lay the groundwork for re-ordering their experience. This may take several years (Becker 1997). As long as there is hope or another treatment option becomes available, it is difficult to mourn what is (or may be) lost and take control of a new life plan and new identity.

Making plans for the future which require any kind of long term commitment, such as changing jobs or furthering one's education, is often not possible while living in the "limbo" and ambiguity of infertility (Abbey, Andrews et al. 1992). A permanent reconstruction of reality, one's planned life trajectory and identity, then, is difficult or impossible until hope and a search for a solution can be relinquished (Matthews and Matthews 1986b; Sandelowski 1987). Yet the ambiguous nature of experiencing conception difficulties reinforces hope and thus prolongs the search for a solution, 
making the disruption to identity an enduring process. As long as a person tries unsuccessfully to conceive and does not find a way to successfully manage the infertile identity (by overcoming, circumventing or reconciling infertility) she remains permanently "in limbo" (Olshansky 1987a, 62). Wirtberg $(1999,122)$ suggests that they are "stuck" in one phase of their lifecycle, unable to get to the next phase: "Their lifestyle, their expectations, their thoughts and their feelings were all prepared for the transition from a couple to a family- a transition that did not take place."

The effect of infertility on identity, then, is like that of chronic illness (Greil 1991b) or terminal illness (Exley and Letherby 2001) and may be experienced as "biographical disruption" (Bury 1982). Like terminal or chronic illness, infertility or involuntary childlessness challenges any notion of a planned, or previously defined life course (Becker 1994; Exley and Letherby 2001). People experience inner chaos and disruption when expectations about the life course are not met because they represent a loss of the future (Becker 1994). Greil (1991b) aptly invokes Bury's (1982) concept of biographical disruption, which was developed in reference to chronic illness, to describe the impact of infertility on one's sense of self. Indeed, comparing the impact of infertility on one's identity to that of chronic illness does not overstate the impact of infertility. Domar and colleagues (Domar, Zuttermeister et al. 1993) found that infertility patients have anxiety and depression levels similar to women with cancer, hypertension, heart disease and HIV positive status.

Bury describes biological disruption in relation to chronic illness in the following way: “... illness, especially chronic illness, is precisely that kind of experience where the structures of everyday life and the forms of knowledge which underpin them are 
disrupted (Bury 1982, 169)". Chronic illness forces people to recognize possibilities which previously seemed remote, such as death and long term disability and dependency (Bury 1982). Infertility similarly forces people to reconsider the future, their self-concept and their biography as they consider the possibility of a future without children or navigate the maze of possibilities (various medical interventions, fostering, adoption, etc) in the "quest" (Sandelowski, Harris et al. 1989) for a child. The goal of having children, a goal that is associated with normalcy, worthiness, femininity, self-efficacy, and happiness is blocked (Clark, Henry et al. 1991).

Like sufferers of chronic illness, people experiencing conception difficulties are forced to pay attention to their body and body processes that are not normally brought into consciousness and they are required to make decisions about seeking help and disclosure (Bury 1982). Charmaz (2002) talks about how the self is redefined in chronic illness through new habits and the ability or inability to maintain previous habits associated with one's healthy self. A new self-concept is also developed in infertility through habits which may involve constant monitoring of one's body for signs of approaching ovulation, pregnancy, or menstruation. The effect of infertility on one's self and biography is not unlike the effect of chronic illness on the self as described by Corbin and Strauss $(1987,249)$ : “Unless the illness is mild, or its effect on activity is relatively negligible, the who I was in the past and the who I hoped to be in the future, in whole or in part, are rendered discontinuous with the me of the present. New conceptions of who and what I am, past, present, and future must arise out of what remains."

In relation to chronic illness, (specifically arthritis) Bury (1982) notes that the condition implies premature aging for the affected individual and thus "... it marked a 
biographical shift from a perceived normal trajectory through relatively predictable chronological steps, to one fundamentally abnormal and inwardly damaging. The relationship of 'internal and external reality' was upset (Bury 1982, 171)". Likewise, infertility upsets one's anticipated trajectory as individuals must shift from the "normal" path on which they assumed they were traveling (the path where they assumed children would arrive when desired), to an "abnormal," less certain path. It disrupts women's assumptions about how they will live their lives and contradicts the course and sequence of events they assumed they would follow (Franklin 1997a). Infertility can thus feel devastating when the life goal of having children is very important to them and their concepts of life fulfillment and happiness (Clark, Henry et al. 1991).

Like chronic illness, infertility is characterized by uncertainty and the everpresent "hope for a miracle" (Greil 1991a, 49). Infertility may especially be experienced as biographical disruption because it means that an important and expected life fantasy may not be fulfilled (Mahlstedt 1985). This is a goal that is not easily replaced or substituted (Clark, Henry et al. 1991). The experience can mean losing the experience of being pregnant and giving birth, the inability to continue their bloodline, or, at the very least, one loses the opportunity to experience conception without effort and/or medical intervention (Clark, Henry et al. 1991). Mahlstedt (1985, 339-340) describes it like this:

They are both frustrated and sad that they have been unable to have a child and at times hopeless that they will be able to do so in the future. They may never be parents and thus never experience all that accompanies parenthood socially, personally, and religiously: from being pregnant and giving birth, to preparing for baptism and later selecting a school, to escorting a daughter down the aisle in matrimony- and so beginning again the continuous cycle of life. 
Additionally, for many people, having a child means growing up and becoming an adult themselves and thus represents a psychological passage into adulthood and represents their idealized image of their adult self (Mahlstedt 1985). The capacity to reproduce is thus associated with full adult identity (Cousineau and Domar 2007). Failure to attain this ideal, then, can threaten one's adult identity and disrupt plans that may have been laid decades earlier. In this way, infertility may be seen a roadblock, or a disruption, to a person's growth and development. In most cases, this disruption is unexpected. Again, findings from the TTC Story Gallery were consistent with these earlier findings and further suggest that pronatalist ideals continue to shape women's expectations for their futures and continue impact upon responses when they are not easily met.

\section{Surprise and the Disrupted Ideal in the Stories}

A common theme related to identity, biography and conception difficulties was how the difficulty came as a surprise and forced women to relinquish and sometimes grieve the loss of some of their ideals, dreams, and plans about their future. Many women indicated that becoming a mother was their primary planned adult identity, something that had been anticipated since childhood, something they took for granted as natural and normal, and that difficulty achieving this came as a disappointing and disruptive shock. Some women indicated that they were initially ambivalent about trying to conceive, yet conception difficulties still were experienced as a disappointment and surprise. For women who had delayed childbearing, an increased sense of urgency surrounded the situation. This sense of surprise does not appear to be very different from that discussed by Barbara Menning in 1977 (104-105). Although women may be more likely to delay childbearing, and there is greater media attention to issues of infertility, women still 
assume that they will be able to get pregnant when they desire and expect to be able to plan their pregnancies. The responses from the Story Gallery support the concept of infertility as biographical disruption as discussed above. This continues to be an apt characterization of the experience in spite of increased role options for women over the past generation. Findings from this study support earlier work portraying the experience as surprising, all-consuming and disruptive to life plans and goals (Menning 1977; Matthews and Matthews 1986a; Sandelowski 1987; Rehner 1989; Sandelowski, Harris et al. 1989; Clark, Henry et al. 1991; Greil 1991b; Abbey, Andrews et al. 1992; Forrest and Gilbert 1992; Becker 1994; Wirtberg 1999; Exley and Letherby 2001; Kirkman 2003) and also suggests that this impact exists even when women have delayed childbearing and have pursued alternate, satisfying roles in the past. While women may delay childbearing and pursue alternate roles and may now anticipate combining a variety of roles, motherhood remains paramount. This again highlights the persistence of the pronatalist context in which the experience takes place- a context where motherhood, for the participants writing in the Story Gallery, continues to be an unquestioned desire and anticipated adult role following marriage and economic independence. This was expressed in the following ways:

\section{Something I've always wanted}

A number of women expressed that becoming a mother was something they had "always wanted". For many, becoming a mother and having children was part of their "ideal" life plan and the inability to attain something that had been anticipated for so long was experienced as a disruption. Women articulated their desire both to "be a mom" and "have children." 
I have been wanting to be mom ever since I can remember! We have decided that we would like to have our first baby! (story37514134299; United States; Age: 23; Months TTC: 0)

I am young I know, but ever since I can remember I have always wanted to have a wonderful hubby and a big happy family. $\mathrm{My} \mathrm{DH}$, Matthew wanted the same. We planned on waiting for the family, but soon after our marriage, we both decided we couldn't wait any longer! I come from a family of 7 children, so having only two people in the house seemed a little lonely, even though we are both VERY happy. (still honeymooning!) (story64901501303; United States; Age: 21; Months TTC: 4)

I have wanted this since I was a little girl and it will break my heart if we couldn't have children. (story451307654521; United States; Age: 24; Months TTC: 18)

I have wanted to be a mom for a long time, and my husband is also very keen to start a family, so we began TTC right away. (story34362859849; United States; Age: 37; Months TTC: 3)

I've wanted to have babies since I was one myself. (story671049489062; New Zealand; Age: 28; Months TTC: 1)

I want a big family and would have liked to be done being pregnant by my early 30 's...I have wanted to have kids ever since I can remember. My life long dream was to be a stay at home mom and a good wife... (story911266305294; United States; Age: 27; Months TTC: 17)

\section{Surprise}

Many women writing in the TTC Story Gallery expressed surprise at the difficulties they were experiencing with conception. The unexpected nature of conception difficulties, for many, meant that they had to adjust or grieve the loss of their expectations for their life plans and futures.

I feel robbed of the TTC experience I always thought I'd have. I always dreamed of the picture-perfect experience - telling my husband, announcing it to our families, and just glowing in the happiness of it all. (story231562469931; United States; Age: 28; Months TTC: 21)

I just thought that it would happen, and I would get pregnant. It didn't. (story75766615057; United States; Age: 26; Months TTC: 12) 
Of course, as a young girl, you never think you are going to have any problems TTC. I had my blinders on for many years...including the first 11 months of active TTC. (story16462648414; United States; Age: 33;

Months TTC: 16 )

\section{Life Progression: Marriage then Children}

A number of the stories indicated that the women writing were recently married or expected to conceive soon after marriage. Parenthood appeared to be the natural "next step" after marriage and difficulty progressing to this next phase of life was experienced as a disruption. Several stories, by way of introduction, mentioned the length of time of marriage, also perhaps indicating that as a married, heterosexual couple, it was appropriate to want and try to have children. This also constructed them as "worthy" potential parents. This will be addressed again in relation to marriage in the following chapter.

I married the man of my dreams in July and we're now ready to start a family! (story79629564672; United States; Age: 26; Months TTC: 1)

My DH and I decided to try to have kids after getting married. (story101215069536; United States; Age: 26; Months TTC: 3 )

I just recently married a wonderful man who was an only living child and has never fathered any children. We then decided to take the journey of trying to conceive. (story121687063834; United States; Age: 39; Months TTC: 7)

I then went back on the pill for one month, because we did not want to conceive before we got married. I got my period the day before the wedding and then went off the pill again since we were now ready to conceive. (story261708421221; United States; Age: 28; Months TTC: 2)

\section{Everything is in Place, Add Baby}

Several women also noted how the "time was right" to have a child, yet conception difficulties meant that plans could not proceed as anticipated. This was 
illustrated with the following themes: economic stability, home ownership, completed education and job security. The stories indicate further the appropriateness of parenthood for stable, secure, couples and the way difficulties with conception can upset planned life courses. Again, this also constructs the participants as worthy, deserving, "fit" potential parents. It also demonstrates the social expectation among middle class women that it is possible to plan and control one's future.

We have been TTC for almost three years now. I was 31 when we started TTC and my husband was 34 . We were married almost five years before starting TTC as we wanted to wait until we owned our own home and were secure in work before bringing a child into the world. (story36818748967; Ireland; Age: 34; Months TTC: 34)

DH and I have always wanted children but it has never been the right time. We wanted to wait until we had a decent job and some money in the bank. Now that we are both working full time and have some savings, we thought it would be the right time. (story891888747417; United States; Age: 31 ; Months TTC: 12 )

My husband and I got married in August 2001. After buying our home, and being in steady careers for a few years, we decided that we were ready to TTC in May 2005. It seemed that we both had family members conceive fairly easily, so we didn't expect that it would take us long. We thought for sure by the end of the year. (story581646153300; United States; Age: 28; Months TTC: 17)

My husband and I have been together for 7 years, married for a little over 2. We always knew we wanted to have a family and waited until we thought the time was right: I was out of grad school, we had a new house, and decent jobs. Many of our friends have kids already and I was excited that several of my girlfriends and I would be going through this new experience together... (story30493850334; United States; Age: 30; Months TTC: 6 )

I wanted to finish college, get a job in my field, buy a house, car, etc. We bought our first car in Jan 2005, then we bought a house and I started a new job at the same time in May 2005, and then I went through a lot of stress financially. A year after we bought the house, I told my fiance that I was going to stop my birth control pills and we were going to start trying 
to conceive. I went off the pill on June 3rd, 2006. (story87351897116;

Canada; Age: 23; Months TTC: 6 )

\section{Life is on Hold}

Biographical disruption and feelings of ambiguity were also expressed by the feeling of life being "on hold", or "on pause", being unable to make plans for the future, "living in limbo" and feeling left behind as others who started in a similar place progressed forward.

TTC is a lonely and sad process when it takes a long time, in my experience. Not to mention frustrating, I felt for 3 years that my life was on hold... When we decided to stop, it was almost a relief, we felt like we were in a holding pattern for so many years. (story271416980512; United States; Age: 41 ; Months TTC: 40 )

I think of all the things that I have given up or put on hold for TTC, and it makes me sad that all this work, and money and stress may never result in a baby of our own. (story121687063787; United States; Age: 25; Months TTC: 16 )

Living in limbo is what our situation feels like at the moment. My husband and I firmly believe that we have a happy and fulfilled future ahead of us and that we will live and enjoy life, whatever direction it takes us. But at the moment we can't take any decisions regarding careers, etc. as we just don't know what the situation will be. I have found it extremely difficult to live with this uncertainty. I am a meticulous planner and to have everything in the air for year after year is something I find very uncomfortable. But I have had to learn to live with it! (story36818748967; Ireland; Age: 34; Months TTC: 34 )

I feel as if my life is on pause while everyone else just keeps going. (story501920540485; United States; Age: 28; Months TTC: 20)

We've been trying for 35 months. It's been hard. All our friends started later than us and have all had their beautiful babies within the last 2 years...but here we are! (story101215069591; Australia; Age: 35; Months TTC: 35) 


\section{Time and Age}

Relatedly, responses also highlight the pressure associated with time and age that some women trying to conceive feel when they are unable to meet their (and society's) anticipated reproductive goals "on time". This again points to the continued normative nature of childbearing, and the continued second-class status of non-motherhood, even for women who were previously ambivalent about motherhood and had previous roles that were not associated with childbearing. Pressure increases as women feel they might miss their opportunity, even when childbearing has been delayed due to circumstance or to pursue other opportunities. Pursuing non-reproductive goals and delaying childbearing does not appear, for the women in this sample, to have had the impact of diluting the importance of their reproductive goals, but rather to increase their urgency. The urgency also sets the stage for seeking to resolve the problem within the medical sphere.

I am in my mid-30s. I did not feel we had the freedom of time that most TTC couples have and I did not wish to waste six months or a year TTC on our own. (story111989311439; United States; Age: 34; Months TTC: 10)

We would like to have more than one child and I'm already 36 , so time is not my friend. I just wish we had more time... (story481468590274; United States Age: 36 Months TTC: 1)

My husband and I have been married 14 months and started TTC in May 2006. Had it not been for our ages (he's 38 and I am 40), we probably would not have started TTC so early in our marriage. (story951127757522; United States; Age: 40; Months TTC: 8)

I was so much older that I also thought time was running out. I was 38 and fast approaching 39. (story261708421289; United Kingdom; Age: 42;

Months TTC: 23) 
I have been a very focused career woman and got married at the age of 32 . About a year after I got married I woke up one morning and had this very strong desire to start a family. I have had desires to do other things in my life, but nothing came close to this. Fortunately my husband agreed...I worried about my body clock ticking. I didn't want to be an old parent and I had read all the information about how your fertility decreases as you get older. My husband was 39 when we started trying and after a few months panic set in. (story20319571620; Australia; Age: 34; Months TTC: 17)

MY advice to anyone trying to conceive, especially over 35 is DON'T PROCRASTINATE!... Also, if it is not happening within a reasonable time frame (say six months if you are over 35) go to the doctor with your charts. (story33661315371; Australia; Age: 38; Months TTC: 5)

...we both agreed to not have any children - then 2 weeks before my 30th bday something hit me - "oh my god I want to have children... and I better not waste anytime doing it!!!" (story33661314790; United States; Age: 30; Months TTC: 4)

\section{All Consuming: "It Takes Over"}

Conception difficulties, for many, became the primary focus of their lives and identities, usurping other aspects of their lives and identities and making it difficult to attend to other aspects of their lives and goals. This was expressed consistently and continuously throughout the stories in terms such as "all consuming", "obsessed", "taking over", "running my life", and "always on my mind". Several women noted that part of this was related to the daily reminders, such as taking ovulation prediction tests and temperatures, physician appointments and constantly noting and being attuned to body changes.

The journey has taken over my life and thoughts... (story351126333063; United States; Age: 35; Months TTC: 108)

TTC has taken over my life for the last year. It has been a rough ride, and I am looking forward to having it all behind me. (story65598268538;

United States; Age: 26; Months TTC: 11) 
I think about it all the time... (story87351897522; United Kingdom; Age: 32; Months TTC: 6 )

TTC has become the sole focus of everything over the last 21 months. (story231562469931; United States; Age: 28; Months TTC: 21)

I am obsessed with this process... (story76469800658; United States; Age: 33; Months TTC: 7)

At this stage TTC has taken over our lives. (story55415587449; Australia; Age: 29; Months TTC: 15)

For myself everything seemed to revolve around it for over a year. Taking temps every morning, taking medicine most everyday, waiting, waiting and more waiting. (story011804289454; United States; Age: 26; Months TTC: 15$)$

Never could I have imagined when I pictured my life one day that this is the thing that would consume so much of it. TTC can completely take over your life. I have joked about how your life revolves around what is going on in your cycle but it is so true. Everything from do I have enough OPK to where will we be when I am going to be ovulating can drive you a little crazy! TTC was always right there in front of me. (story73296122050; United States; Age: 28; Months TTC: 38)

I didn't realise that it could take over my life like it has, TTC is the first thing on my mind in the morning and the last thing before I go to sleep. (story621502273322; United Kingdom; Age: 29; Months TTC: 52)

TTC is harder than I could have ever expected, it takes over every single part of your life, you live your life in 28 day cycles, you forever know what your body is doing, your heart plummets if your temp is low in the morning, or you're excited all day if your temp was high. (story15762298920; United Kingdom; Age: 36; Months TTC: 60)

I was feeling that TTC was running my life. Every minute of every day was consumed by me thinking about babies, wanting babies, crying, feeling sorry for myself, you name it. (story261708422064; Canada; Age: 21; Months TTC: 9)

$\mathrm{DH}$ and I were consumed with this goal for over a year. It was a shadow hanging over every happy occasion, every trip, every single day. (story98214780763; United States; Age: 31; Months TTC: 14) 


\section{Grief and Emotions}

The monumental disruption caused by infertility has been described as a painful emotional experience that can be likened to grief or significantly painful losses (Sherrod 2004) and the distress is likely to increase as the struggle endures with repeated failure to conceive (Downey, Yingling et al. 1989; Daniluk 1997b). Menning (1977, 104-112) characterizes the emotional experience as encompassing surprise, anger, denial, isolation, anger, feelings of guilt and unworthiness, depression and grief. The inability to proceed with life goals and transition to the "next step" as planned represents a significant loss; and repeated "failures" can result in feelings of frustration; and the seemingly neverending cycle of hope and despair can be emotionally destabilizing (Clark, Henry et al. 1991). Losses include not only the loss of the wished-for child, but the loss of a life goal and the pregnancy, birth, and parenting experience, loss of identity, loss of control, and the loss of relationships with friends and family members who "don't understand" (Conway and Valentine 1988; Sherrod 2004). More abstract losses include a loss of selfconfidence, loss of status, loss of security, loss of self-esteem and loss of pride and the loss of fulfilling a fantasy (Mahlstedt 1985).

Feelings associated with these losses include sadness and frustration, inferiority and shame, moodiness and powerlessness as well as anger and resentment, envy, stress, guilt and anxiety, feelings of isolation and alienation, grief and depression and a feeling of emotional instability with each recurrent cycle of hope and despair (Seibel and Taymor 1982; Mahlstedt 1985; Lalos, Lalos et al. 1986; Forrest and Gilbert 1992; Greil 1997; Williams 1997b; Sherrod 2004). Gonzalez (2000) suggests that on an emotional level, 
infertility is experienced as a "transformational experience" whereby a woman must mourn the loss of her reproductive function and parenting role and make restitution for her feelings of powerlessness to fulfill a social role and participate in societal rituals and ties of descent. To this end, a number of scholars, beginning with Menning in 1977, and continuing with authors of medical textbooks in 2007 (Haessler and Rosenthal 2007) make use of Kèubler-Ross's (1975) model of the stages of dying (denial, anger, bargaining, depression, acceptance) to reflect upon the grieving process also inherent in the infertility experience. This model, wherein successful resolution is reached with the "acceptance" phase, may be appropriate for those where there is an absolute diagnosis preventing conception and/or a decision has been made to stop trying. Bury's (1982) concept of chronic illness as biographical disruption, also cited by Griel (1991) in relation to conception struggles, and discussed earlier in this chapter, may be more appropriate for those who are still engaged in the often ambiguous and on-going process of trying to conceive. Woods et al $(1991,181)$ explain why "chronic sorrow" characterizes the experience more aptly for those still engaged in the process than the sequential grief model of Kèubler-Ross:

Sorrow better reflects the painful emotions that are caused in part by the therapies for infertility. The unusual, contrived procedures to produce the child are unnatural, controlled by others, impersonal, and often painful and expensive. Moreover, emotional responses to infertility do not follow a sequential pattern, as is true for the grief response. An infertile woman may find her responses to infertility and its treatment intertwined and triggered by her menstrual period, pregnancies of other women, insensitive comments from others, test results, treatment failures, frustrations with the health-care system, miscarriages, communication difficulties with a partner, and breakdown in her support network.

The emotional experience is chronic because individuals struggling with conception difficulties often do not fully grieve their losses until there are no treatment 
options remaining or they have exhausted their emotional and financial reserves (Daniluk 1997b). The ambiguous nature of the experience, as discussed earlier in this chapter, means that resolution may be significantly delayed. The emotional crisis may take years to resolve (Butler and Koraleski 1990). While infertility may initially be felt as an "acute crisis" it eventually becomes an "ongoing stressor" without a clear solution (Forrest and Gilbert 1992). Individuals can become "trapped" in the trying to conceive process, endlessly ruminating, as their own goals and their continued hope prevent them from reaching a phase of acceptance and resolution (Clark, Henry et al. 1991).

Further, the pain of the losses is often exacerbated by the sense that it is not understood or acknowledged by those around them (Sherrod 2004). Because people experiencing infertility and the associated losses must grieve something that they never really had, it is difficult for others to understand, and so they often grieve alone, in isolation. Mahlstedt $(1985,336)$ explains it like this: "Who can mourn the loss of someone who has never been born or possibly conceived? The fact that there is nothing tangible to represent the loss actually intensifies the pain and makes the loss more difficult to understand. There is much to cry about, and there is nothing to cry about. Everything is lost, and nothing is lost." Because the experience is not normative, there is no social ritual to acknowledge the loss and there is no socialization to prepare people for the experience of loss. Forrest and Gilbert (1992) note that these "losses of potential" are actually more complicated and difficult to integrate psychologically than more obvious losses.

There is ... no recognized method for acknowledging closure and the expression of grief, such as a funeral, for those experiencing infertility month after month. Couples must find ways to deal with a loss that is not recognized or validated by society. The mourning process can be lengthy, 
because the cause, and consequently, the outcome of infertility take time to determine. This creates confusion about whether to accept infertility as the final outcome and to grieve the loss of the ability to have a biological child or to continue hoping for what might still occur. (Forrest and Gilbert 1992, 47)

Since infertility is largely regarded as a medical issue, there has been a relative disregard of emotional aspects (Cousineau and Domar 2007). Nonetheless, there has been some recent, increased awareness regarding the emotional impact of infertility as a significant life crisis and a source of anxiety and depression for those affected (Gonzalez 2000). Much of this research, however, particularly that from the medical community, has focused on alleviating individual emotional disturbances through counseling so that medical treatment could be continued rather than examining social conditions that influence reactions to the experience (Gonzalez 2000). According to Gonzalez (2000, 620): "An awareness of the social, cultural and biological meanings of parenthood to women choosing to undergo methods of reproductive technology such as in vitro fertilization, may also assist in planning appropriate psychotherapeutic and supportive interventions for this population." The emotional impact needs to be understood from the infertile woman's frame of reference (Gonzalez 2000).

For many women, this frame of reference continues to be largely influenced by the social context of pronatalism which may contribute to the emotional distress they feel (Gonzalez 2000). Kirkman's (2003) notion that the work of mourning in infertility must involve revising one's "autobiographical narrative" to account for the disruption of infertility, may be useful. In this vein, Clark et al $(1991,167)$ suggest that individuals can begin to find resolution by questioning their parenthood goals, for example, by asking: "Why do I want to get pregnant?" and "Why do I want further treatment?" In this way, 
they suggest, people can become open to the idea that parenthood may not be an essential path to personal or marital fulfillment or recognize other paths to parenthood that may be available to them (Clark, Henry et al. 1991). Sandelowski et al (1989), refer to this process as "reframing desire". However, as Kirkman (2003) notes, social and cultural factors, including the dominance of the motherhood narrative, an absence of an alternative "non-mother" narrative, a lack of support or desire for alternatives, as well as continued hope, may act as barriers to this reconstruction. Additionally an intolerance for regret, along with external pressure from others, including physicians, can also delay this reframing (Sandelowski, Harris et al. 1989).

\section{Grieving, Loss and Emotions in the Stories}

Participants writing in the Story Gallery did not, for the most part, appear to be involved in reconstruction of their ideals or to be approaching acceptance of childlessness. They expressed similar emotional reactions to the experience of trying to conceive as those discussed in previous studies (Menning 1977; Matthews and Matthews 1986a; Daniluk 1988; Woods, Olshansky et al. 1991; Forrest and Gilbert 1992). They did not, however (perhaps because they were largely writing at earlier stages of the experience), generally appear to be involved in the work of mourning, identity reconstruction, or attempting to come to terms with the possibility of childlessness such as those represented in studies involving participants later in the process or those for whom treatment did not succeed (Matthews and Matthews 1986b; Daniluk 1996). Women writing in the Story Gallery talked about the emotional aspect of trying to conceive in terms of losses, dashed hopes and disappointments, sadness and depression, anger, frustration and the feeling of being on an "emotional rollercoaster". Women 
writing in the Story Gallery, who were mostly still trying to conceive, largely did not express resolution for their emotional disruptions, but expressed them as ongoing.

Loss, dashed hope and disappointment

Women expressed their feelings of loss, dashed hopes and disappointment in the following ways:

Four and a half years into our TTC journey, I had been emotionally depleted... the constant let down of failure loomed each month, seemingly lasting longer each time. (story37514134118; United States; Age: 31; Months TTC: 60)

Every time AF arrives, it feels like another loss. I often doubt we will ever have children. (story43842133710; United States; Age: 38; Months TTC: 54)

My TTC experience was exciting at first -- after years of birth control pills we got pregnant right away. I was so happy to get that first BFP. Since then (and three miscarriages later) my TTC experience has evolved into frustration. So many folks around me just get pregnant and have no issues. We've had hope three times and that hope dashed every time. (story451307654622; United States; Age: 35; Months TTC: 24)

I alternate on my feelings. Some days I feel happy and hopeful, and I'm sure all our trouble is behind us and that we will finally have a child. I find ways to make all the bad things worthwhile---I find lessons to be learned. Some days, I feel that I might be pregnant and I'm happy. Other days, like today I feel beaten down by the experience. I feel like giving up. I feel like tearing my hair out. I feel like screaming. Right now, my period is ten days late and just yesterday I took a pregnancy test and it was negative. I still have a little hope, but I am really down. I was sure that I was pregnant. (story32965671119; United States; Age: 22; Months TTC: 21)

TTC without success is like mourning a death and the emotions are similar. (story64901501022; United States; Age: 38; Months TTC: 36)

When my DH and I got a +HPT I was elated! I couldn't wait to experience motherhood...I was so scared to fall in love with the sweet baby inside of me, because I didn't want to be hurt. But when I heard that little heart beating, my heart melted and I fell head over heels for our little one...Our baby's heart stopped beating May 3, 2006...I held [him] in my hand. He was tiny, and perfect. But my arms ached... and they still do. (story64901501303; United States; Age: 21; Months TTC: 4) 


\section{Depression and Sadness}

A number of women also noted a generalized sadness, or loss of enjoyment in their lives since struggling with conception. Several talked specifically about depression and the possibility of seeking medical help for it as well.

I have been undergoing treatment for depression and even with medication I still have many bad days. (story261708421153; United States; Age: 28; Months TTC: 20)

I also cannot believe how this is turning my life upside down. I have been very depressed. (story20319571484; United States; Age: 24; Months TTC: 11)

I have been feeling down in the dumps and I know this will not help our efforts in TTC. I have decided to revisit my therapist to seek her professional opinion as to whether or not I need to restart medication. (story681834256497; United States; Age: 40; Months TTC: 8)

I used to laugh a lot more but now I find myself much more cynical and I get tired/sad a lot more often. (story521322670314; United States; Age: 29; Months TTC: 46)

I felt sad, depressed, and hopeless as the months wore on and no pregnancy. (story84183990631; United States; Age: 29; Months TTC: 12)

\section{Anger}

Several women noted that their sadness was also accompanied by anger. Anger, possibly a seemingly less acceptable emotion, was always noted in conjunction with feelings of loss or sadness.

I am somewhat surprised by how angry I was after our second miscarriage, though my sorrow was no surprise at all. It seems as if I tried to insulate myself against the pain of loss, and was infuriated that I was hurt anyway. (story111989311439; United States; Age: 34; Months TTC: 10) 
On the second time I got my period (two days late) after my miscarriage. I was that upset and angry that I broke the vacuum cleaner head. On the third time I got in my car absolute devastated and drove to my sister's house $400 \mathrm{kms}$ away. I yelled and screamed at God for half the journey... (story20319571620; Australia; Age: 34; Months TTC: 17)

We went to 2 different doctors and had all the necessary tests done, we did 5 IUI's, 1 IVF cycle ( 2 perfect embryos by the way) and with no success. We were so devastated after the IVF Cycle. It was very disappointing. I had such a heavy feeling in my heart. I became so angry deep inside I started thinking I would never get pregnant, that I was not going to ever experience motherhood. (story911266305852; United States; Age: 37; Months TTC: 17)

\section{Frustration}

A number of women talked about feeling frustrated as months of trying wore on without success.

I have a strong feeling of frustration where I go in stages of being depressed to angry to just plain obsessed. (story351126333063; United States; Age: 35; Months TTC: 108)

Our hearts are forever bruised as we have managed to piece them back together with the help of family and friends. We continue to TTC again but the frustration and disappointment that is so familiar is returning and I don't ever want to go back to that place... (story64901501022; United States; Age: 38 ; Months TTC: 36 )

After the first month, I, like a lot of other TTCers, became frustrated because I thought it would happen on the first try. (story821856146270; United States; Age: 22; Months TTC: 5)

My journey so far has been frustrating and disappointing. (story181995168476; United States; Age: 27; Months TTC: 21)

\section{A "rollercoaster"}

Repeatedly, women invoked the metaphor of a rollercoaster to describe the emotional experience of trying to conceive. Each cycle starts with hope, followed by an agonizing wait to determine if efforts were successful, then follows with despair when the 
next menstrual cycle begins with no pregnancy. Then a new cycle begins. This may be exacerbated when there are medical treatments involved because the discomfort and expense of the treatment make the stakes higher. Participants talked about the "rollercoaster" like this:

This is just one big nasty rollercoaster every cycle. I begin by feeling hopeful, and excited, then when I realize that the cycle is going to be a bust, I get sad, and depressed and as soon as my period comes, I'm devastated for about 3 or 4 days... then the cycle repeats. (story121687063787; United States; Age: 25; Months TTC: 16)

I found the journey to be very stressful. Every month was like a roller coaster. I would wait to see if I ovulated and if I did I would hope and pray that "this would be it". The more times I got my period the sadder I got. (story351126332936; Canada; Age: 32; Months TTC: 22)

When my menstrual cycle started a week late after many days of hopeful 'pregnancy' symptoms I was again down emotionally. It was even worse this time around than either of my miscarriages. TTC has been a huge emotional rollercoaster! (story071045618551; United States; Age: 31; Months TTC: 12)

It's been frustrating to ride the rollercoaster of two weeks of hope and waiting, then two weeks of looking forward to trying again. (story602115950777; United States; Age: 25; Months TTC: 3)

Actively TTC is an emotional roller coaster. I never thought that I would hope for something as bad as I have hoped for a BFP. (story66286129658; United States; Age: 37; Months TTC: 48)

\section{The Body and Control}

While emotional instability and feelings of otherness and deviance in relation to conception struggles are experienced due to an inability to meet a societal value, this disruption to identity is also partially located in the physical body. The feeling that one should be able to control one's body and the sense that persistence and effort should result in rewards are also socially constructed dominant ideals. Failure to meet these 
ideals also figure in characterizing the experience of conception difficulties as one of disruption.

Concepts of the self are formed via one's body (Corbin and Strauss 1987; Kelly and Field 1996; Corbin 2003). The body and the self are a unit, but only until the body cannot do what it is willed to do, at which time there becomes a differentiation of the body and the self. The sense that one is in control of one's body, and hence one's future, is disturbed when the body does not do as it is willed (Kelly and Field 1996; Corbin 2003). The body affects one's sense of self and identity when a 'failing' of the body inhibits one's capacity to engage in social roles (Kelly and Field 1996). In health, a person has control over her body and pride in body achievements builds self-esteem (Corbin 2003).

Notions of the body and control are also relevant to discussions about conception problems, disruption and identity since the ability to fulfill the role of biological parent is very closely tied to one's sense of their body's proper functioning and their sense of sexual identity (Lasker and Borg 1994, 15). For a woman, this means being able to experience pregnancy, birth and possibly breastfeeding (Lasker and Borg 1994, 15). Conception difficulties can thus challenge a woman's sense that she is in control of her reproduction (Cousineau and Domar 2007) and is especially distressing in a society where fertility is increasingly seen to be under an individual's control (Matthews and Matthews 1986a). Indeed, the sense of loss of control is often exacerbated and comes as a shock after years of conscientiously avoiding pregnancy through the use of contraception (Abbey, Andrews et al. 1992). Conceptualizing the disruption as a physical problem located in the physical body sets the stage for the mode of interpretation and attempts at 
resolution as well. A physical problem of the body is interpreted and resolved in the medical sphere.

Clarke et al $(2006,103)$ focus on the body and the embodied self and note that the "failing body" and the need for infertility treatment result in the perception of oneself as deviant, shameful and inadequate. This "failing" of the body can fracture one's sense of self, resulting in "identity shock" that threatens one's sense of femininity, sexuality and worthiness as a spouse (Clarke, Martin-Matthews et al. 2006) as well as a perception of oneself as healthy. While good health and a positive body image enhance one's selfesteem, conception difficulties can diminish this (Mahlstedt 1985). Infertile women frequently feel betrayed by their bodies, victimized by treatments and in the control of medical professionals and fate (Butler and Koraleski 1990). This sense of loss of control and the sense of one's body having failed also threatens socially constructed normative beliefs about control and self-efficacy. It means that previously held notions that one is in control of her body and her future and that she is successful as a result of her own efforts must be redefined. According to Mahlstedt (1985, 339):

People who have been self-directed, been in control of their lives, and believed that hard work leads to success in all tasks are devastated by the infertility experience. Despite the enormous price they pay in terms of money, time, persistence, commitment to a schedule, and sacrifice, to self and marriage, they cannot do what everyone else can do with little effort: get pregnant. Competence in this task is beyond their grasp- no matter what they do or how hard they try. This failure invades all aspects of their lives.

Women experiencing conception difficulties may attempt to regain control over their bodies by such means as practicing acupuncture and yoga, drinking herbal teas and eating pineapple, praying and trying to think positively (Cousineau and Domar 2007). 
Clarke et al $(2006,109)$, in reference to the significance of the body to one's sense of self in relation to infertility suggest the following: "In infertility, the body becomes the source of continuity and discontinuity for the self. While in any circumstances, the body is always a strong influence on the self, in infertility it is the physical inabilities and failings of the body that shape the meanings of femininity, masculinity, parenthood and adulthood." Infertility, then, shatters previously held notions of identity associated with one's body, including perceptions of one's self as healthy and in control.

\section{The Body and Control in the Stories}

The impact of conception difficulties on the identities of the women writing in the Trying to Conceive Story Gallery was also frequently expressed in terms of the "failed" body. The experience of disruption was associated with a sense of body malfunction (Clarke, Martin-Matthews et al. 2006). Responses below show the ways in which the participants expressed feelings about their bodies being "defective" or unable to do what they "should" be able to do; menstruation as a reminder of their "failed" bodies; and the way that body "failures" resulted in feelings of loss of control. Findings support Clarke, Martin-Matthew's et al's (2006) suggestion that failings of the body in infertility culminate in a sense of failing of the self and Mahlstedt.'s (1985) suggestion that perceptions of a failed body impact upon one's sense of control and self-efficacy. Additionally, the sense of a "failed body" sets the stage for medical interpretations and solutions which will be discussed in Chapter Five. 


\section{Failed Body, Defective Body}

Feelings of failure, shame and defectiveness, and the associated disruption to self esteem and identity were frequently expressed in the stories written for the TTC Story Gallery. In many cases this was mentioned in terms of the physical body which had "betrayed" or "let down" the woman and her husband by not doing "what it is supposed to do". When the body was unable to fulfill the will of the self, the result was feelings of loss of identity, loss of confidence and loss of self esteem and a sense of failure. Again, this reinforces the strong pronatalist context in which conception difficulties take place since positive identity and a positive body image for many women, at the time they were writing the stories, were expressed in terms of their ability to bear a biological child. It also reflects societal ideals which suggest that the body is something one should be able to control and it sets the stage for medical interpretations and solutions which will be discussed later in the thesis.

I feel like my body has failed both myself and my husband. (story571956681163; United States; Age: 44; Months TTC: 17)

It's been hard to accept that my body isn't doing what it should and that every cycle is another disappointment. (story701224552694; United States; Age: 28; Months TTC: 52)

I never thought I would have trouble sustaining a pregnancy, it was a big blow when I did. I was able to get pg very quickly but was not able to sustain them. It really did shake my confidence in myself. (story75766615238; United States; Age: 28; Months TTC: 13)

I began to hate my body and loathe the fact that I couldn't do what I was "supposed" to do as a woman and bear a child. I felt that my body had failed me and I began to battle depression that was directly related to ttc/infertility/pregnancy loss. (story521322670314; United States; Age: 29; Months TTC: 46)

It changes how I feel about my body and about who I am as a woman and as a human being. (story36818748967; Ireland; Age: 34; Months TTC: 34) 


\section{Period as monthly reminder of the failing body}

The nature of conception difficulties also reinforces the sense that feelings of failure and defectiveness are located in the physical body. The body itself provides a conspicuous reminder of one's "failure" with each unsuccessful menstrual cycle. Many women talked about the feelings of failure and devastation associated with their menstrual periods.

I'm so devastated every time I get my period. (story36818749332; United States; Age: 22; Months TTC: 5 )

You also find yourself abstaining from alcohol most of the time only to drown your sorrows when your period arrives. (story532099601993; United Kingdom; Age: 34; Months TTC: 26)

... of course whenever my period arrived there was the crushing feeling that we had failed again. (story532099601993; United Kingdom; Age: 34; Months TTC: 26)

I cry every month when my period comes, wondering why my body won't seem to work anymore. (story311271565868; United States; Age: 31; Months TTC: 19)

After about 4 cycles, I became depressed when I got my period for the next couple of months. (story951127757522; United States; Age: 40; Months TTC: 8)

I think it drove me nuts because I would sob uncontrollably when I got my period. You think about all the effort you put into that cycle and then it was all for nothing. (story8838645741; United States; Age: 27; Months TTC: 8)

...it hurts so bad each time I get my period... (story171227918071; United States; Age: 27; Months TTC: 12)

I get so sad every time my period comes. It is so depressing and it takes me a couple of days to regain my hope and confidence. (story20319571816; United States; Age: 29; Months TTC: 18) 


\section{Sense of Control Damaged}

Feeling like one had "lost control" was also a significant theme in the stories. For a number of the women, this was the first experience where they were not in control of the outcome of something in which they invested considerable effort and this negatively impacted their self esteem and sense of identity. Several women spoke about how they were able to achieve other things in their lives and how they had managed their reproduction in the past through contraception and were surprised that reproduction no longer felt under their control. These responses further demonstrate idealized social values about being able to control the body and that their efforts result in rewards.

I control most aspects of my life but I can't control this!! (story59272081136; United Kingdom; Age: 29; Months TTC: 3)

Everything else I've wanted in my life I've been able to get either by working hard and earning the money for it, or working hard and achieving it. Either way, I've somehow earned things. Pregnancy, on the other hand, can not be earned or achieved. So much of it is completely out of my control, so in that respect, it can be a very frustrating thing to do all the right things and still not have success. (story05590011819; United States; Age: 40; Months TTC: 9)

I expected my TTC journey to be fast and happen the month I had planned it to happen. Well, things didn't work like that...You can break or keep moving forward and we kept moving forward and it made me realize that some things are just out of your control. (story84183990631; United States; Age: 29; Months TTC: 12)

I really thought that it would be easy for me to get pregnant, because most things in my life come easily. On the positive side, it is good to be reminded that you can't plan everything in life, and you can't be in control of everything. (story041968077903; United States; Age: 33; Months TTC: 9) 


\section{Action and Resistance}

In the previous pages, I have talked about the ways that women's identities were negatively affected by conception difficulties and the ways in which their biographies and perceptions of themselves and their bodies were disrupted by their struggles. I discussed the ways in which ideals associated with pronatalism and other socially constructed values played a role in this disruption and how they continue to impact on the experience in spite of societal changes that offer women increased role options outside of motherhood. It is also important to note that there was some evidence in the stories of the means with which women resisted these negative aspects and worked to maintain control over their selves, lives and identities. The importance of support to counteract feelings of "otherness" has been noted (Greil 1991a, 146; Woods, Olshansky et al. 1991) and Parry (2005), based on the experiences of women who had resolved their long term infertility in some way, has identified the ways in which work and leisure pursuits can counteract the negative impact of pronatalist messages. Additionally, Riessman (2000) found that childless women in India employed a variety of strategies to resist hegemonic definitions of themselves as deviant.

In this sample, women resisted the negative impact by seeking support (Greil 1991a; Woods, Olshansky et al. 1991), seeking to take control (Cousineau and Domar 2007), taking care of themselves (Cousineau and Domar 2007), seeking information (Cousineau and Domar 2007) and setting limits to their pursuit (Sandelowski, Harris et al. 1989). While some responses to the negative impact of conception difficulties on identity from participants in this study are similar to previous findings (Menning 1977; Pfeffer and Woolett 1983; Miall 1985; Miall 1986; Sandelowski, Harris et al. 1989; Greil 
1991a; Woods, Olshansky et al. 1991; Monach 1993), findings about taking an active role in seeking information, making decisions and taking control over the experience (Greil 2002; Cousineau and Domar 2007), were not prominently mentioned until recently, perhaps indicating that women are currently exerting more influence and control over their experiences, even if they are not challenging the assumptions within the constructs that frame them.

\section{Support and Resisting Stigma}

Page $(1984,18-20)$ notes that some people with feelings of stigma accept the sense of inferiority, while others engage in "stigma disavowal" and suggest that it is the reactions of the stigmatizers that are reprehensible, rather than their own discrediting attribute. Parry (2005) notes that women may respond to the pronatalist notion that their social worth is tied to procreation through their participation in work, leisure or support groups. Support groups also allow collective action to offer mutual support or counter negative stereotypes. Feeling supported by one's social network is important for preserving one's self esteem and sense of mastery over life (Woods, Olshansky et al. 1991). Several such support and advocacy groups have been established for this purpose for people experiencing infertility, however, the stigmatizing nature of infertility, discussed earlier in this chapter, may prevent some people from seeking support, as it has been noted that people are less likely to seek support in situations where their self-esteem is threatened (Slade, O'Neill et al. 2007). People who have been trying for less time or those who have not sought medical help also may not seek help in organized support groups. 
RESOLVE, arguably the most prominent infertility support group, defines its mission as follows:

RESOLVE: The National Infertility Association, established in 1974, is a non-profit organization with the only established, nationwide network of chapters mandated to promote reproductive health and to ensure equal access to all family building options for men and women experiencing infertility or other reproductive disorders. The mission of RESOLVE is to provide timely, compassionate support and information to people who are experiencing infertility and to increase awareness of infertility issues through public education and advocacy (RESOLVE 1998-2004).

Support groups such as RESOLVE are frequently recommended for infertile people to help ease isolation and counter feelings of depression and worthlessness and to help reintegrate themselves with former support groups of family and friends (Butler and Koraleski 1990). These support groups simultaneously keep hope alive and counter the painful sense of loneliness and defectiveness felt by people experiencing conception difficulties (Apfel and Keylor 2002). They are also said to normalize, validate and empower their members (Apfel and Keylor 2002) and reduce distress (Slade, O'Neill et al. 2007). More recently, individuals are likely to search for information and support to seek to ease their isolation on the internet (Cousineau and Domar 2007). More people, and people with more diverse characteristics, may be likely to seek support on the internet due to ease of access and its inherent private nature. Women writing in the Story Gallery often talked about the importance of support.

\section{Support in the Stories}

Several women talked about how positive support from people who understood their experiences reduced their feelings of defectiveness, loneliness and isolation. 
Also, through a local infertility support group that I began attending after two years TTC, I have met two wonderful women with whom I am now close friends. Meeting real live women in the same boat as me has turned this experience around for me. Prior to meeting them, I thought I must be going mad to be having some of the terrible thoughts I was having. Now I know I am not mad, just normal. And I know I can say anything to these women and it will not be news to them! I think I have found friends for life in these two women. (story36818748967; Ireland; Age: 34; Months TTC: 34$)$

TTC has also bought me two very good friends who I have met through support groups, and both of them are still struggling with TTC as well... (15762298920; United Kingdom; Age: 36; Months TTC: 60)

Because the sample was from people who were already using an internet-based support system, they mostly talked about the positive impact of online support groups.

The support that I received was incredible...It helped reinforce to me that I was not alone and that my problems are not all that uncommon. (76469800667; United States; Age: 31; Months TTC: 8)

The groups that I have been part of here on line kept me sane. Yes, I was sinking into a depression but I think it would have been much worse if not for friends going through the same thing and in some cases at the same time. (story852023096631; United States; Age: 35; Months TTC: 48)

The friends I have made online have provided more support and knowledge than I imagined. I've learned so much about my own fertility from their stories and experiences. It's been a relief to find a group of women I can talk to openly and who can completely relate to my feelings and experiences. (story701224552694; United States; Age: 28; Months TTC: 52)

I honestly don't know if I could have lasted this long on this journey without the support of the Fertility Friend community. The group I'm a part of is an amazing source of support for those of us TTC \#1 for over 2 years. These women are the ones that understand why I can't attend baby showers or why I resent others when it comes so easy. They are also the ones I run to when I need advice or input on an upcoming procedure. And they make me laugh. (story831557536387; United States; Age: 28;

Months TTC: 37 )

The online support groups I have been part of have helped me in so many ways, I would be lost without them now. The women I have "met" are 
wonderful and supportive and have helped me through some of the hardest times in my life. (story32965671341; United States; Age: 34; Months TTC: 144)

I have belonged to a FF [FertilityFriend.com] group since about the beginning of 2005. We are a group of about 16 women that were going through IVF (mostly for the first time) at the same time. We are still going strong and I consider these women to be some of my best friends. All but two of us have conceived and we have a "junior" membership of 22 babies! Some of us have meet in person, some of us talk on the phone, but mainly it is daily communication on the internet to check on how everyone is doing. Without these women I don't think I would have been able to make it through some of the things I have been through. Not just the IVF experiences but life! (story181995168651; United States; Age: 39; Months TTC: 30 )

It has been the greatest experience in my life. I have made so many friends and the support here is fantastic. Without any support during my loss I would have never made it through. (story54707676946; United States; Age: 25; Months TTC: 7)

I thought I was the only one going thru this. I was so wrong. Meeting all of these great women who are in the same boat was very reassuring. I never had someone say, "Just be patient, it'll happen." I could support those thru what I knew, and they could help me thru my rough days. It was the most important thing that I found. (story281110581933; United States; Age: 26; Months TTC: 11)

Selectively "coming out" in real life also seemed to have a positive impact and reduce feelings of isolation and defectiveness for some women who were able to garner support from their friends and families.

TTC has greatly affected me and my family. For the first year we didn't let anyone in the family know we were TTC. We eventually told them and they all just seemed to know we were having trouble. I started to share more with my mom and sisters and they would ask how appointments had gone. It really helped to have their support. (story701224552694; United States; Age: 28; Months TTC: 52)

Tired of smiling mysteriously at the would-be well wishers, I started to slowly tell people what was going on. I think that has relieved a LOT of pressure for me. It's also been nice that, sometimes I'll tell someone what is going on, and they reply with, "I know what you are going through. I went through the same thing". And I didn't even realize it! It helps to see 
others have success with infertility treatments. (story392055460360;

United States; Age: 29; Months TTC: 18)

\section{Taking Back Control}

Although women writing their stories often noted a sense of loss of control and the feeling that trying to conceive was taking over their lives, they also expressed ways in which they were able to resist the loss of control and maintain some sense of mastery over the experience and their bodies. They did this in the following ways: by seeking medical attention and following medical protocols and by trusting God (discussed in Chapter Five), by actively engaging in healthy living and breaking perceived unhealthy lifestyle habits, by engaging in "positive thinking", by setting limits and by taking breaks from actively trying to conceive. None of these methods of claiming control challenges the constructs that initially caused the participants to feel "out of control", and they also reflect dominant middle class values. Nonetheless, they helped to normalize the experience within the confines of the social ideals that they accepted.

\section{Healthy Living}

Healthy living emerged as a significant theme in the stories and was one way participants managed a feeling of loss of control over their bodies. Participants talked about losing weight, exercising (or stopping exercising), taking vitamins, cutting out unhealthy products like caffeine and alcohol, and eating healthier foods.

I have drastically changed my lifestyle - no more martial arts, hardly go running, cut nearly all caffeine, hardly any alcohol.... so, major changes indeed. (story87351897522; United Kingdom; Age: 32; Months TTC: 6)

DH takes vitamins every day that include iron. I take prenatal vitamins. (story311271565868; United States; Age: 31; Months TTC: 19) 
DH quit smoking, ate better, did all the things you're supposed to do (even wore boxers...), and we repeated the test 6 weeks later. (story392055460731; United States; Age: 31; Months TTC: 11)

I've tried changing my diet and activities (which hasn't helped me conceive, but I am a much healthier person). I exercise more, don't touch caffeine or alcohol, drink more water, etc. I've tried various herbal formulas and have found that they didn't work for me. I've taken vitamins and extra folic acid supplements for 18 months... (story931742093105; United States; Age: 25; Months TTC: 17)

I started trying to make a difference in the way I lived. I lost weight and exercised more. I started eating organic foods and cut back on the sugar. I started going to a chiropractor for my back pain. (story32965670930; United States; Age: 23; Months TTC: 14)

I have adopted a very healthy diet, no smoking and no drinking so our normal social life has now even changed! In truth the whole process is wearing very thin. (story55415587618.html; United Kingdom; Age: 28; Months TTC: 10 )

I started working out and trying to be as healthy as possible... (story742144173517; United States; Age: 25; Months TTC: 17)

\section{Fighting to maintain Control: "Mind over Matter"}

"Positive thinking," similar to "maintaining hope" was also a strategy that some women used to maintain a sense of control over their lives when faced with the feeling of loss of control and disruption associated with conception problems. The feeling that one could exert some control over one's body with one's mind through positive thinking and that positive thinking could stave off dejection was expressed in the following ways:

TTC has made me realize that not all things in life come easy! However, it's reinforced my view that you have to truly believe in the things that you want. Sometimes when things, like a baby, seem so far out of reach, you just have to know in your heart that someday it will be yours! (story392055460663; United States; Age: 29; Months TTC: 12) 
I think that I will conceive again. It is a matter of time and informed choices. I just have to be positive about it until the pain of getting a BFN is greater than my ability to keep trying. (story73296122015; United States; Age: 41; Months TTC: 13)

In this journey, you need to stay strong, positive... (story181995168476; United States; Age: 27; Months TTC: 21)

Finally, I decided I needed to be calmer in order for my body to be more willing/able to actually conceive. (story951127757522; United States; Age: 40; Months TTC: 8 )

I also know that I need to be happy in order to conceive...We've been trying to remain positive. (story681834256497; United States; Age: 27; Months TTC: 4)

We have mostly been extremely positive, knowing that thoughts become things... (story631196712998; United States; Age: 28; Months TTC: 5)

I know I need to stay positive but--being something of a worrier by nature-I sometimes find that hard to do. (story34362859849; United States; Age: 37; Months TTC: 3 )

I went to church again, trying to find a sense of spiritual balance in my life. That last part is something I've been working on for years, but it's finally starting to fall into place. (story32965670930; United States; Age: 23; Months TTC: 14 )

\section{Managing Obsession and Setting Limits}

A number of the women writing for the TTC Story Gallery made active attempts to manage the sense that trying to conceive was taking over their lives. They did this, largely, by taking breaks and setting limits to what they would do in their quest to conceive. Additionally, many made a conscious effort to attend to other important areas of their lives and began to come to terms with the possibility that they might not conceive biological children. Trying to conceive, though it could sometimes make them feel obsessed, overwhelmed and out of control, would not be allowed to define them or 
restrict them forever. The Story Gallery writers talked about setting limits, letting go, adjusting their ideals and managing obsession in the following ways:

My husband and I want a child; however, have since grown to accept that it may not ever happen. After 9 years of TTC, a person comes to a point to think when is enough, enough? I will never give up trying, but find that obsessing about it isn't the answer either. I don't blame myself anymore, nor am I going to ruin my relationship with my husband because of it. (story351126333063; United States; Age: 35; Months TTC: 108)

When I am very discouraged, I remind myself that at some point this nightmare will end and we will either give up on having children or find a way to have a child by some means. I know at some point in the future I will be happy with my life . . however it turns out. (story43842133710; United States; Age: 38; Months TTC: 54)

I spent approximately 8 months where I banned myself from the internet, all baby shows, baby everything was gone. It was so difficult. I avoided talking baby with others and kept away from anything that had to do with babies, including friends and family. I had my [husband] hide my thermometers and I threw away all my OPKs and tests. My focus was on my health. I began losing weight, eating right and working out and felt GREAT! It didn't feel like a challenge to not be focused on TTC about 2 months into my mission. (story37514134118; United States; Age: 31; Months TTC: 60 )

When we hit 3 years TTC I finally had enough, it was affecting everything in my life or what life I was letting myself have. I had actually noticed that I was feeling a little depressed, DH and I were fighting more, and I started to wonder what all of this was doing to the child we already had. So I took a break, just a few months but it made me see things in such a different way. I could continue TTC without letting it take over my life. And if I ever begin to feel like it is again I know that it is alright to step back a give myself a break. (story73296122050; United States; Age: 28; Months TTC: 38)

At first you allow TTC to rule your life, not booking holidays or making long term plans "in case" you might be pregnant. Eventually we didn't allow this to happen... (story532099601993; United Kingdom; Age: 34; Months TTC: 26)

I try not to dwell on the fact that I may never have another child, but instead try to enjoy the children around me. (story87351897325; United States; Age: 39; Months TTC: 156) 
Keeping busy with things other than TTC really helped me out. Focusing on my last semester of school kept me occupied and allowed me to be able to enjoy TTC more! (story77164215397; United States; Age: 26; Months TTC: 6)

\section{Negotiating Dreams}

Although most women writing in the Story Gallery were still immersed in the trying to conceive experience and were actively trying to meet their reproductive goals, some women were at various stages of the process of negotiating their dreams, allowing for the possibility that they might not have their desired number of children, or they might not achieve them in the anticipated manner.

So, we were faced with IVF or adoption. We went home that day, I threw out my BBT charts, thermometer and everything and submitted paperwork to adopt a little girl from China. A year later, we were blessed with a darling, wonderful daughter. We do not regret this decision in the least, and love her to pieces. (story24188365246; United States; Age: 32; Months TTC: 60)

During our last break from TTC, my partner and I began to look into adoption. We have an agreement now that I will try to get pregnant for another few months. If I still do not get pregnant, and when we feel ready, we will begin adoption proceedings. I know now that we will be mothers one way or another- I don't feel like I HAVE to give birth to our children for them to be ours. (story56111715299; United States Age: 28 Months TTC: 12)

I've always wanted 5 children but now I think 2 will be OK.I hope that by the end of this year I'll be pregnant again. Of course I'll never forget my 1 st baby but having another baby will perhaps make the pain a little more bearable. (story171227917830; Mauritius; Age: 28; Months TTC: 10)

I come from a large family and wanted a large family. My older daughter is 10 and there will be huge spaces; instead of me raising a cohesive family I am sort of raising a few only children. (story72608905679; United States; Age: 31; Months TTC: 39) 
I find that I'm pretty much obsessed with thoughts of TTC. I feel this underlying sense of panic, as I watch my biological clock ticking closer and closer to 40 . I used to think that I wanted at least three kids, but now I'm thinking that if we could just have one, I would be sooo happy. (story79629564731; United States; Age: 36; Months TTC: 15)

\section{Opportunities for Personal Growth}

Difficulty conceiving and its associated disruption also provided opportunities for personal growth, some degree of challenge to idealized social norms, and the development of alternate ideals. These expressions and recognitions of self growth have not been widely noted in earlier research, although it has been noted that the experience of infertility can lead to "... a re-ordering of priorities among infertile individuals [that] may enable them to see some positive aspect of their experience of infertility (Clark, Henry et al. 1991, 158)." The woman cited below notes that the experience, which challenged her sense of herself as a "real" woman, ultimately altered her notion that you need to be a mother to be a "real" woman.

Another growth process I went through was feeling like I wasn't really a woman since I didn't have children and was having trouble conceiving. I finally believed $100 \%$ that being a mother can be part of being a woman, but you can still be a real woman without being a mother.

(story05590011819; United States; Age: 40; Months TTC: 9)

Several women also noted that they learned patience and an acceptance that there are aspects of life that are not within their control. This challenges the social ideal of self-efficacy and the notion that persistence and hard work will always be rewarded.

Trying to conceive a child was really an amazing journey. I learned so much about my body -- how it works, what it needs to function correctly. I also matured as a person, learning to accept what I could not change, 
changing what I could... (story351126333049; United States; Age: 35; Months TTC: 29)

I really thought that it would be easy for me to get pregnant, because most things in my life come easily. On the positive side, it is good to be reminded that you can't plan everything in life, and you can't be in control of everything. While frustrating, it is also kind of a relief because it limits the amount of pressure you put on yourself. (story041968077903; United States; Age: 33; Months TTC: 9)

Some women also noted that they had become stronger and more sensitive and sympathetic to others:

You become bitter and negative at times, but you also become understanding, insightful and sensitive. I would never ask a couple when they're going to have children - who knows, they may have been trying for years. (story281110582075; United States; Age: 30; Months TTC: 55)

I know that having gone through a miscarriage has made me more sensitive; more sensitive to other people's feelings and more emotional in general. Recently, two of my sister-in-laws and my sister had their first (and hopefully only) miscarriages. I truly believe that I was able to be an encouragement to them during that time because I could relate to their pain personally. (story701224552694; United States; Age: 28; Months TTC: 52)

I have greater understanding and compassion than I ever would have. I also have an inner knowledge that it isn't all in my hands. For better or worse, it gives my husband and I peace. We are closer and I am proud of the ordeal. I take much less for granted and love far more openly than I once did. (story77164215552; United States; Age: 35; Months TTC: 13)

I do think that infertility and the loss of our baby has changed me forever. I hope that it has made me more sensitive to others--more compassionate. (story79629564731; United States; Age: 36;Months TTC: 15)

I have become a more caring and sympathetic person due to this journey, as well... (story34362860181; United States Age: 25; Months TTC: 2)

I've lived through three years of infertility, several close family deaths, my husband's 6 month deployment to a war zone plus his 9 months gone to Army schools, 4 interstate moves and I'm still standing. Am I stronger? Sure. But I'm also more compassionate to the struggles that others may be surviving. And that's what I'm most proud of. (story831557536387; United States; Age: 28; Months TTC: 37) 
When I look back on my experience, I wouldn't change it as difficult as it has been. I think I am a better, stronger person for it and hopefully, it will continue to help me in the future. Would I do it again? That I really don't know, but am I glad that I did. (story631196713728; Canada; Age: 26;

Months TTC: 30 )

\section{Results from Bivariate Analysis of Identity-Related Themes in the Stories}

\section{Time Trying to Conceive}

Results from a bivariate analysis of the themes mentioned in the stories of participants yielded some fruitful results. Cross-tables representing the analysis discussed here can be found in Appendix 6. In many cases there was no correlation found between participant characteristics (length of time trying, with or without medical help, age and parity) and the likelihood of their story containing a particular theme discussed above. In other cases, the theme was found to correlate in an expected way. For example, women who had been trying to conceive longer (twelve months or more compared to less than twelve months) were more likely to write stories where the following themes were identified: perceptions of a failed body; perception of a damaged identity or feeling like a failure; importance of perseverance and the possibility of miracles; feelings of jealousy; describing the experience like a "rollercoaster"; grief and sadness; dashed hopes; broken plans; feeling the experience to be "all-consuming"; negotiating dreams; expressing no tolerance for regret; feeling like life is on hold; managing obsession; insensitive others; "others succeed, why not me?"; and depression (See Appendix 6, Tables 1-14). It is not surprising that the negative impact appears to increase as the experience continues without resolution. It is notable, however, that these themes were also mentioned (though 
less frequently) by women who had not been trying for a full year. Additionally, it is notable that these differences were found among women who had been trying for just one year or more compared to women trying for less than a year. Previous studies that showed similar negative impact on self perceptions, emotions and biography, such as those described above, involved women who had been trying, on average, for much longer than a year (Greil 1991a; Monach 1993; Clarke, Martin-Matthews et al. 2006), though many studies do not note the length of time participants were trying to conceive (Greil 1997). It is presumed that most, if not all, previous studies only examined the experiences of women who had been trying for more than a year- the standard definition of infertility. Results from this study may indicate that the personal impact of conception difficulties is felt after as little as twelve months of trying (even earlier among some respondents).

\section{Trying to Conceive with/without Medical Assistance}

Because most studies about personal experiences with conception difficulties have recruited participants primarily from fertility clinics or related support groups (Connolly, Edelmann et al. 1992; Domar, Broome et al. 1992; Monach 1993;

Sandelowski 1993; Abbey, Andrews et al. 1994; Becker 1994; Whiteford and Gonzalez 1995; Edelmann and Connolly 1998; Oddens, den Tonkelaar et al. 1999; Fassino, Piero et al. 2002; Clarke, Martin-Matthews et al. 2006), there has been some ambiguity about whether the impact they described was related to the experience itself or the effect of treatments (Daniluk 1997a; Newton 2006). This sample includes both women who did and did not seek medical help and so allows for some comparison between these two groups and allows for some speculation about the impact of the experience alone and 
with fertility treatments. Many of the themes mentioned in relation to identity, biography and emotions were mentioned both by women who did and did not seek medical help and did not show significant differences in responses among the two groups, suggesting that the impact of medical treatment alone is not solely responsible for all aspects of the impact.

Some themes, however, were mentioned more frequently among women who did seek medical help. Women who sought medical help, for example, were more likely to mention themes related to "failed body" (Table 15). It is unclear whether feelings of a failed body led to seeking medical help or whether encounters within the medical sphere reinforced the notion of a failed body. There is likely to be an element of interplay among this initial perception of a failed body, which may lead to seeking medical help, and interactions within the medical domain which may reinforce it. Locating the problem (failure) within the body sets the stage for medical solutions and interpretations and reflects dominant ideals about the appropriateness of biomedicine to fix the broken (failed) body-machine (Whiteford and Gonzalez 1995; Greil 2002; Nettleton 2006). The way biomedical interpretations and biomedical language shape the personal experience (Haraway 1991, 204) are also evident in this theme. Clinical language and medical encounters which focus on failure and brokenness buttress this perspective. "If the machine breaks, manifesting as injury or disease, the practitioner seeks to fix it, drawing upon a reservoir of scientific knowledge concerning how the machine works, and employing the technologies of repair (Leder 1992)." Women and their doctors appear to mutually reinforce the concept of conception difficulties as a manifestation of a "failed" 
or "broken" body which is in need of repair, thus locating the problem in the medical domain.

Themes related to "perseverance and miracles" (Table 20) were also mentioned more frequently among women who sought medical help, again linking the value of the pursuit with the appropriateness of medical solutions for some women (Becker and Nachtigall 1994; Lasker and Borg 1994). Medicine services pronatalist values and pronatalist values drive reproductive medicine. Themes identified as "rollercoaster", "anxiety of waiting", "frustrating" and "all-consuming" (Tables 21-24) were also found with greater frequency among women who sought medical help (although they were also mentioned, but with less frequency by women who did not seek medical help) suggesting that treatment and its demands and intensity and the added financial, emotional and physical pressure may exacerbate these feelings. (It is also possible that women feeling a high degree of anxiety and distress are more likely to seek medical attention).

The themes "only others with similar experiences understand" and "insensitive others" (Tables 51-52) were also identified more frequently in the stories of women who noted that they had sought medical help. This may support the position that women seek medical treatment to combat feelings of otherness and stigmatization (Whiteford and Gonzalez 1995) such as that reflected in stories with these themes. It may also reflect the general lack of knowledge about medical options among people who have not experienced conception difficulties who may be prone to be unwittingly insensitive due to lack of understanding. Either way, the lack of understanding and sensitivity (real or perceived) among people who have not experienced difficulty conceiving testifies to the continued, non-normative (deviant) nature of the experience. It is something that is 
experienced as outside of the range of perception for most people who expect to get pregnant easily and "naturally."

Some themes associated with personal growth were also mentioned with greater frequency among women who sought medical help. Women who had sought medical help were more likely to write stories saying that they had become more sensitive, stronger, and would not take things for granted in the future (Tables 25-27), suggesting, perhaps, that the experience with the medical sphere led them to relinquish some of their previously held ideas and expectations and embrace alternate ones. Likewise, women who sought medical help were more likely to be engaged in "negotiating dreams" (Table 30). This may mean that they were coming to terms with needing medical treatment to conceive, or accepting the possibility that treatments might not succeed, or perhaps deciding that they were unwilling to pursue aggressive medical options. Medical treatment may force individuals to make decisions about what they are willing to do to conceive a biological child and begin to consider alternatives.

Women who sought medical help were also more likely to mention feelings associated with the pressure of passing time (Table 29). This suggests that medical solutions may be used to cope with pressure to conceive quickly due to delayed childbearing, or, perhaps, the medical experience itself, due to treatment demands, reinforces the pressure and passing of time. Women who had sought medical help were also more likely to write stories where the theme "no tolerance for regret" (Table 31) was identified, suggesting that medical treatment was part of the process of ensuring one had done everything possible so that they would not look back at some point in the future with regrets. Finally, the theme "life is on hold" (Table 32) was more likely to be 
identified in the stories of women who had sought medical help. While it is possible that women sought medical help to alleviate the feeling of life being on hold, it is also possible that treatments put life on hold and made it difficult to attend to other things. This finding could support the position of critics of the medicalization of infertility who suggest that the medical experience, where there is always some hope, prevents people from reaching resolution and realizing other valuable aspects of their selves and lives (Whiteford and Gonzalez 1995). Findings related to medicalization of conception difficulties will again be relevant in Chapter Five.

\section{Trying to Conceive a First or Subsequent Child}

Comparing the themes identified in the stories of women trying to conceive a first or subsequent child (parity) showed surprisingly few differences. Most identity and biography-related themes could be found in the stories of both women who were trying for a first and subsequent child. These findings suggest that it is not just unwanted childlessness that impacts emotions and perceptions of one's self and disrupts life goals, but the experience of trying to conceive itself and the inability to meet personal and expected reproductive goals, whether they involve trying for a first or subsequent child. It may also testify to the norm that more than one child is ideal (Menning 1977, 137) so that trying for a second or third child is felt similarly. There were, however, a few differences between the stories of women trying for their first and subsequent children. For example, women trying for their first child were more likely to write stories in which the following themes were identified: healthy living (Table 33); broken plans (Table 35); career issues (Table 36); perfect set up (Table 37) and "others succeed, why not me?" (Table 38). These themes suggest and reflect middle class values that one should be able to control 
and plan one's life and a sense of bewilderment when this does not turn out to be the case.

\section{Age}

Most themes related to identity, emotions and biography occurred with similar frequency among women who were thirty and older and those under thirty, suggesting that most aspects of the experience are similar for younger and older women. Some themes did occur more frequently among women who were thirty or older. Older women, for example, were more likely to mention themes associated with the pressure of time (Table 43) and age (Table 44). This is not surprising as older women are more likely to be affected by the sense that time is running out to meet their reproductive goals. Older women were also more likely to mention career issues (Table 45) and previous ambivalence (Table 46) suggesting that career ambitions or indecision may have delayed childbearing for these women. Younger women were more likely to mention the following themes in their stories: "broken plans" (Table 41); "undeserving others" (Table 47); and "others succeed, why not me?" (Table 48). This may simply be because younger women are less likely to anticipate a problem and may be more likely to be in contact with others who are younger who are having children without difficulty.

\section{Chapter Summary}

This chapter focused on the ways in which conception difficulties disrupted women's identities and biographies and the ways in which these disruptions were shaped by social ideology, particularly pronatalism. Additionally, ways in which the women writing the stories resisted these negative impacts were also discussed. Pronatalism was 
reinforced and expressed in the stories through discussions of hope, persistence and miracles and also through comments about worthy versus unworthy parents. Pronatalist values which were associated with a sense of disruption to a normative life trajectory and anticipated normative identity included comments about children and motherhood being something that was always desired, something that was a "normal" life progression after marriage, and that a baby was needed to complete an otherwise perfect picture. Disruption to biography and identity was experienced in the following ways: a feeling like life was "on hold"; that thoughts of conception difficulties were "all consuming"; a feeling that one's sense of control was disturbed; a sense that the body had failed or was "defective"; a feeling of "otherness" and isolation; feelings of worthlessness and incompleteness as a woman; feelings of envy and injustice; a feeling of being misunderstood by others; and feeling the need to control information. Emotionally, this disruption was experienced as grief, loss, dashed hopes and disappointment, depression, sadness, anger, frustration and like a continuous cycle of hope and despair. Disruption associated with conception difficulties also provided opportunities for self-growth and the re-examination of personal and social values and ideals. Results from a bivariate analysis of the themes mentioned by women writing in the Story Gallery were discussed in reference to time trying to conceive, seeking medical help, trying for a first or subsequent child and age.

\section{Conclusions}

The experiences of the women writing for the Trying to Conceive Story Gallery demonstrate that conception struggles continue to have a significant impact on one's identity and biography. They are disruptive to life plans, important relationships and the 
concept one has of one's self and the relationship between the body and the self. They can leave a person feeling confused, sad, angry, defective, out of control, isolated and unsure of the future. These findings are largely consistent with previous findings about the negative personal impact of infertility on the identities, biographies and emotional stability of individuals affected (Matthews and Matthews 1986b; Miall 1986; Greil 1991a; Greil 1991b; Monach 1993; Becker 1994; Whiteford and Gonzalez 1995; Greil 1997; Clarke, Martin-Matthews et al. 2006). Women in this sample appeared to be somewhat more likely to mention ways of resisting and mediating the negative impact, but without challenging dominant ideals about motherhood wholesale. This testifies to the continuing persistence and strength of pronatalist values, at least among respondents in this sample, even though a full generation spans the time between the earliest of these findings and the current study.

Over the past generation, the landscape framing the experience has changed. The age at which most middle-class women decide to start a family has increased (and thus the likelihood that women have some established identity outside of the anticipated motherhood role); new role options are available for women; and there is a greater societal acceptance of child-free lifestyles. One may have expected that increased economic and role opportunities for women within this time span would have resulted in a loss in the grip of pronatalist values and a less difficult transition to living with childlessness and embracing alternative, meaningful roles. However, results from this study show that the impact is as strong as ever and as far-reaching as ever. They affect women who have been trying just a short time as well as those trying longer. They affect women who are older and younger and they affect women who do and do not seek 
medical help and they affect women trying for their first and subsequent children. Indeed, some changes within this time span may have further reinforced pronatalist expectations and values: there are increased medical options and some realistic hope that they can work; a greater sense of reproductive control among women who have successfully prevented pregnancy until it was desired; a perception (though possibly faulty) that parenting responsibilities will be shared by spouses within the context of an egalitarian relationship; social concern about population aging and baby shortages among educated women and policies that promote childbearing/rearing among these women; media images that have adapted to make motherhood look appealing within the context of current values; and time-related pressure ("biological clock") for women who have delayed childbearing to pursue education or career goals. Certainly, in spite of changes in the past generation, motherhood continues to be an important source of anticipated identity and status for women and pronatalist values continue to promote and reinforce this. The inability to attain biological parenthood when desired continues to be a wrenching experience.

Indeed, an increased availability of medical options and a decrease in the availability of social options for parenthood may have had the impact of increasing pronatalist pressures by encouraging the pursuit of biological parenthood via reproductive technologies. It is also possible that changes in role expectations have actually had the impact of furthering pronatalism and the motherhood mandate since career minded women who may have previously chosen childlessness are no longer forced to choose between parenting and employment roles. While these women may delay childbearing (and thus increase their likelihood of experiencing conception difficulties), they can now 
choose to combine parental and career roles and may expect a partner to share parental responsibilities. Changed gender role expectations, then, may actually increase the desire and expectation for childbearing among some categories of women. Pursing a demanding career no longer precludes childbearing and parenting. While the current ideal for most middle class women is to combine satisfying employment with a satisfying family life that includes parenting in partnership with one's spouse, exchanging the apron for the briefcase and (ideally) sharing household and economic roles has not diminished the social directive requiring motherhood.

Additionally, a new genre of pronatalist images and policies may be making an impact. These may include tabloids featuring celebrities with their children who may or may not have been conceived with reproductive technologies and television shows featuring working mothers (the work is in the background) who are always available to attend appropriately to their children's needs. ${ }^{24}$ There are new terms for sexy, desirable mothers, ${ }^{25}$ indicating that women do not have to sacrifice their attractiveness, fashionsense and sexuality to adhere to the motherhood mandate. Further, social policies (such as extended parental leave and subsidized daycare) supposedly intended to promote gender equality, work/life balance (and breeding) may also play a role. While these programs and policies are valuable and necessary for employed parents, they make parenting more attractive and may increase the suffering of those who would like to make use of them if they had the opportunity. Pronatalism has morphed to make it more palatable to today's would-be mothers, but it has not lost its hold.

\footnotetext{
${ }^{24}$ Children's television now largely features families with two working parents (for example Arthur and George Shrinks) yet the parents are usually present in the home and available to respond to life's trials in the most politically correct manner.

${ }^{25}$ Yummy Mummy, MILFs (Mothers l'd Like to F..k)
} 
The feeling that one's identity and biography is disrupted by conception difficulties continues to be shaped in large part by the pervasive social context of prontalism. Women experiencing conception difficulties, however, are not a universal group and they are more or less affected by this social context. It is also important to note the time sensitive nature of the experience and its impact. Identity is fluid. The stories for the TTC Story Gallery were solicited either during a difficult struggle to conceive where the outcome was still unknown, or soon after achieving a much desired pregnancy after a difficult or lengthy experience of trying to conceive. Most women, at the time of writing, maintained a perspective of hope and perseverance. Some were beginning the process of negotiating and adjusting their ideals and identities. 


\section{Chapter Four: Gender, Sex and the Spousal Relationship}

\section{Introduction}

Although there has been a trend towards delaying childbearing in recent years (Lampic, Svanberg et al. 2006), most couples still consider having biological children together to be a central aspiration of their marriages (Mosher and Bachrach 1982;

Daniluk 1988; Abma and Martinez 2006). Only about 5\% of married couples worldwide deliberately choose to remain childless (Daniluk 1988). An inability to meet this normative social and personal directive, then, represents a major disruption to the lives, goals and relationships of the significant number of married couples ${ }^{26}$ who planned to have children but found that it did not happen as expected. The social factors which impact upon individual identity and goals that were discussed in the previous chapter are also relevant to the experience of couples and relationship impacts. Expectations about marriage, gender roles, and interaction between spouses adds a further dimension to the experience.

A number of socially constructed ideals play a role in the impact of conception difficulties on the spousal relationship. Along with the pronatalist ideal that having children within marriage is "normal" (Menning 1977; Miall 1986; Greil 1991a; Monach 1993) and that married, middle-class couples are deserving, worthy, potential parents (May 1995; Meyers 2001; Park 2002), the following socially constructed ideals related to gender and marriage also figure in the nature of the experience with regards to the

\footnotetext{
${ }^{26}$ I deliberately use the term "married couple" not to be heterosexist or fail to recognize the validity of alternate family structures but to call attention to the societal values which require parenthood for some people (married, employed, etc) and discourage or attempt to deny it for others (homosexuals, welfare recipients, drug addicts, etc.).
} 
spousal relationship: the ideal that it should be easy and romantic to make a child together (Pfeffer and Woolett 1983); sex and related issues are private (Pfeffer and Woolett 1983; Greil, Porter et al. 1989a; Michie and Cahn 1997); the idea that making a child is "natural"(Pfeffer and Woolett 1983; Michie and Cahn 1997); the notion that couples in positive relationships do not have conflict; the ideal that the purpose of sex in a heterosexual relationship is for romantic bonding (Greil, Porter et al. 1989a; Adams 1997); the idea that men, rather than women, initiate sex (Pfeffer and Woolett 1983); the belief that reproduction is the domain of women (Greil 1991a); and the idea that potency and virility are linked for men (Greil 1991a; Monach 1993). These values can be seen within the stories of women writing in the Story Gallery and they also impact upon the experience, particularly when conception difficulties threaten their hold. The experience of conception difficulties highlights these constructs, but rather than calling the constructs themselves into question, participants were more likely to seek ways to cope with their impact and navigate their relationships within their confines.

Almost without exception, any broad discussion about the social and personal dimensions of conception difficulties includes mention of the ways in which this difficult experience affects couples for whom parenthood was considered a central and necessary aspect (if not the most important aspect) of their life plans together (Pfeffer and Woolett 1983; Greil 1991a; Monach 1993; Sandelowski 1993). The women who wrote stories for the Story Gallery also frequently talked about the ways in which their trying to conceive struggles affected their spousal relationships and their feelings about themselves and their spouses in the context of their relationships, though they were not asked directly to talk about this. 
Findings from the Story Gallery suggest that the spousal relationship was disrupted by conception struggles in the following ways: conflict arose due to differences in perspectives and attitudes about the struggle to conceive; disagreements about options; differences among partners in their commitment to conceive; a perceived lack of understanding on the part of the male partner about the despair and suffering his partner was experiencing; as well as feelings of blame, regret and guilt, depending on where the "source" of the problems lay. Findings additionally suggest that the female partner perceives that she generally takes the lead in managing the response to conception difficulties (yet feels some ambivalence about this), with the male partner taking on a supporting role.

Disruption within the spousal relationship was not always negative. The experience also provided opportunities for growth and increased closeness within the relationship. For example, a number of respondents felt that their spousal bond was strengthened due to increased communication, a renewed appreciation for their spouse, a sense of the spousal relationship taking priority, a feeling of being supported by their spouse, their sense of personal and shared growth, a feeling of shared loss and grief, and a feeling that they were facing a significant crisis together as a team. A number of respondents noted that they actively managed their relationships and their responses to their conception difficulties to limit or mitigate spousal conflict and disruption.

Sexuality was affected in the following ways: the feeling that sex was a "chore"; scheduling sex; the feeling that sex was a pressure-filled event; a lack of sexual feelings and a lack of sexual contact during the non-fertile times; the feeling that passion had been removed from sex; a feeling of sexual exhaustion; and the emergence of sexual problems 
such as impotence and/or an inability to have an orgasm. Several couples used humor as a way to reconcile and alleviate sexual difficulties. Responses from participants writing in the TTC Story Gallery support earlier findings about the impact of conception difficulties on the spousal relationship, discussed in more detail below, indicating, perhaps, that traditional roles for men and women and traditional expectations for marriage persist, in this sample, in spite of societal changes over the past generation which have led women to expect more egalitarian relationships. Although the women writing in the Story Gallery did express some dissatisfaction when they felt they were insufficiently supported and misunderstood or felt they were doing more than their share of the "work" related to managing the experience, and many couples actively worked to mitigate the negative impact, social constructs such as those mentioned above continue to impact upon the experience and continue to be reflected within women's stories. Responses, nonetheless, show some tension between the continuing reality of traditional role expectations and the anticipated promise of more egalitarian spousal relationships which appears not to have materialized in a significant way for the participants of the TTC Story Gallery. This suggests their persistence in spite of societal changes over the past several decades and the persistence of traditional gender roles within marriages (at least within this sample).

Most surprising, perhaps, in this vein, was the absence of voices from women who were not in traditional, heterosexual marriages. Responses were almost exclusively from married, heterosexual women who fit the pronatalist image of the ideal mother-to be. They took care of themselves through healthy living (eating right, thinking positively, exercising and avoiding exposure to toxins); they had homes and educations and jobs (but 
none that took precedence over childrearing); they were not too young or too old; and they were not poor or addicted to substances. Most importantly, they had husbands. Although $26 \%$ of births in Canada in 2006 were to unmarried women (Statistics Canada 2008) and it is increasingly acceptable for unmarried and lesbian women to have children, these women, with just a few exceptions, were not writing stories in the Story Gallery about trying to conceive. Alternative family structures may be tolerated, but they do not seem to be widely accepted as having equal status. If a large number of unmarried or lesbian women are actively and deliberately trying to conceive, they do not appear to be talking about it in mainstream venues. This lack of alternative voices speaks loudest in indicating the persistence of values associating mothering with the "right" (married, heterosexual, middle-class) women. Comments from participants cited in the previous chapter in relation to worthy parents, as well as comments included later in this chapter with regards to the suitability of married couples as parents indicate the endurance of this pronatalist value.

A bivariate analysis of the themes mentioned in the stories in relation to sex and the spousal relationship allowed for the possibility to explore the impact of trying to conceive on the spousal relationship in relation to the length of time trying, whether or not medical treatment was sought, age, and whether the couple was trying for a first or subsequent child. Results showed some differences in responses based on the length of time participants were trying to conceive, but few significant differences were found in responses from women who had sought medical help compared with those who did not, making it impossible to identify the source of relationship and sex issues as related to conception difficulties or treatment effects. Additionally, significant differences were not 
found based on age or whether or not a couple was trying for a first or subsequent child. These findings will be discussed at the end of this chapter.

\section{Marriage, Parenthood and Pronatalism}

The impact of conception difficulties on spousal relationships, like the impact of conception difficulties on identity, is mediated and shaped by the societal and cultural expectations and ideologies in which individuals live. As noted above, these particularly include pronatalist values associated with the normalcy of having children and wanting children (Veevers 1980; Miall 1986) that children strengthen marriage and are an expression of love between the spouses (Monach 1993, 46) and that normative heterosexual relationships are bound via satisfying, romantic sexual activity (Adams 1997). These themes occur repeatedly in the stories and literature, but the pronatalist backdrop is rarely acknowledged explicitly in relation to the impact on the spousal relationship.

Respondents did not talk directly about feeling that society, ideology or learned values demanded that parenthood would be an aspect of their marriages or that it was societal pressure to have a marriage including children that contributed to their grief, conflict, anxiety, distress and willingness to pursue disruptive and sometimes painful medical solutions when conception did not occur as planned. Rather, it appears that these values were so ingrained and accepted that there was rarely a mention of alternatives such as living happily without children and accepting alternate aspirations or relinquishing parenthood as a primary goal within their marriages. This was the case even when the quest to conceive caused distress and disruption both personally and in the spousal relationship. Instead, the couples (or, perhaps more accurately, the women), as discussed 
in the previous chapter, often seemed to feel as if they had somehow failed at something basic, making them part of a deviant group (Veevers 1973b; Veevers 1980; Miall 1986;

Sandelowski 1993, 73; Letherby 1999; Letherby 2002a).

Even much of the academic literature focusing on the impact of infertility on individuals and marriages, most of which is from the fields of counseling and psychology, nursing and medicine, rarely acknowledges the socially constructed nature of the experience. According to Griel $(1997,1693)$ :

The literature takes what should be understood as a characteristic of a social situation and transforms it into an individual trait. To put it a different way, the psychological distress literature takes the question "Is infertility stressful?" and transforms it into the question, "Are the infertile distressed?" In doing so, it presents what is essentially a medical model of the psycho-social impact of infertility.

So culturally embedded is the notion that biological parenthood is the norm for married couples (and that married couples are the people that should reproduce) that it is difficult for even the most broad-minded among us to consider alternatives as anything other than second class. According to Matthews and Matthews (1986b, 643): "To the extent that the couple regard having children as a fulfillment of both their marriage and even their purpose on earth, infertility calls into question the meaning and purposes of both their marriage and their very existence."

Voluntarily childless women and couples have had to actively respond to this assumption that parenthood is a required component of marriage and that motherhood is the central role for adult women, resisting the notion of deviance and carving out and defending alternatives (Veevers 1973b; Gillespie 2000; Park 2002). The experience of involuntarily childless women and couples and those struggling with conception difficulties is somewhat different. They too must respond to pronatalist conventions that 
define them as outsiders and deviants. Unlike couples who actively and deliberately choose not to have children in spite of societal pressure, these couples, who likely assumed that children would be part of their married life, struggle because they are not able to meet values and ideals which they themselves accept (Ulbrich, Coyle et al. 1990). They are normal in that they want children, but abnormal and deviant for not having them (Sandelowski 1993, 73). They have no choice (Monach 1993).

Conception difficulties, then, though they are decidedly a private experience for most couples, occur within a prevailing social context that still requires (suitable) married men and women to have children after a certain time of marriage (Sandelowski 1993, 78). Even though alternative options have increased in recent years, particularly for women, couples struggling to conceive without success tend to accept a pronatalist ideology, even if they deliberated over the ideal time to start their families. For women with career and education goals, the question was rarely whether to have children but when to have them. While the predominant cultural ideology may have shifted to one where women are expected and sometimes able to have both career and family aspirations ("having it all"), the expectation that a marriage will at some point include parenthood appears not to have waned.

The results from this study as well as the literature reviewed in this chapter indicate that couples struggling to conceive see parenthood as "something natural" and an expected, required component of their marriages. In this context, difficulty conceiving represents a significant setback and a disruption to plans for couples wishing to start or complete their families. Sarah Franklin (1997a, 133) puts it like this:

Having taken for granted their abilities to bear children, and, in some cases having already given birth to a child or been pregnant, the discovery of 
infertility, either their own, their partner's or simply 'unexplained', was for many women difficult to accept, or even to comprehend. This discovery opened up a 'gap' separating them from the life they had expected to lead. It also opened up a number of 'gaps' in relation to their marriages, which they felt could not be 'completed' or 'fulfilled' without a child. Infertility presented an obstacle to the 'normal' and 'natural' progression they had anticipated from marriage to parenthood, and thus from marriage to family. For many women, this had not even been a fully conscious expectation, so self-evident was the assumption that they would have children of their own.

That the discovery of conception problems creates such a crisis in relationships, that the impact is so far-reaching, and that couples continue to pursue biological parenthood in spite of the strain, stress, conflict and life disruption is testament to the still-powerful hold of pronatalism and the extent to which pronatalist values and the roles they promote have been internalized for so many women and men. The discussion and data analysis that follows illustrate the ways in which conception difficulties represent a disruption to the expectations embedded in the spousal relationship and the ways in which individuals respond to and attribute meaning to these experiences and their relationships in this context.

\section{Marriage, Planning, and Worthiness in the Stories}

In the introduction to the thesis and in the previous chapter, in relation to identity, I discussed how pronatalism encompassed the concept of worthy versus unworthy parents. This concept was very much present in the stories of women writing in the Story Gallery who often constructed themselves as "worthy" by virtue of their marriages and planning to have children only after they were married. Here pronatalist values and associated middle-class values which promote parenting only after marriage and careful planning are evident. In spite of societal changes which allow for more diversity in 
family structure, the strength of the value associating marriage and parenthood and the prominence of the nuclear family as the ideal family structure appear to be as strong as ever. Marriage and parenthood are very much linked and the participants demonstrate that they "deserve" to be parents by virtue of their loving marriages and careful planning.

My DH and I have been married for almost 13 years and are very much in love. He is my best friend. (story101215069476; United States; Age: 32; Months TTC: 2)

After being with my DH for almost 9 years of dating and a few months of marriage, we decided to TTC\#1... (story261708421357; United States; Age: 27; Months TTC: 9)

After being married just a year my DH and I started talking very seriously about wanting to TTC. (story901582528408; United States Age: 24

Months TTC: 5)

I am 31 and my DH is 35. We have been married since November 2004. We decided to start TTC in Aug 04. (story571956680829; Netherlands; Age: 31; Months TTC: 27)

We had waited for our wedding night to have sex for the 1st time. We didn't use any contraceptive because we wanted a baby as soon as possible. (story171227917830; Mauritius Age: 28 Months TTC: 10)

My husband and I are both 26, we have been married for almost 3 years. We have been actively TTC for 12 months. I stopped taking $\mathrm{BC}$ about 1 yr after we were married. (story75766615057; United States; Age: 26; Months TTC: 12 )

\section{Relationship Disruption}

Although most literature discussing the impact of conception difficulties on relationships does not mention the pronatalist backdrop framing marital expectations, it has been widely noted that the marital and sexual relationship is frequently affected when couples experience conception difficulties (Shapiro 1982; Burns 1987, 110; Raval, Slade et al. 1987; Daniluk 1988; Greil, Porter et al. 1989a; Hirsch and Hirsch 1989; Abbey, 
Andrews et al. 1991; Pepe and Byrne 1991; Abbey, Andrews et al. 1994; Daniluk 1997a; Epstein and Rosenberg 1997; Leiblum 1997; Ponjaert-Kristoffersen and Baetens 1999; Monga, Alexandrescu et al. 2004; Peterson, Newton et al. 2006a). Couples experiencing conception difficulties are said to have greater stress, greater marital distress and decreased sexual satisfaction, with increased stress as the struggle progresses with no satisfactory outcome (Connolly and Cooke 1987; Benazon, Wright et al. 1992; Beyer, Dye et al. 2004). Though it is usually just one member of the couple who ultimately receives a diagnosis (when there is a diagnosis), both partners and the relationship itself are affected (Shapiro 1982; Jordan and Revenson 1999) though they may be affected differently (Greil, Leitko et al. 1988; Ulbrich, Coyle et al. 1990; Abbey, Andrews et al. 1991; Greil 1991a; Daniluk 1997a; Jordan and Revenson 1999; Pasch, Dunkel-Schetter et al. 2002; Peterson, Newton et al. 2006b).

Like the biographical disruption discussed in reference to identity in the previous chapter, the spousal relationship experiences a similar disruption. An important, previously taken-for-granted aspect of the pair's plans together as a couple and as a family becomes a struggle. The future, previously mapped, becomes unknown (Shapiro 1982; Woollett 1991; Ponjaert-Kristoffersen and Baetens 1999). This usually comes as a shock to the couple as their plans for the future are disrupted and need to be reconsidered, remapped (Menning 1980; Shapiro 1982). The impact on the couple can be similarly described as a disruption such as that discussed in relation to biography and identity in the previous chapter.

The experience of conception difficulties and the couple's response to them has been described as both a crisis and a mourning process (Menning 1980; Shapiro 1982). 
As the quest to conceive ensues, the relationship may become fraught with feelings of guilt, blame, shame, helplessness, anger, tension and conflict as each member of the couple deals with the setback in different ways or has different feelings about the path to take to find a resolution (Shapiro 1982; Ulbrich, Coyle et al. 1990; Abbey, Andrews et al. 1991; Andrews, Abbey et al. 1991; Berg, Wilson et al. 1991; Benazon, Wright et al. 1992; Gerrity 2001; Monga, Alexandrescu et al. 2004). Individual feelings of depression, grief, anxiety, diminished self-worth, isolation, loss of control and distress can also affect the couple relationship (Pfeffer and Woolett 1983; Connolly and Cooke 1987; Schroeder 1988; Greil, Porter et al. 1989a; Abbey, Andrews et al. 1991).

Monga et al (2004) suggest that infertility causes marital discord due to the physical, psychological, emotional and financial burdens that it places on couples. Epstein and Rosenberg (1997) suggest that couple-conflict arises over the following issues: decisions and stress about money; hassles over the "nitty-gritty" issues such as giving and receiving injectibles, waiting for phone calls, taking basal body temperatures and ovulation kits; the feeling that the couple's life is on hold; decisions about when or whether to end treatment; and differences about how to deal with social situations. Shapiro (1982) suggests that indirect channeling of anger over infertility causes tension to surface between the spouses. Leiblum (1997a) says that women frequently feel insufficiently supported and misunderstood by their spouse. Andrews, Abbey et al (1991) offer that the stress induced by infertility causes an increase in marital conflict. Further, a diminished sense of femininity or masculinity which leaves the infertile individual feeling inadequate and like a "failure" is often reported by infertile men and women and 
this can also affect the marital and sexual relationship between the spouses (Abbey, Andrews et al. 1991; Andrews, Abbey et al. 1991).

Because the cause of infertility can usually be attributed to just one of the spouses, blame and guilt especially are recurrent themes in the relationships of spouses experiencing conception difficulties (Newton 2006). Even the search for a cause may be threatening and sometimes damaging to the couple (Connolly and Cooke 1987). The guilt felt by the partner "responsible" or believed responsible for the conception difficulty may place a burden on the relationship and he or she may directly or indirectly encourage their spouse to find a new, fertile partner (Shapiro 1982, 389; Abbey, Andrews et al. 1991; Leiblum 1997). Guilt may additionally be felt by the fertile spouse who fears that his or her grief may increase the guilt and sadness of the other partner (Shapiro 1982, 389). Conversely, the fertile partner may feel angry and resentful of the infertile partner and may express this directly with accusations or indirectly by withdrawing emotionally or physically (Leiblum 1997). Gerrity (2001) suggests:

Infertility forces the fertile partner to reevaluate his or her affiliation with his or her chosen partner. The person with the reproductive problem often takes the blame for the inability to have biological children and feels guilty for not fulfilling his or her role as partner. He or she may also feel unworthy of his or her partner and/or feel that he or she is holding the partner back from being in a normal family environment.

Blame over conception difficulties may also arise when the initial decision to get pregnant was postponed because one spouse wanted to delay while the other was ready (Leiblum 1997).

When one partner (usually the woman) becomes "obsessed" and preoccupied with infertility, this can also result in feelings of estrangement and isolation (Leiblum 1997). Further, a couple often has no one to turn to but each other when dealing with infertility 
(Abbey, Andrews et al. 1991; Andrews, Abbey et al. 1991). While this can strengthen the relationship, it also places an enormous burden on it, especially if the spouses are at different stages of adjustment and have different emotional needs (Andrews, Abbey et al. 1991, 240). Gender differences in perceptions and coping mechanisms can also be a source of conflict for couples (Epstein and Rosenberg 1997). Burns (1987) suggests that the stress of infertility can lead to sexual dysfunction, extramarital affairs and the inability to make decisions about adoption and medical treatments. Gerrity (2001) notes that stresses emerge due to being unable to plan for the future, due to financial strain, due to the need to attend to daily details and decisions about infertility and the difficulty of using usual coping strategies to deal with infertility stress. Finally, Leiblum (1997a) notes that the vitality of relationships can be sapped when couples endure years of frustrations and disappointments and that relationships can be rendered joyless if they are not tended.

Few researchers have noted that the experience of conception difficulties can have a positive impact on spousal relationships, but it has been noted that the shared experience can bring couples closer together through increased communication (Greil, Porter et al. 1989a; Leiblum 1997; Schmidt, Holstein et al. 2005b) and affirming the supportiveness of one's partner (Franklin 1997a, 140). It is also important to note that not all couples are affected equally by conception problems. There is great variability in the effects of infertility on the spousal relationship. While some couples experience deleterious effects and a deterioration of their relationship, others emerge from the struggle closer and more satisfied than before (Pasch, Dunkel-Schetter et al. 2002). Zatylny (2006), for example, reported that couples who communicated effectively, supported one another and focused on normalcy and had faith in a positive outcome were 
more likely to stay together and become closer than couples who lacked balance and identity in their relationships, who had lost friends and shared less sexual and emotional intimacy.

\section{Spousal Conflict in the Stories}

The most significant sources of conflict in the marital relationship, according to the respondents in this sample, stemmed from differences in perspectives about the struggle to conceive; disagreements about options; perceived differences among partners about their commitment to conceive; a perceived lack of understanding on the part of the male partner about the despair and suffering his partner was experiencing; as well as feelings of blame and guilt, depending on where the "source" of the problems lay. The strain on some couples was severe enough that divorce was considered. These experiences are in line with findings from previous studies with participants with differing characteristics (Shapiro 1982; Greil, Leitko et al. 1988; Greil, Porter et al. 1989a; Ulbrich, Coyle et al. 1990; Abbey, Andrews et al. 1991; Andrews, Abbey et al. 1991; Berg, Wilson et al. 1991; Benazon, Wright et al. 1992; Gerrity 2001; Monga, Alexandrescu et al. 2004) and suggest that traditional role expectations within marriage persist and a "failure" to meet these expectations continue to result in marital strain and tension. Indeed, it appears that some women expected some change in values and gender roles that did not materialize. These values impact upon the experience and are also expressed and reinforced within participants' stories.

\section{Conflict about differences in extent of commitment}

Conflict or strain between spouses arose when the female partner perceived that she was more committed to achieving a pregnancy. The perceived greater commitment of 
the female partner would appear to indicate the persistence of traditional gender roles which place reproduction concerns within the female domain, however, many women expressed some frustration that their partner was not as committed and did not participate as much as they wished. These findings may suggest that women have expectations about changes in gender roles that are not matched by reality. Respondents expressed this in the following ways:

At times, I think it has caused arguments. We might feel like it is the others fault it is not happening. And now, DH has decided he doesn't want to try anymore. He says maybe since I want a child, then I need to divorce him and find someone who does want to child. But at other times, he is ready to go and says, "Let's do it!" The TTC experience has definitely been a roller coaster ride! (story041968078316; United States; Age: 28; Months TTC: 14)

Sometimes I resent my [husband] for not getting me PG, but I know it does no good. He doesn't care whether he has a child or not; he just wants to make me happy. (story87351897325; United States; Age: 39; Months TTC: 156 )

The TTC process was also a little hard on my relationship with my husband. He felt really pushed into [having sex] on fertile days, and wanted a lot of advance warning. (I think he thought that I could tell a week ahead of time, and was pretty surprised when I explained that ovulation was not always easy to predict.) $\mathrm{He}$ is also older, so numerous [intercourse] sessions were unrealistic. I would get very upset when pregnancy tests came back negative, and worry that I would never get pregnant. And because he was a little ambivalent about being a father so late in life, he wasn't as upset as I was. This caused some friction. (story671049489130; United States; Age: 40; Months TTC: 5)

I am learning how to be patient with myself, and my husband. Even thought we both want it, it seems that I want it more, and I wonder if that is the case with most couples. (story181995168324; United States; Age: 37; Months TTC: 10 )

When we first decided to TTC\#1 my husband was a flip-flopper. One day he was onboard and the next he was not. I decided that I had to be consistent with the treatment purely because it was my body that the PCOS was affecting. (story461008663877; Canada; Age: 26; Months TTC: 24) 
It seems to be all that I can concentrate on and my poor husband is along for the ride. (story76469800658; United States; Age: 33; Months TTC: 7)

\section{Differences in Coping Strategies}

Strain and conflict was also experienced when partners had different ways of coping with conception difficulties and different ways of making sense of the experience.

The miscarriage put a strain on our marital relationship, as he differed from me in the opinion that he felt it wasn't "like losing one of our children". I, of course, felt that it was our child from the time I knew of its existence. (story311271565868; United States; Age: 31; Months TTC: 19)

TTC was the first joint medical crisis DH and I experienced. We dealt with it very differently emotionally, with me basically wallowing in selfpity a lot of times, and him verging heavy on the denial. I talked about it with friends and family, he kept it quiet. (story392055460731; United States Age: 31 Months TTC: 11)

It's been a long and hard 12 months. My husband and I have argued and I have cried every month that I get my period. He feels I am stressing too much and that's causing an issue. I keep wondering if maybe one or both of us has a problem and needs to be tested. (story 171227918071; United States; Age: 27; Months TTC: 12)

It certainly has made it harder to be happy as a couple. We love each other dearly and are closer than ever, but the individual minutes can be difficult as we each cope in our own way ... ways that sometimes directly conflict with each other. (story43842133710; United States; Age: 38; Months TTC: 54$)$

\section{Disagreements about Options}

Disagreements about treatment options and decision making also caused some conflict. When there were disagreements about options, the female partner generally appeared to be more willing to pursue aggressive medical options than the male partner. Again, this points to the greater importance of parenthood for women than for men as women more than men seem to be more likely to want to do "anything" to attain 
biological parenthood. Disagreements about options were expressed in the following ways:

My husband and I have on and off moments relating to our course of treatment, appointments, etc. I think he just wishes that we could just get pregnant by "accident" like so many people do. It's hard for him to except that this is the hand we were dealt. (story252017252236; United States; Age: 25; Months TTC: 52)

I have been on Prometrium for the past two months. I tried to talk to my husband about Clomid. He said I wasn't putting enough faith in God. What do you say in that situation? I felt alone, and that my husband did not understand what I was going through. (story611810700896; United States; Age: 27; Months TTC: 6 )

My relationship with my husband can be tense because he has the thinking that maybe God is trying to tell us we're not suppose to have another child. I've been praying for years that if I wasn't suppose to have another one that God would remove the desire from my heart. Instead it has only intensified! (story041968078814; United States; Age: 27; Months TTC:

30)

During this time also, my husband was convinced that I was focusing too much on trying to find something to fix; he was sure that it would just happen with time. (story43842133634; United States; Age: 30; Months TTC: 11$)$

\section{"He doesn't understand"}

A number of women reported that their partners could not understand what they were experiencing and this also caused some stress and strain in the relationship. The perception that the male partner "doesn't understand" also reinforces and points to the normative belief that reproductive issues are the domain of women.

TTC has largely affected our lives. DH gets annoyed that I get upset when my period comes, doesn't understand why I still "torture" myself thinking about the baby we lost, and I seem obsessed with getting pregnant, temping every morning, BDing when I get a positive OPK (even if neither of us is in the mood), and staring at negative HPTs long after the results are viable, hoping that it will turn positive. (story311271565868; United States; Age: 31; Months TTC: 19) 
I was frustrated at my DH because I had been through all the ups and downs each month and the identity crisis he could never understand. (story37514134118; United States; Age: 31; Months TTC: 60)

Sometimes my husband gets mad at me. He wants a baby as much as I but he can't understand the emptiness I feel within me and why I need to test as soon as I am a day late. (story171227917830; Mauritius; Age: 28;

Months TTC: 10)

DH was happy to be there for me, but he didn't understand the ins and outs of female TTC. He didn't understand the emotional roller coaster. (story32965671228; United States; Age: 34; Months TTC: 9)

My husband tries to understand this whole TTC thing, as much as he can, but he can not possibly understand all that a woman goes through when experiencing trouble conceiving. (story311271565868; United States; Age: 31 ; Months TTC: 19)

My husband at first didn't understand what was so depressing about not getting pregnant each month, he kept saying it will happen next month. (story96829939358; United States; Age: 29; Months TTC: 40)

\section{Blame and Guilt}

Some respondents reported that conflict arose due to blaming each other for fertility problems. Feelings of blame and guilt may be related to feelings of shame and inadequacy discussed in the previous chapter. The conflict that arose due to these feelings was expressed by the participants in the following ways.

It has taken a harder toll on $\mathrm{DH}$ than me to the point he has made me cry at times blaming me for not yet being pregnant. (story481468590495; United States; Age: 25; Months TTC: 7)

Once Christmas was over my husband and I started fighting about his family and I'm sure the extreme stress we were both under about not being able to conceive contributed to these fights. We accused each other of fertility problems and fought often. I got some counseling at this time. My husband and I talked things though, come up with some strategies to deal with his family and apologized to each other. Then we focused on trying to conceive again. Christmas and the fights killed conception for another three valuable months. (story20319571620; Australia; Age: 34 Months TTC: 17) 
Others expressed their partner's sense of guilt and self-blame:

It has affected my relationship with my hubby as he feels under pressure and every month when $\mathrm{AF}$ arrives he feels like he's let me down. (story621502273322; United Kingdom; Age: 29; Months TTC: 52)

We're both young and healthy. We just had no idea how hard this whole process would be. He blames himself because I already have kids and in his mind that must mean it's his fault. I don't know how to tell him it's ok and we'll get through this when I'm so devastated every time I get my period. (story36818749332; United States; Age: 22; Months TTC: 5)

A number of women also reported feeling guilty and responsible for not being able to provide a child to their husbands, indicating that an inability to fulfill their social role expectations was experienced as a failure:

I think one of the hardest things for me, was I felt like I was letting DH down by not conceiving as he was younger than me by 5 years. I always felt that if he'd married someone his own age, he wouldn't have that problem. I always knew he loved me absolutely though and for that I am always grateful and feel so blessed. (story271416980512; United States; Age: 41 ; Months TTC: 40)

At times I feel like a failure for not being able to give $\mathrm{DH}$ the biological son he's always wanted. (story311271565868; Country: United States; Age: 31 ; Months TTC: 19)

My marriage is of course affected, particularly because our diagnosis leaves the 'blame' at my door. I have offered my husband a divorce (which he dismisses) and I hate that he might never have children because he is choosing to be with me. I never expected that the love of my life would be forced to make a decision like that. I feel that infertility, and the fact that it's 'my fault', creates an imbalance in our relationship. I always prided myself on being a good and supportive wife (and I am blessed with a good and supportive husband) but now I feel I have failed my husband in the most fundamental way. My husband, by the way, insists on saying that 'we' have trouble conceiving, it's no-one's fault. He hates to see me blame myself - but it is just part of the process of living with infertility. (story36818748967; Ireland; Age: 34; Months TTC: 34)

As I said before, I never really tried to get pregnant. It just happened all three times. This time, I really thought it would be the same. I am so much happier with my DH now than I ever was before. And he had a terrible 
relationship with his ex, and is barely allowed to see his kids (only when the court says that he can). He never really got a chance to be a real daddy, and I want more then ever to give this back to him. It is just taking a while, and I am getting discouraged. And although he would never say this to me, DH is really disappointed that I am not pregnant yet. I can see it in his eyes, and it breaks my heart. I feel so terrible for letting my ex talk me into getting my tubes tied. I feel so responsible. (story852023096346; United States; Age: 31; Months TTC: 5)

It's been hard for my husband I think. He wonders if we will ever have more children. I see how his face lights up when my period is late, how happy he is. I hate that I can't make him a father. (story32965671119; United States; Age: 31; Months TTC: 5)

I feel like I am unable to provide my husband with what he and I both so desperately want. (story20319571484; United States; Age: 24; Months TTC: 11$)$

\section{Feeling Unfeminine}

Similarly, some women noted that the struggle to conceive made them feel "unfeminine" and inferior as a woman and that this also caused stress in their relationships. Again, expectations about womanhood and femininity can be seen to be linked to the ability to conceive and bear a biological child. An inability to be "feminine" in this context also appeared to be associated with not meeting expectations within one's marriage.

When I was TTC my firstborn it brought a great deal of stress to my marriage and made me feel incomplete and incapable as a woman. (story56111714869; United Kingdom; Age: 31; Months TTC: 13)

Infertility is such a hard lesson to learn, and everyone has a different journey that they have to take with it. It makes you feel less than a woman, it makes you feel useless. (story281110582075; United States; Age: 30; Months TTC: 55)

Though we are expecting any day now, the TTC journey caused a great deal of strife between my husband and I. I felt so inferior and unfeminine. 
How could my body not do what it was made to do? (story78925789786;

United States; Age: 25; Months TTC: 18)

\section{Experience Managed by Female Partner}

A number of women reported that they were responsible for managing all or most aspects of the pregnancy pursuit, even those that involved their partner's bodies. For some this did not appear to be a source of conflict and was not expressed as a problem. Some women did note that they seemed to be making more effort than their spouses. In most cases, it was not stated clearly that the female partner managed experience, but the language used indicated that it was the case. Although responses are only from women, the woman's sense that she is "in charge" of the pursuit of pregnancy again reveals that issues related to reproduction are clearly a woman's domain. It also reveals women's greater commitment to the goal.

In the following case, the female spouse "decided" it was time for her husband to get tested.

Finally, a couple months later with still no pregnancy, I decided it was my Husband's turn to get tested. His semen analysis came back with very high volume and count, but low morphology. His urologist ordered a second to semen analysis to confirm these numbers-- which it did. At this point, the Urologist referred us to a Reproductive Specialist. (story99988039578; United States; Age: 24; Months TTC: 22)

These women note that their husbands take the vitamins that they offer:

It has certainly brought my husband and I closer together. He was incredibly understanding of my obsession with charting and happily took the vitamins I filled him with. (story681834256870; Ireland; Age: 29; Months TTC: 2)

I did some intensive research online, and developed a regimen of supplements for DH to take, in hopes to improve both count and volume. Well, in only TWO weeks....we've seen a drastic improvement!! We had our second round of IUI's this week...and his numbers have DOUBLED 
since the last visit! (story79629564731; United States; Age: 36; Months TTC: 15)

In one case, a woman notes that she changed her husband's diet because he actively refused to take vitamins:

I had dealt with some emotional blocks that were holding me back, got my workload right down, had an extra day off work per fortnight just to rest, took the zinc, multivitamin, Nat Mur, walked more, used the OPK and abstained a few days before I expected to ovulate (to build up my husbands sperm count - by the way I fed him healthy foods and lots of nuts which are packed with zinc, selenium etc as he refused to take any supplements). We had sex three times in 36 hours after we got a positive result from the OPK and after each time I put a pillow under my hips and lay there for 30 minutes without letting the semen out. This time I got pregnant 12 months after first trying. (story20319571620; Australia: Age: 34; Months TTC: 17 )

This woman's husband, whom she has "pumped with vitamins," goes for the sperm analysis only after his wife has been tested and after it was advised by her gynecologist.

She referred me to a gynecologist, who was a most wonderful man. It was him who introduced me to charting, plus he did a lot of blood tests and checked my chart every couple of months, after a few months of this, he did say that there was actually nothing wrong with me, but would my husband kindly take a sperm sample to be tested. Which my husband duly did. The results from that test were not clear, and had to be re-done, and then when that test was complete all we got back from the doctor was "not optimal", At that point I gave up. I still carried on charting, and was pumping myself and my husband with lots of vitamins and changed the way we ate etc....but it was still to be another 2 years.

(story291881172988; Luxembourg; Age: 35; Months TTC: 47)

The language used here indicates that the female partner has arranged her husband's sperm analysis:

I had my DH do an SA to find out if everything on his end is okay. We did the test last month and the results came back all borderline for low sperm count and low motility and morph. His Urologist said that they were not too bad of results and he should really have no problem getting me pregnant. So that is kind of good news - but it still weighs on my 
mind. (story33661314790; United States; Age: 30; Months TTC: 4)

This woman notes that she has been charting her fertility signs, taking ovulation tests and has undergone blood tests, but is having trouble getting her husband to get a sperm analysis. Her language suggests a sense of determination about the sperm analysis:

I've tried BBT and ovulation tests and I am always the same 28 day cycle and know when I'm ovulating with mucus and cramping. I saw an infertility specialist who sent me in for the series of hormonal tests. All tests, FSH, thyroid, etc. came back normal. The next test is my husband's sperm and it's been difficult to get him into the doctor's office :). I started my period this week so he's going in this week! (story221857630752; United States; Age: 36; Months TTC: 12)

Here, a woman who is unable to sleep because she has just learned that she is pregnant, does not wake her husband to share the news, but waits for him to wake up, indicating that not only is the pregnancy more important to her, but that she believes that he would rather sleep that learn the news that is so important to her. The experience is hers.

I couldn't resist, I got out of bed and took the test. It was positive! The fertilised egg must have implanted about 3 days after I stopped breastfeeding. Needless to say, I couldn't sleep the rest of the night. I couldn't wait for my husband to wake up so I could tell him. (story33661315371; Australia; Age: 38; Months TTC: 5)

Another woman's story of buying prenatal vitamins also indicates her greater engagement in the experience:

I called my husband from the Target parking lot after I bought them [prenatal vitamins] and telling him..."guess what...I just bought some prenatal pills." He was like, "huh?" So I guess it wasn't so much of a huge deal for him... (story76469800744; United States; Age: 31; Months TTC: 3)

In a few cases, the sense that the female partner was solely responsible for organizing the experience appeared to cause some resentment:

I did not realize how stressful the TTC would be. One thing that I find particularly stressful is that ${ }^{*}{ }^{*}$ seem to do all the worrying...my husband 
(who is also 37) seems quietly confident that a baby will happen for us. While I suppose I should be grateful for his confidence, it sometimes makes me feel more alone as I go through the TTC process.

(story34362859849; United States; Age: 37; Months TTC: 3)

I definitely felt that I was doing all the work and my husband was just there for the ride...so to speak. (story181995168651; United States; Age: 39; Months TTC: 30 )

\section{Thoughts of Divorce}

Some women noted that the strain of trying to conceive was severe enough that divorce was a possibility. This also points to the possibility that the expectation among some couples that marriage should include children is so great that the marriage cannot withstand the pressure of difficulties or the possibility of a marriage without children:

Me and my husband ended up divorcing. TTC had such a strain on my marriage. (story671049488917; United States; Age: 38; Months TTC: 156)

I am 27 years old and I have a 9 year old daughter. I have been TTC since she was born and here I am 9 years later still trying. I have unexplained fertility issues. Which I think it's the worst kind since they can't tell me what's wrong. My daughter's father and I divorced because infertility was taking its toll on our marriage, and with this marriage I can see the same thing happening now. (story15762299367; United States; Age: 27; Months TTC: 108$)$

\section{Sex Issues}

Sexual intimacy is an expected component of a socially ideal romantic marriage. Sex takes on a new meaning when couples are trying to conceive, however, becoming a means to procreation, and a reminder of the couple's struggle, loss and failure rather than a source of pleasure and bonding (Mahlstedt 1985). No longer a symbol of intimacy and closeness, sex becomes "a chore, a means to an end, a mechanical act (Greil, Porter et al. 
1989a, 135)." Because reproduction is inextricably linked to sexuality, self image, and self-esteem, which are also important components of intimacy in relationships, the pleasurable aspect of sexual intimacy can be negatively affected when couples experience conception difficulties (Repokari, Punamaki et al. 2007). Sex, in the context of trying to conceive, then, can become a source of conflict, frustration and anxiety. "Common feelings of infertility, such as loss, anger, guilt, despair, depression, shame, and anxiety, often overshadow the usual feelings of warmth, affection, and emotional connection... (Burns 2006, 212)." Andrews, Abbey et al. note that "Couples feel guilty if they have sex too often, too seldom, or at the wrong times. Spouses follow each other on business trips or avoid taking vacations so that they can have sex at the appropriate times... (1991, 239)". The sense that one has to "produce" at specific times as well as the feeling that sex is "a homework assignment" can lead to impotence and a reduction in the frequency of sexual activity (Andrews, Abbey et al. 1991, 239). Such focusing on sex for procreation can lead to sexual problems and can turn sex into a "mechanical act" done in a particular way, at a specific time and with predetermined frequency and the association may be with failure and pressure, rather than with pleasure and intimacy (Pfeffer and Woolett 1983, 39; Mahlstedt 1985; Greil, Porter et al. 1989a, 117; Hirsch and Hirsch 1989, 18; Rhener 1989, 54).

The pressure on the male partner to perform can especially cause sexual difficulties and increased anxiety (Pfeffer and Woolett 1983, 38; Mahlstedt 1985). Intimacy may be further affected when couples do not have sex at times in the menstrual cycle when there is no hope of conception, believing that sex is not worthwhile at these 
times (Pfeffer and Woolett 1983, 38; Leiblum 1997). The sex act itself may change dramatically when the purpose is conception. Leiblum $(1997 \mathrm{a}, 159)$ notes:

Time devoted to sensual foreplay may be abbreviated as well as efforts to increase arousal. While male ejaculation is clearly necessary for conception, female orgasm is not and therefore, efforts devoted to stimulating female orgasm are sometimes abandoned. Indeed, the woman herself is often less interested in arousal and orgasm than in her having her husband ejaculate at the right time of the month.

The pressure may be further increased when expensive and sometimes painful injections have facilitated ovulation, making "reliable and prompt ejaculation ...the goal of sexual relations (Leiblum 1997, 159)." When the infertile spouse feels "damaged" or "defective" due to infertility, self-esteem may be affected and this can lead to a decrease in desire and an inability to enjoy sex (Hirsch and Hirsch 1989, 18). For men, a sense of diminished masculinity triggered by a male-factor diagnosis can lead to feelings of failure and sexual inadequacy which can contribute to male sexual dysfunction (Burns 2006). Additionally, conception struggles can change the sexual dynamic of a couple because many women are not used to having to say when sex should take place (Pfeffer and Woolett 1983, 39). In Greil et al's (1989a, 117) article about sex and infertility, couples expressed unsatisfactory sex lives due to the following factors: due to having to schedule intercourse; because intercourse became a means to an end; because privacy was invaded when medical professionals became involved and because intercourse was a reminder of a couple's infertility. Burns $(2006,225)$ notes that for men, during infertility, sex "... becomes obligatory, repetitive, and routine, providing few emotional rewards and little excitement." Men may develop performance anxiety, sexual avoidance or aversion to sex and may feel that their partner is only interested in them for their sperm (Burns 2006). 
Pre-existing sexual problems such as vaginismus, vaginal dryness, erectile dysfunction or ejaculatory problems, which may be exacerbated by the pressure of babymaking sex, can thwart baby-making altogether, either because the problems themselves make sex impossible or because these couples engage in sexual activity only rarely and so intercourse is unlikely to be timed during the most fertile time of the menstrual cycle (Leiblum 1997). Sometimes sexual problems such as impotence or the inability to have an orgasm develop after the discovery of conception difficulties (Connolly and Cooke 1987). While severe sexual dysfunction can cause infertility by preventing or interrupting intercourse, sexual problems, for most couples experiencing conception difficulties are usually due to the following factors: scheduled sex; the pressure to perform on demand; the psychological presence of the medical team; and the couple's own pressure on themselves to conceive (Burns 2006). Burns (2006) notes that the sex lives of couples struggling to conceive are affected in the following ways: increased sex during the presumed fertile time; decreased sex after the fertile time has passed; decreased variety of sexual expression; a change in who initiates sex; occasional impotence or retarded ejaculation and orgasmic difficulty in the presumed fertile time.

Finally, a couple struggling to conceive is forced to relinquish any idealistic fantasies about conception. Pfeffer and Woolet $(1983,38)$ note that baby-making sex usually begins as an exciting and loving enterprise, with the couple taking pleasure in each other with the ultimate goal being to create a new person out of their love for one another. Couples experiencing conception difficulties, however, must “....accept that ... conception will not be a romantic idyll, but a matter of mechanical engineering (Pfeffer and Woolett 1983, 23)." When medical technology is involved, conception, or the 
struggle to achieve it, may, in the end, not involve sexual intercourse at all and this may cause a certain uneasiness as well (Michie and Cahn 1997, 120). All these factors have potential ramifications for the spousal relationship, the sexual relationship, the sexual identity of the partners and sexual functioning.

\section{Sex Issues in the Stories}

A number of respondents in this sample noted that their sexual relationships were indeed affected by the struggle to conceive. Similar to the findings discussed above, reports included that sex felt like a "chore"; that there was increased pressure to have sex; that scheduling intercourse sapped the spontaneity, passion, and intimacy out of lovemaking; that there was a lack of sex during the non-fertile times; that they were "sexually exhausted"; that sex was "cold and scientific"; that sex reminded them of their difficulty; and that the pressure sometimes caused sexual difficulties. Some couples in this sample made an effort to reduce the feelings of pressure by deliberately trying to be more "laid back" or by using humor to mitigate and diffuse the tension.

\section{Exciting at First}

The decision to begin trying to conceive and the initial stages of trying to conceive have romantic aspects that are related to ideals about creating children out of romantic love. Women often feel like they are embarking on something big and important and overwhelming. They may feel like they are about to satisfy a lifelong dream and enhance their bond with their partner. A few women, early in the journey, noted how sex to conceive was exciting:

The first time my husband and I had sex without me on the BCP or any protection, I cried.... It was such an overwhelming experience to think 
that we are now ready to actually make a baby. (story08757547734; United States; Age: 30; Months TTC: 3)

I wanted to wait 3 months of being off my birth control pills before we started trying to conceive, so we bought condoms, but since we never used them in years. We didn't find using them pleasurable, so my fiance and I pretty much started having unprotected intercourse right away. That was a life altering moment that first night we had unprotected intercourse. I thought for sure I had gotten pregnant and who knows possibly twins. (story87351897116; Canada; Age: 23; Months TTC: 6)

\section{Increasing Sexual Pressure and Difficulty}

With increasing time passing, sex to conceive seemed to become less exciting. A number of respondents commented on how scheduled intercourse felt like "pressure" to them and especially their male partners. Additionally, some women protected their husbands from this pressure by omitting to share information about their fertility status. Again, the experience is managed by the female partner and her husband is relegated to a supporting role and sometimes does not have all the information.

The pressure to have intercourse every other day for weeks on end was fine at first, but was becoming a source of argument between me and my husband. I was terribly discouraged and frustrated. (story84183990276; United States; Age: 33; Months TTC: 7)

I would say that $\mathrm{DH}$ noticed that I was keen to $\mathrm{BD}$ at key times of the month and I would put some pressure on him, which he felt very acutely. (story87351897522; United Kingdom; Age: 32; Months TTC: 6)

My husband and I have been married for a year and have been together for five. The first month we TTC, it was really rough. My poor DH said he felt like a "show horse" and that all I needed him for was BD. (story602115950777; United States; Age: 25; Months TTC: 3)

In some cases, the male partner refused to schedule sex as reported by these women:

Along those same lines, getting him to time intercourse at the right fertile times was very challenging during these first five months.

(story43842133634; United States; Age: 30; Months TTC: 11) 
In fact BDing to timescales turned him off so much he did not want to do the deed at all. I had to hide anything to do with TTC and BDing so he was not consciously aware that it was the fertile window.

(story261708421289; United Kingdom; Age: 42; Months TTC: 23)

Sometimes the pressure was so great that sexual difficulties arose:

We got fed up with having to "do the deed" at certain times instead of when we felt like it. I know my husband really felt under pressure to "perform" and eventually found this was causing problems and he couldn't do it. I would then lie in bed feeling terrible, guilty for putting him under pressure, but equally angry with him, as we might have "missed our chance". (story532099601993; United Kingdom; Age: 34; Months TTC: 26)

By this time the stress of having "prescribed" sex was beginning to take its toll on both of us. My husband was sometimes too stressed to maintain an erection and we often ended up frustrated and angry. I became increasing upset and likely to burst into tears. (story701224552807; United Kingdom; Age: 31 ; Months TTC: 10)

We both became frustrated and found there were times where neither one of us could climax. That was a big downer. We thought it would be easier, but since the window of fertility is so small, it is frustrating. (story041968078316; United States; Age: 28; Months TTC: 14)

\section{Sex as a Chore}

A number of women reported that sex felt like a "chore" or "work" while trying

to conceive. This was not the romantic, exciting experience they had envisioned.

Making love has become more of a chore around that time of month when I am most fertile, rather than a spontaneous experience.

(story571956681163; United States; Age: 44; Months TTC: 17)

I felt like I was forcing DH to do the BD and it just wasn't as enjoyable. (story481468590495; United States; Age: 25; Months TTC: 7)

After 3.5 years of TTC, sex isn't exactly a joy anymore. It's scheduled and very much like a chore. There was no spontaneity, excitement, anything that was there before. (story701224552506; United States; Age: 28

Months TTC: 41)

The last thing I expected during the whole TTC process is how it would 
affect our intimacy. Our BD times are so focused on getting a [positive] HPT that it almost became like a chore. (story891888747417; Country: United States; Age: 31; Months TTC: 12)

The first year of TTC was very, very hard and it was emotionally draining and it put stress on our marriage. It is not fun to schedule the time you are intimate month after month. It started to put stress on us and made that time feel like work. (story84183990631; United States; Age: 29; Months TTC: 12)

These women note how sex changed and become less exciting and more like a chore as the struggle to conceive wore on:

The first time we took a "holiday of a lifetime" to the Maldives, to start our TTC journey, and reveled in thinking we might be making a baby while we were there - oh how our feelings towards sex changed over time! It went from being a passionate act of our love for each other, to something that we had to do, regardless of if we felt like it at the time. (story532099601993; United Kingdom; Age: 34; Months TTC: 26)

I never thought TTC would be challenging. It is hard to grasp that our romantic baby making has turned into somewhat of a science project. (story131358590947; United States; Age: 30; Months TTC: 8)

Although this woman also notes that sex for conception is like a chore, her sense of humor lightens the situation:

Sex with my husband has become a chore during our peak times. I have irregular, sometimes very long cycles. Some cycles we're on it every other day for 20 days. While we try to keep it fun and playful, some nights we just "punch the time-clock" as we tease each other. (story681834256750; United States; Age: 29; Months TTC: 5)

One woman commented that the struggle to conceive interfered with their lovemaking because she was unable to think of anything else:

It came to a point, where every intimate moment with my husband was clouded by desperation to conceive. That's all I could think of. (story831557536609; Australia; Age: 30; Months TTC: 15) 


\section{Lack of Sexual Contact outside of the Fertile Time}

A number of women commented that sex occurred only in the fertile window and that there was little or no sexual contact during the non-fertile times of the cycle. In some cases, this caused some tension between the spouses.

I didn't expect to be timing intercourse and then not being interested other times of the month...my husband kind of resented that sometimes. (story72608905385; United States; Age: 28; Months TTC: 7)

TTC made my relationship with my husband very stressful because sex was on demand and pretty much reserved for baby making only. (story94369560855; Canada; Age: 31; Months TTC: 6)

TTC is not fun in the bedroom for me and my DH. I was accused of only wanting to BD when I was ovulating, so I had to prove him wrong!!! (story311271566267; United States; Age: 27; Months TTC: 12)

TTC lost most of our 'sexiness' in our relationship. It was never a very sexy one to begin with but when I was TTC it almost became mechanical, my friends would say just relax and not think about 'fertile periods' but once you know you can only get pregnant 5 days in your cycle - you know it you cant just forget it! My partner often would say I was obsessed because I only wanted sex on those days but I just could not relax if I knew I was fertile. (story96829939704; Australia; Age: 29; Months TTC:

3)

\section{Sexual "Exhaustion"}

Several women noted that they and their partners were "sexually exhausted" from having so much intercourse for their efforts to conceive:

This cycle we were so worn out that when I finally got that positive OPK we were really dreading having to do the deed one more time. (story852023096489; United States; Age: 29; Months TTC: 7)

Instead of charting we decided to have sex every other day for a month because that's what a doctor recommended. Instead, we were disappointed month after month and sexually exhausted!! I couldn't wait to just have sex when I wanted to!! Even though we had only been trying for three months I was starting to get worried. How could we NOT be pregnant after that much sex? (story521322670167; United States; Age: 29; Months TTC: 5) 


\section{Use of Humor to Alleviate Strain in the Sexual Relationship}

Some women commented that they experienced some strain and difficulty in their

sexual relationships, but used humor and laughter as a way to allay the tension:

We managed to get it done, laughing and giggling like little kids because we were so NOT in the mood. Turns out that was probably the crucial night and why I'm pg right now. (story852023096489; United States; Age: 29; Months TTC: 7)

We really only had sex once or twice specifically to TTC, which was a little weird but we laughed about it. (story501920540618; United States; Age: 31 ; Months TTC: 3 )

The night we $\mathrm{BD}$ and conceived, we were actually laughing at what a horrible experience that BD-ing had been. After getting the BFP, it made it ok, funny, but something that I'll leave out of future stories. (story281110581933; United States; Age: 26; Months TTC: 11)

\section{Deliberate Efforts to Manage Strain on the Spousal Relationship}

Some respondents, noticing that trying to conceive was adversely affecting their sexual relationships, made a concerted effort to reduce the strain:

I guess, I have come to the realization that I must take time to enjoy the bedding experiences and not make them a chore. (story041968078316; United States; Age: 28; Months TTC: 14)

It just really zapped the love out of love-making and caused some tension at times between us. Now I have tried to be more laid-back. (story8838645741; United States; Age: 27; Months TTC: 8)

We have re-focused ourselves and have begun to enjoy each other again. (story891888747417; United States; Age: 29; Months TTC: 5)

\section{Gender Differences}

Though causes of infertility (when they are not combined or unexplained) can be attributed equally between men and women (Leiblum 1997; American Society of 
Reproductive Medicine 2000-2007) a number of authors have suggested that women are more affected, more distressed, and their lives and identities are significantly more disrupted by infertility than those of men (Daniluk 1988; Greil, Leitko et al. 1988; Ulbrich, Coyle et al. 1990; Berg, Wilson et al. 1991; Greil 1991a; Wright, Duchesne et al. 1991; Leiblum 1997). The association of motherhood with feminine identity discussed in the previous chapter is again relevant for this discussion. Men have been portrayed as seeing infertility as merely unfortunate whereas women are said to see it as devastating (Greil 1991a). Ulbrich et al (1990) also suggest that men are more easily able to accept a childless lifestyle than women and that men in two-career marriages are more likely to see their marriages as satisfying and enduring- even without children. Men are also said to be more willing and able to abandon medical treatments and investigations after repeated unsuccessful attempts (Daniluk 1997b). Women are described as having greater difficulty making the decision to abandon treatments and accept biological childlessness (Daniluk 1997b) and they are more likely to see their childlessness as "role failure" (Ulbrich, Coyle et al. 1990). They are suggested to be more distressed and this distress may undermine their satisfaction with their marriages (Ulbrich, Coyle et al. 1990). According to Leiblum: (1997a, 150)

For men, it appears that the dynamics and feelings associated with infertility are quite similar to the dynamics of stress reactions associated with other life problems, such as financial or vocational problems. For women, however, fertility problems appear to constitute a unique stressor in that there are stronger and more deleterious effects on sexual selfesteem, sexual dissatisfaction, and a sense of self-efficacy.

Petok (2006) additionally suggests that men and women experience the following differences when experiencing conception difficulties: women experience greater stress than men; women are concerned about their "biological clock" and are jealous of other 
women while men are most concerned about losing their "power" to reproduce and the reactions of their spouse; women are more likely to use escape/avoidance coping and to seek social support while men are more likely to use practical, problem-focused methods of coping to seek solutions. Newton (2006) similarly suggests that women are more likely to reach out for social support, use certain escape/avoidance methods such as "wishing, hoping, fantasizing" while men are likely to practice distancing and distraction and focus on practical problem-solving. Mahlstedt $(1985,337)$ reports how differences in coping with infertility can have dramatically deleterious effects on a couple:

Men... often cope with their pain by keeping it to themselves and focusing on their wives. Women often cope by talking continually about their pain with their husbands, who feeling powerless to take away their pain, sometimes stop listening. In order to get him involved, she escalates her complaints and he, in response, retreats even further and may even cease participating in the treatment process. In these cases, the woman feels abandoned when she needs her husband most, and he feels overwhelmed because she needs him so much. They begin to resent each other and become depressed not only by their failure to conceive but also by their loss of closeness and ability to understand.

It is also proposed that women have more emotional resources and are better able than men to cope with the stress, pain and loss of infertility (Abbey, Andrews et al. 1991), for example by being better able to locate sources of emotional support outside their marriages and by employing more effective coping strategies than their husbands (Daniluk 1997a).

The differences in the portrayed responses of men and women to infertility can be explained in a number of ways. Most importantly, the socialization of women in pronatalist societies, as discussed in the previous chapter in relation to identity and biography, links femininity and motherhood in a way that it does not link masculinity and fatherhood (Morse and Van Hall 1987; Cook 1993). To underscore this point, we can 
again look to discussions about psychogenic "causes" of fertility which, until recently, suggested that women who were unable to get pregnant were unconsciously rejecting their feminine role and inadvertently thwarting conception. Cook (1993) notes that there were never any discussions linking men's infertility with an unconscious rejection of their masculinity. For women, then, infertility is more likely to be experienced as a failure to fulfill their central role via motherhood, while men may be more likely to experience it as a feeling of sexual inadequacy (Cook 1993).

While women are consistently found to see infertility as a problem of greater significance than men (Berg, Wilson et al. 1991), it is likely that the extent of gender role identification rather than an element of gender itself that affects levels of distress, with women who identify with more traditional sex roles experiencing greater levels of distress (Berg, Wilson et al. 1991; Cook 1993). This is discussed within the context of the "social/role theory" (Wright, Duchesne et al. 1991) which "...suggests that the social responsibility for the conception and delivery of babies rests much more on the shoulders of women than men and that women feel more responsible for the etiology of infertility, even when the medical causes are male (Wright, Duchesne et al. 1991, 105)". As discussed in the previous chapter, in this social context, motherhood, for many women, is considered to be intrinsic to achieving full adult status and is something most women anticipate (Abbey, Andrews et al. 1991; Berg, Wilson et al. 1991; Ireland 1993; Becker and Nachtigall 1994).

Societal perceptions about male and female infertility, and couples' adherence to them, may also play a role in the various responses between men and women. Male infertility, for example, may be confused with potency and virility and his sexual 
performance may be called into question (Pfeffer and Woolett 1983, 64; Rehner 1989, 16-17). Since women are expected to "just relax" perceptions about female infertility are concerned more with psychology than performance (Rehner 1989, 17).

As discussed earlier in reference to infertility and biography and identity, the desire and expectation to become a mother is often rooted in early life assumptions about mothering as a primary adult role (Becker and Nachtigall 1994). Childless women thus "...often feel as though they are not fulfilling their own or society's expectations of what a woman 'should' do (Ireland 1993, 42)." Infertility thus prevents them from achieving a significant life goal (Berg, Wilson et al. 1991). This can leave them feeling left behind when their friends become parents in a way that men, whose primary adult role is not defined by fatherhood in the same way that women's role is defined by motherhood, are not (Berg, Wilson et al. 1991). According to (Daniluk 1997a):

For many women... their close friendships with other women are dramatically altered when these women become mothers, and caretaking, domestic, and sometimes occupational responsibilities consume the space that was once reserved for their friendships... She must cope with the many losses associated with being unable to produce a child, as well as dealing with the pain of being excluded from the lives of other significant women in her life who have made the transition into the world of motherhood.

This social context of infertility can also explain why women, more than men, are more uncomfortable with situations such as baby showers which remind them of others' fertility, which they may feel highlights their own lack of progression in their life goals (Berg, Wilson et al. 1991).

Additionally, in the social construction of infertility, conception difficulties are typically thought to be "the woman's fault" (Abbey, Andrews et al. 1991; Petok 2006) even though causes of infertility can be equally attributed to both male and female factors 
(American Society of Reproductive Medicine 2000-2007). This potentially adds to the social stigma felt by women, making them more invested in "solving" the infertility crisis (Abbey, Andrews et al. 1991). It could also explain why marital problems are consistently seen to be greater and the stress of both men and women is increased when a medical cause of infertility is found to actually lie with the man (Connolly and Cooke 1987) since this challenges culturally dominant beliefs about reproduction. Indeed, Daniluk (1997b) reports that couples respond differently to male and female factor diagnoses, saying that women diagnosed with an impediment to conception feel their sense of responsibility (and the associated feelings of shame, guilt, and inferiority) is confirmed and they are anxious to begin treatments irrespective of their invasiveness. Couples met with a male factor diagnosis often express disbelief and the female partner may continue to take responsibility for the problem and seek further investigation (Daniluk 1997b). Men may initially deal with feelings of inadequacy by retreating into their work, athletics or having extra-marital affairs (also potential factors contributing to increased marital problems when there is a male factor diagnosis) although they are also likely to eventually, but with more reticence, submit to treatments (Daniluk 1997b). Indeed, it has been suggested that in cases where men are diagnosed with male factor infertility, their levels of distress are comparable to that of women (Daniluk 1997a; Newton 2006).

Male infertility may result in a loss of self-esteem and a loss of a sense of virility for men (Connolly and Cooke 1987). "Any such feelings may assume precedence over a woman's possible loss of identity and the mother role resulting from the lack of children, particularly with the rapidly changing role of women within our society (Connolly and 
Cooke 1987, 56)." Edelmann and Connolly (2000) further suggest that the research that claims that women are more adversely affected by infertility than men is overly influenced by outdated gender stereo-typing and that men may be as affected by infertility as women. Findings from this study and others would indicate that this may be overstated but it would be more plausible to suggest that women who embrace traditional gender roles may be more affected by conception difficulties.

Additionally, there may be methodological considerations since research on infertility has typically been based on small, homogenous samples of white, middle-class, married couples and findings may not be broadly generalizable (Daniluk 1997a). Questions have also been typically framed around women's experiences and women are more likely to participate in such research when asked (Jordan and Revenson 1999). The result is that men's experiences and feelings have been underrepresented in research compared to those of women (Berg, Wilson et al. 1991; Daniluk 1997a; Jordan and Revenson 1999). Also, women are more likely to discuss and disclose information about personal matters such as infertility, which might imply, correctly or not, that they are more upset about it (Epstein and Rosenberg 1997). The way women and men respond to stress in general may also be different, with women being more likely to become depressed than men (Berg, Wilson et al. 1991). Wright et al (1991) suggest that women are more likely to ruminate than men. "The more she ruminates, the less she engages in work, social, or leisure activities. This reduction in activity level makes her more vulnerable to further ruminations and to heightened depression (Wright, Duchesne et al. 1991, 106)." 
Further, since most studies have been undertaken while couples were involved in fertility investigations, and it is the woman's body that is central to the investigations, even if she is not the partner with impaired fertility, it may be that researchers are reporting on women's responses to infertility treatments rather than the infertility itself (Daniluk 1997a; Newton 2006). Daniluk (1997a, 110) notes that "infertile women endure most of the technological investigations and treatments for the couple's impaired fertility... a fact that has significant implications for both the experience and expression of distress. ${ }^{, 27}$ Also, some treatments, especially hormonal medications such as Clomid, have been known to cause psychological reactions such as mood swings, insomnia, fatigue, irritability and depression and there is no way to know if women's increased emotional impact is in any way a consequence of such medications and treatments (Berg, Wilson et al. 1991; Daniluk 1997a).

Similarly, no matter the source of impaired fertility, it is again the woman's body that demonstrates when she is most likely to conceive and she can observe this by counting the days in her menstrual cycle, taking her temperature, observing her cervical fluid and using tests and devices that measure hormone levels in her saliva, urine and cervical secretions. To find the "right time" she must pay close attention and plan intercourse accordingly. Likewise, the "failure" to conceive is manifest in the woman's body, even if the source of conception difficulties is the male partner, and she is reminded of it with every menstruation (Berg, Wilson et al. 1991; Greil 1991a; Daniluk 1997a) or negative pregnancy tests each cycle. In addition, women more than men experience age-related decline in fertility and this can cause additional distress for

\footnotetext{
${ }^{27}$ Feminist critiques of reproductive technology, discussed in the next chapter, call attention to the female body in infertility treatments, suggesting that the submission of the female body to technological and medical instruments in the hopes of allaying the deviance of childlessness, is a form of social control.
} 
women with each passing menstrual cycle (Berg, Wilson et al. 1991). All this attention to her intimate body processes is likely to increase her engagement and potentially her distress. Women's greater engagement may also be reinforced by health professionals who exclude men from the treatment and investigation process, relegating them to "bit players in the infertility drama" (Daniluk 1997b). ${ }^{28}$

There is also likely to be a great deal of variability among couples in the ways in which gender or socially constructed gender roles may or may not affect feelings and reactions associated with conception difficulties. Newton (2006) notes, for instance, that socioeconomic class and culture differences have an impact on coping styles and gender differences. He suggests that working class couples are more likely to use humor when faced with stress while middle-class couples are less likely to use humor in face of stress. Additionally, encouraging men to express emotions has been found to be beneficial for middle class husbands, but detrimental to lower class husbands who might have different attitudes about expressing emotional vulnerability (Newton 2006). Gender differences were not explored in detail within the stories because the sample included responses from women only. Gender differences may, nonetheless, play a role in spousal conflicts about conception difficulties which were discussed previously in this chapter.

\section{Support, Closeness, and Growth in Spousal Relationships}

Though trying to conceive can be stressful and can cause conflict and strain in the spousal relationship and can adversely affect the sexual relationship of couples, it can also provide opportunities for increased closeness and relationship growth. Respondents

\footnotetext{
${ }^{28}$ Daniluk (1997) suggests that this could be ameliorated by placing both partners' names on office files and encouraging joint attendance at medical consultations.
} 
in this sample reported that the feeling of being supported, the sense of increased communication, facing the crisis together as a team, sharing the loss and grief together and acknowledging the primacy of the spousal bond resulted in a closer relationship.

Others have similarly noted that the experience could result in increased intimacy (Greil, Porter et al. 1989a; Franklin 1997a; Leiblum 1997; Schmidt, Holstein et al. 2005b;

Schmidt, Holstein et al. 2005a).

\section{Positive Support from Spouse}

Many women expressed gratitude about their rewarding relationships and loving husbands. Most notably, respondents reported a feeling of being supported, loved or having the full support of their partners. On the whole, this was expressed in a positive way, even though it sometimes appeared that it was primarily the female partner's struggle rather than a shared struggle that the male partner was supporting.

I have had my ups and downs with my husband who has done nothing but support me and convince me that if it doesn't happen than it's okay. (story351126333063; United States; Age: 35: Months TTC: 108)

I never expected it to be this hard, this physically and emotionally draining. My husband has been my rock... (story281110582075; United States; Age: 30; Months TTC: 55)

My husband is an incredibly generous, positive person. I am often amazed at his capacity to look on the bright side of life, even though I have seen him hurt right along with me. He rarely brings the TTC subject up, but he has upon occasion, and he always lets me talk about it whenever the mood hits (which is, of course, why he rarely has to bring it up). I learn over and over how wonderful he is and how much he loves me by the way he supports our efforts. (story111989311439; United States; Age: 34; Months TTC: 10 )

And my husband has been amazing. He doesn't always understand the depth of my hurt, but he always holds my hand. He always holds me close, lets me rage when I need to and cry when I need to. And at the end of the day he can always make me laugh. He is the only person in the 
world that I can be completely myself around. (story831557536387;

United States; Age: 28; Months TTC: 37)

From the beginning, DH was very supportive of everything. The numerous boxes of OPK's, HPT's and the microscope. He would usually come and look at the "results" whenever I asked or got excited about something. He was my ground and brought me back to earth if I got too excited over a line or ferns. He was also very good about always remembering to pack my BBT thermometer if we were going on a trip. He never once asked why I was temping and he never said "stop doing that, it will happen when it happens." It was a lot of fun, the whole experience, once we got past the first month frustration. (story821856146270; United States; Age: 22; Months TTC: 5)

My relationship with my husband has grown throughout our experience. He is my biggest cheerleader and can get me out of self-pity mode very quickly. He has been a great support system and the perfect partner throughout our experience. (story611810700988; United States; Age: 32; Months TTC: 15)

\section{Increased Communication as Source of Closeness}

A number of women mentioned that increased communication about conception

concerns brought them closer together. This woman notes that increased communication

and facing the journey together strengthened their relationship:

We are best friends, but this journey has brought us even closer. We talked about things we had never talked about before in all of our 20 years together. Our TTC journey has brought us closer in many intimate and tender ways. TTC has really become a together journey. Before TTC, I never would have thought that having your $\mathrm{DH}$ wake you up on time on Saturday morning just so you can take your BBT could make you feel so loved! Our first 2 pregnancies "just happened". We now have such a greater appreciation just for the miracle of conception than ever before. We have so much tender compassion now for others on their TTC journey. We are so thankful for this journey, wherever it may lead us, because it is a journey that we chose to take together. Our lives have been enriched and forever changed. (story911266305331; United States; Age: 37; Months TTC: 6)

One woman notes that the shared crisis, the increased communication and the knowledge that the relationship was strong, even without a child, made the difficult situation easier to bear: 
We had lots of chats during those 32 months and I was upset because I thought it was never going to happen. I asked him "what if I never get pregnant?" he said "well if you think you can get rid of me using that excuse your nuts". So, even though it was rough, I felt ok with the situation. (story811096799028; United States; Age: 27; Months TTC: 32)

This woman notes that turning towards each other during the strain of trying to conceive strengthened the marriage:

This experience, however, has been great for our marriage. We've had lots of trials, and have been able to turn towards one another rather than attack each other. (story291881172702; United States; Age: 30; Months TTC: 4)

\section{Shared Struggle as Source of Closeness}

Several women noted that the shared crisis and the sense of working together brought them closer:

My relationship with my husband hasn't wavered, and is truly stronger for all of this... Really, this is the first major issue we've had to deal with in our 5 years of marriage, and I believe we are closer and stronger for all of this. (story65598268538; United States; Age: 26; Months TTC: 11)

TTC has definitely changed our sex life...although I would say that it is temporary. As for our marriage, I would say that TTC has made us stronger. It has not been easy...but we feel like we're working as a team and conquering the first road block in our marriage together! (story392055460663; United States; Age: 29; Months TTC: 12)

However I do think that the challenge has brought us closer in a way that we never would have known possible. There's something to be said for going through with all of these medical tests together -it has really made both of us a part of the pregnancy journey. (story131358590947; United States; Age: 30; Months TTC: 8)

I have to search to find positives in this awful experience, but I must say that I believe my marriage to be stronger as a result of the struggle we have faced together. I believe our love for each other has got us through and my admiration for my husband has grown as time has gone on. (story36818748967; Ireland; Age: 34 Months TTC: 34 )

My husband and I were closer than ever through our treatments and pregnancy and I wouldn't trade that bond for anything. (story32965671382; United States; Age: 28; Months TTC: 21) 
This woman noted that it was the shared losses that brought her and her partner closer together:

Each of our losses really made our marriage stronger and brought us closer together. (story05590011683; United States; Age: 30; Months TTC: 36)

\section{Primacy of Spousal Relationship}

Several women noted that their marriage relationship was of paramount priority and took precedence over the baby quest:

Another way it has impacted my life is that it has strengthened my marriage. Sometimes being intimate just because the time in my cycle is right is really difficult. My DH and I have learned to be patient with each other in this process. Also, just being real here, early in our marriage I thought back to another man who had wanted to marry me. Just for a moment, I wondered if I would already be a mother if I had not chosen him, but one look in my DH's eyes told me I made the right decision, even if we were never able to have children. We were a family, with or without biological children. (story05590011819; United States; Age: 40; Months TTC: 9)

TTC has been hard, it started to drive DH and me apart for a while, but in the long term it has brought us closer together. As long as I have him, then I'm lucky no matter what else happens. (story15762298920; United Kingdom; Age: 36; Months TTC: 60 )

There are a lot of couples, I know, who have seen their relationships spiral out of control as fertility problems land blow after blow on their peace of mind. I cannot express how incredibly grateful I am that that hasn't happened to my husband and I. Nothing, not even having a baby, is worth destroying my marriage. And as long as we stay on the same page, I don't think I'll have to make that choice, in the end. (story32965670930; United States; Age: 23; Months TTC: 14)

Some women acknowledged the stress of trying to conceive and noted that they

deliberately tried to stay connected with their partners:

I also realized how important it is to stay connected with DH. I realized that this is his journey too, and that every [negative pregnancy test] affects him too. He wants it as much as I do, 
and the stress of the timing was hard for him, since he's not used to BDing being a pressure-filled thing. So, we decided we really need to laugh more and lessen the stress of it all.

(story4271876496; United States; Age: 33; Months TTC: 5)

I do think it has put a strain on our relationship and recently I have decided to try and concentrate on 'us'. (story59272081383; United Kingdom; Age: 35 ; Months TTC: 46)

\section{Results from Bivariate Analysis of Relationship Themes Noted in the Stories}

\section{Time Trying to Conceive}

The broad characteristics of the sample for this project, which included people who had been trying to conceive for just a short length of time, as well as people who had been trying for much longer, allowed me to compare the impact on the spousal relationship based on this factor. Results of this analysis (illustrated in cross-tables in Appendix 6) were as anticipated, with marriage stress and sex issues identified more frequently among the stories of women who had been trying longer (Tables 49-50). These results support the position that the conflict and anxiety associated with the experience increase as time passes without resolution. Conflict, anxiety and sex issues, however, were not only experienced by individuals who had been trying for more than a year. Some individuals who had been trying for less than a year also expressed these themes in their stories, although with less frequency.

\section{Trying to Conceive with/without Medical Assistance}

Additionally, the sample includes both people who did and did not seek medical help, so it was possible to compare findings based on this characteristic as well with an eye towards determining whether it is the experience of conception difficulties or the 
pressure of treatments that is largely responsible for stress and conflict among couples trying to conceive. Results from this analysis (Tables 17-18) do not clearly allow for this speculation. Relationship stress and sex issues were noted both among women who did and did not seek medical assistance. Women who mentioned that they had sought treatment were, however, somewhat less likely to mention "sex issues" than women who had not mentioned this. This is perhaps due to taking the project out of the bedroom where sex may no longer be a required component of conception. Although these results do not allow one to attribute relationship or sexual difficulties solely to either infertility treatments or the condition necessitating them, they allow for some conjecture that it is not medical treatments alone that are responsible for the relationship stress, conflict, and sexual issues noted by women trying to conceive. Additionally, women who had sought medical help were more likely to note that their husbands were supportive, or in a "support role" (Table 16) and that their marriages were closer (Table 19). These findings support the idea that the medical experience of conception difficulties, focusing as it does on the female body, reinforces the perception that reproduction is the domain of women, relegating male partners to a supporting role. It is likely, as participants suggested, that reports of a closer marriage were due to sharing the difficult and often stressful experience of treatments. Further, making decisions about treatments necessitates communication among spouses, so this may also bring couples closer. One could also speculate that women who sought medical help may have been more likely to report closer marriages because these couples may have initially been most motivated to pursue medical options to conceive a biological child. No significant differences in relation to 
the spousal relationship were found based on age or whether a couple was trying for a first versus a subsequent child.

\section{Chapter Summary}

In this chapter, I discussed the impact of conception difficulties on the spousal relationship of affected partners. Social values that were noted as playing a role in shaping this impact include the following: the concept that sex within marriage is a bonding mechanism for the romantic partners; the persistence of traditional gender roles which suggest that conception difficulties are the domain of the female partner and that they are experienced more profoundly by the female partner; the idea that making a baby should be easy, romantic and "natural"; the idea that men do and should initiate sex; the ideal that happy marriages do not have conflict; and especially the ideal that children should be a part of marriage and that having children is "normal". Additionally, the stories reflect the social value that married, heterosexual couples are the people that "should" reproduce. These values were evident in the stories themselves and also impact upon the experience. An inability to meet these ideals resulted in disruption that was experienced in the following ways: with conflict about differences in the extent of commitment to trying to conceive; disagreements about options; feelings of blame and guilt; a feeling of being unfeminine and therefore inadequate as a spouse and sexual partner; and sexual difficulties. It also provided opportunities for growth in the relationship which was experienced through increased communication and the feeling of sharing a struggle and supporting one another. Findings from a bivariate analysis of themes related to the spousal relationship showed increased conflict and sexual issues among women who had been trying to conceive longer but no significant differences 
were found among women who did or did not seek medical assistance, or women trying for their first versus a subsequent child, or older compared to younger women.

\section{Conclusions}

Just as conception difficulties interrupt personal goals and self perceptions due to social meanings associated with motherhood, they also interrupt goals and perceptions in relation to spousal relationships based on dominant values about the meaning of marriage and role expectations within marriage. Findings from the stories support the idea that conception difficulties can represent a major set-back to couples; that they disrupt a couple's plans for their marriage and their future together as a family; that they may be perceived as a crisis and a trauma in the relationship; and that they can add considerable stress and strain to relationships and this strain increases as time passes without resolution. Additionally, responses indicate that, from the point of view of the female partner, she manages most aspects of trying to conceive; conception is more important to her than her husband; and she is more affected by the difficulty. This again points to some degree of persistence of traditional gender roles for men and women among writers in the Story Gallery and reinforces the notion that reproductive concerns are the domain of women in spite of societal changes over the past few decades promoting increased gender egalitarianism. Nonetheless, women expected to be "supported" by their partners and wanted their partners to share the experience. The writers in the Story Gallery felt various degrees of support from their spouses, though it seemed that women who felt more supported and connected to their partners felt more satisfied in their relationships.

The stories also confirmed that a struggle to conceive can precipitate conflicts about options, the future, and differences between spouses in their commitment to 
conceive. In some cases, feelings of guilt, anger, blame and resentment can be so severe that couples consider divorce. Sexuality and the sexual relationship are also frequently affected since sex for intimacy, pleasure, bonding and recreation takes a secondary role to sex for procreation. This can cause pressure and anxiety and can make sex feel like a "chore" and can detract from the pleasurable aspect of lovemaking. A number of couples, however, deliberately employed measures to reduce tension and conflict in their relationships. Many also noted that the shared struggle, increased communication and sense of facing a significant life crisis together as a team strengthened their bond. Responses were entirely from female participants and were therefore limited to the female perspective. Nevertheless, findings support the idea that there are gender differences in the ways that men and women interpret and cope with conception difficulties with women taking on a management role and feeling that they are more affected and more committed to the process, with men taking on a supporting role.

There was a wide range of responses about the effects of conception difficulties on the couples' relationships. While some couples found the stress and strain to pull them apart and cause conflict, others felt it brought them closer together. Respondents that noted the experience brought them closer together talked about staying close by talking to each other, understanding that they dealt with the struggle differently, using humor to reduce tension, making an effort to make the spousal relationship of paramount importance and feeling a sense of love, admiration and gratitude about their spouse. Findings from this study seem to be relatively in line with those from earlier studies related to sexuality, marriage and conception difficulty and thus suggest that traditional gender roles and values associated with marriage and the prominence of the nuclear 
family persist, at least in this sample, in spite of increased awareness and acceptability of alternative options. This was also seen in participants' constructions of themselves as worthy and fit to parent by virtue of their loving marriages. Additionally, the lack of alternative voices in the stories spoke to this as well. If alternative family structures are gaining some acceptability and increasing prevalence in recent years, there were few representative voices among writers in the TTC Story Gallery. Perhaps they still remain in the margins. Nonetheless, several participants highlighted the importance of communication and closeness and noted the value of their marriages with or without children, perhaps suggesting a certain openness to alternative family styles, even if they are not preferred. 


\section{Chapter Five: Making Sense; Medicalization and Alternative Interpretations}

As the previous chapters have shown, conception difficulties are experienced, on a personal level, as a profound and usually unexpected disruption to the lives, biographies, identities, emotional stability, world views and significant relationships of the people affected. Socially constructed, middle-class ideals about identity, life goals and marriage shape the experience and are represented and reinforced within the stories people tell about it. The experience, potentially, could also challenge and destabilize some of these social constructs. Additionally, such unexpected and profound disruption begs explanation and interpretation. Thus, the experience of disruption includes searching for meaning in it. A woman who finds herself unexpectedly unable to conceive after trying for some time, like an individual experiencing a profound biographical disruption due to serious or chronic illness (Bury 1982) is likely to search for meaning to make sense of the experience: Why is this happening? Why now? Why me? How can I solve this? A number of profound existential questions are also raised by the experience of infertility. Questions about how far people can and should go to circumvent nature, fate, or divine will in the search for health and happiness can become grave concerns as people struggle with conception difficulty (Sandelowski and de Lacey 2002).

Social and cultural context, including dominant ideals and religious and spiritual belief systems and the nature of the society in which she lives provide a backdrop for answering some of these questions. Medical sociologists discuss this meaning-making in terms of "illness behavior" (Mechanic and Volkart 1961). This chapter discusses how women experiencing conception difficulties define, interpret and determine methods to 
solve and make meaning of the disruption caused by conception difficulties- and how the social and cultural values of the society in which they live and their own belief systems play a role in shaping this meaning-making and the search for solutions. In the case of conception difficulties, for many women, the questions often come more easily than satisfactory answers. The toolkit used to seek meaning and solutions, however, is surprisingly varied and multiplex. Social values (which may co-exist) that influence ways of interpreting and finding meaning in the disruptive experience of conception difficulties include the following: beliefs about the value of science and medicine and the appropriateness of medical solutions for some categories of women (Becker and Nachtigall 1994; Greil 2002); the conceptualization of the body as a "machine" which includes the idea that when something is "broken" it should be repaired (Greil 2002; Nettleton 2006, 2); ideas about self-efficacy and control (Matthews and Matthews 1986b); the idea that the world is fair and just and ordered rather than unfair and chaotic; the perception that "undeserving" people are punished while "deserving" people are rewarded; and individualistic ideals whereby problems are conceptualized on a personal, individual level rather than on a social level (Whiteford and Gonzalez 1995) ${ }^{29}$.

With some exceptions (Greil, Porter et al. 1989b; Sandelowski, Holditchdavis et al. 1990; Greil 1991a; Monach 1993; Sandelowski 1993; Marsh and Ronner 1996; Franklin 1997b; Greil 2002; Sandelowski and de Lacey 2002; Van Balen and Inhorn 2002) little attention has been paid to the ways in which individuals experiencing conception problems interpret, define and make sense of their personal experiences and how they choose (or do not choose) to make use of available medical, lay, spiritual, and

\footnotetext{
${ }^{29}$ In the context of conception problems, this means, for example, that people look at fixing their own bodies or finding a child for themselves rather than looking at the wider social arena, such as preventing the causes of infertility or making childlessness a more socially rewarding alternative.
} 
alternative options to seek resolution. Indeed, human reproduction as a socially constituted and culturally variable phenomenon has been relatively neglected by scholars until the past couple of decades although there has been a relative recent explosion in work about the social construction of (some aspects) of women's reproductive experiences (Van Balen and Inhorn 2002). ${ }^{30}$

With regards to conception difficulties, there has been discussion about the general social context (pronatalism) in which infertility is experienced which may lead women who do not become mothers to feel deviant and encounter stigmatization (Miall 1985; Matthews and Matthews 1986b; Miall 1986; Rehner 1989; Whiteford and Gonzalez 1995; Remennick 2000); there has been work about the messages conveyed by medical practices which infertile people are likely to encounter (Greil 2002); and there has been some discussion about the process (medicalization) by which infertility came to be constructed as a disease or illness defined in biomedical terms with biomedical interventions viewed as the preferred and expected solutions, at least for certain categories of women in western society (Becker and Nachtigall 1992; Becker and Nachtigall 1994; Marsh and Ronner 1996; Greil 2002; Sandelowski and de Lacey $2002)^{31}$. Becker and Nachtigal (1994) further suggest that the social construction of motherhood as the primary adult role for women, as discussed in Chapter Three, fuels women to look for medical solutions to their infertility, sometimes at considerable risk to their health. "American women take risks in infertility treatment in order to fulfill the cultural norm of motherhood (Becker and Nachtigall 1994, 514)."

\footnotetext{
${ }^{30}$ Van Balen and Inhorn (2002) suggest that this recent explosion is due to the feminist movement and an increase in the number of women in academics.

31 The medicalization of infertility has served to restrict the research agenda to the fields of medicine, epidemiology and medical psychology until recently (Van Balen and Inhorn, 2002).
} 
There has also been much critique about the use of said medical interventions to solve infertility/childlessness, particularly among feminist writers (Corea 1985b; Corea 1985a; Klein 1989b). Still, we do not know much about how individuals actually make sense of their own experiences, how they interpret and navigate medical and non-medical messages about how to define, interpret and solve their infertility/involuntary childlessness, how they may create their own messages, and what kinds of frames of reference they use to ask and answer their existential questions.

Currently, in western society, infertility is predominantly interpreted, defined, experienced and expressed as an illness or a disease. As such, a bio-medical framework is almost exclusively used to define, interpret and give meaning to the experience for middle class women in western society. Medicalization of infertility is also related to pronatalist values because infertility services are largely available to and intended for those women who "ought" to have children (married, middle-class women who can pay for treatments). Additionally, since most studies of infertile women have recruited women from infertility clinics or support groups for women undergoing treatment, most scholarly discussions have privileged the medical paradigm as well, even though most women who experience conception difficulties do not actually seek medical attention (Hirsch and Mosher 1987; Stephen and Chandra 2000; Boivin, Bunting et al. 2007). Participants for this study were not recruited from a clinical sample and were not necessarily undergoing medical treatments but the medical framework was also a central theme for framing and talking about their experiences and seeking solutions. Other significant themes also emerged. 
The authority of the medical model to define the experience of infertility has not been without its vocal detractors, particularly among some unlikely comrades: radical feminists, political economists and religious fundamentalists. The critiques of medical interpretations and medical solutions to infertility deserve attention since they underscore that medicine and science are not value-free and that medical solutions are but one privileged way of seeking help and making sense of illness and disruptive health experiences in general and conception difficulties in particular. The numerous critiques of medical solutions and the medical model, however, often fail to consider the complex, varied and multi-faceted lived experiences of the women who must choose whether or not to seek them and make use of them.

Women writing in the Trying to Conceive Story Gallery certainly did privilege medical definitions and interpretations of conception difficulties, and rarely challenged the authority of the medical model wholesale. They also, on the whole, expressed idealized, romanticized and traditional notions of motherhood, marriage and family and suggested (as discussed in Chapter Three in relation to identity and biography) that no price was too great- in money, time or physical trauma- for the ultimate reward of motherhood. ${ }^{32}$ Nevertheless, they did not use medical definitions and interpretations to the exclusion of other ways of making sense of the experience, nor did it appear that they were "duped" (Sandelowski and de Lacey 2002) or pressured into accepting medical explanations and treatments against their own better judgment or exclusively due to the

\footnotetext{
${ }^{32}$ Tina Miller $(2005,62-64)$ reminds us that stories about motherhood are moral stories and that women may feel they need to conceal difficult or contrary experiences as they may be perceived as too risky. We know, for example, that it is morally correct to "do anything for a child" and this may impact the kind of stories that are told.
} 
pressure to attain the cultural ideal of mandatory biological motherhood (Becker and Nachtigall 1994), or that they made use of them uncritically.

The women experiencing conception difficulties and writing in the Story Gallery overwhelmingly appeared to want their experience to be defined as an experience of illness or disease and often felt undermined or even cheated when such a definition was withheld. This definition constructs them as blameless and therefore entitled to sympathy and "broken" and thus deserving of treatment (Sandelowski and de Lacey 2002). It was true for many participants that the doctor's office was usually among the first stops when they suspected a conception problem and they wanted the doctor to discover, name and cure whatever was impeding conception. They sometimes underwent painful, invasive and time-consuming treatments and tests. Often treatments escalated to become increasingly invasive. Some women endured side-effects and sometimes took medical risks with treatments and drugs. Nonetheless, they navigated the medical system in a way that served their own particular interests and desires. They became educated and immersed in the medical experience of infertility (or their particular condition that was seen to cause infertility) and were able to understand and communicate the potential benefits and drawbacks of particular tests and treatments and advocate (and encourage others to advocate) for themselves. Many women became experts on their particular conditions and often saw themselves as partners with their physicians and did not necessarily accept all doctor recommendations without question. They made decisions and set limits (and sometimes changed their minds) about how much medical intervention they would endure in their quest for a child. The major dissatisfaction expressed with medical experiences was in terms of particular physicians who were said to be 
insensitive, incompetent, inattentive or not sufficiently aggressive in searching for and treating causes of infertility. This was more likely to be solved by switching physicians or by insisting on the pursuit of their preferred agenda than by rejecting medical authority completely. This testifies to the strength of the medical model as the dominant interpretive paradigm for women in this sample. It also shows that they are active in reinforcing and maintaining it, that they exercise a certain degree of control and autonomy and that it is not forced upon them. If it is imposed upon them, or if they are coerced in any manner, it is not overt, but embedded in dominant social constructs that shape their actions and interpretations.

Additionally, women writing in the Story Gallery often incorporated their experiences with the medical system with other ways of interpreting and making sense of their conception struggles, including prayer and faith, alternative healing and Eastern/Chinese medicine such as herbs, tinctures, yoga, meditation and acupuncture. Along with medical interpretations, women writing in the Trying to Conceive Story Gallery interpreted their infertility in the following ways: with reference to God, faith or religion; accepting conception struggles in fatalistic terms like "the hand we were dealt", that "everything happens for a reason" or that "it will happen when the time is right"; as "punishment" for earlier indiscretions, or punishment for previous ambivalence about motherhood or previous reproductive decisions. Additionally, a number of women reported that they were searching for answers and were struggling to make sense of the experience.

Results from a bivariate analysis of themes mentioned in the stories showed little difference in ways of making sense among women who had been trying longer versus 
those who had been trying for a shorter amount of time and those who did versus those who did not seek medical help, older and younger women and those trying for their first or a subsequent child. Aside from a greater likelihood to be "searching for answers" among women who had been trying to conceive for a year or more and greater engagement with the medical realm among women over 30 years of age, themes related to making meaning seemed to be relatively similar for all categories of women writing in the Story Gallery. Notably absent from this search for meaning and ways of framing the experience were non-dominant, alternative frameworks or direct questioning about the validity of the constructs which shape the experience and make it so disruptive. Mainstream, middle-class values almost entirely framed the way people in this sample interpreted the experience and provided the tools for navigating it. Again, this points to their strength, dominance and persistence in spite of the availability of alternatives.

\section{Background}

\section{Medicalization and Making Sense of IIIness}

\section{Illness Behavior and Illness Meanings}

A brief discussion about interpretations of illness and disease is helpful to understand the ways in which people struggling with conception difficulties interpret, frame and make sense of their experiences. Explanatory models for making sense of illness are as ancient as illness itself and include various interpretations of cause and effect including myth, magic and medicine (Segall and Chappell 1991). Belief systems, then, offer an interpretive framework for making sense of human conditions, such as illness (Segall and Chappell 1991). 
Constructing meaning is an on-going process for people with chronic illnesses and disabilities as it challenges their way of looking at the world (Charmaz 2006b). Medical sociologists refer to this meaning-making- the way people perceive, evaluate and act upon health symptoms- as "illness behavior" (Mechanic and Volkart 1961) and distinguish between "illness", "disease" and "sickness". Disease, the domain of physicians, is a biological mechanism in the body; illness is the lived experience of disease (Kleinman 1988, 3; Radley 1994, 2-3); and sickness designates social insufficiency caused by disease (Radley 1994).

Physicians, of course, are taught to be strictly concerned with the (seemingly objective) biological entity of disease rather than the personal experience of illness and the social experience of sickness. They often ignore the personal, cultural and social significance of illness (Kleinman 1988, 254-255). Medical sociologists are concerned with the illness experience and illness behavior and are largely critical of the bio-medical model's claims that disease is a fully physical, value-free, knowable entity that can be seen, made visible and be objectively understood (Kleinman 1995, 30). They note that it is also important to pay attention to the psychological, social and moral elements of the illness experience (Kleinman 1995, 30). No matter the biological grounds of disease, the human, social experiences of illness and sickness, symptoms and care-seeking vary culturally and are meaningfully constituted and interpreted and are linked to the basic values of a society or subculture (Good and Good 1980). According to Good and Good $(1980,175)$ : 
... while all disease has biological or physical correlates or causes, sickness becomes a human experience only as it is apprehended, interpreted, evaluated and communicated- that is, as it enters the world of human meaning and discourse. Illness is constructed from popular medical culture, as the sufferer draws upon available theories and networks of meaning to interpret, reinterpret and communicate a particular experience. Illness as a personal and social reality, and therapeutics directed toward treatment of that reality are inextricably bound to the medium of language and signification.

This social constructionist approach is critical of claims about the existence of essential truths- even scientific, biomedical ones (Lupton 2003, 12). While this perspective does not necessarily question the reality of diseases, it highlights that the experience of illness and the way it is understood and interpreted is a social activity that is dependent on the cultural and social setting (Lupton 2003, 12). The body is simultaneously socially constructed and organically founded (Turner 1992, 17) and the concept of a bounded medical system where diseases are "real" entities is a cultural construct (Lock and Gordon 1988). "What things are depends on how they are defined; how things are defined depends on how the general culture allocates phenomena within the spaces of convention... disease is not a pathological entity in nature, but the outcome of socio-historical processes (Turner 1987, 11)". Calling attention to the cultural construction of biomedicine forces us to question its privileged status in western society and reveals the moral dimension of medical practice (Lock and Gordon 1988). ${ }^{33}$ Conception difficulties, then, like other experiences of illness, are subjective and culturally variable (Van Balen and Inhorn 2002).

\footnotetext{
${ }^{33}$ Even anthropologists, famed for their notion of 'cultural relativity' have rarely noted that western medicine is also a cultural construct (Lupton 2003, 14-15) like the healing systems in the non-western societies they studied.
} 
Meaning-making in the face of a serious or chronic illness is also very personal. Williams (1997a) refers to the way people make sense of the disruption of illness as "narrative reconstruction". According to Williams (1997a, 209): "Narrative reconstruction is an attempt to reconstitute and repair ruptures between body, self, and world by linking up and interpreting different aspects of biography in order to realign present and past and self with society. In this context, the identification of "causes" creates important reference points in the interface between self and society." According to Charmaz (2006b), the decision about what kind of help to seek for illness depends on the way that one accounts for its cause. If the "cause" is interpreted as physiological, individuals are likely to look to medical science for the cure and meaning. If the cause is interpreted in spiritual, environmental, religious or fatalistic terms, they may seek meaning and/or solutions through prayer, faith, alternative healing systems or acceptance. For the participants in this study, the use of one system did not necessarily preclude the use of others, even though medical interpretations were clearly privileged.

Given the privileged status of the medical model for framing and treating illness in western society, it is perhaps surprising that most healthcare discomforts are actually not brought to physicians (Freund and McGuire 1999 166). Additionally, many doctors feel that patients consult them for unimportant reasons and often do not comply with doctor's orders when they do (Freund and McGuire 1999). Most health related actions take place in the home without expert help- medical or non-medical (Freund and McGuire 1999, 167-170), and many 
people seek many types of care and use other systems (such as prayer, homeopathy and herbal medicine) simultaneously and in conjunction with treatments from the biomedical model (Freund and McGuire 1999, 177-179). People also make use of a "lay referral system" whereby they consult a physician only after consulting their spouse, friend, neighbour, etc. (Nettleton 1995, 73). Freund and McGuire $(1999,185)$ note that "[t]he patient is engaged in an ongoing process of evaluation of recommended therapies; whether the recommendation is medically correct is only one, sometimes minor criterion in this evaluation."

\section{Medicalization}

The concept of sickness as social insufficiency, incapacity or deviance, originates with Parsons' (1951) concept of the "sick role" whereby sickness is seen as deviance, but it is not seen to be the fault of the sick person and he/she is excused from social responsibility as long as he/she seeks medical help and tries to get better. Parsons' work was groundbreaking in elucidating the social dimension of the medical encounter, but has been criticized on the basis of neglecting the potential for conflict in the medical encounter (Bury 1997, 5; Lupton 2003, 8) and the negative consequences of defining illness as deviance (Riessman 1994). More recent discussions of medicalization highlight the social control aspect of defining deviant or socially insufficient states as medical conditions. According to this perspective, the medical profession has the power to define a wide range of disapproved, deviant behavior (such as the inability to bear biological children) as "sick" (Freund and McGuire 1999, 126). 
Medicalization refers to the ways in which problems that were previously not defined as medical issues come to be defined and treated as medical problems (Conrad 1992, 209; Gabe, Bury et al. 2004, 59). The key to medicalization is definitional; it means that a problem has come to be defined in medical terms and a medical framework is used to understand it and treat it (Conrad 1992, 211). It is often associated with the control of deviance and the ways in which deviant behaviors that may have previously been defined as immoral, sinful or criminal (and controlled by institutions of law or religion) such as insanity, alcoholism, obesity, child-abuse (Conrad 1992,212-213) come to be defined in biomedical terms and are controlled with medical authority by medical institutions (Conrad and Schneider 1980, 7; Riessman 1994; Gabe, Bury et al. 2004, 59; Conrad 2007, 6). Some natural life processes, such as sexuality, childbirth, child development, aging, and menopause have also become medicalized (Conrad 1992, 212-213).

Conrad $(1992,213)$ suggests the following factors abetting medicalization: diminution of religion, increased faith in science, increased power and prestige of the medical profession and secularization. According to Freund and McGuire $(1999,125)$, the shift towards favoring medical definitions of deviance corresponds with the rapid professionalization of medicine. Medicine, says Conrad $(1992,213)$, has usurped religion as the dominant moral ideology and social control institution in modern societies as deviant conditions have been transformed from sin to sickness. The result of medicalization is that biomedicine is the leading institution of industrial society's management of social reality as increasingly more problems are seen as medical (Kleinman 1995, 38) and the medical encounter is seen as the supreme example of social surveillance (Lupton 2003, 26). "[T]he doctor investigates, questions, touches the 
exposed flesh of the patient, while the patient acquiesces, and confesses, with little knowledge of why the procedures are carried out. In the doctor's surgery the body is rendered an object to be prodded, tested and examined. The owner is expected to give up her jurisdiction of the body... (Lupton 2003, 26)."

Medicalization has been given attention by critics who see medical authority as serving the interests of capitalism and by feminists who see it as serving patriarchy through culturally sanctioned dominance over women's bodies (Gabe, Bury et al. 2004, 61). These critics of medical authority claim that it is a socially constructed mechanism of social control since the ultimate authority is having the power to define and impose meaning on a condition (Conrad 1992, 216). Medicine, although it is assumed to be morally neutral, is influenced by the moral climate of society and involves value judgments (Conrad and Schneider 1980, 249). Simply defining something as a disease makes it undesirable (Conrad and Schneider 1980, 249). The social constructionist argument suggests that "... scientific knowledge and biological discourses about the body, health and illness are produced through subjective, historically determined human interests, and are subject to change and reinterpretation (Gabe, Bury et al. 2004, 130)." From this standpoint, illness is a social state constructed through the power of physicians who create labels and make meaning of experiences (Gabe, Bury et al. 2004, 131). Further, social agenda are embedded within these meanings (Riessman 1994). When problems are defined in medical terms, physicians take on a social control function, acting as "gatekeepers" who are responsible for separating the "deserving" from the "undeserving" (to claims of sympathy, social support, sick leave, insurance, etc) (Starr 1982, 20; Freund and McGuire 1999 128). 
Defining conditions as diseases also has relevance for political purposes. When a condition is defined in the medical sphere, this is can be used to justify medical control and to legitimate medical care for that disease, and (most importantly for the case of infertility) to attain insurance reimbursement (Freund and McGuire 1999, 191-192). Freund and McGuire $(1999,192)$ note that "[t]hese categories, accepted by the medical establishment, become the basis for funding research, treating patients, and institutionally establishing treatment programs. By putting these ideas into practice, medicine gives the disease categories a reality of their own."

Additionally, supporting a medical approach to framing and treating illness, critics argue, promotes an individualized image of sickness and ignores the social dimension of sickness as an expression of social dissent or unmet human needs (Freund and McGuire 1999, 132). For example, offering medication or medical treatment for stress, alcoholism, drug abuse and other conditions means that we do not have to look at the source of the problem, which may have a social, rather than individual basis (poverty, working conditions, etc). In this way, western medicine can be seen to reflect particular values in western society and may protect other interests of society, including pharmaceuticals, biotechnology industries, hospitals, nursing homes, insurance companies, etc. (Freund and McGuire 1999 198). Biomedicine, then, reflects the same value system at work within society but situates illness within the individual rather than as a product of social and cultural relations (Becker and Nachtigall 1992). Additionally, the medical model, as a way of making sense of the disruption caused by illness is more technical than interpretive (Greil 1991a, 157). According to Greil (1991a, 157): "Not only does the medical model declare the interpretive and the technological aspect of 
health problems intellectually separable, but it also sees the interpretive as irrelevant to its essentially technological mission."

Feminist critiques of medicalization and medical authority were largely developed in relation to the medicalization of pregnancy, childbirth and motherhood which were experiences which were predominantly managed in the domain of women prior to the professionalization of medicine and gynecology (Oakley 1993; Davis-Floyd and Sargent 1997; Davis-Floyd 2003). Women's lives, feminist critics suggest, have been particularly affected by increased medicalization (Riessman 1994). They ask why normal physiological events such as menstruation, pregnancy and menopause are turned into illnesses and social problems (Lorber and Moore 2002, xi) and suggest that patriarchal relations in the larger culture are replicated in doctor-patient interaction in the clinical domain (Riessman 1994). Feminist critics of medical authority over women's reproductive processes have noted that as the medical profession gained supremacy over pregnancy and childbirth, there was a devaluation of alternative knowledge systems (that of lay midwives, for example) which were portrayed as "backwards" (Jordan 1997). Women's own bodily experience and knowledge were suppressed and only medical knowledge "counted," resulting in a hierarchical system (Jordan 1997). With childbirth as her illustration, Davis-Floyd $(2003,46)$ notes that biomedicine reflects the core values of society where science, technology, patriarchy and institutions are seen to be superior to nature, individuals, families and women. She says that "[t]he demise of the midwife and the rise of the male attended, mechanically manipulated birth followed close on the heels of the wide cultural acceptance of the metaphor of the body as machine in the west and the accompanying acceptance of the metaphor of the female body as defective machine 
(Davis-Floyd 2003, 51)". More recently, this position has been criticized for romanticizing traditional midwifery and failing to acknowledge the power dimensions that were present in those relations and encounters (MacDonald 2004).

On the subject of medical knowledge and authority, Lazarus $(1997,138)$ says: "It is unequally distributed... and connected to matters of power and control. In biomedicine, control is limited by the power held by the medical profession and more and more by medical institutions. Because the doctor-patient relationship is asymmetrical, power becomes domination." Jordan (1997) notes that the physician's unquestioned status and authority rest on a social construct which grants that authority. Opponents of medicalized reproductive care suggest that our (socially constructed) faith in modern obstetrics is not justified (Foster 1995).

Medicalization, nonetheless, is an interactive process, and not necessarily fully the result of total medical imperialism (Conrad 1992, 219; Conrad 2007, 3). Patients and other stakeholders may also be involved in the medicalization process (Conrad 1992, $219)$ as is certainly the case for infertility. Conrad $(2007,7)$ suggests that a number of factors may affect the degree of medicalization of a particular condition. Becker and Nachtigall (1994) suggest that Americans feel that medical risk-taking is their own prerogative when a failure to meet cultural mandates with regards to norms, values, rights and responsibilities is seen as health-related. This, in turn, triggers medicalization and medical technology is given limitless scope (Becker and Nachtigall 1994).

Medicalization is not entirely negative. Positive aspects include increased opportunities for the alleviation of symptoms or a cure and a reduction in the stigma and censure that may be attached to the condition (Gabe, Bury et al. 2004, 62), as well as the 
extension of the "sick role" for "deviants" and a more flexible social control mechanism (Conrad and Schneider 1980, 246). It may also improve the status of individuals with such stigmatized conditions by offering explanations that attribute less responsibility for the condition to the individual than was associated with previous explanations (Becker and Nachtigall 1992). Finally, non-medical, "lay health beliefs" often co-exist along with medical health interpretations (Segall and Chappell 1991).

\section{Medicalization of Infertility and Making Sense}

\section{Infertility and the Medicalization Process}

The medicalization of involuntary childlessness/infertility may be considered both medicalization of deviance, since it is abnormal and socially undesirable to have no children in the context of pronatalism, and, where infertility is age-related due to delayed childbearing, medicalization of a natural life process. Medicalization of involuntary childlessness (now infertility) is nearly complete for middle class women in western society (Becker and Nachtigall 1992; Greil 2002). ${ }^{34}$ A combination of increased professional interest in infertility along with an increasing trend towards treatment for infertility among white, middle class couples with high educational and occupational attainment has contributed to the medicalization of childlessness (Greil 1991a, 33). The social problem of involuntary childlessness has become the medical, individual problem of infertility (Becker and Nachtigall 1992), at least for middle class women (Greil 2002). This means that infertility is described in medical language; it is treated in medical institutions; and sufferers are regarded as patients (Greil 1991a, 34).

\footnotetext{
${ }^{34}$ Critics argue that western medical definitions are also being increasingly applied (inappropriately) in non-western cultures as well where they have little cultural relevance (van Balen and Inhorn 2002).
} 
Greil (1991a, 38-45) provides a brief history documenting the process by which infertility became medicalized and industrialized, noting the increased possibilities for medical treatments with the development of modern reproductive endocrinology in the middle of the twentieth century; the demographic trend towards delayed childbearing which has meant an increase in demand for infertility services as women experiencing primary infertility consult medical practitioners earlier due to the sense that time is running out; an increased faith in science; a decreased availability of non-medical solutions (such as a small supply of infants available for adoption); the feeling among women (many of whom had previously used contraception to avoid unwanted pregnancy) that reproduction is something they should be able to control; and an oversupply of obstetricians and gynecologists relative to need (after the birthrate sank after the baby boom they needed to provide other services, such as infertility services). Further, in contemporary societies, reproduction, including pregnancy and childbirth as well as infertility is increasingly defined in terms of risk and danger rather than as an experience that is natural and controlled by women (Becker and Nachtigall 1994).

Most significant, perhaps, is the social value of children in a pronatalist society. Children's central place in societal organization is key to the medicalization of involuntary childlessness since medical treatments offer some hope of overcoming the disruption and feelings of stigma and deviance associated with childlessness (Becker and Nachtigall 1994). If a "take-home-baby" is seen as a "priceless benefit" then any risk is worthwhile (Becker and Nachtigall 1994). The potential danger of inaction and not pursuing medical treatment (remaining childless) is perceived as much greater than the cost and risk associated with pursuing treatment (Becker and Nachtigall 1994). 
Additionally, the medicalization of childlessness, whereby medicine defines the inability to reproduce biologically as "abnormal" demonstrates how societal values are reflected in medicine (Becker and Nachtigall 1994). According to Sandelowski (1993, 11-12):

Locating infertility in the domain of disease serves to underscore the normative aspects of conditions such as infertility. The cultural mandate to procreate in marriage, the longstanding association of fertility with normal adulthood (particularly womanhood), and the prevalent view that reproduction is part of the natural design of the human species are among the factors that make infertility an undesirable condition, place it outside the boundaries of health and normality (if not wholly within the domain of disease)...

With the help of reproductive technologies, then, physicians can produce socially desirable "happy families" (Franklin 1995). Likewise, the desire to feel that every option has been pursued in the attempt to conceive a child so that one can later look back without regret also fuels the use of medical technology (Franklin 1995).

Though infertility is now primarily a medical issue, a number of circumstances must be at play for childlessness to become infertility: " $\ldots$ it arises only when there is a relative or absolute inability to conceive, in combination with a psychologically, socially, or culturally driven wish to have a child, and the existence of personal, social and financial circumstances which mean that childbearing is seen as an appropriate choice by the individual or couple involved (Lee 1998, 59)". Nonetheless, even though infertility is almost exclusively constructed as a medical issue, the actuality that most couples experiencing infertility do not seek medical services (Hirsch and Mosher 1987; Stephen and Chandra 2000; Boivin, Bunting et al. 2007) indicates that the medical model is not the only way in which people choose to frame and interpret the experience. Additionally, some people do not have access to medical solutions. 
There is also a class dimension at play within medical help-seeking for infertility and this relates to selective anti-natalism which was discussed previously. Affluent couples who are perceived to be "fit" are more likely to seek medical resources to solve involuntary childlessness than less advantaged couples, even though infertility is actually more common among less socio-economically advantaged couples (Greil 1991a, 28). Notions about worthy versus unworthy parents are thus reflected in treatment-seeking decisions and access to treatment. Reissman (1994), in her discussion of women and medicalization, suggests that class has been overlooked in discussions of medicalization. She says: "Physicians and women from the dominant class joined together- albeit out of very different motives- to redefine certain human events into medical categories (Riessman 1994, 104)." According to Becker and Nachtigall (1994, 515):

The acceleration of medicalization also results in social and economic disparities between different sectors of society... Whereas risk calculations of this nature may be viewed as ostensibly medical, they in fact express social inequalities within American society. Namely, such policies reflect American values about repairing the health problems of middle-class persons but not those who are poor, and they reinforce medical risk-taking as an activity of the upper classes.

Likewise, the social definition of infertility as a medical problem versus a social problem has implications for access to services. If infertility is a medical problem, ...then infertile couples may be recognized as having a health problem and, consequently, their treatment for infertility is accepted as a necessity. Most important, the costs of such treatment must be paid or reimbursed by the national health care system. However, if not having a child constitutes a social problem of involuntary childlessness... then the absence of children is a personal issue for which society bears no responsibility. From this perspective, children may just be one of the things in life that an individual may want but cannot necessarily have- like a steady partner, a house, a car, or a full-time job. In other words, childlessness is a matter of fate that one must accept, and it is not something that a society's health care system can be expected to remedy (Van Balen and Inhorn 2002). 
Infertility also differs from other illnesses or health conditions in several ways: it usually affects couples rather than individuals, even though the physical impairment may be present in just one member of the couple; no matter which person is impaired, the infertility is displayed on the female as she is the one that does not get pregnant; the person with the impairment may not be the person who is treated; infertility is not really a pathological condition, but the absence of a desired condition (Greil 1991a, 47). Further, infertility only becomes an illness after the choice to have a child has been made (Sandelowski, Holditchdavis et al. 1990). Finally, infertility is different from other illnesses because it has solutions other than pregnancy (adoption or choosing to remain childless) (Greil 1991a, 48).

Still, solutions other than biological parenthood are frequently not considered until medical options have been exhausted (Becker and Nachtigall 1992). This is because the only acceptable solution once the problem has been characterized in the medical realm is the production of a biological child (Becker and Nachtigall 1992). Alternative solutions, frameworks and interpretations become less acceptable and less accessible (Becker and Nachtigall 1992). Indeed, the existence of reproductive technologies may be seen to extend an additional burden to women who have access to them since they must make additional choices and decisions associated with using them (Sandelowski, Holditchdavis et al. 1990).

While medical solutions are often preferred and are usually perceived as offering the best hope for overcoming childlessness, and provide the comfort of "doing something," Becker and Nachtigall (1992) suggest that medical solutions ultimately do not satisfy most of the women for whom they are intended. The problems, they suggest, 
are threefold: they do not work as easily, frequently, or as quickly as expected; medical definitions of fertility conditions construct infertile women as "abnormal" and do not alleviate their sense of deviance; the exhaustion and immersion of treatment competes with the desire to overcome childlessness and health concerns begin to contaminate intimate aspects of daily life (Becker and Nachtigall 1992). Feelings of deviance are reinforced in the infertility medical encounter in the following ways:

The designation of infertility as a disease and individuals' own feelings of failure to meet cultural norms affect perceptions that infertility is something for which we are at fault. Diagnosis becomes the catalyst for the experience of abnormality, while the focus of medical treatment becomes the restoration of normality. The shared perception of individuals seeking care and health professionals- that it is abnormal to be unable to biologically reproduce and that an illness must exist- shapes the nature and course of infertility treatment and patients' responses to it. Infertility treatment becomes a symbol of negative cultural attitudes about childlessness, as it inadvertently reinforces a sense of abnormality by juxtaposing that which is considered normal against that which is not. Instead of diminishing feelings of abnormality when treatment is sought, values that are embedded in the health care system facilitate the growth of such feelings (Becker and Nachtigall 1992, 468).

Once immersed in treatments, it is difficult to give up on medical efforts (Becker and Nachtigall 1992). Treatments become increasingly invasive in a small amount of time and the effect of treatments is cumulative (Becker and Nachtigall 1992). Furthermore, it has been proposed that the medicalization of infertility acts to manage the liminality and ambiguity felt by those experiencing infertility by proposing technological solutions and explanations and a sense of taking action (Allan 2007). Allan (2007, 136) notes: "Much of the medical practice in the fertility clinic, such as recording menstrual calendars, sexual positioning, advice about food and rest and intrauterine insemination were not based on sound clinical evidence but were enacted as something to do in the face of no evidence or resources to treat effectively." Medicalization may also be 
important for managing the chaos of infertility and the transition to the social role of infertile woman (Allan 2007).

\section{Feminism, Reproductive Technologies and Medicalization}

Feminist critics of the medicalization of reproduction were initially concerned with the ascendancy of the medical profession over pregnancy, childbirth, motherhood and contraception and later expanded their critique to include reproductive technologies designed to combat infertility (Foster 1995). They suggest that the dominant public perception that reproductive technology is a response to a desperate demand from infertile women conceals the reality that it is driven by profit and science objectives (Foster 1995, 49). "Women are pulled into medical research programmes with the carrot of the possibility of pregnancy followed by a live birth but in the very recent past many women have been misled as to the likelihood that they themselves would take home a healthy baby (Foster 1995, 54)." Feminist critics further suggest that the use of reproductive technologies reinforces the 'cult of motherhood' in male dominated societies and forces women to reproduce at great cost to themselves (Foster 1995, 53). Some feminists (though they are not at all united in this perspective and this position has become more nuanced since the late 1980s) have suggested that the "all-consuming drive" many women feel for a biological child is purely socially constructed and that reproductive technology and the medicalizaton of women's bodies reflects patriarchal society's emphasis on women as child bearers (Michie and Cahn 1997, 124). This position is based on the assertion that women cannot really freely choose reproductive technologies, but are rather coerced to use them since they are culturally valued only as mothers (Michie and Cahn 1997 124-127). According to Klein (1989a, 2-3): 
Why children at any price? Is it- as many say- the individual passionate desire to care for and nurture children? The wish for intimacy? To become a 'proper' adult and assume responsibility? Is it to achieve a sense of identity and importance... How much of the pain of infertility is a result of the enormous stigma attached to the inability to give birth to one's own child? How often is pressure put on a woman to give her husband 'his' child? And how deeply ingrained is the assumption that all women have always wanted and needed to be mothers...? Is this 'choice' or, rather, should we speak of coercion?

Further, the use of reproductive technology, which is largely restricted to middleclass, married, heterosexual women means that those who are deemed unsuitable are not given a choice (Foster 1995, 64). Likewise, academic data is largely restricted to this demographic as well, and feminists especially call attention to the silence of those who do not fit this "socioeconomic elite" group (Van Balen and Inhorn 2002).

Sawicki $(1991,91)$ suggests that the hierarchical nature of medical authority makes it difficult or impossible for women to make a decision about the use of reproductive technologies:

What makes new reproductive technologies especially dangerous to women is not so much that they objectify and fragment bodily processes, but that they are designed and implemented by experts in contexts where scientific and medical authority is wielded with insufficient attention to the prerequisites for democratic or shared decision-making. The often unchallenged authority of experts makes possible an imposition of treatments and regimes that is dangerous to women.

Additionally, according to Woollett (1996), there is the assumption that well-adjusted women should use reproductive technology simply because it is available. Again, this reinforces the position that pronatalist values are at play since these (worthy) women are encouraged to use technology to assist with reproduction. Klein (1989a) suggests that the perception of infertility as a disease that can be cured, along with the very existence of 
reproductive technologies produces feelings of guilt, anxiety, loss of self-esteem and depression and the sense among women that they have to keep trying to meet the social ideal to reproduce. Resistance to medical treatment is undermined, seen as "giving up" and this perspective is reinforced both by doctors and self help groups who exhort women to keep on trying for the "longed-for child" (Woollett 1996). The self help groups and physicians, Woollett (1996) claims, speak for and to only those women who pursue medical treatments and exclude those who do not, or those for whom treatments are not successful.

Klein (1989b) suggests that rather than investing in reproductive technologies, we should attack the myth that women need to have children to be "proper" women as well as the perception that a couple needs their own biological child to be happy. According to Pappert $(1989,203)$ :

Because reproductive technology fixes on biological parenting as the only 'real' way to parent, it enforces the idea that the only child worth having is a child you give birth to. This fixation on biological procreation as the only acceptable method of parenting excludes a supportive view of other parenting options like adoption and a recognition of how many children are currently in need of parents. It is a philosophy that is profoundly antifeminist which devalues both children and parenting

Further, infertile women should be given real support when they must remain involuntarily childless (Klein 1989b).

Finally, feminist critics suggest that not only do reproductive technologies for infertility increase medical control over women's lives and improve profits for the health care industry and increase the status and prestige of physicians and researchers, they do not even work very well to help most women who are suffering from infertility (Foster 1995). Women who use them, they claim, are used as guinea pigs and assume great risks 
with low success rates while doctors are more concerned with science, research, progress, fame and prestige (Klein 1989b).The inequality and male bias in medical treatments, feminist critics claim, is highlighted by the fact that even in cases of male infertility, women assume risky, expensive, and invasive procedures (Van Balen and Inhorn 2002). It would be better, they suggest, to work on prevention, working hard to eliminate causes of infertility, rather than seeking technological cures for infertility (Pappert 1989). The difference is in fundamental values. The technological, medical solutions are based upon values associated with individualism, while preventive measures and ideological changes would be based on social values.

There has been, however, a call for a more nuanced feminist position on reproductive technologies (Woollett 1996; Ulrich and Weatherall 2000) that does not portray infertile women who seek medical help as mad, bad, or desperate (Ulrich and Weatherall 2000). Feminist perspectives are limited in several ways and there has been a loss of certainty among feminists about their position with regards to reproductive technologies (Franklin 1995). Sawicki $(1991,86)$ suggests that feminist positions have largely failed to recognize women as actors, rather than passive subjects:

The repressive model of power assumes that all women and men occupy essentially the same position in relation to patriarchy, namely that of victims who are blinded by the ideology of science or perpetrators of violence respectively. Like the discourses and practices they criticize, radical feminist discourse often position women as passive subjects not potential activists, as causally conditioned not self-determining...

Infertile women are seen as naïve, accepting doctors as great benefactors, and so thankful for reproductive technology that they do not mind the pain, humiliation, exhaustion or expense of treatment (Rehner 1989, 40). These perspectives fail to recognize the ways in which women have participated in the construction of 
medical definitions and they do not question the reasons that women participate, nor do they discuss the ways in which women can gain as well as lose when conditions are interpreted in a biomedical framework (Riessman 1994).

Particularly, interpreting infertility in the medical domain legitimates the claims of infertile people to a share of social resources for medical concerns (Sandelowski 1993, 12).

Also, from the dominant feminist perspective, medical practitioners are all painted with the same brush, as conspirators in techno-patriarchy, when they cannot be so easily categorized (Marsh and Ronner 1996). Finally, the dominant perspective of feminist critics (that motherhood creates obstacles to personal development and freedom and is not worthy of a high stakes medical quest) has created some divide among feminists, some of whom have found it necessary to hide their own child-desire and medical investigations (Van Balen and Inhorn 2002).

Critics of the feminist argument say that women do not only want to reproduce to fulfill a socially constructed motherhood mandate. They also desire children because they want to be parents and share love, family traditions and heritage (Marsh and Ronner 1996, 5). Constructing their desire to be mothers and their subsequent suffering as wholly socially constructed and suggesting that they could choose not to suffer and instead recognize the oppressiveness of patriarchal constructs is diminishing and undermines their claims to sympathy and subsidized health and social services (Sandelowski 1993, 19-20). Indeed, Sandelowsi and de Lacey (2002) suggest that the feminist and social constructionists' criticism of 
reproductive technologies may be misplaced, that the representation of infertile women as patients is the least objectionable of possible representations, the most useful to the infertile themselves since it justifies public expenditures, and does justice to the sense of disruption that they feel. Looking at interpretations of infertility as only socially constructed and infertility only as a cultural problem also obscures the individual experience as the focus shifts away from the infertile themselves while pronatalism, patriarchy, capitalism and technology are targeted and criticized (Sandelowski 1993, 42-43). Again, the issue is one of fundamental values: the social/collective versus the individual. Both are relevant and there is no reason that attention and resources towards one should preclude attention to the other. Perhaps it would be most beneficial to consider a perspective that at once recognizes pronatalism as a social construct but the feelings associated with an inability to meet its ideals as very real. Relatedly, it should be possible to attend to social/collective issues (such as prevention of infertility and promoting ideological adjustments that can reduce feelings of alienation and stigmatization) without eliminating the possibility for individuals to seek individual solutions as they desire.

\section{Infertility and personal meaning-making}

Few studies of the personal experience of infertility discuss the ways in which people make sense of their own experiences and make decisions about their future. Particularly in discussions about reproductive technology, the voices of infertile women themselves are surprisingly quiet (Woollett 1996; Kirkman and Rosenthal 1999). Work in the fields of psychology and medicine privileges accounts given by doctors and 
psychologists and work done by feminists ignores the voices of women who do not interpret their experiences via the explanatory plot of patriarchy (Kirkman and Rosenthal 1999). Of course women experiencing conception difficulties do seek to explain and make sense of the disruptive experience. Franklin (1995) additionally notes that coping with infertility is eased by an acquisition of some explanation for why conception fails. A brief review of some of the work that does take personal and social meanings into account is included here.

Sandelowski $(1993,93)$ suggests that infertility patients have a great deal of faith in medicine but also (especially less advantaged women) believe that their future is "in God's hands" with more socio-economically advantaged women having a more ambivalent relationship with God, praying but also feeling angry at the injustice. She also found that infertility patients were engaged in a "calculus of pursuit" whereby they would weigh their options and pursuits and proceed according to what they were willing to invest (Sandelowski 1993, 95). They considered how far away from "nature" they were willing to go; how much risk to their marriage they were willing to take; potential drug side effects; and the potential for future regret if they stopped treatment (Sandelowski 1993, 95-104). Sandelowski, Holditchdavis et al (1990) also noted that

Infertile couples exhibited a range of epistemic stances toward infertility, ranging from the frankly empirical to the searchingly metaphysical, locating the origins of their problems in fate or somewhere in a more scientific chain of causation. Accordingly, they varied in their ideas about infertility as a cause (of childlessness) and consequence (of dysfunction, fate or transgression)...

Confusion, uncertainty and ambiguity were also noted as themes in women's attempt to find meaning in their experience of infertility (Sandelowski and Pollock 1986).

Sandelowski and Pollock (1986) further noted that infertility treatment was often seen as 
a way to feel in control of the experience. They noted that the ambiguous nature of the experience, in which there were no definite answers, meant that they could not give up trying to have biological children (Sandelowski and Pollock 1986).

Griel, $(1991 \mathrm{a}, 5)$ in Not Yet Pregnant: Infertile Couples in Contemporary America states one of his objectives as determining how people decide to identify infertility as a problem which requires medical intervention. He notes that "... the process of being infertile is dialectical; husbands and wives interpret, respond to, and give meaning to physical symptoms and physiological conditions (Greil 1991a, 6)." He suggests that infertility is not a static condition as much as a socially conditioned process whereby couples define their inability to conceive the desired number of children as a problem and then attempt to interpret and solve this problem (Greil 1991a, 7). To make his case that infertility is a socially constructed phenomenon, he discusses various non-western cultures that have different definitions of what infertility means that make sense in those particular cultural contexts (Greil 1991a 7-10). He suggests that the medical approach to infertility, though it is the dominant cognitive approach for interpreting the experience in western society, is just one approach among many and that accepting it has a dramatic impact on the experience of infertility (Greil 1991a, 11).

Griel (1991a, 15) also noted that people experiencing infertility often feel a sense of loss of control and that that seeking medical help is an effort to regain a sense of control. The medical encounter, however, is one in which there is a power imbalance whereby the patient must accept a passive position when taking on the role of the patient (Greil 1991a, 77-78). "Thus, when infertile wives and husbands decide to seek treatment for infertility, they place themselves in a paradoxical situation, because- to regain a sense 
of control- they have found it necessary to place themselves in a situation where they have very little control indeed. (Greil 1991a, 78)." Nonetheless, patients are not powerless and will make use of all resources available and will use the medical encounter strategically (Greil 1991a, 79-80). Additionally, people may use alternative solutions and pretend to fully accept the medical model, when, in fact, they use physicians' services very selectively (Greil 1991a, 80). He further notes that women gain control by becoming experts and "fertility contractors"; they complain when doctors are perceived as insensitive or incompetent; and they exert control by changing doctors (Greil 1991a, 80). Contrary to the frequent portrayal of infertile women as passive recipients, pressured to use reproductive technologies, women pressure physicians to be more aggressive at the early stage of treatment (Greil 1991a, 88). Greil (2002) suggests that women using reproductive technology can most aptly be described as "working the system". "Infertile women are neither passive victims of biomedicine nor uncritical consumers wanting to take advantage of all available medical technology. Rather, they are problem solvers, operating creatively within a system they do not control (Greil 2002, 103)."

Decision-making about infertility solutions is potentially more complicated than that of some other illnesses since infertility is not life threatening (Greil 1991a, 101) and it is experienced more like a chronic condition that never seems to leave, than a crisis (Greil, Porter et al. 1989b; Greil 1991b). There is no objective state of "being without options". Couples need to make the decision that they have run out of options (Greil 1991a, 101). This is difficult because the uncertain nature of infertility means that biological parenthood rarely seems completely unachievable, so it is not surprising that 
infertile women are often so willing to subject themselves to demanding and dehumanizing treatments (Greil 1991a, 104).

Further, the uncertainty and open-endedness of infertility makes it difficult to find meaning or closure in the experience. Greil (1991a, 172-173) suggests that the use of the medical model to explain infertility makes it hard to accept since it is viewed as a technical problem to be overcome rather than something mysterious to be accepted. "The same developments that have made infertility easier to handle practically may have made it harder to handle cognitively (Greil 1991a, 173)." While infertility is defined by medical professionals, the public and couples as a medical problem, medical solutions only address one small element of infertility (Greil 1991a, 176). Technical aspects are attended, but social, emotional and cognitive aspects- such as concerns about feelings of loneliness and failure and threats to the sense of the world as a meaningful place- are ignored or only rarely addressed (Greil 1991a, 176-177). Indeed, many women are unable to find satisfactory answers and are frequently unable to use religious resources to effectively deal with the meaning threatening aspects of infertility (Greil, Porter et al. 1989b). Conversely, previous reality beliefs may even be threatened by the experience of infertility (Greil, Porter et al. 1989b). Part of the difficulty of making sense of conception difficulties outside of the medical realm may also be that there are a limited number of ways of considering experiences that do not fit recognized cultural scripts (Miller 2005).

Sandelowski (1990) notes that a central theme in making sense of infertility is that of volition or blame- that women are somehow responsible for their own trouble conceiving or that they somehow inadvertently or unconsciously chose to be infertile due to life choices that they made. The characterization of infertility as a disease, 
Sandelowski (1990) suggests, has not removed the burden of volition from infertile women. In her historical analysis of concepts of volition and infertility, Sandelowski $(1990,492)$ notes: "Virtually no behavior of the infertile woman was free of clinical suspicion." Delayed childbearing, previous use of contraception and "sterilization regret" affirm the role of volition for involuntary childlessness (Sandelowski 1990b). Delayed childbearing is seen as particularly sinister as anything that defers motherhood becomes transformed into a cause of infertility (Michie and Cahn 1997, 150). Michie and Cahn (1997, 145-148) suggest that the concept of women's culpability for her own infertility leaves her feeling like it is also her responsibility to solve it and encourages medical solutions. Rapp $(2006,420)$ notes that medical interpretations exist alongside alternative and theological interpretations. “... fertility doctors, social workers, and secretaries are wearing antiseptic scrubs, but we continually rediscover the importance of Jesus, Yaweh, Buddha, and other existential tools for making meaning in their offices." This is also evident in the stories from the writers in the Story Gallery.

\section{From the Story Gallery}

Stories from the TTC Story Gallery addressed many of the significant issues discussed above with regards to making sense of conception difficulties. Interpretations, particularly medicalized ones, reflected dominant ideals associated with pronatalism and other socially dominant values. Nonetheless, the stories also revealed great diversity in interpreting and finding meaning in the experience of conception difficulties. They also did not use one model of interpretation to the exclusion of others. The stories show the ways in which women made use of the medical model to interpret and seek solutions for 
their conception difficulties and also the ways that they navigated the medical system to serve their own interests. Additionally, questions about science and nature were also raised as the availability of reproductive technology meant that individuals had to decide how far from the ideal of "nature" they were willing to stray. Concepts of volition and culpability were also important as women revisited past decisions to determine how or if they impacted upon their current predicament. Finally, faith and God were also important for many women as they struggled to make sense and find meaning. Some women were left unable to make sense at all.

The most relevant finding perhaps, was what was not said. While the stories revealed diverse ways that women struggled to interpret and resolve conception difficulties, the questions they sought to answer (Why me? How can I solve this? Do I deserve this? How can I find comfort? What caused this?) did not really challenge the foundation of the dominant social constructs that made the experience so painful. They did not ask questions about finding meaning and purpose in alternate roles and they rarely questioned whether a biological child, or any child, was really "worth it." A baby was almost always worth it and motherhood remained the most important and rewarding role. For the most part, they did not question the seemingly natural ideals associated with pronatalism or the interpretive model of medicine, even when conception difficulties forced them to confront them. Meaning making took place within the constraints of dominant, socially constructed middle-class values and did not significantly shake up their hold. Interpretations showed reverence for Science, Medicine, God, and Justice. While Science, Medicine, God and Justice were scrutinized to some degree, the value of raising children and the importance of the motherhood role were largely left unexplored. 


\section{The Medical Maze: Accepting, Interpreting, Challenging and Navigating Experiences within the Medical Model}

The medical model was so much the model used for making sense of conception struggles that it was rarely considered as an interpretive framework for making meaning by the women themselves. It was largely taken for granted that conception difficulties are experienced as a medical problem with medical solutions. This may certainly indicate that medicine and medical authority have a significant jurisdiction over defining the experience of involuntary childlessness and the associated sense of deviance. Medicine, then, plays a role in reinforcing social norms by offering an opportunity for childless, middle-class couples to have their "own" biological children (Becker and Nachtigall 1994; Greil 2002). A number of women did indeed express that medical solutions are "worth it" because children are the ultimate prize, thus demonstrating the relationship between pronatalism and medicalization (Becker and Nachtigall 1994). Responses also show, nonetheless, that women exert a significant amount of control and autonomy within the medical framework and within the medical encounter. Similarly, the responses from a number of women express acceptance of medical authority and comfort in seeking medical solutions and placing themselves within medical care. Seeing a doctor after continued non-conception was seen as "taking action" and offered a sense of "doing something" and gaining control. This was also noted by Greil (2002) and suggests that critics of medicalization who have focused on the hierarchical power imbalance within the medical encounter (Corea 1985b; Davis-Floyd and Sargent 1997) may have overstated this. It may also show the ways in which the interplay between middle-class women and professionals creates and maintains dominant social ideals about worthy parents (Oakley 1993; Riessman 1994). 
Although findings suggest that the participants were active themselves in locating the experience in the medical sphere and that this was their preferred paradigm, I have also included extracts from stories which show that women experienced a number of uncomfortable side effects from treatments and that treatments frequently escalated to become increasingly invasive in a short amount of time. This does not necessarily indicate that women are passive or pressured into seeking medical care or accepting medical solutions to their own detriment or solely to fulfill patriarchal, pronatalist, societal expectations. Responses also reveal, similar to Greil's (2002) findings, that women do not accept medical authority uncritically, that they often see themselves as partners with their physicians, that they become "experts" in their conditions and push for their preferred agendas. When they perceive that physicians are not sufficiently aggressive, competent or sympathetic, they frequently switch doctors or seek second opinions. In these ways they navigate the medical maze in a way that serves their own particular interests and agenda. Likewise, they do not accept medical interpretations and solutions exclusively. A number of women combined their use and acceptance of western medicine with alternative healing systems or chose to use alternative healing before or after using western medicine.

\section{It's worth it!}

Extracts from the stories below show that women pursue medical treatment because a baby is seen as the ultimate reward. No sacrifice of time, money or discomfort is seen to be too great for this most valuable pursuit. While this may be interpreted as pronatalism at play and illustrates the relationship between pronatalism and medicalization (Becker and Nachtigall 1992; Becker and Nachtigall 1994; Greil 2002), it 
also helps one to understand why many women choose medical solutions, why they make sense for some women in this context, and why they are willing to undergo invasive tests and treatments in their pursuit.

Never, ever give up hope! There are ways to go about achieving your dreams, no matter what your circumstances! (story131358590745; United States; Age: 31; Months TTC: 4)

So I say don't give up because there is always hope that one way or another you will get to hold your very own precious child in your loving arms and look into their eyes as they smile up at you with all the hope in the world for the future. (story73296122050; United States; Age: 28; Months TTC: 38 )

I hope everyone knows how worth it is never to give up on having your own baby and experiencing pregnancy. Never give up, whether it takes medical assistance, egg donation, whatever. I highly recommend it! (story742144173432; United States; Age: 34; Months TTC: 34)

After [IVF] transfer, we behaved as though I was pregnant - we would talk to the embryo and say things like "do what you need to do little one, we love you"... We found out a day earlier than expected that I was pregnant - it was so emotional - all the pain and discomfort was worth it...I would say to anyone who is afraid of IVF, go for it, it is an emotional roller coaster but is worth it in the end! (story401759697101; Australia; Age: 28; Months TTC: 16)

Every day I took my Metformin, my aspirin, my vitamins and minerals and suffered the horrible side effects; but somehow I knew that it would work and it would be worth it. (story19623271530; United Kingdom Age: 31 Months TTC: 49)

\section{Accepting Medical Authority and finding Comfort with Medical Model}

Citations from the stories below reveal a strong acceptance of the medical model as the appropriate response to conception difficulties. Many women writing in the gallery expressed positive experiences with medical encounters and physicians and found great comfort in relinquishing their problem to the realm science, medicine and technology. They "believed" in medicine. In many cases, it 
felt like they were taking control and taking action to combat their problem. They particularly expressed positive feelings about physicians and medical experiences when they felt they were supported and understood and when medical practitioners were available and communicative. Seeking medical help is perceived as the "right thing to do" for (suitable) women experiencing conception difficulty and counteracts feelings of powerlessness and loss of control (Becker and Nachtigall 1992; Becker and Nachtigall 1994; Greil 2002). The responses below demonstrate the acceptance of the medical model among the respondents and also show the mutually reinforcing ideals of middle class women and their physicians (Oakley 1993; Riessman 1994; Davis-Floyd and Sargent 1997). The women cited below are "good patients" who "believe" in medicine and their doctors. The doctors are presented as very sympathetic towards these potential "fit" mothers. I suspect that lesbian, poor, unmarried or very young or very old women might not report similarly, but they are not significantly represented in this sample. With the assumption that the writers exemplify the model of the "worthy" parent (they have constructed themselves this way, as illustrated in the previous chapters in relation to identity and marriage), the citations below demonstrate positive, respectful interactions and mutually reinforcing values among middle-class women patients and their doctors. This again points to the persistence of these ideals and values, even though alternative family styles have gained some acceptability in recent years.

When I had three consecutive miscarriages, my doc was fabulous... He was very caring emotionally and very aggressive with testing. He ran every kind of $b / w$ he could do, tested the tissue from both the 11/05 D\&E 
and the 3/06 D\&C... (story16462648414; United States; Age: 33;Months TTC: 16$)$

The [doctors] I met were amazingly kind and reassuring. My nickname for my [fertility specialist] is Dr. Nice. Now that I'm pregnant, I appreciate that even more. I had a little spotting last week and he encouraged me to come in for an ultrasound. We saw the baby's heartbeat and when I said I felt bad for bothering him, he assured me I could call any time and that he understood how normal it was to worry. (story231562469931; United States; Age: 28; Months TTC: 21)

My Dr. is a great guy, I trust that he does everything within reason to make me happy and give me "goals" to look forward to, within reason. (story602115950928; United States; Age: 35; Months TTC: 8)

The people at Stanford have been very competent and supportive. When I got pregnant, they were so thrilled and happy. They had a good sense of humor and genuinely seem to like what they do. The bedside manner is so important in this field. I think you should feel like your doctor is your coach and teacher -- really wants you to succeed. (story471773134699; United States; Age: 43; Months TTC: 24)

I am now grateful for the treatment and care we have received at the clinic, even though we have not yet had success with them. But I now know that our only chance of having a baby comes from these new techniques and I am thankful to live in a time and place where these options are open to us. (story36818748967; Ireland; Age: 34; Months TTC: 34$)$

We are simply amazed at the technology available for couples TTC. Our $\mathrm{OB}$ has been a constant source of comfort and encouragement... It's sort of like having your own cheering squad complete with loving counselors! ... The medical community that we are in contact with has been supportive and encouraging. It has made such a difference in our stress levels. (story911266305331; United States; Age: 37; Months TTC: 6)

\section{Seeking medical help as first step and taking action}

Unlike most medical conditions with outward symptoms and/or discomfort, conception problems are determined by a non-event, the absence of conception (Becker and Nachtigall 1992). Most women suspected a problem after a certain amount of time had passed with continued unwanted non-conception. 
For some women this was a few years. For others this was just a few months, but in most cases, the physician's office was perceived as the appropriate first step to solve conception difficulties when a problem was suspected. Locating the "problem" as a failing of the body (Corbin and Strauss 1987; Corbin 2003; Clarke, Martin-Matthews et al. 2006) set the stage for seeking to resolve the problem in the medical sphere, the first place to go to repair the broken bodymachine (Greil 2002; Nettleton 2006, 2) and the place to find hope for resolution (Becker and Nachtigall 1992; Becker and Nachtigall 1994). These responses again show the link between pronatalism and medicalization of conception difficulties and also demonstrate the middle-class value of seeking to solve a problem with all available resources (Edwards 2005). Seeking medical help is responsible and appropriate for middle-class women. Women writing in the Story Gallery expressed this in the following ways:

After a year of trying, and very few cycles I knew I needed some help, so I went to see my regular OB. (story701224552694; United States; Age: 28; Months TTC: 52 )

I had been TTC for 11 cycles when I experienced yet another chemical pregnancy [a positive pregnancy test quickly followed by menstruation]. I was feeling really upset by this stage and begged my doctor to do something. She referred me to a fertility specialist. (story252017252021; New Zealand; Age: 32; Months TTC: 18)

When 2 years had passed after stopping the pill, I started to get worried, what was up? So I made an appointment with my doctor. (story291881172988; Luxembourg; Age: 35; Months TTC: 47)

I have seen my OB/GYN but that was about 6 months into trying and she advised me to keep trying another 6 to 8 months. Well it's about 6 more months later and still nothing. We are giving it another two months and if no luck we are seeing a specialist at the beginning of the year. (story171227918071; United States; Age: 27; Months TTC: 12) 
We started out trying with the thoughts of "whatever happens happens" method. We did that for about 8 months and after two months of spotting mid cycle, I decided it was time to talk with my dr. (story181995168476; United States; Age: 27; Months TTC: 21)

I went off birth control pills and we "tried." Four months later I decided to see my ob/gyn.... (story231562470330; United States; Age: 29; Months TTC: 28 )

After three months of charting, I could see something was wrong with my cycle. I'm not the "relax and wait and see" type, I just wanted to get pregnant as soon as possible, so I made an appointment with my OB/Gyn and felt good that I was taking action. (story33661315371; Australia; Age: 38; Months TTC: 5)

\section{Side effects and discomfort from drugs and treatments}

While the women writing stories privileged medical interpretations and sought medical help, the stories in the gallery often indicated not only the emotional suffering from continued conception difficulties but also the suffering and discomfort caused by treatments. I have included extracts from women talking about the side-effects of hormonal drugs, particularly clomiphene citrate, (Clomid) to indicate how uncomfortable some medical treatments can be, even though people gained comfort and hope from seeking them. These are the kinds of responses that might make a critic of medicalization question why a woman would willingly subject herself to this kind of discomfort and suggest that coercion is at play (Klein 1989a). They are included here to show that women do indeed mind the discomfort and this can be a reason to reject continued treatment or seek alternate treatment or begin the process of weighing whether or not it is still "worth it". The last extract is from a woman who decided the treatments, along with the difficult emotional aspects made the experience too difficult to 
pursue further. The possible payoff of a take-home, biological baby, in her case,

did not warrant the stress and discomfort of continued treatments.

The side effects of the drugs also had an effect - clomid in particular gave me incredible mood swings, and I became depressed, angry and sometimes violent, throwing things across the room on occasion. Normally I am very placid! I also had headaches, migraines for the first time, and hot flushes, waking up having soaked the bed in sweat. (story532099601993; United Kingdom; Age: 34; Months TTC: 26)

It was hard knowing that the first cycle was unsuccessful because the side effects [of Clomid] were very hard on me emotionally and physically. Hot flashes, blurred vision, mood swings, headaches and many other things were daily occurrences and hard to stomach. (story99988039578; United States; Age: 24; Months TTC: 22)

The side effects of the Clomid are not fun, and they just add to the stress of TTC. (story121687063787; United States; Age: 25; Months TTC: 16)

My cycles were always long to begin with, but they just seemed to be getting longer and longer and it was frustrating. So my doctor decided to start me on 50mg of Clomid to see if that helped. The side effects of Clomid are really nasty and annoying. And at the end of that cycle, all for nothing. My progesterone level pre-Clomid was 0.7 and on my first cycle it was still 0.7. So frustrating. (story701224552506; United States; Age: 28; Months TTC: 41)

Clomid was an emotional nightmare for me but I know people who have taken it with no side effects at all. I reacted much better to the injectible Follistim. (story77164215533; United States; Age: 35; Months TTC: 12)

I've taken four cycles of Provera with all the attendant mood swings. (story3296567111; United States; Age: 22; Months TTC: 21)

I was then diagnosed with polymenorrehea, and given three months of Provera. It made me have horrible mood swings but I was able to achieve a regular cycle that I have maintained for a few months. (story09444455350; United States; Age: 22; Months TTC: 12)

In 2002 my doctor diagnosed me with PCOS and I then had a bi lateral wedge resection of my ovaries then went on Clomid but got off because my parents had to move in with me and the mood swings from the medicine was always causing my mom and me to fight. In 2004 we decided to adopt because ttc is just too emotional. (story59272081182; United States; Age: 29; Months TTC: 9) 


\section{Escalating tests and treatments}

Below I have included a few extracts from the Story Gallery which show how treatments can escalate to become increasingly invasive rather quickly once medical attention has been sought. Again, these are included here to demonstrate how quickly the experience can come to be subsumed within the medical domain and how far-reaching it can be. Women indeed appear to be willing to endure a great deal of intervention to satisfy their desire for a biological child. Again, the link between pronatalism and medicalization is clear and the discomfort of women engaged in treatments is evident, suggesting again that socially constructed values mean that "it's worth it!" Nevertheless, nothing in the responses indicates that the women were explicitly pressured to pursue a medical agenda against their own will or better judgment. Again, the mutually reinforcing values of middle-class women and their physicians demonstrate that medical treatments are constructed as appropriate for "worthy" women, such as those writing in the gallery.

I really appreciate my RE - she's a wonderful doctor and I feel that I couldn't have better care anywhere else. I have undergone countless lab tests and ultrasounds. I've had an HSG. My husband had a semen analysis. I underwent laparoscopic surgery to remove a persistent ovarian cyst, and it was then discovered that I had stage III endometriosis, which was treated at that time. After my failed IUI, I underwent an endometrial biopsy. I'm not sure there's a whole lot left for them to do to me. (story261708421153; United States; Age: 28; Months TTC: 20)

After 6 months TTC without success, we met with my OB again and began the tests. At this time I was 39. I had an HSG which was normal, I did the CCT (Clomid Challenge Test) to check my ovarian reserve and it was good for any age, excellent for mine. DH had a SA, which indicated some morphology issues, but not too severe. We moved to an RE after the initial barrage of tests and did a PCT (post coital test) which indicated that I had poor CM and all the sperm was dead. We tried an unmedicated IUI 
which failed. We then tried Clomid and timed IUI which also failed. The third cycle, we tried injectibles which failed. We tried again a fourth cycle which failed. My insurance was changed and we lost fertility insurance so tried on our own for a year with no success. Insurance was changed again, this time with an insurance cap of $10 \mathrm{~K}$ for fertility treatments. We made a decision to try IVF one time as our last and final shot TTC... (story271416980512; United States; Age: 41; Months TTC: 40)

I have been TTC for 9 years now. After one ectopic, one miscarriage, 9 laps, 2 IVF's, and 2 reconstruction tubal surgeries, I feel I have done just about everything possible to have a child of my own. (story351126333063; United States; Age: 35; Months TTC: 108)

Our RE (fertility specialist) immediately told me to start charting (totally new to me) and ordered CD 3 and 21 blood work. All were normal, my cycles were like clockwork and my levels were all normal. I had ovulated every month, no problem. So, after that he said he wanted me to go for an HSG. The HSG was a piece of cake and my tubes were clear. Sooo, after that he wanted me to go for a laparoscopy (Feb/05). Well, he found some fibroid tumors, two of which he removed (the larger ones). He also found some scarring of my left tube and did what he called "lysis of adhesions". He cut the scarred part off. He told me I shouldn't have any problems after that, I was excited! Fast forward to November/05, still not pregnant so he wanted me to go on Clomid just to give my eggs a little boost. Three cycles of Clomid and no BFP. Fast forward to Sept/06. I had my second HSG which was very very painful. I almost started to cry because of the pain I was in. The RE said that my right tube was clear, but the left was dilated and blocked (this is the tube that had the lysis). A hydrosalpinx. I was crushed! My next step now is another lap. My RE wants to try to repair the tube... In the meantime, I am on another 3 rounds of Clomid. (story101215069197; Canada; Age: 30; Months TTC: 42)

Although the above citations show that fertility treatments can be invasive and uncomfortable, responses from the Story Gallery also show that women actively navigate the medical world in ways that serve them.

Physician as partner

Above I have shown how women trying to conceive often choose medical solutions because they offer hope of overcoming their conception difficulties and the associated disruption to their life course, relationships and identities. They, as 
"fit" women who anticipate and deserve motherhood are encouraged and expect to use this technology. The ultimate reward of a baby to bring home is so great that it justifies all kinds of invasive procedures and uncomfortable side-effects and their associated risks. The physician's office is the logical "go-to spot" when seeking the cause and solution to conception struggles and seeking medical help offers a sense of comfort and control. These findings support the conceptualization of involuntary childlessness, a deviant status that was previously defined as a social problem, as a medical problem, now firmly within the medical sphere (Becker and Nachtigall 1992; Greil 2002; Sandelowski and de Lacey 2002).

As discussed earlier, there has been much critique of medicalization as it has been suggested that it is an instrument of social control. Comments about the social value (it's worth it!) of children as well as evidence that the medical model has almost completely usurped jurisdiction over definitions of the experience of involuntary childlessness for middle class women, along with comments from women about the invasiveness and the negative impact of treatments would appear, on the face of it, to support the position of medicalization critics. Responses from the women writing in the TTC Story Gallery, however, show that women actively navigate the medical system in a way that serves their own interests, that they are not powerless, and that they see themselves and expect to be seen by their physicians as partners in their own medical care. Greil (2002, 103) suggests that critiques of medicalization

...share a common flaw in that they treat women's responses as an epiphenomenon of medical definitions. [They]... give primacy of place to 
medical constructions of reality; women's options seem limited to either acquiescing to medical metaphors and interpretations or resisting them. Neither analysis makes enough room for women's creativity and agency in working within the medical framework to achieve their own ends. Missing ...is the response most striking among the middle class women that are the focus of this study: working the system.

This characterization is also apt for the participants in this study. They did not resist dominant social constructs. Indeed, these constructs were very much reflected in their stories and their experiences were shaped by them. Nonetheless, they certainly could not be described as "dupes" (Sandelowski and de Lacey 2002). Extracts below show how women position themselves as partners with their doctors and take an active role in managing their medical care. Again, this may only be relevant for middle-class women who are able to position themselves in this way and are accepted by their physicians as partners with shared values.

After my continued research and reading, I asked my doctor about Femara, and he told me of successes he'd had with older, ovulatory patients of his who had not conceived on Clomid but had success with Femara. He agreed to prescribe it. I'm currently in the middle of my first Femara cycle, with plans to do trigger and IUI. (story811096799041; United States; Age: 40; Months TTC: 10)

Because of my age, I waited the full year before seeing a doctor. When I went for annual exam that year, I talked to her about how long we had been TTC. I took her my charts and showed her that ovulation appeared to be a problem. She set me up with a referral to a large military hospital four and a half hours away. It was one of the few military bases that had a reproductive endocrinology program. I was very lucky and only had to wait a month for my first appointment. (story831557536387; United States; Age: 28; Months TTC: 37)

My RE noted my anxiousness and I was very pleased when he didn't just blow me off. He did note that a woman with my predictable cycles, age and ease in TTC prior to this point might have a true, new issue and he offered to test me with routine blood work and advised an HSG. The bloodwork revealed slightly low progesterone, but great estrogen, TSH and FSH results. In all I tested FSH 3 times over the course of 6 months and it was about 6.2-7 during that time consistently. The HSG was clear, 
even revealing great ovaries and a well shaped uterus the RE said. I seemed to be ovulating but not always with the punch he might like to see. I felt from the way he treated me in the process, as a partner in my own fertility, open to my hunger for knowledge and answers, that he was the right doctor if choose to go further. (story77164215552; United States; Age: 35; Months TTC: 13)

...He agreed that it looked like I had a short luteal phase and possibly low progesterone. (story33661315371; Australia; Age: 38; Months TTC: 5)

\section{The expert patient, taking charge}

Likewise, women became experts in their own conditions through their own research and networks and so did not need to rely on the authority of their physicians to fully interpret (or fail to interpret) medical knowledge. They also expressed the position that they (and others) should become educated, advocate for themselves, and generally take charge of their own experiences.

I think that the most important thing to me about TTC was learning so much about fertility. I never really read a lot on it until I started TTC my 3rd child. It was empowering to know so much about my body and my cycle and to be able to talk to the Dr's armed with knowledge about the process and about my particular cycles. (story76469800667; United States; Age: 31; Months TTC: 8)

...When I go to see my doctor I already know most of the answers to the questions I ask him. I ask him anyway just to be sure the information I have read is correct. So far it has been. (story471773134775; United States; Age: 31; Months TTC: 40)

Keep your chin up and keep pushing forward! ... You know what you are doing! Don't be afraid to question your doctor, or to show him research you've done. Change doctors if he refuses to listen to you. (story681834256531; United States; Age: 25; Months TTC: 8)

You have to be your own advocate. Push the docs for answers, ask them to explain every test and procedure if you don't understand. (story24188365246; United States; Age: 32; Months TTC: 60) 


\section{Maintaining a critical position}

A number of women who were engaged with the medical profession also indicated that they maintained a critical position with regards to medical authority. They expressed concern about side effects of drugs and treatments, criticism about the authority of medical interpretations and the importance of making their own conclusions and they were not afraid to question medical authority. This may again be an attribute of the sample as these were women who were actively managing their experience via fertility charting and internet use.

I finally met with my doctor about my long cycles and she suggested I start Clomid, but I was very worried about using drugs and how they would affect me physically and emotionally. (story84183990276; United States; Age: 33; Months TTC: 7)

What was critical for us was that we did not just swallow what our local fertility clinic told us; they pretty much wrote us off and were not at all supportive. We did our own research and drew our own conclusions and we were RIGHT - with the proper medical assistance, we absolutely could get pregnant with his sperm and my eggs! (story891888747379; United States; Age: 35; Months TTC: 24)

My new knowledge and charting also gives me a unique perspective on the medical establishment. While we were in emergency room the doctor asked me how far along I was. I told him how far along the pregnancy was and how old the fetus was. He was shocked that I could be so precise, even though I had already indicated that I had consulted with my doctor for fertility issues. After the ultrasound, he argued with me about how far along I was because, as far as he was concerned, the ultrasound showed the exact age. I did not know embryos were date/time stamped, nor that you could see the stamp with an U/S. (story111989311439; United States; Age: 34 ; Months TTC: 10)

\section{Switching doctors and seeking second opinions}

The most common method of maintaining control within the medical model was by switching doctors. Women switched doctors when they perceived 
their physician was not competent, respectful, sympathetic or sufficiently

aggressive in searching for solutions.

After 3 more months of trying and still no BFP, I called my doctor to ask what to do next. I was told, "Well you are ovulating so just keep trying." That was my signal to switch doctors. (story852023096631; United States; Age: 35 ; Months TTC: 48)

I was referred to my second doctor, who took me off of the Clomid in May of this year, advising me to keep taking the progesterone. I found myself dissatisfied with his service, as he told me common sense things such as have sex while you are ovulating, use OPKs, and lay still for afterwards for two hours (I'd only been laying still for 30 minutes after, with a pillow propped up under my hips). He ran no fertility testing in the three appointments that I saw him, and expressed his disbelief that we weren't pregnant yet with all his advice. We'd been using OPKs, timing BD sufficiently, using the progesterone after $\mathrm{O}$ was confirmed for well over a year by that time. I switched doctors... I went to a new doctor, who immediately (when I say that, I mean that day) ordered an FSH/Estradiol test... (story311271565868; United States; Age: 31; Months TTC: 19)

I saw 2 different care providers who both ran several blood tests. I really didn't know what questions to ask or what the results should have been and my doctors never really discussed them with me. That should have been my first clue I should be seeing someone else. (story701224552694; United States; Age: 28; Months TTC: 52)

I started telling myself that it's okay, it's totally normal to go even a YEAR w/o a successful pregnancy or BFP. Then the year came and went. But my OB/GYN didn't really seem too concerned so I wasn't concerned. Then another year came and went and when the doctor still wasn't too concerned but got a SA for DH I started feeling like this isn't right, they should be doing more. So I found someone else and he confirmed what I was thinking, they should have been doing more much sooner! (story701224552506; United States; Age: 28; Months TTC: 41)

I had been seeing a doctor who wasn't doing much for me at all, so I left her to go and see my current doctor. He immediately ran all sorts of blood tests and did an ultrasound on me and diagnosed me with Polycystic Ovarian Syndrome. (story72608905602; United States; Age: 27; Months TTC: 7)

My dr was dumb....kinda brushed me off... Literally talked with me for 5 minutes....left feeling worse than when I came in. Decided it was time to 
get a new dr. (story181995168476; United States; Age: 27; Months TTC:

21)

\section{Pushing for more aggressive agenda}

Similarly, women expressed a desire for more aggressive testing and treatments and often expressed dissatisfaction when their physicians were perceived to be not sufficiently aggressive. At times they also "insisted" on more aggressive testing or demanded particular treatments. Again, this reveals the ways in which women themselves orchestrated their own care and their own experiences within the medical domain. This also shows that medicalization is not necessarily heavy-handed and imposed by medical practitioners. Women themselves play a role in medicalization and the values associated with medicine and science have so much permeated individuals that they expect medical solutions.

...Since then I have had to push my GP to even talk about my fertility (for some reason sticking very rigidly to the 18 month rule that applies in the UK). However, I recently saw a lovely Health Care Assistant at the surgery and she has helped enormously and is referring me to a Consultant Gynecologist, which gives me great hope. (story891888747025; United Kingdom; Age: 22; Months TTC: 11)

After 120 of my period with no rest I finally had enough and marched right into my doctors office and demanded that they find out what was wrong with me ... I finally convinced one doc to do surgery on me, and to not sew me back up until she found something wrong. (story581646153320; Canada; Age: 24; Months TTC: 17)

My OBGYN was reluctant to send me to an RE, because I was "so young" but we felt we had as much right to a family as anyone else... When we started talking to my OBGYN about treatment we WERE young, but we were definitely treated like we were just being impatient, though it had been a year (and we were YOUNG, for goodness sakes!). He did send my husband for a semen analysis, but that's it. He wasn't really willing to work much with us. I still feel this way--even after all the treatments and not being pregnant after over 2 years, he acted the same at my last annual, saying that we'd get pregnant in time and we should try relaxing (because, 
DUH, that's more effective than IVF). (story121687063945; United States; Age: 22; Months TTC: 26)

...I called the OB office where my midwife works and pretty much demanded a laparoscopy. (story392055460731; United States; Age: 31; Months TTC: 11)

\section{Alternative healing}

Several women also discussed their engagement with alternative healing models such as acupuncture, herbs, yoga, recipes and Chinese medicine. For some women this was seen as a "first step" prior to engaging with the medical community. For some it was used in conjunction with western medicine. For others still it was used after an expressed dissatisfaction with western medicine. These responses also demonstrate that allopathic medicine has not completely usurped alternative and traditional interpretations.

I charted and tried to time intercourse appropriately. The charts told me I was ovulating, but still after three cycles, no pregnancy. I started going to an acupuncturist and took Chinese herbs...After the miscarriage we waited one cycle and then tried for three more. I began doing acupuncture and Chinese herbs and, a month before my success, I started fertility yoga. (story461008664358; United States; Age: 38; Months TTC: 10)

I am a firm believer in alternative medicine. I am convinced that doing fertility yoga, acupuncture and following a traditional Chinese medicine diet for infertility as well as being happier and more present in the moment gave me more and better embryos for IVF \#2 compared with our first IVF. (story43842133710; United States; Age: 38; Months TTC: 54)

I take fish oil and flax seed oil to help bind my estrogen. I eat peppers and sometime tuna fish, also to bind estrogen. I try to buy meat that comes from a no estrogen source. (story59272080956; United States; Age: 37; Months TTC: 55)

I decided to take 6 months to try alternatives, such as herbs, diet, supplements and improve my fitness levels overall and also to increase our savings and then to consider assisted conception. (story261708421289; United Kingdom; Age: 42; Months TTC: 23) 
I ate baby carrots, drank grapefruit juice, used Robutussin...Decided to start acupuncture for fertility after not pregnant in 3 months of actively trying. (story911266305197; United States; Age: 38; Months TTC: 4)

I finally had enough of the weight gain from the hormones. I sought help from an acupuncturist and started taking Chinese herbs. Trying to regulate my cycles after stop taking all those hormones. My last cycle at the doctor's office was an unsuccessful IUI procedure. (story121687063834; United States; Age: 39; Months TTC: 7)

\section{Science versus nature and public versus private}

The availability of reproductive technology to treat conception difficulties raised some ethical, spiritual and moral issues for some women. By no means did all women accept the use of reproductive technology as something that was taken for granted or to be used without consideration for some of the deep, meaningful, ethical and existential issues raised by them. Several people debated about how much technological intervention they could accept to combat infertility and have a biological child. In many cases this was expressed in terms of the "natural" versus the "unnatural" with natural being perceived as the far more desirable option..$^{35}$ In some cases, people had to reconcile religious beliefs with their desire to have a biological child. Some had to adjust to feelings about science taking a role in (and bringing to the public sphere) what they perceived to be a very private activity.

With some of these issues in mind, some people decided to forgo technology altogether.

After the infertility doctor found my progesterone issue he issued Clomid. My greatest challenge was deciding whether to take Clomid or not. I wanted a baby so badly but yet I thought I had this issue for a reason and that this reason was because God wanted it this way but in my heart and

\footnotetext{
${ }^{35}$ Michie and Cahn (1997) note that the concept of "nature" cannot be used unproblematically as it is also socially constructed.
} 
mind I wanted a baby so I had to make that tough decision... I came to terms with the fact that taking Clomid is okay because we were given these brains and the knowledge to create such medication so why not take advantage of it. It's a way for me to accept how I was able to get pregnant. (story84183990631; United States; Age: 29; Months TTC: 12)

At first DH thought IUI was "fake" and didn't want to consider it. After 12 months with no success, we were ready to try anything.

(story98214780763; United States; Age: 31; Months TTC: 14)

My doctor offered fertility treatment to increase my chances to conceive, but my husband and I decided not to go that route and just try to conceive naturally. (story311271566335; United States; Age: 41; Months TTC: 2)

The stories above demonstrate a variety of ways that women writing in the TTC Story Gallery engaged with the medical model to make sense of, interpret and seek to solve their difficulty conceiving a biological child. While the medical model was perceived as the most logical and legitimate instrument to seek help and solutions, women did not accept its authority uncritically and worked within it in a variety of ways to achieve their own desired outcomes. A class dimension was also evident. It appeared that middle-class women have influence within the medical encounter and share values with their physicians. It is not clear if women from lower socio-economic groups would exert a similar influence.

\section{God, Faith, Fate and Religion}

There has been very little exploration of the role of faith and spirituality with regards to making sense of conception difficulties (Roudsari, Allan et al. 2007). Domar, Penzias et al's (2005) article examining the role of religion in relation to coping with infertility-related distress and Greil, Porter et al's (1989b) discussion of couples "theodicies of infertility" are notable exceptions. Domar and colleagues (2005) found that 
religion was instrumental in helping couples cope with infertility and that couples with a strong religious faith were significantly less likely to experience infertility-related distress. Greil, Porter et al (1989b), however, found that participants in their sample were unable to make religious sense out of their conception difficulties. Differences in findings may be an attribute of the different sample characteristics as Greil and colleagues' sample was not selected based on the strength of their religious beliefs (Greil, Porter et al. 1989b). Among women writing in the TTC Story Gallery, there was evidence of faith and spirituality based meaning-making and this did seem to offer comfort. For many participants, faith and feelings about God played an important role in making sense of their conception difficulties. This was expressed in the following ways: that their experience was "God's will" or part of "God's plan"; that it would happen in "God's time"; that their difficulty brought them closer to God or renewed their faith; and that their faith brought them comfort in their difficult time. Faith-based interpretations show that the medical model does not entirely dominate meaning-making for conception struggles. Making sense through a lens of faith did not necessarily mean that women did not also accept the medical model. A number of women talked about making sense of their experience with both faith and medicine. Additionally, offering a role to faith did not necessarily mean relinquishing one's own will. While interpretations that privilege medicine demonstrate social values such as efficacy, control and the power of science, faith-based interpretations demonstrate beliefs about justice and goodness. In medical interpretations, personal power is relinquished to Science while in faith based interpretations it is relinquished to God. In both interpretive models there is a belief that the deserving will be rewarded. 


\section{Prayer, Faith and God's Will/ God's Plan}

A number of women talked about how their faith or their relationship with God gave them comfort as they struggled with conception difficulties. They talked about gaining comfort through prayer, knowing that God had a plan for them or that their experience was the will of God.

I know that God has a plan for us, and that we don't know what it is yet, but I really hope that one day it includes babies. (story121687063787; United States; Age: 25; Months TTC: 16)

I pray everyday, that someday, GOD will allow me to have a child. (story861714566172; United States; Age: 24; Months TTC: 36 )

I don't know if my TTC journey will end in a baby for us or not. I pray that a healthy baby would be our happy ending. I guess only God knows that, and I am going to try to be a little more patient and wait a little longer. I can't believe that we were brought this far without us having the happy ending. (story571956681163; United States; Age: 44; Months TTC: 17)

My DH and I have been married over 6 years, and we love the Lord our God with all our hearts. He is the only reason I can sit here today still without a child, and tell you my story...He immediately found out what was wrong and wanted to move forward, the only problem was God would not give me permission to move forward. I prayed and prayed about it... I was all for doing whatever it took... but God had a diff. plan. He had things he wanted to do in my heart first. And a little over 4 years later he finally gave me a peace about moving one step ahead. So here I am. Waiting on God's leading to show me what is next... (story401759697396; United States; Age: 27; Months TTC: 56)

The biggest thing that helped me was relaxing. I had to give it to God or I would start to go crazy. I had in the back of my mind that I would never have a child, but that I was going to continue to try just in case. (story171227918311; United States; Age: 26; Months TTC: 48)

I just wish that God would be nice to me and give me a bundle of joy, he gave me my fantastic husband, is asking for a family too much? (story77164215748; United Kingdom; Age: 20; Months TTC: 7)

I love my children and I am a firm believer that God has a plan for my life. That being said, I also believe that God has put the desire in my heart to 
have another baby. If another baby was not meant to be then he would take the desire from me. I pray daily about this. (story221857631050; United States; Age: 34; Months TTC: 5)

I think for now I need to breathe and trust God to work it out. (story4989789733; United States; Age: 29; Months TTC: 1)

\section{In God's Time}

Likewise, a number of women felt that they would be "blessed" in "God's time". This often gave them comfort as they struggled while waiting a long time to conceive.

I have come with a new realization that though I can do all the temperature testing, predict the days I am ovulating...it really is up to the man upstairs. It is his will when I will have a child and I hope and pray that he graces me with one soon. I have learned a valuable lesson in this whole thing, which is patience. (story401759697200; United States; Age: 24; Months TTC: 2 )

I keep telling myself that it will happen in God's perfect timing. Just hard for my heart to listen to it. (story471773134699; United States; Age: 32; Months TTC: 6 )

I have come to expect that God is going to give me a baby when the time is right. (story481468590133; United States; Age: 23; Months TTC: 8)

Very frustrating months going by with not even a little positive. We had a lot of people praying for us, but we are firmly in the belief that it's not OUR time, but GOD'S time. Although I didn't expect it to take this long... (story231562470375; United States; Age: 36; Months TTC: 7)

My advice to anyone TTC their first baby is to take one month at a time. We had recently purchased a new home and the second month we were in it is when we got our BFP. God really does know what's best and will bring a baby to you when the time is right. (story72608905385; United States; Age: 28; Months TTC: 7)

\section{Comfort from Faith}

Faith and prayer also provided a great deal of comfort and strength to some women. Some women commented that their faith was renewed or reinforced 
by their difficulty conceiving as they sought answers and support in the spiritual

realm. Faith also helped people maintain a positive and hopeful attitude.

I still remain hopeful that someday, somehow, we will have our little family. God is still good...and He still desires to bless us. (story79629564731; United States; Age: 36; Months TTC: 15)

My DH and I are Christians, so God has a HUGE role in our TTC process and we look to Him for our ultimate comfort and guidance. We want His will in our lives, and know that He holds our tomorrows. (story64901501303; United States; Age: 21; Months TTC: 4)

This journey has reinforced my faith in God, He is always looking out for us. (story041968078196; United States; Age: 30; Months TTC: 36)

We both just trust God completely on this...I believe God is big enough to protect us and to tell us clearly if this isn't what he wants and so far he hasn't. I just have peace and trust in Him. (story401759697396; United States; Age: 27; Months TTC: 56)

But I had wonderful people around me, especially my mum, and my husband who had more faith than me. Slowly I started praying with faith, that it will happen as God wants it for me and nothing on earth will stop it, and I just need to put my mind at rest. In order to do this I started going to this old chapel near work and started telling the promises of God and positive things to myself, which helped me relax emotionally. (story831557536609; Australia; Age: 30; Months TTC: 15)

\section{Punishment from God}

The concept of "barrenness" as punishment from God, Old Testament style, was surprisingly absent from the stories, even though God and faith were important for many people as they struggled to make sense of their experiences. There was just one comment that reflected this position, and even then, it was qualified as turning out for the best in the end.

I'm a very religious person so when it took 6 months to conceive my second child it felt like God was punishing me or that I wasn't a good enough mom to my first child so he didn't want me to have another one. But, I realize now that it was almost a gift that I didn't get pregnant until 
now. My pregnancies are terrible and I'm pretty much bedridden for 6 of the 9 months. I got to focus on my relationship with my husband and sweet toddler son, go on some amazing vacations and I was even in a play! (story532099602274; United States; Age: 23; Months TTC: 6)

\section{Faith and medicine sharing the stage}

Faith-based and medical interpretations were not at all mutually exclusive. Many women who talked about their faith and religious/spiritual beliefs also talked about their medical experiences. Several women who talked about their medical experiences also talked about prayer and miracles. A few women expressed how they combined medical and spiritual interpretations.

Some people in my family were not so supportive about the surgery. My grandma told me if God wanted me to have another child I would have one and I should just pray. I tried that, it didn't work. I just feel like if your ship doesn't come in sometimes you have to swim out to meet it. I swam, it is in God's hands now. I just hope I swam to right ship! (story471773134775; United States; Age: 31; Months TTC: 40)

But thus far, a healthy baby is inside me and we are humbled and excited and amazed. My RE said that I could make up the story, he could provide the stage, but only God could bring on the actor(s). Fun way to look at it... (story77164215552; United States; Age: 35; Months TTC: 13)

The second RE specializes in laparoscopic surgeries so he said he could take my fibroids through small incisions in the abdomen, so I had the surgery scheduled for 1/06; however, I have prayed a lot for a miracle, and I asked God that if I would get pregnant this month I would take it as a sign that he would grant me the miracle of a healthy pregnancy and child because I was not going to try anymore until after my surgery, and I didn't want to loose anymore babies. So I hope, and continue to pray for the final and true miracle, a healthy baby nine months from now and ever. (story66286129658; United States; Age: 37; Months TTC: 48)

Faith was important to a number of women writing in the Story Gallery, but discussions about God, faith and spirituality were not nearly as common as discussions about medical treatments and solutions. Unlike, medical 
interpretations, spiritual interpretations were largely consciously discussed as a way to find meaning and comfort in the experience. They were not seen as "given" in the same way. Nonetheless, they demonstrate the resistance of age-old ways of interpreting an age-old problem and the ways in which a variety of interpretations can co-exist.

\section{Culpability, Regret and Volition}

Culpability, regret and volition, also discussed by Sandelowski, Holditchdavis et al. (1990), and Monach $(1993,40-41)$ were also common themes in the Story Gallery as women sought to find meaning in their struggle to conceive. Where medical interpretations find a cause for infertility in a failing of the body, and faith-based interpretations are mysterious, interpretations that focus on culpability and regret show conception difficulties to be a consequence of an individual failing or past behavior or decision (Sandelowski, Holditchdavis et al. 1990). In this vein, women sometimes felt guilty, experienced regret or suggested they were being punished for previous indiscretions or previous decisions, particularly reproductive decisions. Repeatedly, women talked about regret about their reproductive past and previous reproductive choices, such as having abortions, taking birth control pills, having sterilization procedures and delaying childbearing. The difficulty for some women was coming to terms with past decisions when viewed through current difficulties that could never have been predicted. The perception that they might somehow be "undeserving" of children due to past behaviors or decisions also underscores the impact of dominant ideologies about worthy and unworthy parents. Monach (1993, 40-41) suggests that this may be reinforced within medical encounters: 
Infertile people are encouraged to review their histories in the sort of detail which makes it likely that they will find something about which to feel guilty. Those without a fertility problem could have identical histories but, without the pressures of fertility investigation, would not be made to feel guilty. Everyone, given the opportunity for such a review, would find something discreditable. The careful search for a cause which infertility investigation involves may lead to self-blame...

Additionally, interpretations of the disruption that focus on women's culpability may threaten women's autonomy and independence and reinforce values related to traditional gender roles. Women's activities that might otherwise be a source of empowerment are recast as "sterilizing". When conception difficulties are constructed as being the cause of something related to women's independence and autonomy, such as delayed childbearing (because she was meeting educational goals, attaining economic independence, and work satisfaction) or reproductive control, such as contraception or abortions (because she was deciding independently when to reproduce) or even premarital sex, this jeopardizes those gains. Interpretations from Story Gallery participants that focus on culpability, regret and volition are cited below. Revisiting decisions that seemed to offer women autonomy (contraception, abortion, delayed childbearing) and reinterpreting them in light of conception difficulties suggests, perhaps, that the independence gained by virtue of these decisions is rather tenuous.

\section{Punishment for previous indiscretions}

At times, women expressed the feeling that they were being punished because they had done something wrong to deserve infertility. In most cases this was expressed as punishment for "indiscretions" such as promiscuity, abortions, and expressing ambivalence about motherhood in the past. 
My DH and I were TTC for 11 months. I felt that I was being punished because I had previously had an abortion. (story281110581933; United States; Age: 26; Months TTC: 11)

It is a stressful situation. I spent many years of my life praying for AF to show and suddenly was wishing she wasn't. I know it only took me 2 cycles and other woman take much longer but I found myself wondering if I was being punished for past indiscretions. (story30493850185; United States; Age: 32; Months TTC: 2)

I started to believe all of my own stories about how my past medical history was my fault and about how the very idea of saying OUT LOUD that I didn't want kids was coming back to haunt me. (story20319571475; United States; Age: 32; Months TTC: 6)

\section{Revisiting previous reproductive decisions}

Not surprisingly, conception problems caused women to revisit prior reproductive decisions when looking to interpret their current experience of infertility. Women wondered if prior use of contraception, previous abortions, delayed childbearing or sterilizations that had now been reversed were the source of their problems. Looking back at prior decisions through the lens of their current difficulty often caused feelings of regret or culpability.

\section{Contraception}

Many women talked about hormonal contraception, such as birth control pills and Depo-Provera as being the potential source of current problems. They talked about how their cycles were irregular after discontinuing contraception or they simply worried that continued use of contraception might have caused a problem, or, they noted the irony of trying to avoid conception for so long, only to find out that conceiving was not so easy. This also highlights the perception that reproduction is something that can be controlled via science. 
I also had an awful experience on Depo-Provera a couple of years before TTC. I had horrible reactions, and I really hoped that it didn't prevent me from conceiving. I was on the pill after this for a couple of years, and stopped taking it about 9 months or so before we started TTC. (story701224552514; United States; Age: 23; Months TTC: 1)

I started the Depo Provera shot when I was 17 and it totally messed up my body. I was on it for a year and a half. I had no idea how badly it had hurt my fertility until TTC \#1! (story821856146168; United States; Age: 24;

Months TTC: 18 )

I am a little nervous about being on the pill for so many years. We made sure to prevent a pregnancy so hard now that we are trying I'm scared it's going to be really difficult! (story37514134299; United States; Age: 23; Months TTC: 0 )

My husband and I have been trying to conceive for the last 10 months and have found it a little frustrating. I was on the birth control pill for 16 years before we started trying and I truly feel that it messed up my cycles for quite some time. (story521322670107; Canada; Age: 35; Months TTC: 10)

It was only after coming off the pill that I read about the side effects of continued use and was quite upset that I was not advised of these when first starting, now I wonder whether having been on birth control for thirteen years is going to make conception impossible!

(story54707677135; New Zealand; Age: 27; Months TTC: 4)

\section{Sterilization Regret}

Women who had sterilizations or husbands who had sterilizations often talked about regretting this decision. They were very much aware that the sterilization, even when it had been surgically reversed, would likely impede an easy conception.

My husband and I had two wonderful children together. After getting a vasectomy, we regretted it almost immediately. For a few years, we tried to settle with that decision, but we just couldn't. So, we went back to the urologist and had a vasectomy reversal. Now we are praying for more children. (story911266305331; United States; Age: 37; Months TTC: 6)

I had my first child when I was 19. I didn't have any fertility issues with any of my three children. I got divorced after my third child was born and had a Tubal Ligation. More because of my youngest child's father 
pressuring me. I regretted that decision. I also knew that if I remarried, I would want to see about having a child with him. I remarried to a wonderfully loving man. He's awesome with children. We decided that we wanted a child together. I started looking into ways for us to have one. First was In vitro, which was very very expensive. The second was a Tubal Ligation Reversal. Seeing this was more affordable. Not by much though. (story471773134699; United States; Age: 32; Months TTC: 6)

I was devastated over the vasectomy and wanted another child. It was a few months before I told DH about my desire and conviction. To my surprise the Lord had been showing him the very same things. We both asked the Lord for forgiveness and began to pray that he would reverse our mistake and bless us with a child. After 1 year we began to discuss having a reversal. We found a local Dr. who now did only vasectomy reversals ... as a ministry. (story36818748955; United States; Age: 29; Months TTC: 6)

\section{Abortion Regret}

Women who had abortions earlier in their lives had the difficult experience of having to revisit this time of their lives as they struggled with making sense of current conception difficulties. Looking back at past abortions through the lens of infertility often filled them with regret or remorse.

I must add, when I was 20 , I had an abortion. The pregnancy was accidental. I am amazed at how differently I look at life, and regret what I did. When not even trying, I got pregnant. 15 years later, after months of trying, no luck. It's "funny" how and why things happen. (story602115950928; United States; Age: 35; Months TTC: 8)

When I was 19 I got pregnant by my boyfriend at the time, but decided to have an abortion. We were young and jobless. If I only knew the battle I would have later on in life... Who ever knew it would of come to this, who knew my TTC journey was going to be so hard. If I would of known what I know now I would of never had that abortion when I was younger. (story671049488917; United States; Age: 38; Months TTC: 156)

After the three miscarriages, my attitude began to change about TTC. I started looking at the psychological as well as the physiological reasons for failing to carry a baby to term. And, I realized that I was still carrying a lot of guilt from 3 prior terminations earlier in my life. Two at 21 and 22, and one@32. I was extremely fertile in my youth and pretty irresponsible 
in some ways, too. A bad combination. (story532099601925; United

States; Age: 43; Months TTC: 24)

\section{Delayed Childbearing}

When looking for reasons for their current difficulty, or when framing their experience, women in their thirties and forties talked about their delayed childbearing and factors in their lives which prevented them from trying to conceive sooner. In many cases, jobs and career aspirations or the absence of a suitable partner prevented women from trying sooner. Again, the interpretation changes when examined through the difficult disruption of conception difficulty. Waiting for a suitable spouse and establishing a career only became regrettable choices in the wake of conception problems. Previous valuable roles outside of motherhood did not appear to lessen the impact of conception difficulties. Rather, they were perceived as being partially responsible for them.

...the second miscarriage was much more difficult. The pain really hit me. It made me feel incompetent and OLD. I also felt a tremendous amount of regret for not trying to have children younger. I was very angry about my job and how it contributed to me not having kids earlier. I had a lot of trouble sleeping. I also was very disappointed in myself that I felt like this. (story09444455239; United States; Age: 36; Months TTC: 18)

I have a feeling it's age. I am 35. (story602115950928; United States; Age: 35 ; Months TTC: 8 )

Being 37 we did not have a lot of time... (story381284681573; United States; Age: 37; Months TTC: 6)

At the time, I was a university professor and had put all my energy into career, career, career... when suddenly we met and my clock started ticking and tocking. I was 41 when we began TTC in earnest. (story532099601925; United States; Age: 43; Months TTC: 24) 


\section{Secular Meaning-Making}

A number of women who did not talk about God or faith, spoke similarly to those who did, suggesting that they gained comfort from a sense that the world was a beneficent place where things worked out. This was expressed in terms like "everything happens for a reason" or "everything works out for the best" or "it will happen when the time is right". Many of these stories revealed a strong sense of optimism and hope. Some women, however, did not find any sense of meaning or explanation for their struggle and suggested that it was "just the way it was" or that there was "no reason" for their trouble or it was just "the hand they were dealt." Others commented that they were searching for reasons and answers, but could find none and suggested that they could find peace and comfort if they had answers. Even within secular responses, there appeared to be a widely held belief in the world as a just and ordered place where things ultimately work out for the best.

\section{Fate/Everything happens for a reason/for the best}

Suggestions that "everything happens for a reason" and "works out for the best" were not uncommon among women writing in the Story Gallery. Some of these responses were from people who had "happy endings" but others were from people who appeared to believe that with patience and optimism, life would work out for the best, even if they were unaware, in present time, what the best future would look like.

I was devastated after my ectopic, but if it would not have happened then I probably would not be the mother of two beautiful twins right now. (story06290852550; United States; Age: 36; Months TTC: 52)

The best advice I can give to anyone is to realize that things happen for a reason. I truly believe that it took us as long as it did to conceive because 
we were not ready for a baby before that. (story351126332936; Canada; Age: 32; Months TTC: 22)

I guess I want to share that everything does seem to happen for a reason and will happen at the right time in your life. It never feels that way while you are going through it, but in the end, it will all work out. (story041968078196; United States; Age: 30; Months TTC: 36)

Life has a plan we just don't know it yet and everything has a reason, when the time is right you'll figure out what the reason is to why everything is the way it is. (story581646153320; Canada; Age: 24; Months TTC: 17$)$

\section{When the time is right}

Similarly, a number of women suggested that conception would occur when the time was right and that if it had not happened yet, it was because the timing was wrong. Again, this reveals a tremendous sense of hope, patience and optimism.

It will happen when it's supposed to, not a day before or a day later. (story532099601925; United States; Age: 43; Months TTC: 24)

I'm learning to just be at peace with our current situation and let the rest take care of itself. Some days are harder than other days. I know it will all fall into place when it's supposed to, so for now I take a deep breath, relax and enjoy. (story291881172702; United States; Age: 30; Months TTC: 4)

I have learned that when it is the right time it will happen. There is a reason that it did not happen before... story911266305852; United States; Age: 37 ; Months TTC: 17)

I have great faith that we will conceive soon... when the time is right for a healthy baby to grow and be nurtured by my healthy body! (story631196712998; United States; Age: 28; Months TTC: 5)

\section{No reason/Hand we were dealt}

Some women, on the other hand, were less optimistic, perhaps due to being at different stages in the experience. They suggested that perhaps there was 
no reason for their difficulty, that it was just unfortunate they were dealt a bad

hand.

I hope that sometime in the near future I'll get my wish, but I'm trying to face that fact that it may never happen. Medical technology can only do so much. (story261708421153; United States; Age: 28; Months TTC: 20)

I realize now that my difficulties conceiving is not some curse sent to me by someone or something, it's just what I've been handed. It's no one's fault- not even mine. (story56111715299; United States; Age: 28; Months TTC: 12 )

\section{Searching for Answers}

A number of women, particularly those with "unexplained infertility" (where a medical cause cannot be determined) expressed a feeling of dissatisfaction with having no explanation or reason for their conception difficulties. They talked about wondering what was wrong with them, wanting answers and suggesting that they could find some peace and comfort if they had some answers.

I don't think anyone realizes the emotions every month of trying to conceive. You wonder what is wrong with you. (story571956681163; United States; Age: 44; Months TTC: 17)

Sometimes, I wonder, however, if it would be easier if I had some explanation for why it takes me so long... (story602115950928; United States; Age: 35; Months TTC: 8)

Unfortunately, my "whys" have never been answered properly... (story291881172988; Luxembourg; Age: 35; Months TTC: 47)

My feelings right now is what is wrong with me? (story351126333040; United States; Age: 28; Months TTC: 15)

More than anything, I want to know what is wrong. I can accept and come to terms with what the problem means -- whether that means there's no chance of conception or not. But I need to know what's wrong. I need to know why my body isn't doing what it should be. I need to know. (story32965670930; United States; Age: 23; Months TTC: 14) 


\section{Results from Bivariate Analysis of "Making Sense" Themes in the Story Gallery}

Not surprisingly, themes associated with medical interpretations of conception difficulties were more likely to be found in the stories of women who had sought medical help. It is also not surprising, given concerns about agerelated infertility and the pressure of time for older women, that women who were thirty years of age and older were more likely to express acceptance of the medical model (Table 39) and were more likely to view seeing a physician as taking action (Table 40). Women who had been trying for a year or longer, were also more likely to be "searching for answers" (Table 50) which is also not surprising. Otherwise, the interesting thing about this analysis is that there were virtually no significant differences in the frequency of "making sense" themes (God, faith, religion; "everything happens for a reason"; questioning previous reproductive decisions; and searching for answers) among women writing in the Story Gallery based on age, time trying to conceive, whether or not they had sought medical treatment and whether they were trying to conceive a first or subsequent child. This may testify to the strength of socially dominant ways of making meaning among all categories of women. It was particularly interesting to note that there was no significant difference in the likelihood of mentioning God, faith and spirituality (Table 28) and seeking medical help, suggesting that the use of one system of making meaning, did not preclude the use of another. These frameworks do not appear to be incompatible for the women who wrote their stories. 


\section{Chapter Summary}

Previous chapters discussed the ways in which conception difficulties were experienced as a disruption due to a failure to adhere to dominant cultural norms. This chapter focused on the ways that women make sense of this disruption. Ways of making sense were also influenced by socio-cultural norms. Most notably, medical explanations and solutions were privileged as the acceptable way to interpret and solve conception difficulties for middle-class women. In this paradigm, a biological child is perceived as more desirable than alternate possibilities (such as adopting or remaining childless). Women saw seeing a doctor as the natural starting point when conception difficulties were suspected and they were willing to tolerate uncomfortable and invasive tests and procedures in their pursuit of a biological child. They were not, however, overtly coerced by their physicians, but rather saw their physicians as partners or as a resource to be exploited to meet their own particular goals. Though the medicalization thesis proposes that medicine and the doctor/patient encounter act as an institution of social control, this was not so clear cut for the participants of this study who already were looking for ways to meet culturally dominant ideals. Rather, it appears that women's experiences with the medical realm mutually reinforced existing pronatalist ideals about the value of biological parenthood for married, middle-class women. Discussions about regret and guilt also played a role in making sense as difficulty conceiving caused women to question previous reproductive decisions and called into question whether or not they "deserved" to be mothers. This is important for issues related to women's autonomy because constructing choices that empower women as potentially sterilizing has implications for maintaining that autonomy. The hopefulness and trust that things will 
"work out" that is evident in the stories, both in religious and secular comments reveals the optimism of the participants and their sense of the world as a just place. Socialized to believe that they will be rewarded for their goodness and hard work and that perseverance pays off, the participants anticipate that they will be rewarded. Interpretations were almost exclusively made with an individual, personal focus. Virtually no respondent talked about wider social issues and solving and interpreting conception difficulties in the social rather than the individual realm. The frameworks that they used to make sense dealt with understanding their own misfortune and solving their own problems, but they did not question the social foundations that constructed them as unfortunate.

\section{Conclusions}

Throughout this thesis, I have talked about the multitude of ways that conception struggles disrupt one's sense of self and identity and interfere with major life plans and significant relationships and cause emotional instability for those affected. Here, I have discussed the various ways that people find and make meaning from this experience and the social backdrop in which this meaning-making occurs. In the first part of this chapter, I reviewed the feminist and sociological literature with regards to medicalization in general and infertility in particular as well as some of the findings from studies which considered personal interpretations of illness experiences and infertility. In the second part of this chapter, I offered some detailed descriptions from the Story Gallery regarding ways in which women trying to conceive made sense of their experiences, found meaning, sought comfort and determined how they would seek to resolve their difficulty. Responses showed that most women interpret their experience within a medical framework and see medical solutions as most appropriate. They indicate that the social 
value of children and their desire to mother make the risk of medical treatment worth the priceless benefit. This also demonstrates the social value of self-efficacy and the expectation that one is supposed to "fix" a problem that is perceived to reside in the body with medical solutions. Medical treatments are described as painful, uncomfortable, and escalating to become increasingly invasive. Doctors and middle-class women do seem to be in some collusion and likely share similar value systems, but the authority of medical professionals over the women they treat appears to have been overestimated by feminists and medicalizaton critics. Responses here show how middle class women participate in medicalization. Women gain control over their medical experiences by researching and becoming experts on their conditions, by switching doctors and seeking second opinions when they are unsatisfied (and they are frequently unsatisfied) and by suggesting or insisting on their preferred (usually more aggressive) treatment strategies. They do not accept medical solutions and medical authority uncritically, nor do they ignore the larger, existential issues raised by the use of reproductive technologies when making treatment decisions. Rather, they expect to be seen as partners in their own care and ultimately they make their own decisions with various degrees of guidance. Questions about ethics and concepts of "nature versus science" and "private versus public" also figure into the decisions they make regarding framing and seeking to solve their conception difficulty within the context of the medical model. Not everyone chooses to pursue invasive medical solutions.

Ways of understanding the disruption associated with prolonged conception difficulty outside of a medical framework have rarely been investigated, but the stories here show that medicine does not have exclusive jurisdiction over making sense of the 
experience. In most cases where alternative ways of interpreting and solving infertility are used, they are used in conjunction with medical interpretations. In addition to medicine, women make use of a variety of alternative systems, including meditation, herbs, yoga, vitamins and acupuncture. For many women, faith and God and concepts of fate and understandings of the world as a fair and just place also play a significant role in finding meaning and seeking comfort, but again, usually not to the exclusion of medicine.

Several women looked to their reproductive past when trying to understand the problems of their reproductive present, revisiting decisions about contraception, sterilization, abortions, promiscuity and delayed childbearing. From a feminist perspective, this may be alarming because it harkens to the idea of empowerment having a sterilizing effect and can potentially be used to dissuade women from seeking reproductive autonomy and empowerment.

Some women suggested that there was no meaning to be found in their experience and still others talked about how they were still searching for answers. The strength of dominant values and dominant ways of meaning-making was perhaps most evident in the way women sought to interpret their "failures" on a personal, individual level. When they were unable to meet the social demands of normalcy by having biological children, they did not look at the norms as faulty, but rather they looked at their bodies and their choices as faulty. There was, however, a wide variety of responses and a wide range of ways of seeking and finding meaning. Different women made different decisions based on their own belief systems and backgrounds. It is really not possible to paint all women struggling with fertility problems with the same brush. They and their experiences are varied and complex. They are actors in their own unique stories navigating a maze of 
possibilities and interpretive modes to find their own best futures and their own ways of understanding. 


\section{Chapter Six: Conclusions}

\section{Thesis Summary}

With conception difficulties utilized as an illustration, I examined the ways in which disruption was experienced when individuals were not able to attain a socially idealized normative identity and life course. I identified social ideals which continue to impact the experience of trying to conceive in spite of societal changes over the past several decades, and I discussed the ways in which failure to easily achieve these ideals was experienced as a disruption. The dimensions of this disruption were explored in relation to identity, biography and the body; sex and the spousal relationship; and interpretive strategies.

In relation to identity, the following dominant social norms impacted the experience when women struggled with conception difficulties: norms and values associated with pronatalism (motherhood is needed to confer full adult status on women; children are necessary for happiness; motherhood should be reserved for "deserving" women); and norms associated with self-efficacy and control (one should be able to control the body with one's will and effort should result in rewards). Disruption related to identity and biography when these ideals were not met was expressed and experienced in the following ways:

- A sense that life is "on hold"

- A sense that the experience is all consuming

- Feeling defective, like a failure

- Feeling isolated and left out

- Feelings of envy, otherness and injustice 
- Feeling like others do not understand

- Feeling like others are insensitive

- Asserting one's worthiness

- Feelings of shame and loss of self-worth

- Feeling a need to manage information and keep secrets

- Feeling pressure from others

- Feelings of loss of control

- Feelings of grief and sadness

- Anger

- Frustration

- Efforts to regain control

- Resistance of negative impact

- Opportunities for self-growth

In relation to the spousal relationship, the following idealized social norms impacted the experience: norms and values associated with pronatalism (children are needed to make a "family", having children is a natural life progression after getting married; married couples should have children; marriage makes one worthy of children); values associated with traditional gender roles (reproduction is primarily the responsibility of women; parenthood is more important to women than men; conception difficulties are the "fault" and responsibility of the female partner; virility and potency are linked for men and men should initiate sex); ideals about sex and marriage (mutually satisfying sex is an important aspect of a romantic, heterosexual marriage and "good" 
relationships do not have conflict). Disruption when these ideals were not met was experienced in the following ways:

- Spousal conflict

- Feelings of guilt or blame

- Loss of sexual satisfaction

- Asserting one's worthiness by virtue of married status

- Feelings of being supported by one's spouse

- Opportunities for relationship growth

- Deliberate resistance of negative impact on relationship

When women experienced conception difficulties and the associated disruption, they sought ways to interpret and make sense of the experience. Ways of interpreting the experience were also influenced by social norms. Social norms that impacted ways of making sense included the following: norms associated with pronatalism (worthy women should pursue biological parenthood; biological parenthood is preferable to alternatives such as adoption; past socially undesirable behavior may make one "unsuitable" for motherhood; a child is a priceless benefit that is worth any price); self efficacy (taking control); values associated with faith in science and medicine (medicine offers the most appropriate solutions to a problem perceived to reside in the body, doctors are benevolent); a belief in the world as just. Additionally, women tended to interpret and seek solutions within an individualistic, rather than a social/collective framework and did not question the foundations on which these values were built. These values were expressed in the following ways: 
- Seeking medical help is appropriate and responsible

- Invasive or painful tests and treatments are "worth it"

- Regret of previous reproductive decisions

- Conception will happen when the time is right, or in God's time

- Deliberate influencing medićal protocol

The thesis discussed and described the ways that conception difficulties were experienced as a disruption in a variety of contexts and the ways in which pronatalist values continue to impact upon the experience, in spite of increased role options for women and the increased acceptability of alternative family structures that may or may not include biological children. While negative aspects of disruption were noted, the participants also talked about ways in which they resisted these negative aspects and how the disruption provided opportunities for personal and relationship growth and sometimes challenged previously accepted social ideals.

\section{Contribution}

First, this work offers an opportunity to build upon disruption as a sociological concept. With conception difficulties as an illustration, I have highlighted a number of ways that a failure to meet idealized social norms results in disruption and I have identified several dimensions of this disruption. This is a potential stepping stone towards a more comprehensive analysis of the concept of disruption in a variety of contexts. It may be useful to apply to other similar situations such as divorce, facing a spouse's infidelity, job loss, homelessness, injury, or otherwise unanticipated experiences for which there has been no socialization. 
Another contribution of this thesis is my perspective that includes both the social context as well as the personal meanings of those affected by conception difficulties. I have tried to elucidate the social context without detracting from the authenticity, uniqueness and value of the participants' personal experiences. I have suggested that the disruptive experience of conception difficulties is shaped by the social values and ideologies of pronatalism, but that does not make individuals struggling to conceive any less entitled to sympathy, support or resources such as access to medical technology and insurance claims for infertility services. It does not make their desire to conceive less rational. It is simply situated.

It has been difficult to maintain this perspective at times. I have felt the need to say "yes, but...!" each time I called on the social constructionist's toolkit, because my desire to portray the participants as intelligent actors in their own unique stories (they are!), making rational decisions that make sense for them (they do!), and navigating a difficult and unfair situation with poise, dignity and grace (they do!) has been more important to me than deconstructing enduring, pronatalist social values about motherhood and infertility. Still, I hope I have succeeded somewhat at doing both and that this results in contributing to a more nuanced perspective about women's experience of conception difficulties- one that does not sacrifice the importance of social context for that of personal meanings or vise versa.

Next, a significant contribution lies in my method and my unique sample. Using the internet, I have been able to access hundreds of diverse voices that may have previously gone unheard. My sample includes women from all over the English-speaking world and includes a significant proportion of women who have not sought medical help 
or joined organized support groups. It also includes women who have not been trying long and many women who were trying for a subsequent, rather than a first child. Many of these women would have been inaccessible using traditional recruiting methods. I have been able to compare responses based on these characteristics of my unique sample.

Finally, the most notable contribution of the thesis, I believe, is the Trying to Conceive Story Gallery itself. The stories are accessible online and publicly viewable as an asset to the participants themselves and any interested party. Participants noted that reading the stories of others eased their sense of isolation and they felt positive and validated by sharing their own experiences as well. The stories could also be beneficial for people working with individuals experiencing conception difficulties as well as for close friends and family who want to understand the experience of their loved-ones. Increasing public awareness about the experience could help to reduce its stigma and can educate people about ways to be sensitive and sympathetic to those affected. Given that the stories have attracted over 415,000 page views at the time I am writing these conclusions, this does not seem overly optimistic. They are a living resource and their value extends beyond this thesis.

\section{Limitations}

The sample also poses some limitations. Although the sample is unlike other samples, and in many ways is more diverse, it is not representative of all women, or even all women who use the internet. The stories were written by women using one particular internet site- one where they charted their fertility signs using an internet-based software. Their experiences cannot be presumed to be like others who do not use the internet or those who would not chart their fertility signs or who would not chart their fertility signs 
on an internet site. These women are highly motivated to conceive and were motivated to learn about fertility awareness. Given their dedication (fertility charting involves observing morning temperatures and other observations and takes some effort) they may be more likely to accept pronatalist ideals than other women and they may be more inclined to take personal control of their health and future.

The sample is also limited in that the stories are snapshots in time. I have inferred that the women writing the stories accepted and were influenced by pronatalist values, traditional gender roles and other socially dominant ideals. It is important to note that this was while they were trying to make babies. As the reproductive years pass and women either become mothers and their children grow or they accept a child-free lifestyle, they are likely to embrace other ideals, interests and values as well. Also, because just one story at one particular time was solicited and considered for each participant, it was not possible to examine how perspectives may change over time and the life course.

Another limitation is that the data does not include some demographic information that would have been interesting to compare the experiences of women from different socio-economic, ethnic and religious backgrounds. As discussed in the Methodology chapter, this was specifically not solicited after careful consideration about the long term purpose of the Story Gallery. Nevertheless, its absence means that this comparison is not possible. Additionally, responses are only from women and so any inference about the experience of men is speculative and from their spouse's point of view. Finally, the sample is nearly completely from heterosexual, married women and so does not address the experience of non-traditional or lesbian and single women who may want to conceive. While it has been possible to explore the impact of conception 
difficulties and the role of pronatalist ideals as experienced by women with traditional values, it is not possible to infer that the impact affects all women in a similar or universal manner. Women with less traditional lives and expectations may have different experiences.

\section{Future Directions}

The issues that were addressed in this thesis could be enhanced by future work which includes a wider variety of respondents. Responses from men, more nontraditional women and women recruited from a variety of sources could allow a deeper investigation of ways in which the experience varies across social contexts. A longitudinal study about shifts in values and ideals associated with parenting and identity issues throughout the life course could also yield interesting results. This could allow a more comprehensive exploration of the circumstances under which the experience of conception difficulties is disruptive.

A comparison of a variety of different disruptive life experiences and their impacts on relationships, emotions, identity and biography and ways of making sense could also prove valuable. A number of life experiences could be described as disruptive to anticipated life trajectories and socially ideal identities. Losing one's job, one's home, getting injured, having a disabled child, becoming a refugee, getting divorced or failing an educational program are all disruptive experiences that are associated with a failure to meet social ideals. Further investigation of the concept of disruption with these or other illustrations could further develop the concept and determine which elements of disruption apply to a variety of experiences. It could also be possible to determine if there 
is any particular process involved in the experience. For example, does one aspect precede another? Are some elements always present?

Looking at seemingly positive disruptions could also offer some insight into social values and norms and the processes by which people experience transitions. Winning the lottery, starting a new job, falling "in love", getting married, moving to a new town for an opportunity, going to university, or immigrating to a more prosperous country may also be experienced as a disruption, even if it is expected to be positive. Looking at the dimensions of these apparently positive disruptions and comparing them to negative or unanticipated disruptions could offer additional insight into the concept of disruption.

Finally, my original research question is also now a "future direction". This thesis was initially intended to be an investigation and exploration of ways that internet use could challenge traditional medical practice and medical authority. I planned to use the questions about medical experiences and the use of the internet to explore this issue. Because the responses regarding the personal meanings of infertility and conception difficulties turned out to be so rich, and disruption emerged as the central theme, this was not the research question that I explored in the end. However, it still has merit and deserves attention. Questions solicited more specifically about internet use and its effect on medical experiences from a variety of respondents using the internet for a variety of health reasons could shed more light on these issues.

\section{In Closing}

This thesis examined the experiences of women trying to conceive and the ways that they made sense of their experiences and attributed meaning to them. Stories from 
327 women trying to conceive, or recently pregnant after trying to conceive, were analyzed qualitatively using a grounded theory methodology. Themes identified in this qualitative analysis were further analyzed to compare the experience based on time trying to conceive, age, parity and whether or not medical assistance was sought. The qualitative analysis revealed that the central theme of the experience was that of disruption and this was seen to be due to an inability to meet idealized social norms which endure in spite of societal changes which offer women alternative role opportunities. Although the cultural landscape is quite different from that of a few decades ago when infertility was initially described as painful and stigmatizing due to the inability to meet social norms (Menning 1977; Miall 1985; Miall 1986), the impact is experienced similarly. Participants noted disruptions to their life plans and goals (biography), their identities, and their concepts of themselves as healthy, whole, in control, feminine, and normal. Relationships with spouses and others were also disrupted. Their experiences were often discussed in terms of "failure" and loss. Feelings of failure were often reinforced through contact and interaction with others but also through the participants' own social outlook which also often appeared to be influenced by pronatalist values and other socially dominant ideals. This offered an opportunity to develop disruption as a concept with conception difficulties providing the illustration. It also allowed for the opportunity to examine the extent to which pronatalist ideals and values continue to shape the experience of women trying to conceive.

While the participants' stories revealed that their lives were indeed disrupted due to conception difficulties, participants in this study were particularly active in shaping their own experiences and did not submit unquestioningly to medical authority. Although 
dominant social constructs were largely left unchallenged, they utilized a variety of means and methods to maintain control and mitigate the negative impact of the experience on their identities, biographies and relationships. They sought and shared support. They made deliberate decisions about controlling contact with others (such as avoiding baby showers or pregnant sisters-in-law, or managing information). Many couples made an effort to communicate and maintain closeness and several noted that their spousal relationship was strong with or without children. They took breaks, set limits and employed other strategies to avoid becoming overwhelmed and all consumed. They educated themselves about fertility and any particular condition that was inhibiting conception. They sought (or chose not to seek) medical help and alternative healing methods and made their own, educated, critical calculations about medical tests and procedures. They did so based on their own careful and rational evaluations about what they deemed was best for their own futures. When they were unsatisfied with their care, they made efforts to change caregivers or otherwise exert influence. They enjoined others to empower themselves as well. Overall, the tone of the stories is hopeful, positive and optimistic. The stories also revealed that the experience of disruption offered opportunities for self and relationship growth. 


\section{References Cited}

Abbey, A., F. Andrews, et al. (1991). "Gender's role in responses to infertility." Psychology of women quarterly 15(2): 295-316.

Abbey, A., F. Andrews, et al. (1992). "Infertility and Subjective Well-Being: The Mediating Roles of Self-Esteem, Internal Control, and Interpersonal Conflict." Journal of Marriage and the Family 54(2): 408-417.

Abbey, A., F. M. Andrews, et al. (1994). "Psychosocial Predictors of Life Quality: How are they affected by Infertility, Gender, and Parenthood?" Journal of Family Issues 15(2): 253-271.

Abma, J. and G. Martinez (2006). "Childlessness Among Older Women in the United States: Trends and Profiles." Journal of Marriage and Family 68(4): 1045-1056.

Adams, M. L. (1997). The trouble with normal : postwar youth and the making of heterosexuality. Toronto; Buffalo, University of Toronto Press.

Allan, H. (2007). "Experiences of infertility: liminality and the role of the fertility clinic." Nursing Inquiry 14(2): 132-139.

American Society of Reproductive Medicine (1996-2008). Frequently Asked Questions About Infertility, http://www.asrm.org/Patients/faqs.html. 2008.

American Society of Reproductive Medicine (2000-2007). Frequently Asked Questions About Infertility, http://www.asrm.org/Patients/faqs.html\#Q2:. 2007.

American Society of Reproductive Medicine (2003). Age and infertility: a guide for patients, http://www.asrm.org/Patients/patientbooklets/agefertility.pdf. Patient Information Booklets. American Society of Reproductive Medicine. 2008.

Andrews, F. M., A. Abbey, et al. (1991). "Stress from infertility, marriage factors, and subjective well-being of wives and husbands." J Health Soc Behav 32(3): 238-53.

Apfel, R. and R. Keylor (2002). "Psychoanalysis and Infertility: Myths and Realities." International Journal of Psycho-Analysis 83(1): 85-104.

Arnst, C. (2002). "The Loneliness of the High-Powered Woman." Business Week April 29: http://www.businessweek.com/magazine/content/02_17/b3780031.htm.

Atwood, J. and S. Dobkin (1992). "Storm clouds are coming: Ways to help couples reconstruct the crisis of infertility." Contemporary Family Therapy 14(5): 385403. 
Auerbach, C. F. and L. B. Silverstein (2003). Qualitative data : an introduction to coding and analysis. New York, New York University Press.

Babbie, E. R. (1998). The practice of social research. Belmont, CA, Wadsworth Pub. Co.

Baldwin, W. H. and C. W. Nord (1984). "Delayed childbearing in the U.S.: facts and fictions." Popul Bull 39(4): 1-42.

Becker, G. (1994). "Metaphors in disrupted lives: infertility and cultural construction of continuity." Medical Anthropology Quarterly (New Series) 8(4): 383-410.

Becker, G. (1997). Disrupted lives : how people create meaning in a chaotic world. Berkeley, University of California Press.

Becker, G. and R. Arnold (1986). Stigma as a Social and Cultural Construct. The Dilemma of Difference: a multidisciplinary view of stigma. S. Ainlay, G. Becker and L. Coleman. New York, Plenum: 39-57.

Becker, G. and R. Nachtigall (1994). "'Born to be a mother': the cultural construction of risk in infertility treatment in the U. S.: Interpreting infertility: medical anthropological perspectives." Social science \& medicine(1982) 39(4): 507-518.

Becker, G. and R. D. Nachtigall (1992). "Eager for Medicalization - the Social Production of Infertility as a Disease." Sociology of Health \& Illness 14(4): 456471.

Benazon, N., J. Wright, et al. (1992). "Stress, sexual satisfaction, and marital adjustment in infertile couples." J Sex Marital Ther 18(4): 273-84.

Berg, B., J. Wilson, et al. (1991). "Psychological sequelae of infertility treatment: the role of gender and sex-role identification." Soc Sci Med 33(9): 1071-80.

Beyer, K., L. Dye, et al. (2004). "Coping with involuntary childlessness. A problem relevant for psychotherapy?" Psychotherapeut 49(5): 331-340.

Boivin, J., L. Bunting, et al. (2007). "International estimates of infertility prevalence and treatment-seeking: potential need and demand for infertility medical care." Human Reproduction 22(6): 1506.

Bos, H. (2007). "The influence of social and cultural factors on infertility and new reproductive technologies." Journal of Psychosomatic Obstetrics \& Gynecology 28(2): $65-68$.

Bromberg, H. (1996a). Exploring Virtual Worlds: Computer-Mediated Communication and Perceptions of Community, Identity and Reality. Sociology and Anthropology. Ottawa, Carleton University: 140. 
Bromberg, H. (1996b). Are MUDs Communities? Identity, Conciousness and Belonging in Virtual Worlds. Cultures of Internet: Virtual Spaces, Real Histories, Living Bodies. R. Shields. London, Sage Publications.

Brothers, S. C. and J. E. Maddux (2003). "The goal of biological parenthood and emotional distress from infertility: Linking parenthood to happiness." Journal of Applied Social Psychology 33(2): 248-262.

Bunting, L. and J. Boivin (2007). "Decision-making about seeking medical advice in an internet sample of women trying to get pregnant." Human Reproduction 22(6): 1662.

Burns, L. (1987). "Infertility as Boundary Ambiguity: One Theoretical Perspective." Family Process 26(3): 359-372.

Burns, L. H. (2006). Sexual Counselling and Infertility. Infertility Counselling: A Comprehensive Handbook for Clinicians. S. N. Covington and L. H. Burns. Cambridge, Cambridge University Press.

Burr, V. (2003). Social constructionism. London; New York, Routledge.

Bury, M. (1982). "Chronic illness as biographical disruption." Sociol Health Illn 4(2): $167-82$.

Bury, M. (1986). "Social constructionism and the development of medical sociology." Sociology of Health \& Illness 8(2): 137-169.

Bury, M. (1997). Health and illness in a changing society. London; New York, Routledge.

Butler, R. and S. Koraleski (1990). "Infertility: A Crisis with No Resolution." Journal of Mental Health Counseling 12(2): 151-63.

Chapman, M. B. (2005). "Gender Identity and a Fertile Life: Development Issues of the Fertility Challenged Female." Journal of Fertility Counselling 12(3): 28-32.

Chapple, A. and S. Ziebland (2004). "The role of humor for men with testicular cancer." Qual Health Res 14(8): 1123-39.

Charnaz, K. (2002). "The self as habit: the reconstruction of self in chronic illness." Occupational Therapy Journal of Research 22: 315-415.

Charmaz, K. (2006a). Constructing grounded theory. London; Thousand Oaks, Calif., Sage Publications.

Charmaz, K. (2006b). "Measuring pursuits, marking self: Meaning construction in chronic illness." International Journal of Qualitative Studies on Health and WellBeing 1(1): 27-37. 
Christie, G. L. (1998). "Some socio-cultural and psychological aspects of infertility." Hum Reprod 13(1): 232-41.

Clark, L., S. Henry, et al. (1991). "Cognitive examination of motivation for childbearing as a factor in adjustment to infertility." Infertility: Perspectives from stress and coping research: $157-180$.

Clarke, L. H., A. Martin-Matthews, et al. (2006). "The continuity and discontinuity of the embodied self in infertility." Canadian Review of Sociology and AnthropologyRevue Canadienne De Sociologie Et D Anthropologie 43(1): 95-113.

Clifford, J., G. E. Marcus, et al. (1986). Writing culture : the poetics and politics of ethnography : a School of American Research advanced seminar. Berkeley, University of California Press.

CNN (2002). Study: Fertility Declines in Late 20s, http://archives.cnn.com/2002/HEALTH/04/30/fertility/.

Coleman, L. (1986). Stigma: an enigma demystified. The Dilemma of Difference: A Multidisciplinary View of Stigma. S. Ainlay, G. Becker and L. Coleman. New York, NY, Plenum: 211-27.

Connolly, K. J. and I. D. Cooke (1987). "Distress and Marital Problems Associated with Infertility." Journal of Reproductive and Infant Psychology 5: 49-57.

Connolly, K. J., R. J. Edelmann, et al. (1992). "The Impact of Infertility on Psychological Functioning." Journal of Psychosomatic Research 36(5): 459-468.

Conrad, P. (1990). "Qualitative Research on Chronic Illness - a Commentary on Method and Conceptual Development." Social Science \& Medicine 30(11): 1257-1263.

Conrad, P. (1992). "Medicalization and Social Control." Annual Review of Sociology 18(1): 209-232.

Conrad, P. (2007). The medicalization of society : on the transformation of human conditions into treatable disorders. Baltimore, Johns Hopkins University Press.

Conrad, P. and J. W. Schneider (1980). Deviance and medicalization : from badness to sickness. St. Louis, Mosby.

Conway, P. and D. Valentine (1988). "Reproductive losses and grieving." Journal of Social Work and Human Sexuality 6(1): 43-64.

Cook, R. (1993). "The relationship between sex role and emotional functioning in patients undergoing assisted conception." J Psychosom Obstet Gynaecol 14(1): $31-40$. 
Corbin, J. (2003). "The Body in Health and Illness." Qualitative Health Research 13(2): 256.

Corbin, J. and A. Strauss (1987). "Accompaniments of chronic illness: changes in body, self, biography and biographical time." Research in the Sociology of Health Care 6(3): 249-281.

Corea, G. (1985a). Man-made women : how new reproductive technologies affect women. London, Hutchinson.

Corea, G. (1985b). The mother machine : reproductive technologies from artificial insemination to artificial wombs. New York, Harper \& Row.

Cousineau, T. and A. Domar (2007). "Psychological impact of infertility." Best Pract Res Clin Obstet Gynaecol 21(2): 293-308.

Daniluk, J. (1988). "Infertility: intrapersonal and interpersonal impact." Fertil Steril 49(6): 982-90.

Daniluk, J. (1996). "When Treatment Fails: The Transition to Biological Childlessness for Infertile Women." Women and Therapy 19: 81-98.

Daniluk, J. (1997a). Gender and Infertility. Infertility: Psychological Issues and Counselling Strategies. S. R. Leiblum. New York, John Wiley \& Sons, Inc.: 103125.

Daniluk, J. (1997b). "Helping Patients Cope With Infertility." Clinical Obstetrics and Gynecology 40(3): 661.

Davis-Floyd, R. (2003). Birth as an American Rite of Passage, University of California Press.

Davis-Floyd, R. (2000). Technologies of the Exterior, Technologies of the Interior: Can We Expand the Discourse of Reproductive Studies? Body Talk: Rhetoric, Technology, Reproduction. L. J. G. Mary M. Lay, Clare Gravon, and Cynthia Myntti. Madison, University of Wisconsin Press: 277-300.

Davis-Floyd, R. and C. Sargent (1997). Childbirth and Authoritative Knowledge: CrossCultural Perspectives, University of California Press.

Deveraux, L. and A. Hammerman (1998). Infertility \& Identity: New Strategies for Treatment. San Francisco, Jossey-Bass.

Domar, A., A. Broome, et al. (1992). "The prevalence and predictability of depression in infertile women." Fertility and sterility 58(6): 1158-1163. 
Domar, A., A. Penzias, et al. (2005). "The stress and distress of infertility: Does religion help women cope?" Sexuality, Reproduction \& Menopause 3(2): 45-51.

Domar, A., P. Zuttermeister, et al. (1993). "The psychological impact of infertility: a comparison with patients with other medical conditions." J Psychosom Obstet Gynaecol 14: 45-52.

Downey, J., S. Yingling, et al. (1989). "Mood disorders, psychiatric symptoms, and distress in women presenting for infertility evaluation." Fertil Steril 52(3): 42532.

Dunson, D. B., B. Colombo, et al. (2002). "Changes with age in the level and duration of fertility in the menstrual cycle." Hum Reprod 17(5): 1399-403.

Edelmann, R. and K. Connolly (2000). "Gender differences in response to infertility and infertility investigations: Real or illusory." British Journal of Health Psychology 5(Part 4): 365-375.

Edelmann, R. J. and K. J. Connolly (1998). "Psychological state and psychological strain in relation to infertility." Journal of Community \& Applied Social Psychology 8(4): 303-311.

Edwards, A. (2005). "Time, Technology, and Meritocracy: The Disciplining of Women's Bodies in Narrative Constructions of Age-Related Infertility." Narratives, Health, and Healing: Communication Theory, Research, and Practice.

Epstein, Y. M. and H. S. Rosenberg (1997). He Does, She Doesn't; She Does, He Doesn't: Couple Conflicts about Infertility. Infertility: Psychological Issues and Counselling Strategies. New York, John Wiley \& Sons, Inc.

Exley, C. and G. Letherby (2001). "Managing a disrupted lifecourse: issues of identity and emotion work." Health 5(1): 112-132.

Eysenbach, G. and J. Till (2001). "Ethical issues in qualitative research on internet communities." British Medical Journal 323(7321): 1103-1105.

Fassino, S., A. Piero, et al. (2002). "Anxiety, depression and anger suppression in infertile couples: a controlled study." Human Reproduction 17(11): 2986-2994.

Flicker, S., D. Haans, et al. (2004). "Ethical dilemmas in research on Internet communities." Qual Health Res 14(1): 124-34.

Forrest, L. and M. Gilbert (1992). "Infertility: An Unanticipated and Prolonged Life Crisis." Journal of Mental Health Counseling 14(1): 42-58.

Foster, P. (1995). Women and the health care industry: An unhealthy relationship? Buckingham, Open University Press. 
Foucault, M. (1973). The birth of the clinic; an archaeology of medical perception. New York, Pantheon Books.

Foucault, M. (1988). The history of sexuality. New York, Vintage Books.

Foucault, M. (1995). Discipline and punish : the birth of the prison. New York, Vintage Books.

Franke-Ruta, G. (2002). "Creating a Lie: Sylvia Ann Hewlett and the myth of the baby bust." American Prospect 13(12): 30-33.

Franklin, S. (1995). Postmodern Procreation: A Cultural Account of Assisted Reproduction. Conceiving the New World Order: The Global Politics of Reproduction. F. D. Ginsburg and R. Rapp. Berkeley, University of California Press: $323-345$.

Franklin, S. (1997a). Embodied progress : a cultural account of assisted conception. London; New York, Routledge.

Franklin, S. (1997b). Making Sense of Missed Conceptions. Situated lives : gender and culture in everyday life. L. Lamphere, H. Ragonâe and P. Zavella. New York, Routledge: 99-109.

Freund, P. E. S. and M. B. McGuire (1999). Health, illness, and the social body : a critical sociology. Upper Saddle River, N.J., Prentice Hall.

Gabe, J., M. Bury, et al. (2004). Key concepts in medical sociology. London; Thousand Oaks, CA, Sage Publications.

George, L. (2007). "Can we feed the need to breed?" Macleans May 28: 40-45.

Gergen, K. (1985). "The social constructionist movement in modern psychology." American Psychologist 40(3): 266-275.

Gerhardt, U. (1990). "Qualitative Research on Chronic Illness - the Issue and the Story." Social Science \& Medicine 30(11): 1149-1159.

Gerrity, D. (2001). "A Biopsychosocial Theory of Infertility." The Family Journal 9(2): 151.

Gillespie, R. (2000). "When no means no: Disbelief, disregard and deviance as discourses of voluntary childlessness." Womens Studies International Forum 23(2): 223-234.

Glaser, B. G. and A. L. Strauss (1967). The Discovery of Grounded Theory: Strategies for Qualitative Research. New York, Aldine de Gruyter. 
Goffman, E. (1963). Stigma; notes on the management of spoiled identity. Englewood Cliffs, N.J.,, Prentice-Hall.

Gonzalez, L. (2000). "Infertility as a transformational process: a framework for psychotherapeutic support of infertile women." Issues in Mental Health Nursing 21(6): 619-633.

Good, B. and M. Good (1980). The meaning of symptoms. A cultural hermeneutic model for clinical practice. The relevance of social science for medicine. Dordretch: D. Reidel Publishing.

Goode, E. and N. Ben-Yehuda (1994). Moral panics : the social construction of deviance. Oxford, UK ; Cambridge, USA, Blackwell.

Grant, J. and S. Hoorens (2006). "The new pronatalism?" Public Policy Research 13(1): 13-25.

Greil, A., T. Leitko, et al. (1988). "Infertility: His and Hers." Gender and Society 2(2): 172-199.

Greil, A. L. (1991a). Not yet pregnant : infertile couples in contemporary America. New Brunswick [N.J.], Rutgers University Press.

Greil, A. L. (1991b). "A Secret Stigma: The analogy between infertility and chronic illness and disability." Advances in Medical Sociology 2: 17-38.

Greil, A. L. (1997). "Infertility and psychological distress: a critical review of the literature." Soc Sci Med 45(11): 1679-704.

Greil, A. L. (2002). Infertile Bodies: Medicalization, Metaphor, and Agency. Infertility around the globe : new thinking on childlessness, gender, and reproductive technologies. M. C. Inhorn and F. v. Balen. Berkeley, University of California Press: 101-118.

Greil, A. L., K. L. Porter, et al. (1989a). "Sex and Intimacy among Infertile Couples." Journal of Pscyhology and Human Sexuality 2(2): 117-138.

Greil, A. L., K. L. Porter, et al. (1989b). "Why Me - Theodicies of Infertile Women and Men." Sociology of Health \& Illness 11(3): 213-229.

Haessler, A. and M. Rosenthal (2007). Psychological Aspects of Obstetrics \& Gynecology. Current Diagnosis \& Treatment Obstetrics \& Gynecology. A. DeCherney and L. Nathan, McGraw-Hill's AccessMedicine.

Haigh, C. and N. Jones (2005). "An overview of the ethics of cyber-space research and the implication for nurse educators." Nurse Education Today 25(1): 3-8. 
Hall, W. A. and P. Callery (2001). "Enhancing the rigor of grounded theory: Incorporating reflexivity and relationality." Qualitative Health Research 11(2): 257-272.

Hammersley, M. and P. Atkinson (1983). Ethnography : principles in practice. London ; New York, Tavistock.

Haraway, D. J. (1991). Simians, cyborgs, and women : the reinvention of nature. New York, Routledge.

Herxheimer, A., A. McPherson, et al. (2000). "Database of patients' experiences (DIPEx): a multi-media approach to sharing experiences and information." Lancet 355(9214): 1540-3.

Herxheimer, A. and S. Ziebland (2003). "DIPEx: fresh insights for medical practice." J R Soc Med 96(5): 209-10.

Hewlett, S. A. (2002a). Creating a Life: Professional Women and the Quest for Children. New York, Hyperion.

Hewlett, S. A. (2002b). "Executive women and the myth of having it all." Harv Bus Rev 80(4): 66-73, 125.

Hewlett, S. A. (2004). "Fast-track women and the quest for children." Fertil Steril 81 Suppl 2: 15-8.

Hirsch, A. M. and S. M. Hirsch (1989). "The effect of infertility on marriage and selfconcept." J Obstet Gynecol Neonatal Nurs 18(1): 13-20.

Hirsch, M. B. and W. D. Mosher (1987). "Characteristics of infertile women in the United States and their use of infertility services." Fertil Steril 47(4): 618-25.

Hollingworth, L. (2000). "Leta S. Hollingworth on Coercive Pronatalism." Population and Development Review 26(2): 353-363.

Ireland, M. S. (1993). Reconceiving women : separating motherhood from female identity. New York, Guilford Press.

Jordan, B. (1997). Authoritative knowledge and its construction. Childbirth and authoritative knowledge: Cross-cultural perspectives: 55-79.

Jordan, C. and T. Revenson (1999). "Gender Differences in Coping with Infertility: A Meta-Analysis." Journal of Behavioral Medicine 22(4): 341-358.

Kelly, M. and D. Field (1996). "Medical sociology, chronic illness and the body." Sociology of Health and Illness 18(2): 241-257. 
Kèubler-Ross, E. (1975). Death : the final stage of growth. Englewood Cliffs, N.J., Prentice-Hall.

Kirkman, M. (2003). "Infertile women and the narrative work of mourning: Barriers to the revision of autobiographical narratives of motherhood." Narrative Inquiry 13(1): 243-262.

Kirkman, M. and D. Rosenthal (1999). "Representations of reproductive technology in women's narratives of infertility." Women Health 29(2): 17-36.

Klein, R. D. (1985). What's 'new' about the 'new' reproductive technologies? Man Made Women. London, Hutchinson.

Klein, R. D. (1989a). The Making of this Book. Infertility: Women speak out about their experiences of reproductive medicine. London, Pandora Press: 1-7.

Klein, R. D. (1989b). Resistance: From the exploitation of infertility to an exploration of in-fertility. Infertility: Women speak out about their experiences of reproductive medicine. R. D. Klein. London, Pandora Press: 229-295.

Kleinman, A. (1988). The illness narratives : suffering, healing, and the human condition. New York, Basic Books.

Kleinman, A. (1995). Writing at the margin : discourse between anthropology and medicine. Berkeley, University of California Press.

Lalos, A., O. Lalos, et al. (1986). "Depression, Guilt and Isolation among Infertile Women and their Partners." Journal of Psychosomatic Obstetrics and Gynaecology 5: 197-206.

Lampic, C., A. Svanberg, et al. (2006). "Fertility awareness, intentions concerning childbearing, and attitudes towards parenthood among female and male academics." Human Reproduction 21(2): 558-564.

Lasker, J. and S. Borg (1994). In search of parenthood : coping with infertility and hightech conception. Philadelphia, Temple University Press.

Lazarus, E. (1997). "What Do Women Want?" Childbirth and Authoritative Knowledge: Cross-Cultural Perspectives.

Leder, D. (1992). The Body in Medical Thought and Practice, Kluwer Academic Pub.

Lee, C. (1998). Women's health : psychological and social perspectives. London Thousand Oaks, Calif., Sage Publications.

Leiblum, S. R. (1997). Love, Sex, and Infertility: The Impact of Infertility on Couples. Infertility: Psychological Issues and Counselling Strategies. S. R. Leiblum. New York, John Wiley \& Sons, Inc. 
Letherby, G. (1994). "Mother or Not, Mother or What - Problems of Definition and Identity." Womens Studies International Forum 17(5): 525-532.

Letherby, G. (1999). "Other than mother and mothers as others: The experience of motherhood and non-motherhood in relation to 'infertility' and 'involuntary childlessness'." Womens Studies International Forum 22(3): 359-372.

Letherby, G. (2000). "Images and representation of non-motherhood." Reproductive Health Matters 8(16): 143-143.

Letherby, G. (2002a). "Challenging Dominant Discourses: identity and change and the experience of 'infertility' and 'involuntary childlessness." Journal of Gender Studies 11(3): 277-288.

Letherby, G. (2002b). "Childless and bereft?: Stereotypes and realities in relation to 'voluntary' and 'involuntary' childlessness and womanhood." Sociological Inquiry 72(1): 7-20.

Letherby, G. and C. Williams (1999). "Non-motherhood: Ambivalent autobiographies." Feminist Studies 25(3): 719-728.

Lisle, L. (1996). Without child : challenging the stigma of childlessness. New York, Ballantine Books.

Lock, M. and D. Gordon (1988). Introduction. Biomedicine Examined, Kluwer Academic Pub: 3-16.

Lorber, J. and L. J. Moore (2002). Gender and the social construction of illness. Lanham, Rowman \& Littlefield.

Lupton, D. (2003). Medicine as culture : illness, disease and the body in Western societies. London; Thousand Oaks, CA, Sage Publications.

MacDonald, M. (2004). Tradition as a Political Symbol in the New Midwifery in Canada.

Mahlstedt, P. P. (1985). "The psychological component of infertility." Fertil Steril 43(3): 335-46.

Marcus, G. E. and M. M. J. Fischer (1986). Anthropology as cultural critique : an experimental moment in the human sciences. Chicago, University of Chicago Press.

Marsh, M. S. and W. Ronner (1996). The empty cradle : infertility in America from Colonial times to the present. Baltimore, Johns Hopkins University Press.

Marshall, M., Jennings, V. and Cachan, J. (1997). "Reproductive health awareness: an integrated approach to obtaining a high quality of health." Advances in Contraception 13: 313-318. 
Mason, M.-C. (1993). Male infertility--men talking. London; New York, Routledge.

Matthews, A. M. and R. Matthews (1986a). "Beyond the Mechanics of Infertility Perspectives on the Social-Psychology of Infertility and Involuntary Childlessness." Family Relations 35(4): 479-487.

Matthews, R. and A. M. Matthews (1986b). "Infertility and Involuntary Childlessness the Transition to Nonparenthood." Journal of Marriage and the Family 48(3): 641649.

May, E. T. (1995). Barren in the promised land : childless Americans and the pursuit of happiness. New York, BasicBooks.

McAllister, F. and L. Clarke (1998). Choosing Childlessness, Family Policy Studies Centre.

Mechanic, D. and E. H. Volkart (1961). " Stress, Illness Behavior, and the Sick Role." American Sociological Review 26( 1): 51-58.

Menning, B. (1980). "The psychological component of infertility." Fertil Steril 43: 335.

Menning, B. E. (1977). Infertility : a guide for the childless couple. Englewood Cliffs, N.J., Prentice-Hall.

Menzies, H. (1994). The social construction of reproductive technologies and of choice. Misconceptions: The social construction of choice and the new reproductive and genetic technologies. G. Basen, M. Eichler and A. Lippman. Prescott, Voyageur Publishing. 2: 17-32.

Meyers, D. (2001). "The rush to motherhood-Pronatalist discourse and women's autonomy." Signs 26(3): 735-73.

Miall, C. E. (1985). "Perceptions of Informal Sanctioning and the Stigma of Involuntary Childlessness." Deviant Behavior 6(4): 383-403.

Miall, C. E. (1986). "The Stigma of Involuntary Childlessness." Social Problems 33(4): 268-282.

Michie, H. and N. R. Cahn (1997). Confinements : fertility and infertility in contemporary culture. New Brunswick, New Jersey, Rutgers University Press.

Miller, T. (2005). Making sense of motherhood : a narrative approach. Cambridge ; New York, Cambridge University Press.

Monach, J. (2005). "The evidence base for infertility counselling." Journal of Fertility Counselling 12(3): 33-40. 
Monach, J. H. (1993). Childless, no choice : the experience of involuntary childlessness. London; New York, Routledge.

Monga, M., B. Alexandrescu, et al. (2004). "Impact of infertility on quality of life, marital adjustment, and sexual function." Urology 63(1): 126-30.

Morell, C. (1994). Unwomanly Conduct: The Challenges of Intentional Childlessness, Routledge.

Morse, C. A. and E. V. Van Hall (1987). "Psychosocial aspects on infertility: a review of current concepts." Journal of Psychosomatic Obstetrics and Gynecology 6: 157164.

Mosher, W. and C. Bachrach (1982). "Childlessness in the United States: Estimates from the National Survey of Family Growth." Journal of Family Issues 3(4): 517.

Mosher, W. and W. Pratt (1993). "The demography of infertility in the United States." Annu Prog Reprod Med 37: 43.

Motherwell, L. and S. Prudent (1998). "Childlessness and group psychotherapy: Psychological and sociological perspectives." Group 22(3): 145-157.

Murray, C. D. and J. Sixsmith (2002). " Using Internet posts and archives in health research." Health Informatics 8(2): 11-28.

Nettleton, S. (1995). The sociology of health and illness. Cambridge [England] ; Cambridge, MA, Polity Press.

Nettleton, S. (2006). The Sociology of Health and Illness, Polity.

Newton, C. R. (2006). Counselling the Infertile Couple. Infertility Counselling: A Comprehensive Handbook for Clinicians. S. N. Covington and L. H. Burns. Cambridge, Cambridge University Press.

Norris, S. (2001). Reproductive infertility: prevalence, causes, trends and treatments. In Brief. Ottawa, Parliamentary Research Branch, Library of Parliament.

Oakley, A. (1993). Essays on Women, Medicine and Health, Edinburgh University Press.

Oddens, B. J., I. den Tonkelaar, et al. (1999). "Psychosocial experiences in women facing fertility problems--a comparative survey." Hum Reprod 14(1): 255-61.

Olshansky, E. (1987a). "Identity of self as infertile: an example of theory-generating research." ANS Adv Nurs Sci 9(2): 54-63.

Olshansky, E. (1987b). "Infertility and its influence on women's career identities." Health Care Women Int 8(2-3): 185-96. 
Olshansky, E. (1996). "A counseling approach with persons experiencing infertility: implications for advanced practice nursing." Adv Pract Nurs Q 2(3): 42-7.

Page, R. M. (1984). Stigma. London; Boston, Routledge \& Kegan Paul.

Pappert, A. (1989). A Voice for Infertile Women. Infertility: Women speak out about their experiences of reproductive medicine. R. D. Klein. London, Pandora Press: 198- 206.

Park, K. (2002). "Stigma Management among the Voluntarily Childless." Sociological Perspectives 45(1): 21-45.

Parry, D. (2005). "Work, Leisure, and Support Groups: An Examination of the Ways Women with Infertility Respond to Pronatalist Ideology." Sex Roles 53(5): 337 346.

Parsons, T. (1951). The social system. Glencoe, Illinois, Free Press.

Pasch, L., C. Dunkel-Schetter, et al. (2002). "Differences between husbands' and wives' approach to infertility affect marital communication and adjustment." Fertil Steril 77(6): 1241-7.

Paulson, J. D., B. S. Haarmann, et al. (1988). "An investigation of the relationship between emotional maladjustment and infertility." Fertil Steril 49(2): 258-62.

Peck, E. and J. Senderowitz (1974). Pronatalism: the myth of mom \& apple pie. New York, Crowell.

Pepe, M. and T. Byrne (1991). "Women's Perceptions of Immediate and Long-Term Effects of Failed Infertility Treatment on Marital and Sexual Satisfaction." Family Relations 40(3): 303-309.

Peterson, B., C. Newton, et al. (2006a). "Coping processes of couples experiencing infertility." Family Relations 55(2): 227-239.

Peterson, B., C. Newton, et al. (2006b). "Gender differences in how men and women who are referred for IVF cope with infertility stress." Human Reproduction 21(9): 2443.

Petok, W. D. (2006). The Psychology of Gender-Specific Infertility Diagnoses. Infertility Counselling: A Comprehensive Handbook for Clinicians. S. N. Covington and L. H. Burns. Cambridge, Cambridge University Press.

Pfeffer, N. and A. Woolett (1983). The Experience of Infertility. London, Virago Press Limited. 
Ponjaert-Kristoffersen, I. and P. Baetens (1999). "Counselling patients with infertility problems." International Journal for the Advancement of Counselling 21 : 249261.

Prinjha, S., A. Chapple, et al. (2005). "Many people with epilepsy want to know more: a qualitative study." Fam Pract 22(4): 435-41.

Radley, A. (1994). Making sense of illness : the social psychology of health and disease. London; Thousand Oaks, Sage.

Rapp, R. (2006). "Reason To Believe." Culture, Medicine and Psychiatry 30(4): 419-421.

Raval, H., P. Slade, et al. (1987). "The Impact of Infertility on Emotions and the Marital and Sexual Relationship." Journal of Reproductive and Infant Psychology 5: 221234.

Rehner, J. (1989). Infertility: Old Myths, New Meanings. Toronto, Second Story Press.

Reid, E. (1994). "Cultural Formations in Text-Based Virtual Realities." MA Thesis, University of Melbourne, at http://www. ee. mu. oz. au/papers/emr/cult-form. html.

Remennick, L. (2000). "Childless in the Land of Imperative Motherhood: Stigma and Coping Among Infertile Israeli Women." Sex Roles 43(11): 821-841.

Repokari, L., R. Punamaki, et al. (2007). "Infertility treatment and marital relationships: a 1-year prospective study among successfully treated ART couples and their controls." Human Reproduction 22(5): 1481.

RESOLVE (1998-2004). About Us

http://www.resolve.org/site/PageServer?pagename=abt home.

Rheingold, H. (1993). The Virtual Community: Finding Commection in a Computerized World, Addison-Wesley Longman Publishing Co., Inc. Boston, MA, USA.

Rhener, J. (1989). Infertility : old myths, new meanings. Toronto, Second Story Press.

Riessman, C. (2000). "Stigma and Everyday Resistance Practices." Gender and Society 14(1): 111-135.

Riessman, C. K. (1994). Women and Medicalization: A New Perspective. Dominant issues in medical sociology. H. Schwartz. New York, McGraw-Hill: 101-121.

Roudsari, R., H. Allan, et al, (2007). "Looking at infertility through the lens of religion and spirituality: a review of the literature." Human Fertility 10(3): 141-149.

Royal Commission on New Reproductive Technologies (1993). Proceed with Care. Ottawa, Minister of Government Services Canada. 
Sandelowski, M. (1987). "The color gray: ambiguity and infertility." Image J Nurs Sch 19(2): 70-4.

Sandelowski, M. (1988). "Without child: the world of infertile women." Health Care Women Int 9(3): 147-61.

Sandelowski, M. (1990a). "Fault Lines - Infertility and Imperiled Sisterhood." Feminist Studies 16(1): 33-51.

Sandelowski, M. (1993). With child in mind : studies of the personal encounter with infertility. Philadelphia, University of Pennsylvania Press.

Sandelowski, M. (2006). "'Meta-jeopardy": The crisis of representation in qualitative metasynthesis." Nursing Outlook 54(1): 10-16.

Sandelowski, M. and J. Barroso (2006). Handbook for synthesizing qualitative research. New York, NY, Springer Pub. Co.

Sandelowski, M. and S. de Lacey (2002). "The Uses of a" Disease." Infertility Around the Globe: New Thinking on Childlessness, Gender, and Reproductive Technologies: 33-51.

Sandelowski, M., B. G. Harris, et al. (1989). "Mazing: infertile couples and the quest for a child." Image J Nurs Sch 21(4): 220-6.

Sandelowski, M., D. Holditchdavis, et al. (1990). "Living the Life - Explanations of Infertility." Sociology of Health \& Illness 12(2): 195-215.

Sandelowski, M. and C. Pollock (1986). "Women's Experience of Infertility." Image J Nurs Sch 18(4): 140-144.

Sandelowski, M. J. (1990b). "Failures of Volition - Female Agency and Infertility in Historical-Perspective." Signs 15(3): 475-499.

Sawicki, J. (1991). Disciplining Foucault : feminism, power, and the body. New York, Routledge.

Schmidt, L., B. Holstein, et al. (2005a). "Communication and coping as predictors of fertility problem stress: cohort study of 816 participants who did not achieve a delivery after 12 months of fertility treatment." Human Reproduction 20(11): 3248-3256.

Schmidt, L., B. Holstein, et al. (2005b). "Does infertility cause marital benefit? An epidemiological study of 2250 women and men in fertility treatment." Patient Educ Couns 59(3): 244-51.

Schroeder, P. (1988). "Infertility and the world outside." Fertil Steril 49(5): 765-7. 
Scritchfield, S. (1995). "The Social Construction of Infertility: From Private Matter to Social Concern." Images of Issues: Typifying Contemporary Social Problems: $131-46$.

Segall, A. and N. Chappell (1991). "Making sense out of sickness: lay explanations of chronic illness among older adults." Advances in Medical Sociology 2: 115-133.

Seibel, M. M. and M. L. Taymor (1982). "Emotional aspects of infertility." Fertil Steril 37(2): $137-45$.

Shapiro, C. (1982). "The impact of infertility on the marital relationship." Soc Casework: J Contemp Soc Work 7(3): 387-93.

Sherrod, R. (2004). "Understanding the emotional aspects of infertility: implications for nursing practice." J Psychosoc Nurs Ment Health Serv 42(3): 40-7.

Sixsmith, J. and C. D. Murray (2001). "Ethical issues in the documentary data analysis of Internet posts and archives." Qual Health Res 11(3): 423-32.

Slade, P., C. O'Neill, et al. (2007). "The relationship between perceived stigma, disclosure patterns, support and distress in new attendees at an infertility clinic." Human Reproduction.

Søbirk Petersen, T. (2004). "A Woman's Choice?-On Women, Assisted Reproduction and Social Coercion." Ethical Theory and Moral Practice 7(1): 81-90.

Spector, M. and J. I. Kitsuse (2001). Constructing social problems. New Brunswick, NJ, Transaction Publishers.

Starr, P. (1982). The social transformation of American medicine. New York, Basic Books.

Statistics Canada (2008). "Births." The Daily http://www.statcan.ca/english/freepub/84F0210XIE/2006000/bfront1.htm.

Steier, F. (1991). Research and reflexivity. London ; Newbury Park, Calif., Sage.

Stephen, E. and A. Chandra (2000). "Use of Infertility Services in the United States: 1995." Family Planning Perspectives 32(3): 132-137.

Stephen, E. and A. Chandra (2006). "Declining estimates of infertility in the United States: 1982-2002." Fertility and Sterility 86(3): 516-523.

Strauss, A. L. and J. M. Corbin (1998). Basics of qualitative research : techniques and procedures for developing grounded theory. Thousand Oaks, Sage Publications.

Strickler, J. (1992). "The new reproductive technology: problem or solution?" Sociology of Health \& Illness 14(1): 111-132. 
Taylor, A. (2003). "ABC of subfertility: Extent of the problem." BMJ: British Medical Journal 327(7412): 434.

Turkle, S. (1995). Life on the screen, Simon \& Schuster New York.

Turner, B. (1997). "From governmentality to risk: Some reflections on Foucault's contribution to medical sociology." Foucault, Health and Medicine.

Turner, B. S. (1987). Medical power and social knowledge. London; Beverly Hills, Sage Publications.

Turner, B. S. (1992). Regulating bodies : essays in medical sociology. London, England ; New York, N.Y., Routledge.

Ulbrich, P., A. Coyle, et al. (1990). "Involuntary childlessness and marital adjustment: his and hers." J Sex Marital Ther 16(3): 147-58.

Ulrich, M. and A. Weatherall (2000). "Motherhood and Infertility: Viewing Motherhood through the Lens of Infertility." Feminism \& Psychology 10(3): 323.

Van Balen, F. and M. Inhorn (2002). Introduction. Interpreting infertility: A view from the social sciences. Infertility around the globe. New thinking on childlessness, gender, and reproductive technologies: 3-32.

van Balen, F. and T. Trimbos-Kemper (1995). "Involuntarily childless couples: their desire to have children and their motives." J Psychosom Obstet Gynaecol 16(3): $137-44$.

Veevers (1980). Childless by Choice. Toronto, Butterworth \& Co.

Veevers, J. (1972). "The violation of fertility mores: Voluntary childlessness as deviant behavior." Deviant Behavior and Societal Reaction: 571-92.

Veevers, J. (1973a). "Voluntary Childlessness: A Neglected Area of Family Study." The Family Coordinator 22(2): 199-205.

Veevers, J. E. (1973b). "Voluntarily Childless Wives - Exploratory Study." Sociology and Social Research 57(3): 356-366.

Weschler, T. (2002). Taking Charge of Your Fertility. New York, HarperCollins Publisher.

White, L., J. McQuillan, et al. (2006). "Explaining disparities in treatment seeking: the case of infertility." Fertility and Sterility 85(4): 853-857.

Whiteford, L. M. and L. Gonzalez (1995). "Stigma: the hidden burden of infertility." Soc Sci Med 40(1): 27-36.

Wikipedia (2008) en.wikipedia.org/wiki/Tag_cloud 
Williams, G. (1997a). "The genesis of chronic illness: narrative reconstruction." Memory, Identity, Community: The Idea of Narrative in the Human Sciences.

Williams, M. (1997b). "Toward greater understanding of the psychological effects of infertility on women." Psychotherapy in private practice 16(3): 7-26.

Winstein, M. (1999). Your Fertility Signals: Using Them to Achieve or Avoid Pregnancy Naturally. St. Louis, Smooth Stone Press.

Wirtberg, I. (1999). "Trying to become a family; or, parents without children." Marriage and Family Review 28(3-4): 121-133.

Wischmann, T. (2003). "Psychogenic Infertility-Myths and Facts." Journal of Assisted Reproduction and Genetics 20(12): 485-494.

Woods, N., E. Olshansky, et al. (1991). "Infertility: women's experiences." Health Care Women Int 12(2): 179-90.

Woollett, A. (1991). Having Children: Accounts of Childless Women and Women with Reproductive Problems. Motherhood : meanings, practices, and ideologies. A. Phoenix, A. Woollett and E. Lloyd. London, Sage Publications.

Woollett, A. (1996). "Infertility: From "Inside/Out" to "Outside/In"." Feminism \& Psychology 6(1): 74-78.

Wright, J., C. Duchesne, et al. (1991). "Psychosocial distress and infertility: men and women respond differently." Fertil Steril 55(1): 100-8.

Zatylny, R. (2006). "Surviving Infertility: Determining Characteristics of Successful and Unsuccessful Relationships." JOURNAL OF FERTILITY COUNSELLING 13(2): 18.

Zelizer, V. A. R. (1985). Pricing the priceless child : the changing social value of children. New York, Basic Books.

Ziebland, S., A. Chapple, et al. (2004). "How the internet affects patients' experience of cancer: a qualitative study." Bmj 328(7439): 564. 


\section{Appendix 1: Questionnaire and Consent Form}

In the next few pages you will be led through an interview process to document your experience in greater detail. No personally identifying information will be asked or allowed.

\section{Information, Consent and Disclosure What is the FertilityFriend.com TTC Story Database?}

FertilityFriend.com's story database is a place to share and find real life, authentic stories about all aspects of the Trying to Conceive (TTC) journey. FertilityFriend.com members are encouraged to share their personal stories and experiences. We welcome stories from members at all stages of the TTC journey and those who have already become pregnant. The online database of stories can be browsed or searched by keywords and categories on FertilityFriend.com. What is the purpose of the FertilityFriend.com TTC Story Database? The purpose of the TTC Story Database is to help people learn from and share with others who are experiencing or have experienced similar situations. Sharing your story can help others to feel less alone. Reading and writing about our journeys can be healing, encouraging and empowering. We would also like the story database to grow into a resource that provides a broad awareness and understanding about all aspects of the Trying to Conceive (TTC) experience- for people living the experience and also those who work with and are close to those experiencing conception difficulties.

Is my personal identity confidential?

Yes. Your personal identity (name, FertilityFriend.com nickname, email address, or other personally identifying details) will never be shared or associated with your story. To protect your anonymity and privacy, we also require that you do not include any personally identifying information in your story.

What will FertilityFriend.com do with my story?

After your story is submitted and accepted, it will become part of the online searchable database of stories. In addition, your story may be published in a variety of other media as well. Your story, without any personally identifying information, may also be used, in whole or in part, or in aggregate form, in scholarly, academic, promotional and popular publications to raise awareness and understanding about the trying to conceive experience, fertility charting, and the internet as a source of support and information for health related issues. Your story may also be used (without any personally identifying information) by health and social researchers seeking to better understand the trying to conceive experience and the potential of the internet for promoting positive health outcomes.

Who will read my story?

Your story may be read by anyone with an internet connection who searches or browses the database of stories on FertilityFriend.com. We expect that most readers of your story will be people who are trying to conceive and charting their fertility signs using FertilityFriend.com. Your story may also be read by healthcare professionals and scholars in an effort to better understand the personal experiences of people who are trying to 
conceive, the issues that are important to them and the impact of the Internet on facilitating support and education about healthcare issues.

Is submission of a story voluntary?

Yes, submitting your story is completely voluntary and will have no impact on your use of FertilityFriend.com. If you do not wish to participate, simply do not submit a story.

\section{Can I withdraw my submission?}

You can remove your submission from the online database at anytime. If your story is later also published in print or other media, it may not be possible to remove it from those media.

What can I expect when I submit my story?

FertilityFriend.com will guide you through a series of open-ended interview questions about your personal Trying to Conceive (TTC) experience. Depending on how much detail and information you provide, telling your story may take anywhere from a few minutes up to an hour or more. Usually people enjoy telling their personal stories, find that it raises self awareness and find it personally satisfying and even healing. Most people also are pleased with the knowledge that their story may provide comfort, awareness, encouragement and understanding to others. Occasionally, telling personal stories of a sensitive nature can arouse feelings of distress. If telling your story leaves you feeling distressed, depressed or anxious, please contact your personal health care provider.

Before entering any information, we require that you agree to the following:

- You acknowledge that you have read, agree to and understand the usage of the TTC Story Database outlined above.

- By submitting your data, you grant FertilityFriend.com and its affiliates a nonexclusive right of publication in any media of the data submitted.

- The story you are submitting is your own personal story and does not infringe on any copyright.

- You will not be paid or monetarily remunerated for the submission of your story. You agree to waive any and all claims for compensation of submitted materials.

- Your submission may be reviewed by the FertilityFriend.com editorial staff. FertilityFriend.com reserves the right to refuse publication, edit, or request editing at its sole discretion.

- FertilityFriend.com may occasionally collaborate with scholars or permit academic researchers to use the story database (with no identifying information) for research that will contribute to raising awareness about the trying to conceive experience, fertility charting, or the use of the internet as a tool for facilitating health support and positive health outcomes.

Check to signify that you understand and agree to the purpose and conditions as presented in the insert above. 
Click this button $\rightarrow$ Continue

Click Here to return to the gallery without adding a story.

The purpose of this page is to capture the context of your story and help members find stories that relate to their situations. Please click all that apply to your situation (Required entries are denoted by a *):

*General Category

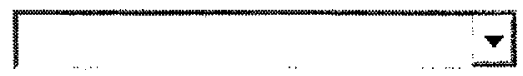

General Context

*Your Age: $\square$ *Months Trying To Conceive: $\square$

*Country:

Please check all that applies

Have been diagnosed with fertility related condition(s)

Have had fertility-related tests and/or

r. Have sought medical help treatments

TTC Your Second Child or More

Click this button $\rightarrow$ Continue

Click Here to return to the gallery without adding a story. Important Recommendations:

- We cannot accept any specific product/service endorsement. To protect the integrity of the database of stories (we wish to prevent marketers and spammers from using it to promote products, services, sites, etc.) please avoid mentioning any brand names or specific products or services. Stories that endorse or promote specific products or services will not be accepted.

- Please tell your own personal story in your own words.

- Your own feelings, your own experiences and your own personal approach are important.

- We are not looking at collecting "recipes" of success but instead we wish to provide a repository of real life experiences.

- Feel free to answer just the questions you would like to answer, that are relevant to you. Feel free to leave any section unanswered.

- Do not provide personal information in your story that would allow you to be personally identified.

- Please use complete sentences and paragraphs to make your story easy to read. 
Keywords:

Please enter a few keywords separated by commas which best describe your story

\section{1-Introduction}

Please describe your general situation here (i.e. medical conditions, reproductive history, personal issues, relationship/family issues, or any other particular situation that you feel is relevant to your TTC experience).

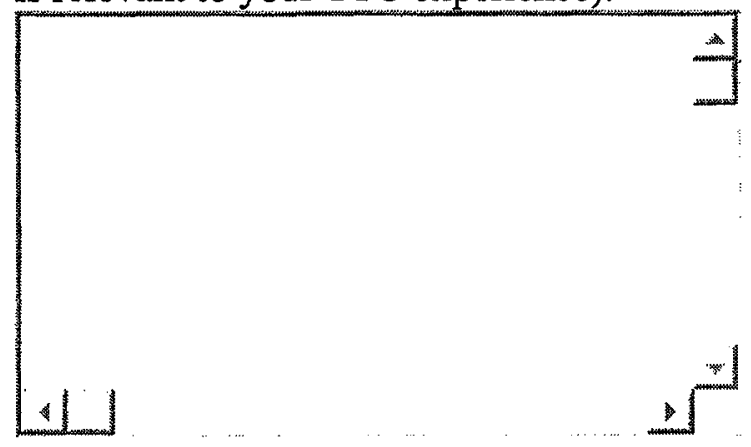

\section{2-Tests, Procedures, Medical consultations}

If applicable, please describe your experiences with any TTC (Trying to Conceive) related medical tests, procedures, consultations and experiences with medical professionals. How did you decide when or whether or not to talk to a health care professional?

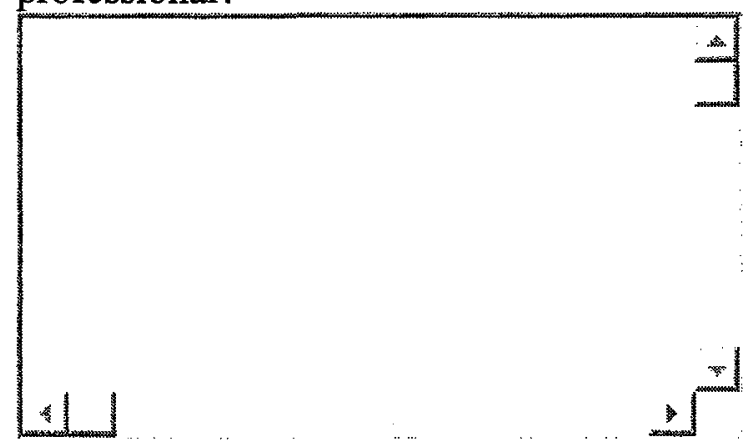

\section{3-Trying-to-Conceive (TTC) experience}

Please tell about important aspects of your Trying to Conceive (TTC) experience. Tell about your journey so far. How have your TTC experiences affected you, your relationships, your feelings about yourself and others? How did you expect your TTC journey to be? How is/was it different from what you expected? How has TTC affected your life? (Please take as much space as you need and feel free to tell about specific instances where TTC has affected you).

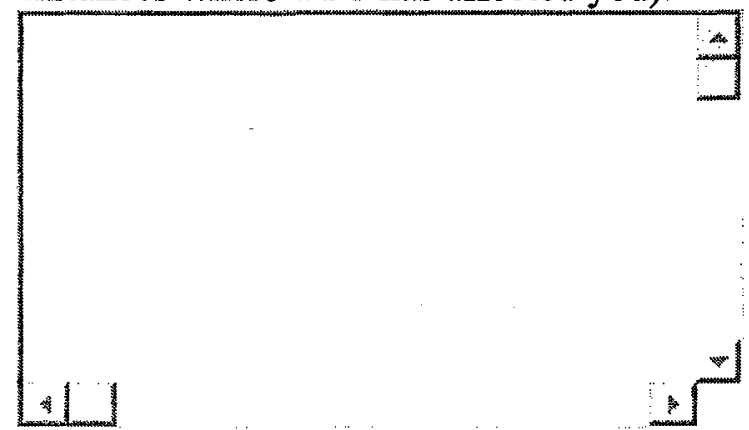




\section{4-Charting Experience}

Please describe the role that fertility charting has played in your TTC experience and what experience or knowledge you have gained from it, if applicable.

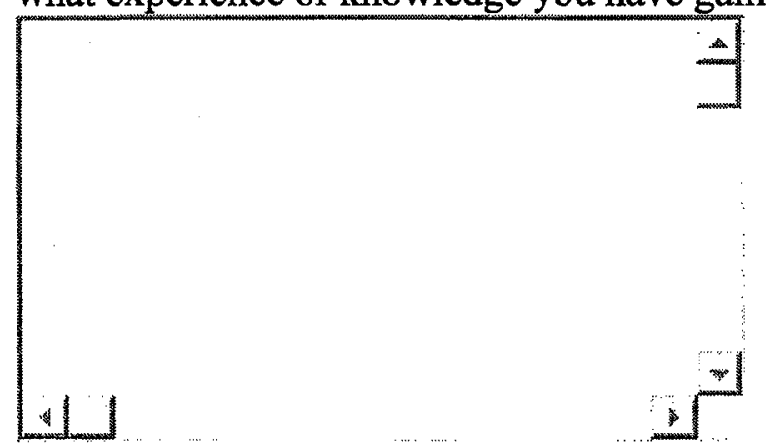

\section{5-The Internet}

As a tool and resource for support and education for health related concerns, the Internet is relatively new. If applicable, please describe your experience of charting, sharing support and information and learning about your fertility signs on the Internet.
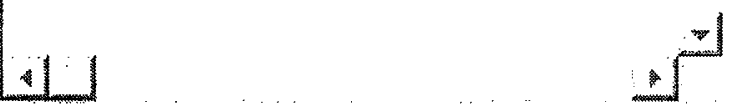

\section{6-Other Thoughts?}

Please use this space to write anything else you would like to share about your experiences or how you see your future.

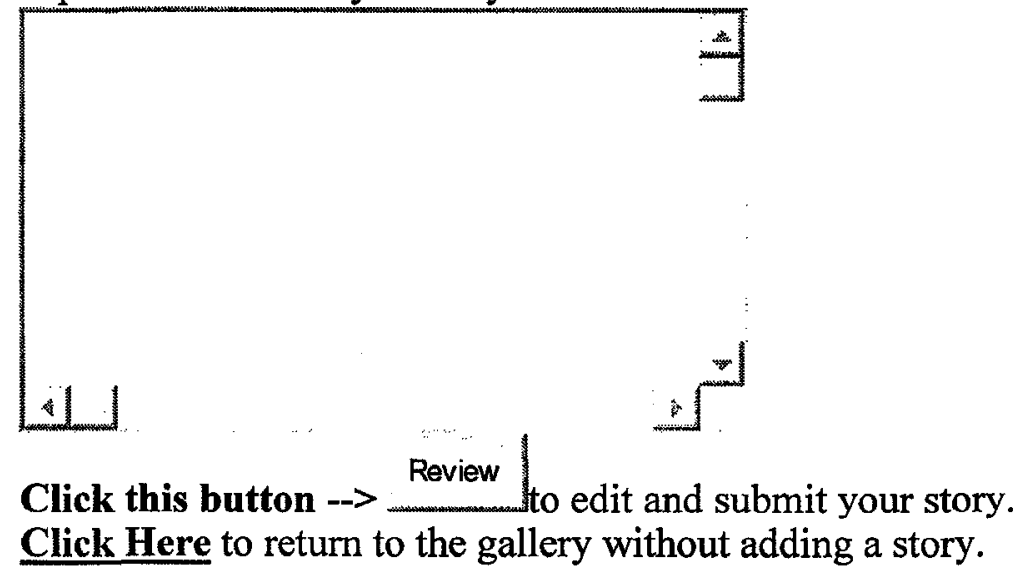




\title{
Appendix 2: Tag Cloud of Free-Form Keywords
}

\author{
\#3 - 12 cycles to conceive - 1983 baby ttc a baby of her own! - 1st baby - 2 other children - 2 years - \\ 2nd child - 2nd trimester miscarriage - 3.5 years of ttc - $35+-36$ y.o. - 42 and still hopeful - 7 months ttc - \\ 7dpo b/w - abortion - acupuncture - adoption - advanced maternal age - \\ after bc - after bc 13 years - after bcp - after bcps - after birth control - \\ after birth control pills - after c-section - after miscarrage - after two $\mathrm{m} / \mathrm{c}$ - ai - ama - \\ amenorrehea - and charting temps - angels - annov cycles after miscarriage - annovulatory -
}

anovulation - anovulatory - antibody disorder - anxiety - arcuate - baby - baby-asprin bcp for 7 years - beta - bfp at 12 dpo - bicornuate uterus - birth control pill - birth control pills birth control problems - blighted ovum - blocked fallopian tubes - blocked tube blocked tubes - bloodwork - borderline sperm results - both in 30's - breastfeeding $2 x /$ day - brother - candida - cervix - charting - checking cervix - chemical pregnancies - chemical pregnancy chinese medicine - chlamydia - C - clomiphene - clotting disorder - cm conceived - conceived naturally - concieved after 3 yrs of unexplained infertilty - confused consistent waking time - cysts - d - d\&c - delayed ovulation - depressing - depression - desperate determined - diabetes - diabetic - donor embryos - donor sperm - early ovulation easily concieved - easy experience - easy first baby easy getting pregnant but have had multiple miscarriages - ectopic - ectopic pregnancy - emotioanl blocks - emotional - endo - Endometrínsis - eptopic - erratic bbt - failed fertility treatment -

family pressure - fear - feel blessed - feelings - femara - femara/letrazole - femera - ferma ferning microscope - fertility - fertility drugs - fertility issues - fet - fibroid removed - fibroids finally success - finding love again and wanting more children after 40 first and secondary unexplained infertility - first baby - first child - first pregnancy - first time follicle study - follistim - following miscarriage - frozen donor - frozen donor sperm - frustrated frustrating - frustration - gastric bypass - gonal-f - happy ending. have just conceived after charting on ff - healthy - healthy llfestyle - heart breaking - heart-breaking heartbreaking - herbs - high blood pressure - high fsh - high fsh mommy - high prolactin levels high risk pregnancy - home - hopeless - hsg - hsg and semen analysis completed - hydrosalpinx hyperthyroid - hyperthyroidism - hypothyroid - hypothyroidism - icsi - implantation cramps in my 20 s - incompetent cervix - infertile - InfertIIV - infertility/miscarriage - infertilty - 
injectibles - insulin resistance - irregular - irregular cycles - irregular menustration irregular periods - iUt - IVf - ivf abroad - ivf conception - ivf w/ icsi - ivf with pgd - ivig known donor - lap - laparoscopy - late 30's - late bfp - late ovulation - lesbian lipiodol flushing - lonely - Iong cycle - Iong cycles - long term be pill user - long term ttc loss - lovenox - low betas - low motility - low post-o temps - low progesterone - low progestrone low semen volume - low sperm count - low sperm volume - Ip bleeding luteal phase defect - luteal phase deficiency - $m / c$ - mad - male factor male factor infertility - male infertility - male infertility factor - marriage - medical condition menopause - metformin - methotrexate - mfi - mid term miscarriage - mid-trimester loss miracle - miracle baby - mirena - MIISCQ minage miscarriage in may - miscarriage progesterone short luteal phase - miscarriage; age - miscarriages miscarried and trying again - miscarry - missed miscarriage - monoamniotic - monochorionic - morphology motherhood - mthfr - mthfr - mullerian anomalies - mullerian anomaly - multiple miscarriage -

multiple miscarriages - multiples - my other two were suprises - natural - naturopathy negative pregnancy tests - never giving up hope of becoming a mum one day. - newlywed - newlyweds no ewcm - no fertility issues - no luck yet - no medical problems - no medications - no meds no miscarriages - no ovulation - no reason why - no symptoms - not as easy as we thought! - obese obsessing - off birth control - older mother (38) - one fallopian tube - one ovary - one ovary/tube one tube - opk's - opks - oral contraceptive use - our journey through infertility - ov watch - ovarian cysts over 30 - over 40 - over six months - overweight - ovidrel - ovulation - ovulation problems -

painfull periods - patience - pco - DCOS - pcos male factor infertility miscarriage -

$\mathrm{pcos} /$ male factor - pg after anovulatory cycles with no meds - philosophy - pituitary mri - polymenorrehea polyps removed - poor morphology - poor responder - ppaf - pregnancy pregnancy after many losses - pregnancy after mc - pregnancy after miscarriage - pregnancy aftet ttc pregnancy and birth - pregnant - pregnant 2. month of ttc - pregnant after ectopic pregnant after inadequate luteal phase - pregnant after miscarriage pregnant after two miscarriages - pregnant with \#1 - pregnant with second child - premature labor primary infertility - progesterone - progesterone blood tests - progetrone - prom - prometrium provera - re - re visits - recurrent miscarriage - recurrent miscarrier - recurring miscarriages regular ovulation - religous - result $=$ baby - retrograde ejaculation - sa - sad - same sex couple scar tissue - scared - second child - second pg was a miscarraige - secondary infertility - septate 
- septate uterus - shettle's method - shettles method - shift work - short cycles - short Ip -

short luteal phase - single using iui - sister - small gestational sac syndrome - soy -

sperm analysis - sperm issues - spotting - starting again after $\mathrm{m} / \mathrm{c}$ - std - stillbirth -

stillborn - stopped birth control - stress - stressful - stressful time in life - success - success at age 40 -

surprise - symptoms - temping - testicular cancer - tests -

the hardest fight i had ever had to battle. - thirties - threatened miscarriage - thrombophilia - thrombophilias

- thyroid issues - timing - tough second - traditional chinese medicine - trigger - triphasic -

triphasic chart - triumphant - trying again! - trying for \#2 - trying for 2 years - trying for baby \# 1 -

trying for baby number 3 - trying later in life - trying over a year - trying to conceive -

trying to conceive first - trying to conceive our first child after being on bcp for 6 years. - EC - ttc \#1 -

ttc \#3 - ttc \#1 - ttc \#1 for 12yrs - ttc \#1 with fibroids - ttc \#2 - ttc \#3 - ttc \#4 -

ttc $12+$ months - ttc 12 mons.+ - ttc 15 months - ttc 1st - ttc 1st child -

ttc 1st with one tube after ectopic pregnancy - ttc 2 years or more - ttc 4 months - ttc 6 months -

ttc 9 months 2nd child - ttc a girl - ttc after 2 children - ttc after 35 - ttc after a miscarriage -

ttc after a missed miscarriage - ttc after bcp - ttc after birth control - ttc after iud - ttc after loss -

ttc after miscarriage - ttc after vasectomy reversal - ttc baby \#2 for more then 2 years now -

ttc daughter - ttc first child - ttc first child after two miscarriages - ttc first time -

ttc for 7 mos after m/c - ttc for over a year - ttc for years - ttc information overload - ttc is hard -

ttc longer than 2 years - ttc more than 6 months - ttc our first child - ttc over 5 years - ttc over a year -

ttc second child - ttc six years - ttc third child - ttc while breastfeeding - ttc while overweight - ttc with a loss

- ttc with mfi. - ttc with one tube - ttc\#1 - ttc\#1 my mo cuishle - ttc\#2 - ttc\#3 - ttcing our 3rd child -

tubal recontruction - tubal reversal - twin - twin pregnancy - twins - two previous miscarriages -

underweight - undiagnosed - unexplained - unexplained infertility - unicornuate uterus -

unusual spotting - upset - using opk - using opks and fertility monitor - uterine abnormality -

uterine anomaly - uterine malformation - uwilling dh - vaginal ultrasound - varicocele - varying Ip -

vasectomy reversal - vulvodynia - weak o - weight loss - yoga - young - 38 - 40 - 


\section{Appendix 3: Initial Taxonomy of Findings/Qualitative Meta-synthesis}

1. The Body: Body Issues and embodiment/Disembodiment

1. -the body as machine

2. -"mind over matter" or "think positive" (idea that mind controls body)

3. -tests/procedures/devices displaying bodily processes (HPT, OPK, ultrasounds/charts)

4. -care of the body through "healthy" living

5. -betrayed by body

6. -weight issues

7. -tracking cycles, body signs

8. - -living in menstrual cycles

9. -failed body

10. -disbelief- "Is it real?" when it happens

11. -"trusting" the body

\section{Gender and Relationship Issues}

1. -TTC as "managed" by female partner; husband's role managed

2. -woman's world

3. -husband acts as "support"

4. -sex issues
a. -frustration of sex on demand
b. -sexually exhausted
c. -romance of ttc is gone
d. -baby making sex is good

5. -Marriage

a. stress

b. closer together

6. -motherhood as source of identity for women

7. -feel unfeminine

8. - "it's something I can't give my husband"

9. -thoughts of divorce

\section{Issues of Stigma, Identity and Roles}

1. -damaged identity

2. -information management (secrets)

3. -isolate self from babies and pregnant women

4. -inferior

5. -failure

6. -feel pity of others

7. -pregnancy is a new stage in life

\section{Morality, Dominant Ideology, Worthiness}

1. -others less worthy having children 
2. -construction of oneself as worthy- married, etc

3. -relative silence regarding alternatives to biological parenthood; biological parenthood as superior

4. -messages of "don't give up hope" and talk of "miracles" perseverance/persistence/never give up/keep trying

5. -no question about the value of the pursuit; "something I've always wanted"

6. -thought of being childless is unbearable

7. "I shouldn't complain"

8. -socially unacceptable thoughts often qualified-ie wanting child of particular gender or not wanting to adopt, or not wanting to persevere

5. Trying to Conceive within the context of Medicalization and the Medical Model

1. -acceptance of medical model

2. -talking like an expert about tests, procedures, medical conditions

3. -ambivalence about medical model

4. -alternative medicine- acupuncture, herbs, etc

5. -rejection of medical model

6. -"natural" vs "unnatural/medical" where natural is construed as superior

7. -surprise doctor with knowledge

8. -private vs public (ie discussion of sex life etc)

9. -physician as "partner"

10. -navigating medical system

11. -litany of medical tests and procedures documented or described

12. -seeing a doctor is "taking action"

\section{Emotional Aspects and The Self}

1. - -stress

2. -jealousy

3. -rollercoaster/yo-yo

4. -grief

5. -hope

6. -worry

7. -anger

8. -learning patience

9. -dashed hopes

10. - everything is affected

11. -anxiety of waiting at end of cycle

12. -feeling incomplete

13. - frustrating

14. -hard to see babies/pregnant women

15. -biological disruption- didn't expect this- not part of the plan

16. - care of self

17. -aching arms, sad

18. -emotionally drained

19. -scared of more loss 
20. - unsure of future

21. -certain there is a baby in the future

22. -all-consuming- always on my mind; obsessed with cycles, getting pregnant

23. -lucky and guilty for being successful quickly

24. -increasingly anxious as time passes

25. -unfair

26. -exhausted

27. -struggle reinforces desire

28. -changed person

a. -more sensitive

b. -stronger

c. -won't take things for granted

\section{Making Sense}

1. -God/Faith/Religion

2. -Medicine/medical condition

3. - "everything happens for a reason"

4. " "hand we were dealt"

5. -"when the time is right"

6. -question or regret previous reproductive choices (abortions and birth control pills)

7. Searching for answers

a. -who is to "blame"?

b. -"what is wrong with me?"

8. -punishment for earlier indiscretions

9. -punishment for earlier ambivalence about wanting kids

10. -karma

\section{Planning, Navigating and Decision Making}

1. -"time", clock, passing time

2. -deciding to be "ready" and getting life in order
a. -money issues
b. -insurance
c. -military
d. -job/career issues
e. -home-ownership
f. -education
g. -"Mr. Right"
h. -marriage/relationship issues
i. -"perfect set-up"

3. -life event or trauma signals decision to start trying

4. -starting out ambivalent about trying

5. -age concerns

6. -want baby for sibling 
7. -negotiating dreams

8. progressing through "steps"

a. Waiting for the next step

b. -adjusting to each new step

c. wondering "what's next?"

d. -phases of "trying"

e. -limit "how far" to go

f. -no tolerance for regret

g. -taking "breaks" for "sanity"

9. -everything (life) is "on hold"; -broken plans; off track in "progress" in life; turning my life upside down

10. -actively managing obsession

11. -pregnancy seen as "achievement"

12. -want to be young parent

\section{Others}

1. -only others with similar experience can understand

2. -insensitive others

3. -people who get pregnant without trying

4. -no one understands

5. -pressure from family/friends, extended family

\section{Internet}

1. -support positive
a. -source of "private" support
b. -happy to tell story for others
c. -enjoy reading others' stories
d. - eases isolation- others who understand

2. support negative

3. support ambivalent

4. -information sceptical

5. -information positive

6. -information ambivalent

\section{More}

-miscarriage/loss

-age issues

-few non traditional couples

-people are not desperate and bitter- they are more than their infertility 


\section{Appendix 4: Selected Analytic Codes}

Entries

keyword

Body- as machine

Body- betrayed by body

count

Body- devices showing body processes

Body- disbelief

Body- failed body

Body- healthy living

Body- living in menstrual cycles

Body- mind over matter

Body-tracking cycles and signs

Body- trusting the body

Body- weight issues

Emotional and Self- all consuming

6

percent

$13 \quad 3.98$

$33 \quad 10.09$

$7 \quad 2.14$

$23 \quad 7.03$

Emotional and Self- anger

11.01

Emotional and Self- anxiety of waiting

Emotional and Self- broken plans, unexpected

Emotional and Self- certain there is a baby in the future

Emotional and Self- changed person- learned patience

0.31

1
13

3.98

64

19.57

13

3.98

13

3.98

Emotional and Self- changed person- more sensitive

30.28

Emotional and Self- changed person- stronger

$\begin{array}{rr}9 & 2.75 \\ 23 & 7.03\end{array}$

3.67

Emotional and Self- changed person- will not take for granted

4.28

Emotional and Self- dashed hopes

5.5

Emotional and Self- depression

Emotional and Self- emotionally drained

3.98

Emotional and Self- feeling incomplete

Emotional and Self- frustrating

7.34

Emotional and Self- fun

Emotional and Self- grief and sadness

2.45

Emotional and Self- hope

1.53

Emotional and Self- increasingly anxious

13.15

0.31

Emotional and Self- jealousy

Emotional and Self- rollercoaster

18.65

Emotional and Self- scared of more loss

Emotional and Self- stress

9.79

5.2

16.82

15.9

3.06

Emotional and Self- struggle reinforces desire

7.95

Emotional and Self- unfair

0.92

Emotional and Self- unsure of future

Emotional and Self- worry

Gender and Relationship- feel unfeminine

4.59

0.92

2.14

Gender and Relationship- husband in support role

Gender and Relationship- managed by female

11.62

Gender and Relationship-Marriage- closer together

4.59

Gender and Relationship-Marriage- stress

Gender and Relationship- motherhood source of identity

12.84

Gender and Relationship- sex issues 
Gender and Relationship- something I canl't do formy husband

Gender and Relationship- thoughts of divorce

Internet- information ambivalent

$\begin{array}{rr}5 & 1.53 \\ 33 & 10.09\end{array}$

Internet- Information positive

Internet- support ambivalent

29.97

Internet- support negative

2.45

Internet- support positive

0.31

Making Sense- blame partner

39.45

Making Sense- blame self

0.31

Making Sense- everything happens for a reason

0.31

Making Sense- God, Faith, Religion

Making Sense- hand we were dealt

Making Sense- punishment for earlier indiscretions

Making Sense- punishment for previous ambivalence about wanting kids

Making Sense- question previous reproductive decisions

Making Sense- searching for answers

Making Sense- when the time is right

Medicalization- acceptance of MM

Medicalization- alternative medicine

Medicalization- ambivalence about MM

Medicalization- drug or treatment effects

Medicalization- litany of medical experiences described

Medicalization- natural vs unnatural

Medicalization- navigating medical system

Medicalization- physician as partner

Medicalization- private vs public

Medicalization- rejection of MM

Medicalization- seeing doctor as taking action

Medicalization- surprise doctor with knowledge

Medicalization- talking like expert

Morality, Ideology, Worthiness- being childless is unbearable, unthinkable

Morality, Ideology, Worthiness- compare with others less fortunate

Morality, Ideology, Worthiness- constructing self as worthy

Morality, Ideology, Worthiness- perseverance and miracles

Morality, Ideology, Worthiness- qualification of socially unacceptable

thoughts

Others

Others- insensitive others

Others- no one understands

Others- only others with similar experience can understand

Others- others succeed, why not me?

Others- pressure from friends and family

Others- undeserving others

Planning and Decisions- age

Planning and Decisions- education

Planning and Decisions- home ownership

Planning and Decisions- insurance

Planning and Decisions- job, career

Planning and Decisions- Let nature decide

Planning and Decisions- Life event signals decision to try

Planning and Decisions- life is on hold, off-track

$13 \quad 3.98$

$41 \quad 12.54$

$2 \quad 0.61$

$3 \quad 0.92$

$2 \quad 0.61$

$21 \quad 6.42$

$18 \quad 5.5$

$10 \quad 3.06$

$154 \quad 47.09$

$31 \quad 9.48$

$51 \quad 15.6$

$11 \quad 3.36$

$83 \quad 25.38$

$19 \quad 5.81$

$25 \quad 7.65$

$14 \quad 4.28$

$9 \quad 2.75$

$1 \quad 0.31$

$92 \quad 28.13$

$\begin{array}{ll}7 & 2.14\end{array}$

$\begin{array}{ll}75 & 22.94\end{array}$

$18 \quad 5.5$

$12 \quad 3.67$

$\begin{array}{ll}76 & 23.24\end{array}$

$52 \quad 15.9$

$2 \quad 0.61$

$9 \quad 2.75$

$31 \quad 9.48$

$10 \quad 3.06$

$13 \quad 3.98$

$61 \quad 18.65$

$12 \quad 3.67$

$31 \quad 9.48$

$30 \quad 9.17$

$2 \quad 0.61$

$7 \quad 2.14$

$18 \quad 5.5$

$18 \quad 5.5$

$5 \quad 1.53$

$6 \quad 1.83$

$16 \quad 4.89$ 
Planning and Decisions- limit how far to go

6.12

Planning and Decisions- manage obsession

4.28

Planning and Decisions- marriage

5.81

Planning and Decisions- military

1.53

Planning and Decisions- money

9.79

Planning and Decisions- negotiating dreams

9.79

Planning and Decisions- no tolerance for regret

3.36

Planning and Decisions- perfect set up

Planning and Decisions- pregnancy as achievement

4.59

Planning and Decisions- progressing through steps

Planning and Decisions- something I always wanted

Planning and Decisions- started naive

Planning and Decisions- started out ambivalent

Planning and Decisions- suitable spouse

Planning and Decisions- take breaks for sanity

Planning and Decisions- time

Planning and Decisions- want baby for sibling

Stigma and Identity

Stigma and Identity- damaged identity, failure, inferior

Stigma and Identity- feel pity of others

Stigma and Identity- information management, secrets

Stigma and Identity- pregnancy as new stage of life

Stories- hope it helped

Stories- interactive

Stories- other stories helpful

Emotional and Self

Emotional and Self -feel isolated

Emotional and Self- care of self

Emotional and Self| feel isolated

Gender and Relationship

Gender and Relationship- Marriage

Gender and Relationship- sex issues- baby

making sex good

Gender and Relationship- sex issues-

sexually exhausted

Internet

Internet- information sceptical

Internet- support positive- eases isolation

Internet- support positive- enjoy others'

stories

Making Sense

Morality, Ideology, Worthiness

Planning and Decisions
Deleted

Deleted

Deleted

Deleted

Deleted

Deleted

Deleted

Deleted

Deleted

Deleted

Deleted

Deleted

Deleted

Deleted

Deleted

Merged

to
Body- betrayed by body 
Emotional and Self- everything affected

Emotional and Self- learning patience Gender and Relationship- sex issuesromance gone

Gender and Relationship- sex issues- sex on demand unsatisfying

Internet- support positive- happy to tell story for others

Internet- support positive- source of private support

Making Sense- Medicine, medical condition Making Sense- searching for answers- what is wrong with me?

Making Sense- searching for answers- who is to blame?

Medicalization

Morality, Ideology, Worthiness- others less worthy

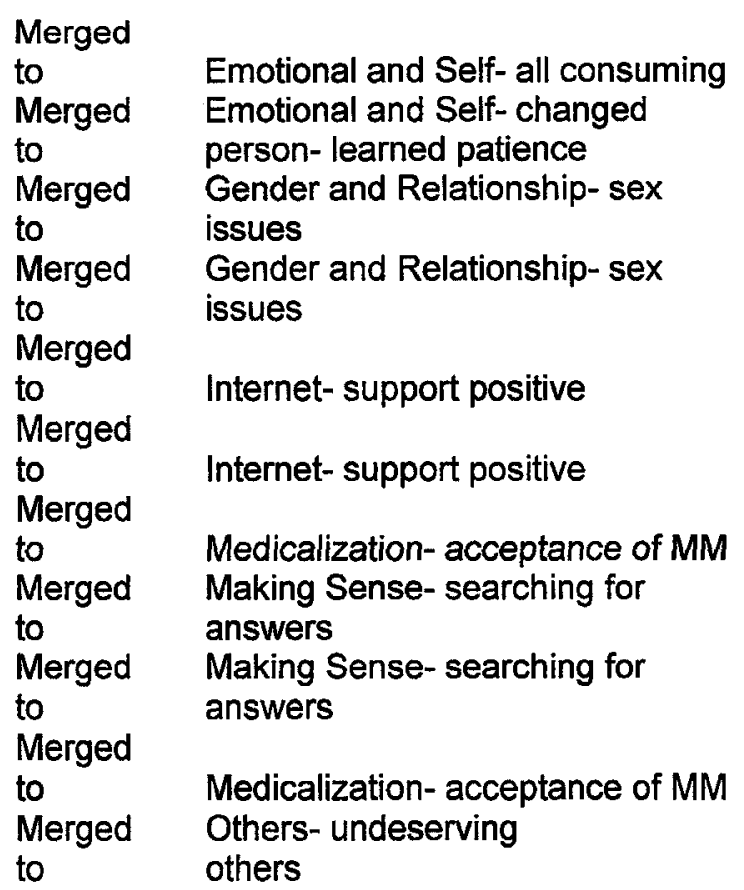




\section{Appendix 5: Selected Screenshots from Fertilityfriend.com}

Figure 9 Sereenshot of FertilityFriend.com front page

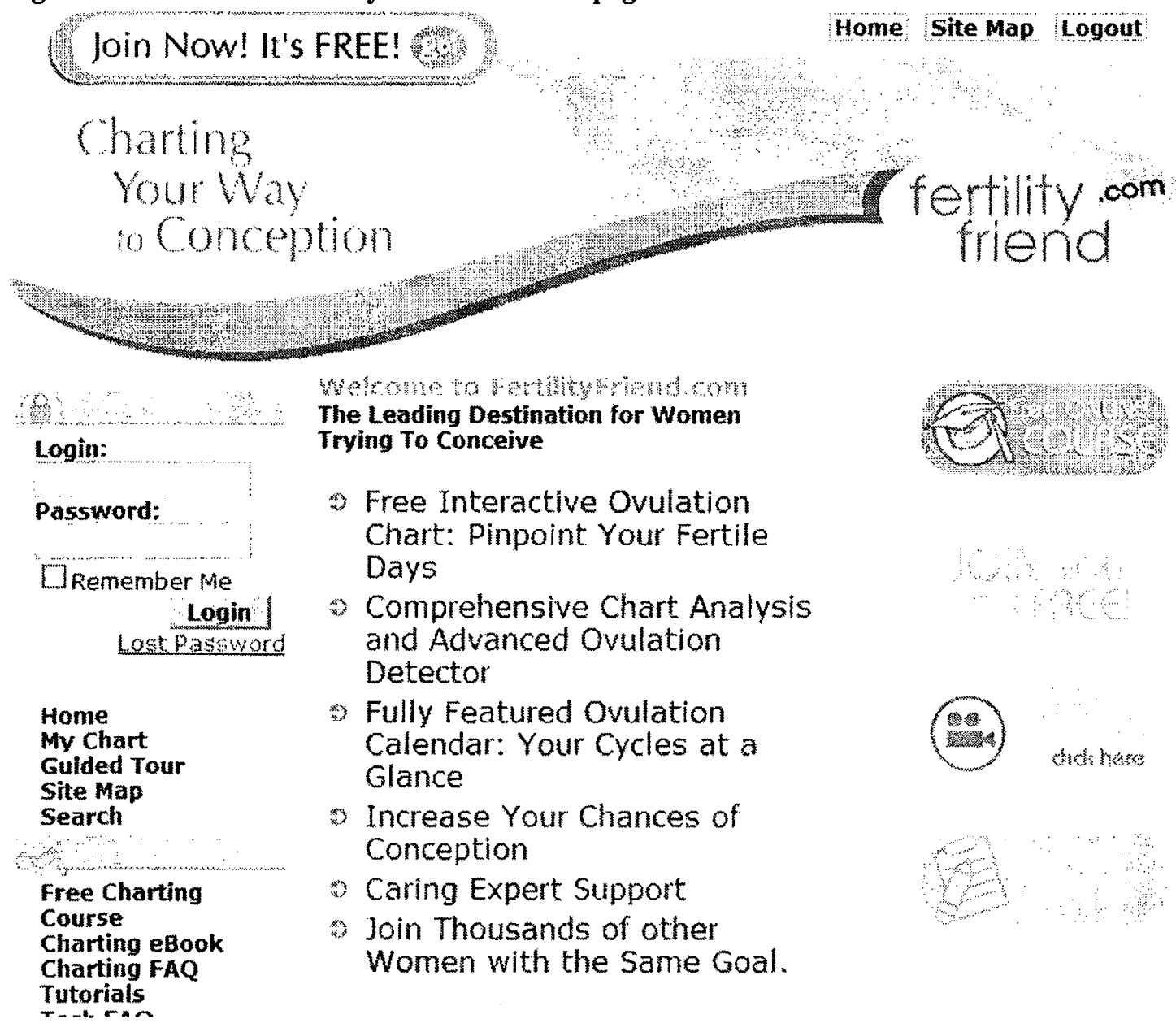


Figure 10 Screenshot of front page of FertilityFriend.com cont.

Story Gallery
Chart Gallery
HPT/OPK Photo
Gallery
Message Boards
Site Blog
Games
Ordering Info
My Account
Support
About Us
Privacy Policy
i.
Pregnancy
Tracker
Ticker Factory

What's New? RESerom

RECENT MESSAGE OOARD POSTS

RECENT VIP suppoRT POs 15

: Wamart het

$:$ Iamso confused?

: Not nure of o- what should imart:

$\therefore$ Testing at 13000 ? on thart?

$:$ : 9050 frugtratedul

$:$ When tid io?

\section{RECENT RNOUUCENENTS}

FEATURED FAOS

: Sulg whee

: Compal fuid pater anjlyzer

$\therefore$ Newchatrooms \& 0355 word protscted forums

$\therefore$ Charinabovefs

$\therefore$ BET ard Travel

$:$ Scant Cervicaifluid

\section{FATUREd TRYTWG TO CONCEIVE STORY}

Category: Trying to Conceive Country: United States

General Context: Have had fertility-related tests and/or treatments II TC Your Second Child or More

Keywords: scar tissue, blocked fallopian tubes

We have been ttc for about 3 years. I have a 7 year old from a previous relationship, which was conceived naturally at age 24. I had a text book pregnancy, no problems. I had HPV at age 19 and had to have my cervics irozen.

Read the full story 
Figure 11 Screenshot of front page cont.

MOST PRCENT CHART GALERY EMTRY

There are currenty 35612 charts in the gallery.

Category: fremeney.

Keywords: Breastreeding | Early HP $\div<<12 \mathrm{dpo}$ / Late Oviation / Uaino

OPK | Checking Cervix I No Meds | Age: 32 | Months TT: I

Fertilityfriend.con

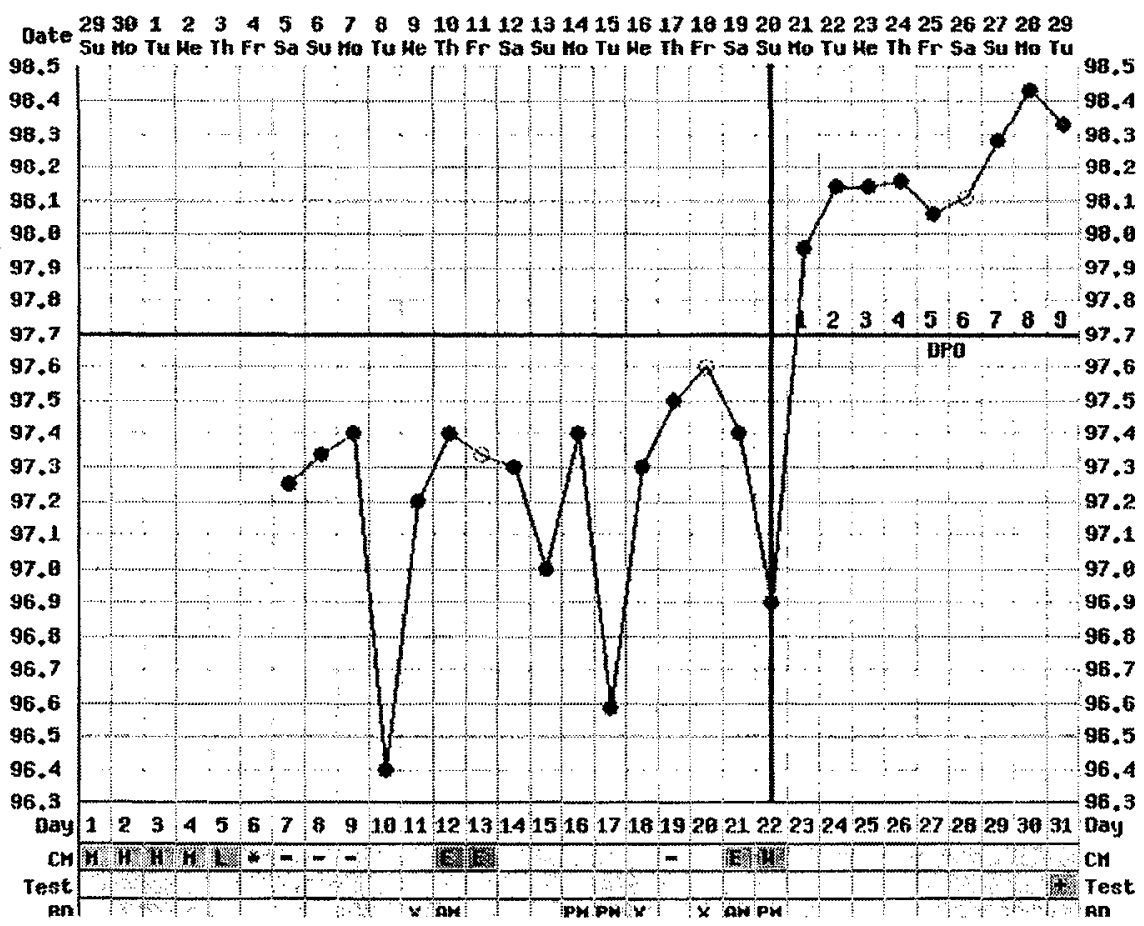


Figure 12 Screenshot of Software Data Entry Page

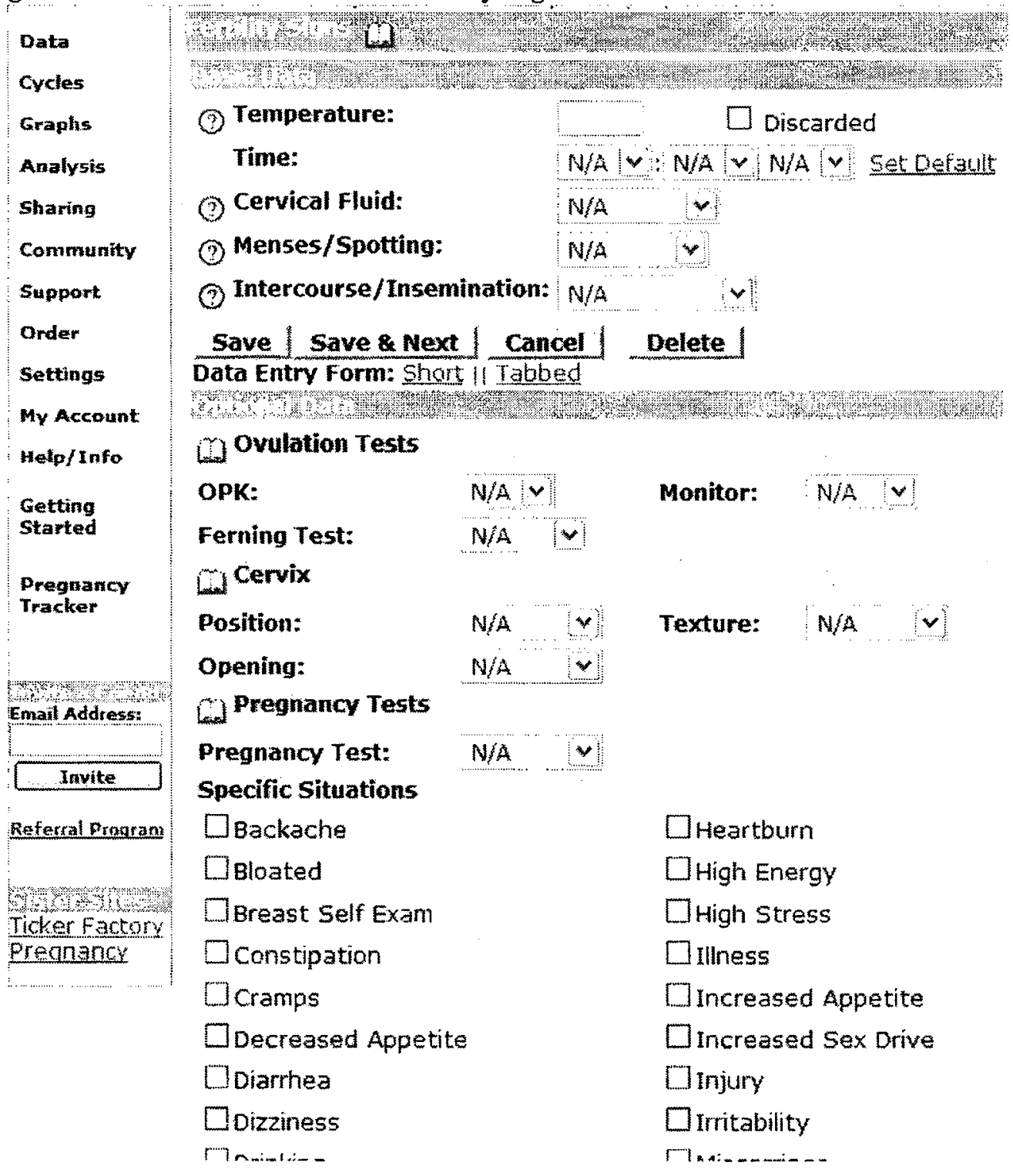


Figure 13 Screenshot of Annotated Fertility Chart

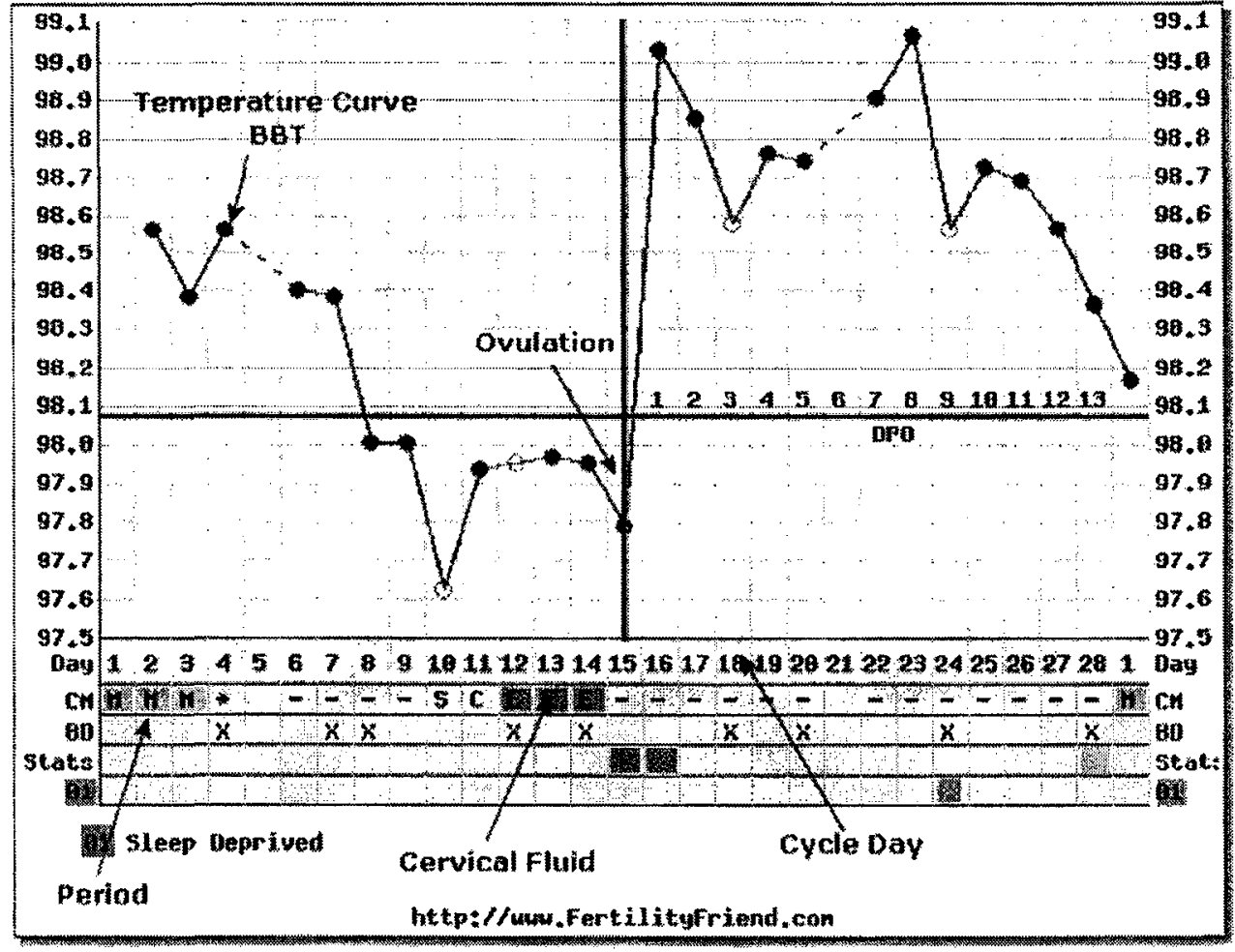


Figure 14 Message Board Screenshots

\section{General TTC}

\section{Waiting To Test}

\section{New Topic Main Circles $\rightarrow$ Waiting To Test}

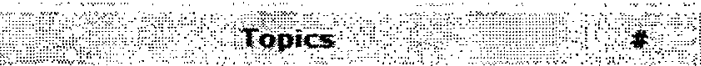

$\rightarrow$ D Let's Talk About Cramping

Q) "Dow pics. DGoto pas: 1,21

(6) $\rightarrow$ another poas for you ladies $90 \%, 1,2$ [DGoto page: $2,2,3]$

(a) $\phi$ D In's been so long since l was

last able to do this....

(a) + Dor thos who wonder about late ish EFPu

[ D Goto page: $1,2.3$ ]

Aryone eise 2 DPO today? Wannat

(a) Aait with me??

[DGoto pige: $1,2, \underline{3}$ ]

(a) posinive OPK on 7 apo

What are your opinions on 'Drink

(a) will in's Pink'?

( Oboto page: 1,2 ]

(0) How heavy can implantation spotting tya?
(4) $\rightarrow[$ anyone due to test 25 jum

(a) Anyone at 6Dro

\section{New Touic Main Circles - $>$ General TTC}

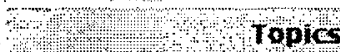

(a) $\rightarrow 0[$ Poll ] CBEFH vs Ferning

Microseope

(6) $\rightarrow$ confused and feetrug on the exp?

(9) $\rightarrow$ D meoplasma

(6) $\rightarrow \mathrm{D}$ Testing egg tuality / Egg "age" 1

24

(0) Need help finding a drit Raleigin / cary areall

3

(4) opk compused...hetpin

6

(3) Molantation spotting?

1

(a) First RE Appt tomorrow-Help 14 please

6) Nidwife vs, of... can anyone help with this:

35

(a) 5 A......is it exponstue??

(0) hoy 1 am sooo scaned to zest.. should just

(3) Heta results

[DGoto page: Ir 2]

(a) mausea before testing

(9) No o any advice please 


\section{Appendix 6: Selected Cross-tables Discussed in the} Thesis

\begin{tabular}{|c|c|c|c|c|}
\hline \multicolumn{5}{|c|}{$\begin{array}{c}\text { Table } 1 \\
\text { Failed Body by Time TTC }\end{array}$} \\
\hline & & \multicolumn{3}{|c|}{ Time TTC } \\
\hline & & -12 Months & 12 Months + & Total \\
\hline \multirow[t]{3}{*}{ Failed Body } & No & $97.5 \%$ & $88.5 \%$ & $92.9 \%$ \\
\hline & Yes & $2.5 \%$ & $11.5 \%$ & $7.1 \%$ \\
\hline & $\mathrm{n}$ & 159 & 165 & 324 \\
\hline
\end{tabular}

Pearson Chi-Square $=9.944, p=.002$

Table 2

Damaged Identity by Time TTC

\begin{tabular}{|l|r|r|r|r|}
\hline & & \multicolumn{3}{|c|}{ Time TTC } \\
\hline & & -12 Months & 12 Months & Total \\
\hline \multirow{2}{*}{$\begin{array}{l}\text { Damaged } \\
\text { Identity }\end{array}$} & No & $95.6 \%$ & $87.9 \%$ & $91.7 \%$ \\
\cline { 2 - 5 } & Yes & $4.4 \%$ & $12.1 \%$ & $8.3 \%$ \\
\cline { 2 - 5 } & $\mathrm{n}$ & 159 & 165 & 324 \\
\hline
\end{tabular}

Pearson Chi-Square $=6.315, p=.012$ 
Table 3

Perseverance and Miracles

by Time TTC

\begin{tabular}{|r|r|r|r|r|}
\hline & & \multicolumn{3}{|c|}{ Time TTC } \\
\hline & & -12 Months & 12 Months + & Total \\
\hline Failed Body & No & $90.6 \%$ & $77.6 \%$ & $84.0 \%$ \\
\cline { 2 - 5 } & Yes & $9.4 \%$ & $22.4 \%$ & $16.0 \%$ \\
\cline { 2 - 5 } & n & 159 & 165 & 324 \\
\hline
\end{tabular}

Pearson Chi-Square $=1.014 \mathrm{E} 1, \mathrm{p}=.001$

Table 4

Jealousy by Time TTC

\begin{tabular}{|r|r|r|r|r|}
\hline & & \multicolumn{3}{|c|}{ Time TTC } \\
\hline & & -12 Months & 12 Months + & Total \\
\hline Jealousy & No & $90.6 \%$ & $75.8 \%$ & $83.0 \%$ \\
\cline { 2 - 5 } & Yes & $9.4 \%$ & $24.2 \%$ & $17.0 \%$ \\
\hline n & 159 & 165 & 324 \\
\hline
\end{tabular}

Pearson Chi-Square $=1.260 \mathrm{E} 1, \mathrm{p}=.000$ 


\begin{tabular}{|r|r|r|r|r|}
\hline \multicolumn{4}{|c|}{ Table 5 } \\
\hline & & \multicolumn{3}{|c|}{ Time TTC } \\
\hline & & -12 Months & 12 Months & Total \\
\hline Rollercoaster & No & $89.9 \%$ & $78.2 \%$ & $84.0 \%$ \\
\cline { 2 - 5 } & Yes & $10.1 \%$ & $21.8 \%$ & $16.0 \%$ \\
\cline { 2 - 5 } & n & 159 & 165 & 324 \\
\hline
\end{tabular}

Pearson Chi-Square $=8.305, p=.004$

\begin{tabular}{|r|r|r|r|r|}
\hline \multicolumn{5}{|c|}{ Table 6 } \\
\hline \multicolumn{3}{|c|}{ Grief and Sadness by TTC 12 Months } \\
\hline & & \multicolumn{3}{c|}{ Time TTC } \\
\hline & & -12 Months & 12 Months & Total \\
\hline Grief and Sadness & No & $88.1 \%$ & $74.5 \%$ & $81.2 \%$ \\
\cline { 2 - 5 } & Yes & $11.9 \%$ & $25.5 \%$ & $18.8 \%$ \\
\cline { 2 - 5 } & $\mathrm{n}$ & 159 & 165 & 324 \\
\hline
\end{tabular}

Pearson Chi-Square $=9.663, p=.002$ 
Table 7

All Consuming by Time TTC

\begin{tabular}{|r|r|r|r|r|}
\hline & & \multicolumn{3}{|c|}{ Time TTC } \\
\hline & & -12 Months & 12 Months & Total \\
\hline All Consuming & No & $86.8 \%$ & $75.8 \%$ & $81.2 \%$ \\
\cline { 2 - 5 } & Yes & 21 & 40 & 61 \\
\cline { 2 - 5 } & $\mathrm{n}$ & 159 & 165 & 324 \\
\hline
\end{tabular}

Pearson Chi-Square $=6.452, \mathrm{p}=.011$

Table 8

Negotiating Dreams by TTC 12 Months

\begin{tabular}{|l|r|r|r|r|}
\hline & & \multicolumn{3}{|c|}{ Time TTC } \\
\hline & & -12 Months & 12 Months & Total \\
\hline $\begin{array}{l}\text { Negotiating } \\
\text { Dreams }\end{array}$ & No & $94.3 \%$ & $86.1 \%$ & $90.1 \%$ \\
\cline { 2 - 5 } & Yes & $5.7 \%$ & $13.9 \%$ & $9.9 \%$ \\
\cline { 2 - 5 } & $\mathrm{N}$ & 159 & 165 & 324 \\
\hline
\end{tabular}

Pearson Chi-Square $=6.235, \mathrm{p}=.013$ 


\begin{tabular}{|l|r|r|r|r|}
\hline \multicolumn{5}{|c|}{ Table 9 } \\
\hline \multicolumn{3}{|c|}{ No Tolerance for Regret by Time TTC } \\
\hline & & \multicolumn{3}{c|}{ Time TTC } \\
\hline & & -12 Months & 12 Months + & Total \\
\hline \multirow{2}{*}{$\begin{array}{l}\text { No Tolerance for } \\
\text { Regret }\end{array}$} & No & $98.7 \%$ & $94.5 \%$ & $96.6 \%$ \\
\cline { 2 - 5 } & Yes & $1.3 \%$ & $5.5 \%$ & $3.4 \%$ \\
\cline { 2 - 5 } & $\mathrm{n}$ & 159 & 165 & 324 \\
\hline
\end{tabular}

Pearson Chi-Square $=4.348, p=.037$

\begin{tabular}{|l|r|r|r|r|}
\hline \multicolumn{5}{|c|}{ Table 10 } \\
\multicolumn{3}{|c|}{ Life is on Hold/ Off-Track by } \\
Time TTC \\
\hline & & \multicolumn{3}{c|}{ Time TTC } \\
\hline & & -12 Months & 12 Months & Total \\
\hline \multirow{2}{*}{$\begin{array}{l}\text { Life is on Hold/ } \\
\text { Off-Track }\end{array}$} & No & $98.1 \%$ & $92.1 \%$ & $95.1 \%$ \\
\cline { 2 - 5 } & Yes & $1.9 \%$ & $7.9 \%$ & $4.9 \%$ \\
\cline { 2 - 5 } & $\mathrm{n}$ & 159 & 165 & 324 \\
\hline
\end{tabular}

Pearson Chi-Square $=6.193, p=.013$ 


\begin{tabular}{|r|r|r|r|r|}
\hline \multicolumn{5}{|c|}{ Table 11 } \\
\hline \multicolumn{3}{|c|}{ Manage Obsession by Time TTC } \\
\hline & & \multicolumn{3}{c|}{ Time TTC } \\
\hline & & -12 Months & 12 Months & Total \\
\hline Manage Obsession & No & $98.1 \%$ & $93.3 \%$ & $95.7 \%$ \\
\cline { 2 - 5 } & Yes & $1.9 \%$ & $6.7 \%$ & $4.3 \%$ \\
\cline { 2 - 5 } & $\mathrm{n}$ & 159 & 165 & 324 \\
\hline
\end{tabular}

Pearson Chi-Square $=4.475, p=.034$

\begin{tabular}{|r|r|r|r|r|}
\hline \multicolumn{4}{|c|}{ Table 12 } \\
\hline \multicolumn{3}{|c|}{ Insensitive Others by Time TTC } \\
\hline & & \multicolumn{3}{c|}{ Time TTC } \\
\hline & & -12 Months & 12 Months & Total \\
\hline Insensitive Others & No & $94.3 \%$ & $86.7 \%$ & $90.4 \%$ \\
\cline { 2 - 5 } & Yes & $5.7 \%$ & $13.3 \%$ & $9.6 \%$ \\
\cline { 2 - 5 } & $\mathrm{n}$ & 159 & 165 & 324 \\
\hline
\end{tabular}

Pearson Chi-Square $=5.510, p=.019$ 


\begin{tabular}{|l|r|r|r|r|}
\hline \multicolumn{4}{|c|}{$\begin{array}{l}\text { Table 13 } \\
\text { Others succeed, why not me? } \\
\text { by Time TTC }\end{array}$} \\
\hline & & \multicolumn{3}{|c|}{ Time TTC } \\
\hline & & -12 Months & 12 Months & Total \\
\hline \multirow{2}{*}{$\begin{array}{l}\text { Others succeed, } \\
\text { why not me? }\end{array}$} & No & $86.8 \%$ & $75.8 \%$ & $81.2 \%$ \\
\cline { 2 - 5 } & Yes & $13.2 \%$ & $24.2 \%$ & $18.8 \%$ \\
\cline { 2 - 5 } & n & 159 & 165 & 324 \\
\hline
\end{tabular}

Pearson Chi-Square $=6.452, p=.011$

Table 14

Depression by Time TTC

\begin{tabular}{|r|r|r|r|r|}
\hline & & \multicolumn{3}{|c|}{ Time TTC } \\
\hline & & -12 Months & 12 Months & Total \\
\hline Depression & No & $96.9 \%$ & $88.5 \%$ & $92.6 \%$ \\
\cline { 2 - 5 } & Yes & $3.1 \%$ & $11.5 \%$ & $7.4 \%$ \\
\cline { 2 - 5 } & $\mathrm{N}$ & 159 & 165 & 324 \\
\hline
\end{tabular}

Pearson Chi-Square $=8.272, p=.004$ 


\begin{tabular}{|l|r|r|r|r|}
\hline \multicolumn{5}{|c|}{ Table 15 } \\
\multicolumn{2}{|c|}{ Failed Body by TTC with medical help } \\
\hline & & TTC with medical help \\
\hline & & No & Yes & Total \\
\hline Failed Body & No & $98.1 \%$ & $90.3 \%$ & $92.9 \%$ \\
\cline { 2 - 5 } & Yes & $1.9 \%$ & $9.7 \%$ & $7.1 \%$ \\
\cline { 2 - 5 } & $\mathrm{n}$ & 107 & 217 & 324 \\
\hline
\end{tabular}

Pearson Chi-Square $=6.625, \mathrm{p}=0.010$

Table 16

Husband in Support Role by TTC with medical help

\begin{tabular}{|l|l|r|r|r|}
\hline & & \multicolumn{3}{|c|}{ TTC with medical help } \\
\hline & & No & Yes & Total \\
\hline \multirow{2}{*}{$\begin{array}{l}\text { Husband in Support } \\
\text { Role }\end{array}$} & No & $93.5 \%$ & $85.7 \%$ & $88.3 \%$ \\
\cline { 2 - 5 } & Yes & $6.5 \%$ & $14.3 \%$ & $11.7 \%$ \\
\cline { 2 - 5 } & n & 107 & 217 & 324 \\
\hline
\end{tabular}

Pearson Chi-Square $=4.151, \mathrm{p}=0.042$ 


\section{Table 17}

Sex Issues by TTC with medical help

\begin{tabular}{|r|r|r|r|r|}
\hline & & \multicolumn{3}{|c|}{ TTC with medical help } \\
\hline \multirow{3}{*}{ Sex Issues } & & No & Yes & Total \\
\cline { 2 - 5 } & No & $83.2 \%$ & $90.3 \%$ & $88.0 \%$ \\
\cline { 2 - 5 } & Yes & $16.8 \%$ & $9.7 \%$ & $12.0 \%$ \\
\cline { 2 - 5 } & n & 107 & 217 & 324 \\
\hline
\end{tabular}

Pearson Chi-Square $=3.455, \mathrm{p}=0.063$

\section{Table 18}

Marriage Stress by TTC with medical help

\begin{tabular}{|r|r|r|r|r|}
\hline & & \multicolumn{3}{|c|}{ TTC with medical help } \\
\hline & & No & \multicolumn{1}{c|}{ Yes } & Total \\
\hline Marriage Stress & No & $89.7 \%$ & $84.8 \%$ & $86.4 \%$ \\
\cline { 2 - 5 } & Yes & $10.3 \%$ & $15.2 \%$ & $13.6 \%$ \\
\cline { 2 - 5 } & n & 107 & 217 & 324 \\
\hline
\end{tabular}

Pearson Chi-Square $=1.482, \mathrm{p}=.223$ 
Table 19

Marriage Closer Together by TTC with medical help

\begin{tabular}{|l|l|r|r|r|}
\hline & & \multicolumn{3}{|c|}{ TTC with medical help } \\
\hline & & \multicolumn{1}{|c|}{ No } & Yes & Total \\
\hline $\begin{array}{l}\text { Marriage Closer } \\
\text { Together }\end{array}$ & No & $94.4 \%$ & $83.4 \%$ & $87.0 \%$ \\
\cline { 2 - 5 } & Yes & $5.6 \%$ & $16.6 \%$ & $13.0 \%$ \\
\cline { 2 - 5 } & n & 107 & 217 & 324 \\
\hline
\end{tabular}

Pearson Chi-Square $=7.661, p=.006$

\section{Table 20}

Perseverance and Miracles by TTC with medical help

\begin{tabular}{|l|l|r|r|r|}
\hline & & \multicolumn{3}{|c|}{ TTC with medical help } \\
\hline & & \multicolumn{1}{c|}{ No } & \multicolumn{1}{c|}{ Yes } & Total \\
\hline $\begin{array}{l}\text { Perseverance and } \\
\text { Miracles }\end{array}$ & No & $92.5 \%$ & $79.7 \%$ & $84.0 \%$ \\
\cline { 2 - 6 } & Yes & $7.5 \%$ & $20.3 \%$ & $16.0 \%$ \\
\cline { 2 - 5 } & n & 107 & 217 & 324 \\
\hline
\end{tabular}

Pearson Chi-Square $=8.714, p=.003$ 
Table 21

Rollercoaster by TTC with medical help

\begin{tabular}{|r|r|r|r|r|}
\hline & & \multicolumn{3}{|c|}{ TTC with medical help } \\
\hline & & No & \multicolumn{1}{c|}{ Yes } & Total \\
\hline \multirow{3}{*}{ Rollercoaster } & No & $89.7 \%$ & $81.1 \%$ & $84.0 \%$ \\
\cline { 2 - 5 } & Yes & $10.3 \%$ & $18.9 \%$ & $16.0 \%$ \\
\cline { 2 - 5 } & n & 107 & 217 & 324 \\
\hline
\end{tabular}

Pearson Chi-Square $=3.946^{\prime} \mathrm{p}=.047$

Table 22

Anxiety of Waiting by TTC with Medical Help

\begin{tabular}{|r|r|r|r|r|}
\hline & & \multicolumn{3}{|c|}{ TTC with Medical Help } \\
\hline & & No & Yes & Total \\
\hline Anxiety of Waiting & No & $92.5 \%$ & $97.7 \%$ & $96.0 \%$ \\
\cline { 2 - 5 } & Yes & $7.5 \%$ & $2.3 \%$ & $4.0 \%$ \\
\cline { 2 - 5 } & n & 107 & 217 & 324 \\
\hline
\end{tabular}

Pearson Chi-Square $=4.978, p=.026$ 
Table 23

Frustrating by TTC with medical help

\begin{tabular}{|r|r|r|r|r|}
\hline & & \multicolumn{3}{|c|}{ TTC with medical help } \\
\hline & & No & Yes & Total \\
\hline Frustrating & No & $93.5 \%$ & $83.4 \%$ & $86.7 \%$ \\
\cline { 2 - 5 } & Yes & $6.5 \%$ & $16.6 \%$ & $13.3 \%$ \\
\cline { 2 - 5 } & n & 107 & 217 & 324 \\
\hline
\end{tabular}

Pearson Chi-Square $=6.286, \mathrm{p}=.012$

\begin{tabular}{|r|r|r|r|r|}
\hline \multicolumn{4}{|c|}{ Table 24} \\
All consuming by TTC with medical help \\
\hline & & TTC with medical help \\
\hline & & No & Yes & Total \\
\hline All consuming & No & $87.9 \%$ & $77.9 \%$ & $81.2 \%$ \\
\cline { 2 - 5 } & Yes & $12.1 \%$ & $22.1 \%$ & $18.8 \%$ \\
\cline { 2 - 5 } & n & 107 & 217 & 324 \\
\hline
\end{tabular}

Pearson Chi-Square $=4.661, \mathrm{p}=.031$ 


\begin{tabular}{|c|r|r|r|r|}
\hline \multicolumn{4}{|c|}{ Table 25 } \\
Changed Person- More Sensitive \\
by TTC with medical help
\end{tabular}

Pearson Chi-Square $=6.145, p=.013$

\begin{tabular}{|l|r|r|r|}
\hline \multicolumn{4}{|c|}{ Table 26 } \\
Changed Person- Stronger \\
by TTC with medical help
\end{tabular}

Pearson Chi-Square $=4.431, \mathrm{p}=.035$ 
Table 27

Changed Person-Will not take for granted by TTC with medical help

\begin{tabular}{|l|r|r|r|r|}
\hline & & \multicolumn{3}{|c|}{ TTC with medical help } \\
\hline & & No & \multicolumn{1}{c|}{ Yes } & Total \\
\hline $\begin{array}{l}\text { Changed Person- } \\
\text { Will not take for granted }\end{array}$ & No & $99.1 \%$ & $92.2 \%$ & $94.4 \%$ \\
\cline { 2 - 5 } & Yes & $.9 \%$ & $7.8 \%$ & $5.6 \%$ \\
\cline { 2 - 5 } & n & 107 & 217 & 324 \\
\hline
\end{tabular}

Pearson Chi-Square $=6.502, \mathrm{p}=.011$

\section{Table 28}

God, Faith, Religion by TTC with medical help

\begin{tabular}{|l|c|r|r|r|}
\hline & & \multicolumn{3}{|c|}{ TTC with medical help } \\
\hline & & \multicolumn{1}{c|}{ No } & \multicolumn{1}{c|}{ Yes } & \multicolumn{1}{c|}{ Total } \\
\hline $\begin{array}{l}\text { God, Faith, } \\
\text { Religion }\end{array}$ & No & $\mathbf{8 6 . 9 \%}$ & $\mathbf{8 7 . 6 \%}$ & $\mathbf{8 7 . 3 \%}$ \\
\cline { 2 - 5 } & Yes & $13.1 \%$ & $12.4 \%$ & $12.7 \%$ \\
\cline { 2 - 5 } & n & 107 & 217 & 324 \\
\hline
\end{tabular}

Pearson Chi-Square $=.027, \mathrm{p}=.870$ 


\begin{tabular}{|r|r|r|r|r|}
\hline \multicolumn{4}{|c|}{ Table 29} \\
\multicolumn{2}{|c|}{ Time by TTC with medical help } \\
\hline & & \multicolumn{1}{|c|}{ TTC with medical help } \\
\hline & & No & Yes & Total \\
\hline Time & No & $99.1 \%$ & $94.0 \%$ & $95.7 \%$ \\
\cline { 2 - 5 } & Yes & $.9 \%$ & $6.0 \%$ & $4.3 \%$ \\
\hline & n & 107 & 217 & 324 \\
\hline
\end{tabular}

Pearson Chi-Square $=4.431, p=.035$

\begin{tabular}{|l|r|r|r|r|}
\hline \multicolumn{4}{|c|}{ Table 30 } \\
Negotiating Dreams by TTC with medical help \\
\hline & & TTC with medical help \\
\hline & & No & Yes & Total \\
\hline Negotiating Dreams & No & $97.2 \%$ & $86.6 \%$ & $90.1 \%$ \\
\cline { 2 - 5 } & Yes & $2.8 \%$ & $13.4 \%$ & $9.9 \%$ \\
\cline { 2 - 5 } & n & 107 & 217 & 324 \\
\hline
\end{tabular}

Pearson Chi-Square $=8.979, p=.003$ 


\section{Table 31}

No tolerance for regret by TTC with medical help

\begin{tabular}{|l|r|r|r|r|}
\hline & & \multicolumn{3}{|c|}{ TTC with medical help } \\
\hline & & \multicolumn{1}{c|}{ No } & Yes & Total \\
\hline $\begin{array}{l}\text { No tolerance for } \\
\text { regret }\end{array}$ & No & $100.0 \%$ & $94.9 \%$ & $96.6 \%$ \\
\cline { 2 - 5 } & Yes & $.0 \%$ & $5.1 \%$ & $3.4 \%$ \\
\cline { 2 - 5 } & n & 107 & 217 & 324 \\
\hline
\end{tabular}

Pearson Chi-Square $=5.615, \mathrm{p}=.018$

\section{Table 32}

Life is on Hold/ Off Track by TTC with medical help

\begin{tabular}{|c|c|c|c|c|}
\hline & & \multicolumn{3}{|c|}{ TTC with medical help } \\
\hline & & No & Yes & Total \\
\hline \multirow{3}{*}{$\begin{array}{l}\text { Life is on Hold/ } \\
\text { Off Track }\end{array}$} & No & $100.0 \%$ & $92.6 \%$ & $95.1 \%$ \\
\hline & Yes & $.0 \%$ & $7.4 \%$ & $4.9 \%$ \\
\hline & n & 107 & 217 & 324 \\
\hline
\end{tabular}

Pearson Chi-Square $=8.299, \mathrm{p}=.004$ 


\begin{tabular}{|c|c|c|c|c|}
\hline \multicolumn{5}{|c|}{$\begin{array}{c}\text { Table } 33 \\
\text { Healthy Living by Parity }\end{array}$} \\
\hline & & \multicolumn{3}{|c|}{ Parity } \\
\hline & & TTC \#2+ & TTC \#1 & Total \\
\hline \multirow[t]{3}{*}{ Healthy Living } & No & $93.8 \%$ & $86.0 \%$ & $88.9 \%$ \\
\hline & Yes & $6.2 \%$ & $14.0 \%$ & $11.1 \%$ \\
\hline & $\mathrm{n}$ & 112 & 186 & 298 \\
\hline
\end{tabular}

Pearson Chi-Square $=4.240, p=.039$

\begin{tabular}{|c|c|c|c|c|}
\hline \multicolumn{5}{|c|}{$\begin{array}{c}\text { Table } 34 \\
\text { Marriage Closer by Parity }\end{array}$} \\
\hline & & \multicolumn{3}{|c|}{ Parity } \\
\hline & & TTC \#2+ & TTC \#1 & Total \\
\hline \multirow[t]{3}{*}{ Marriage Closer } & No & $92.9 \%$ & $83.9 \%$ & $87.2 \%$ \\
\hline & Yes & $7.1 \%$ & $16.1 \%$ & $12.8 \%$ \\
\hline & n & 112 & 186 & 298 \\
\hline
\end{tabular}

Pearson Chi-Square $=5.074, \mathrm{p}=.024$ 


\begin{tabular}{|c|c|c|c|c|}
\hline \multicolumn{5}{|c|}{$\begin{array}{c}\text { Table } 35 \\
\text { Broken Plans, Unexpected by Parity }\end{array}$} \\
\hline & & \multicolumn{3}{|c|}{ Parity } \\
\hline & & TTC \#2+ & TTC \#1 & Total \\
\hline \multirow{3}{*}{$\begin{array}{l}\text { Broken Plans, } \\
\text { Unexpected }\end{array}$} & No & $79.5 \%$ & $63.4 \%$ & $69.5 \%$ \\
\hline & Yes & $20.5 \%$ & $36.6 \%$ & $30.5 \%$ \\
\hline & $\mathrm{n}$ & 112 & 186 & 298 \\
\hline
\end{tabular}

Pearson Chi-Square $=8.461, p=.004$

\begin{tabular}{|c|c|c|c|c|}
\hline \multicolumn{5}{|c|}{$\begin{array}{c}\text { Table } 36 \\
\text { Job, Career by Parity } \\
\end{array}$} \\
\hline & & \multicolumn{3}{|c|}{ Parity } \\
\hline & & TTC \#2+ & TTC \#1 & Total \\
\hline \multirow[t]{3}{*}{ Job, Caree } & No & $98.2 \%$ & $91.9 \%$ & $94.3 \%$ \\
\hline & Yes & $1.8 \%$ & $8.1 \%$ & $5.7 \%$ \\
\hline & $\mathbf{N}$ & 112 & 186 & 298 \\
\hline
\end{tabular}

Pearson Chi-Square $=5.123, \mathrm{p}=.024$ 


\begin{tabular}{|l|r|r|r|r|}
\hline \multicolumn{4}{|c|}{ Table 37 } \\
Perfect Set Up by Parity \\
\hline & & \multicolumn{3}{|c|}{ Parity } \\
\hline & & TTC \#2+ & TTC \#1 & Total \\
\hline Perfect Set Up & No & $100.0 \%$ & $91.9 \%$ & $95.0 \%$ \\
\cline { 2 - 5 } & Yes & $.0 \%$ & $8.1 \%$ & $5.0 \%$ \\
\cline { 2 - 5 } & $\mathrm{n}$ & 112 & 186 & 298 \\
\hline
\end{tabular}

Pearson Chi-Square $=9.511, p=.002$

Table 38

Others succeed, why not me? By Parity

\begin{tabular}{|l|r|r|r|r|}
\hline & & \multicolumn{3}{|c|}{ Parity } \\
\hline & & TTC \#2+ & TTC \#1 & Total \\
\hline $\begin{array}{l}\text { Others succeed, } \\
\text { No }\end{array}$ & $90.2 \%$ & $75.8 \%$ & $81.2 \%$ \\
\cline { 2 - 5 } & Yes not me? & $9.8 \%$ & $24.2 \%$ & $18.8 \%$ \\
\cline { 2 - 5 } & n & 112 & 186 & 298 \\
\hline
\end{tabular}

Pearson Chi-Square $=9.462, p=.002$ 


\begin{tabular}{|l|r|r|r|r|}
\hline \multicolumn{4}{|c|}{ Table 39 } \\
\hline \multicolumn{1}{|c|}{ Acceptance of Medical Model by Age } \\
\hline & & \multicolumn{3}{|c|}{ Age } \\
\hline & & Under 30 & $30+$ & Total \\
\hline Acceptance of & No & $58.9 \%$ & $47.8 \%$ & $53.4 \%$ \\
\cline { 2 - 5 } Medical Model & Yes & $41.1 \%$ & $52.2 \%$ & $46.6 \%$ \\
\cline { 2 - 5 } & $n$ & 163 & 161 & 324 \\
\hline
\end{tabular}

Pearson Chi-Square $=3.988, p=.046$

Table 40

Seeing doctor as taking action by Age

\begin{tabular}{|l|l|r|r|r|}
\hline & & \multicolumn{3}{|c|}{ Age } \\
\hline & & under 30 & $30+$ & Total \\
\hline Seeing doctor as taking action & No & $76.7 \%$ & $66.5 \%$ & $71.6 \%$ \\
\cline { 2 - 5 } & Yes & $23.3 \%$ & $33.5 \%$ & $28.4 \%$ \\
\cline { 2 - 5 } & $\mathrm{n}$ & 163 & 161 & 324 \\
\hline
\end{tabular}

Pearson Chi-Square $=4.167, p=.041$ 


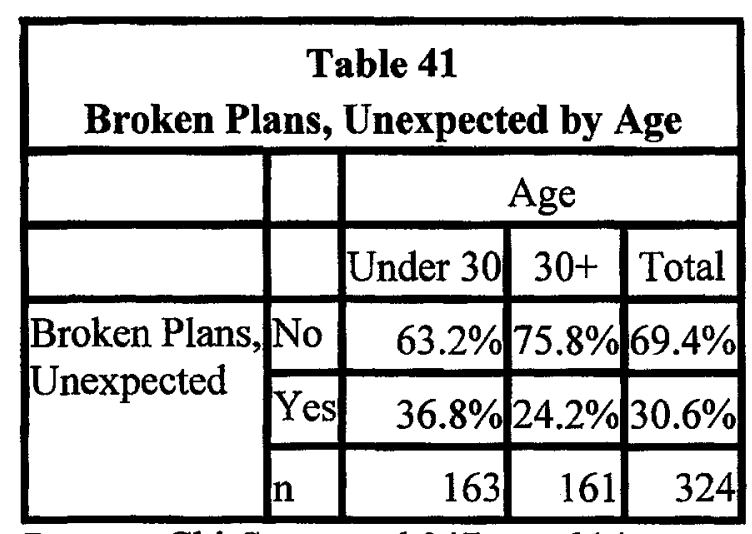

Pearson Chi-Square $=6.047, p=.014$

\begin{tabular}{|c|c|c|c|c|}
\hline \multicolumn{5}{|c|}{$\begin{array}{c}\text { Table } 43 \\
\text { Time by Age }\end{array}$} \\
\hline & & \multicolumn{3}{|c|}{ Age } \\
\hline & & Under 30 & $30+$ & Total \\
\hline \multirow[t]{3}{*}{ Time } & No & $98.8 \%$ & $92.5 \%$ & $95.7 \%$ \\
\hline & Yes & $1.2 \%$ & $7.5 \%$ & $4.3 \%$ \\
\hline & n & 163 & 161 & 324 \\
\hline
\end{tabular}

Pearson Chi-Square $=7.595, p=.006$ 


\begin{tabular}{|c|c|c|c|}
\hline \multicolumn{4}{|c|}{$\begin{array}{c}\text { Table } 44 \\
\text { “Age" by Age }\end{array}$} \\
\hline & \multicolumn{3}{|c|}{ Age } \\
\hline & Under 30 & $30+$ & Total \\
\hline $\mathrm{AgeNc}$ & $99.4 \%$ & $82.0 \%$ & $90.7 \%$ \\
\hline Ye & $.6 \%$ & $18.0 \%$ & $9.3 \%$ \\
\hline n & 163 & 161 & 324 \\
\hline
\end{tabular}

Pearson Chi-Square $=2.918 \mathrm{E} 1, \mathrm{p}=.000$

\begin{tabular}{|c|c|c|c|c|}
\hline \multicolumn{5}{|c|}{$\begin{array}{c}\text { Table } 45 \\
\text { Job, Career by Age }\end{array}$} \\
\hline & & \multicolumn{3}{|c|}{ Age } \\
\hline & & Under 30 & $30+$ & Total \\
\hline \multirow[t]{3}{*}{ Job, Career } & No & $96.9 \%$ & $91.9 \%$ & $94.4 \%$ \\
\hline & Yes & $3.1 \%$ & $8.1 \%$ & $5.6 \%$ \\
\hline & n & 163 & 161 & 324 \\
\hline
\end{tabular}

Pearson Chi-Square $=3.870, p=.049$ 


\begin{tabular}{|l|r|r|r|r|}
\hline \multicolumn{5}{|c|}{ Table 46 } \\
\hline \multicolumn{4}{|c|}{ Started out Ambivalent by Age } \\
\hline & & \multicolumn{3}{|c|}{ Age } \\
\hline & & Under 30 & $30+$ & Total \\
\hline Started out Ambivalent & No & $92.6 \%$ & $85.7 \%$ & $89.2 \%$ \\
\cline { 2 - 5 } & Yes & $7.4 \%$ & $14.3 \%$ & $10.8 \%$ \\
\cline { 2 - 5 } & n & 163 & 161 & 324 \\
\hline
\end{tabular}

Pearson Chi-Square $=4.030, p=.045$

\begin{tabular}{|r|r|r|r|r|}
\hline \multicolumn{5}{|c|}{ Table 47 } \\
\hline \multicolumn{3}{|c|}{ Undeserving Others by Age } \\
\hline & & \multicolumn{3}{|c|}{ Age } \\
\hline & & Under 30 & $30+$ & Total \\
\hline Undeserving Others & No & $87.1 \%$ & $94.4 \%$ & $90.7 \%$ \\
\cline { 2 - 5 } & Yes & $12.9 \%$ & $5.6 \%$ & $9.3 \%$ \\
\cline { 2 - 5 } & $\mathrm{n}$ & 163 & 161 & 324 \\
\hline
\end{tabular}

Pearson Chi-Square $=5.128, p=.024$ 


\begin{tabular}{|l|r|r|r|r|}
\hline \multicolumn{5}{|c|}{ Table 48 } \\
\hline & & \multicolumn{3}{|c|}{ Age } \\
\hline & & Under 30 & $30+$ & Total \\
\hline & Nothers succeed, why not me? By Age \\
\hline \multirow{2}{*}{$\begin{array}{l}\text { Others succeed, } \\
\text { why not me? }\end{array}$} & Yes & $23.3 \%$ & $14.3 \%$ & $18.8 \%$ \\
\cline { 2 - 5 } & n & 163 & 161 & 324 \\
\hline
\end{tabular}

Pearson Chi-Square $=4.319, p=.038$

\begin{tabular}{|r|r|r|r|r|}
\hline \multicolumn{4}{|c|}{ Table 49 } \\
\hline & & \multicolumn{3}{|c|}{ Time TTC } \\
\hline & & -12 Months & 12 Months & Total \\
\hline Sex Issues & No & $84.3 \%$ & $91.5 \%$ & $88.0 \%$ \\
\cline { 2 - 5 } & Yes & $15.7 \%$ & $8.5 \%$ & $12.0 \%$ \\
\cline { 2 - 5 } & $\mathrm{n}$ & 159 & 165 & 324 \\
\hline
\end{tabular}

Pearson Chi-Square $=4.007, p=.045$ 


\begin{tabular}{|r|r|r|r|r|}
\hline \multicolumn{5}{|c|}{ Table 50 } \\
\hline \multicolumn{4}{|c|}{ Searching for Answers by Time TTC } \\
\hline & & \multicolumn{3}{|c|}{ Time TTC } \\
\hline & & -12 Months & 12 Months & Total \\
\hline Searching for Answers & No & $98.1 \%$ & $92.1 \%$ & $95.1 \%$ \\
\cline { 2 - 5 } & Yes & $1.9 \%$ & $7.9 \%$ & $4.9 \%$ \\
\cline { 2 - 5 } & $\mathrm{n}$ & 159 & 165 & 324 \\
\hline
\end{tabular}

Pearson Chi-Square $=6.193, p=.013$

Table 50

Marriage Stress by Time TTC

\begin{tabular}{|r|r|r|r|r|}
\hline & & \multicolumn{3}{|c|}{ Time TTC } \\
\hline & & -12 Months & 12 Months & Total \\
\hline Marriage Stress & No & $91.2 \%$ & $81.8 \%$ & $86.4 \%$ \\
\cline { 2 - 5 } & Yes & $8.8 \%$ & $18.2 \%$ & $13.6 \%$ \\
\cline { 2 - 5 } & $\mathrm{n}$ & 159 & 165 & 324 \\
\hline
\end{tabular}

Pearson Chi-Square $=6.066, p=.014$ 
Table 51

Only others with similar experience understand by TTC with Medical Help

\begin{tabular}{|l|c|r|r|r|}
\hline & & \multicolumn{3}{|c|}{ TTC with medical help } \\
\hline & & \multicolumn{1}{c|}{ No } & \multicolumn{1}{c|}{ Yes } & Total \\
\hline $\begin{array}{l}\text { Only others with similar experience } \\
\text { Understand }\end{array}$ & No & $99.1 \%$ & $94.5 \%$ & $96.0 \%$ \\
\cline { 2 - 5 } & Yes & $.9 \%$ & $5.5 \%$ & $4.0 \%$ \\
\cline { 2 - 5 } & $\mathrm{n}$ & 107 & 217 & 324 \\
\hline
\end{tabular}

Pearson Chi-Square $=3.929, \mathrm{p}=.047$

\section{Table 52}

Insensitive Others by TTC with medical help

\begin{tabular}{|l|l|r|r|r|}
\hline & & \multicolumn{3}{|c|}{ TTC with medical help } \\
\hline & & No & Yes & Total \\
\hline Insensitive Others & No & $96.3 \%$ & $87.6 \%$ & $90.4 \%$ \\
\cline { 2 - 5 } & Yes & $3.7 \%$ & $12.4 \%$ & $9.6 \%$ \\
\cline { 2 - 5 } & n & 107 & 217 & 324 \\
\hline
\end{tabular}

Pearson Chi-Square $=6.275, p=.012$ 